\title{
Synthesis, Structure and Thermochemistry of Selected Group 11 and 12 Metal Compounds
}

\author{
by \\ Todd J. J. Whitehorne, B.Sc.
}

A thesis submitted to the Faculty of Graduate Studies and Research in partial fulfillment of the requirements for the degree of Master of Science

To

The Faculty of Graduate Studies and Research

Department of Chemistry

Carleton University

Ottawa, Ontario

Canada 


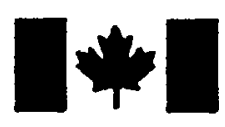

Library and Archives Canada

Published Heritage

Branch

395 Wellington Street

Ottawa ON K1A ON4

Canada
Bibliothèque et

Archives Canada

Direction du

Patrimoine de l'édition

395 , rue Wellington

Ottawa ON K1A ON4

Canada
Your file Votre reférence

ISBN: 978-0-494-60215-7

Our file Notre référence

ISBN: 978-0-494-60215-7
NOTICE:

The author has granted a nonexclusive license allowing Library and Archives Canada to reproduce, publish, archive, preserve, conserve, communicate to the public by telecommunication or on the Internet, loan, distribute and sell theses worldwide, for commercial or noncommercial purposes, in microform, paper, electronic and/or any other formats.

The author retains copyright ownership and moral rights in this thesis. Neither the thesis nor substantial extracts from it may be printed or otherwise reproduced without the author's permission.
AVIS:

L'auteur a accordé une licence non exclusive permettant à la Bibliothèque et Archives Canada de reproduire, publier, archiver, sauvegarder, conserver, transmettre au public par télécommunication ou par l'Internet, prêter, distribuer et vendre des thèses partout dans le monde, à des fins commerciales ou autres, sur support microforme, papier, électronique et/ou autres formats.

L'auteur conserve la propriété du droit d'auteur et des droits moraux qui protège cette thèse. $\mathrm{Ni}$ la thèse ni des extraits substantiels de celle-ci ne doivent être imprimés ou autrement reproduits sans son autorisation.
In compliance with the Canadian Privacy Act some supporting forms may have been removed from this thesis.

While these forms may be included in the document page count, their removal does not represent any loss of content from the thesis.
Conformément à la loi canadienne sur la protection de la vie privée, quelques formulaires secondaires ont été enlevés de cette thèse.

Bien que ces formulaires aient inclus dans la pagination, il n'y aura aucun contenu manquant.

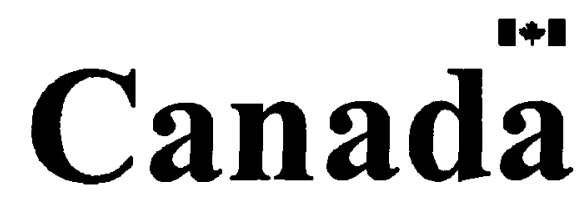




\begin{abstract}
Novel monovalent gold complexes of amidinates and guanidinates were synthesized in order study their thermal chemistry for the purposes of application as CVD precursors. It was found that these compounds decomposed to metallic gold in the presence of light. This resulted in the solution phase deposition of gold metal films using gold (I) acetamidinate as the gold source. The films were characterized by SEM, EDS, and XRD.

Gold (I) dimethyl guanidinate proved to be the only sublimable compound. For this reason it was used as a single source precursor in the deposition of gold metal films by thermal CVD. This was obtained at lower operating temperatures than those previously reported in literature. The films were studied by SEM and EDS.

Monovalent silver guanidinates were synthesized for the same purposes as the gold analogues. These were found to be too unstable to reach the vapour phase and made for poor CVD precursors. The crystal structure of silver (I) dimethyl guanidinate proved to be a trimeric complex.
\end{abstract}




\section{Acknowledgements}

I would like to thank Seán Barry for accepting me as an undergrad into his lab and allowing me the opportunity to continue on to do my Masters work with his group. His in depth knowledge of chemistry made for a great atmosphere for understanding in the lab and in the pub.

Thanks to Carleton University providing funding through scholarships. Also thanks to OGSST and Fluorescence for scholarships. Thanks to Jacques Albert a collaborator through the photonics department who's financial support made the gold project possible.

I would like to thank everyone who was a part of the Barry lab for my three years there. The atmosphere made for great memories. Being surrounded by such brilliant people in my three years made me a better chemist than I thought possible. They will be missed.

Thanks to the technicians who helped me along the way. JJ for all his help on the new SEM imaging the CVD work. Peter Jones who assisted in the photodeposited film imaging. To Keith Bourque who I must have seen for an hour a day for six weeks studying the decomposition of silver and gold guanidinates (even though the data didn't make it into the thesis work). Thanks to Fred Casselman, who's long talks were a welcome dose of reality after long hours in the lab.

I would like to thank my Mother who supported my schooling and writing efforts for so many years. My Father who's company away from school was always the perfect vacation. Thanks to my friends who always had a couch to crash on after a late night of chemistry. Thanks to my girlfriend Stephanie, who kicked me in the ass when it was needed it the most. 


\section{Table of Contents}

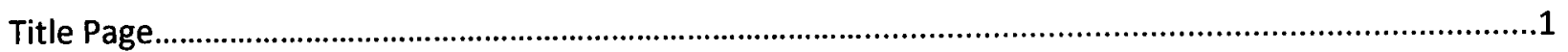

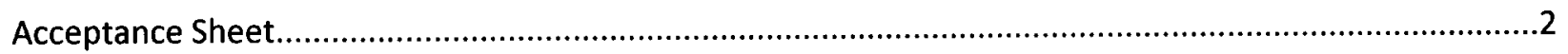

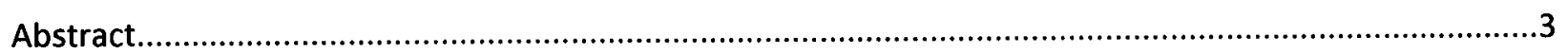

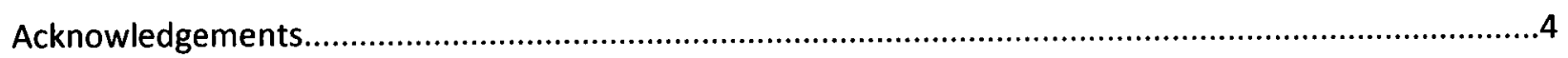

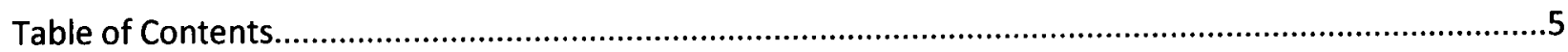

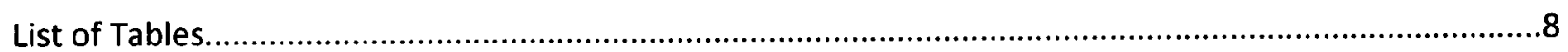

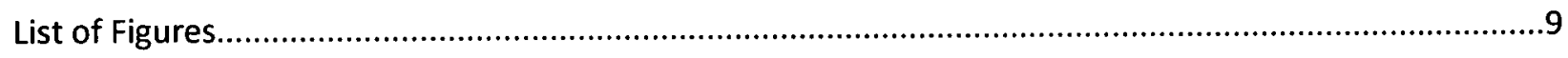

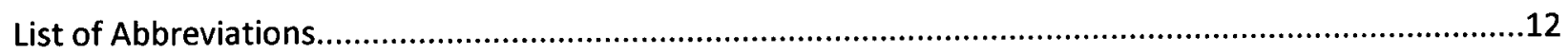

\section{Introduction}

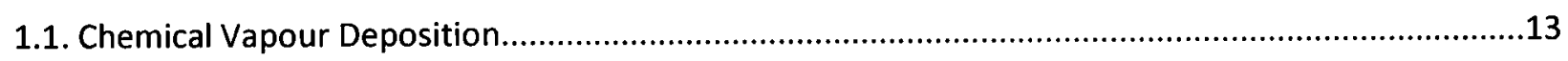

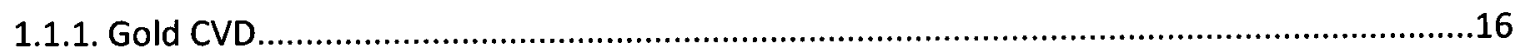

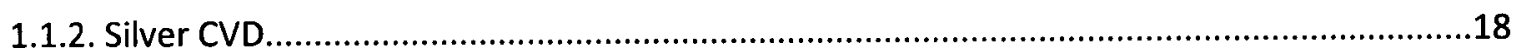

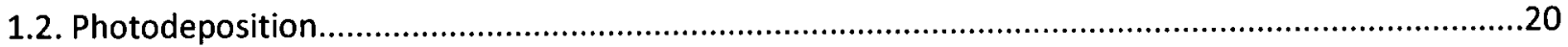

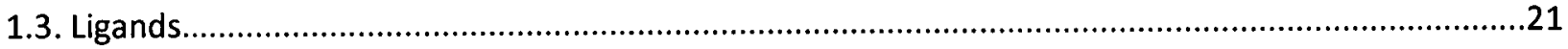

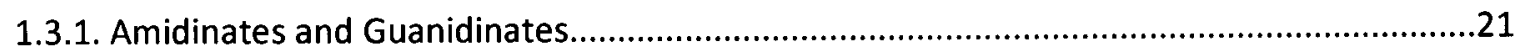

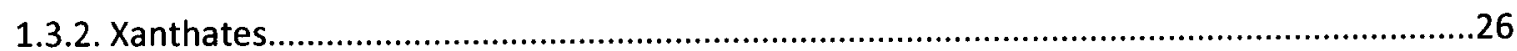

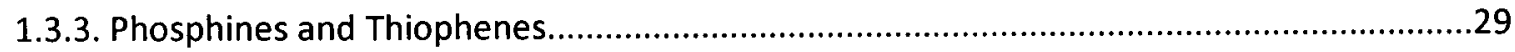

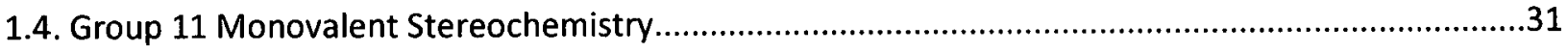

\section{Results and Discussion}

\section{Gold(I) Complexes}

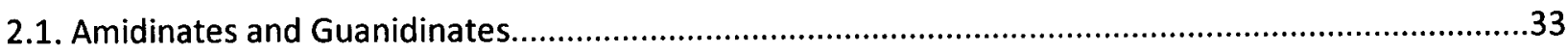

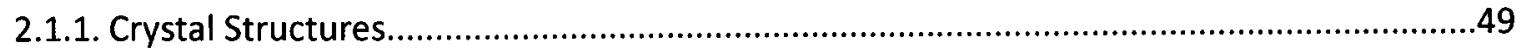

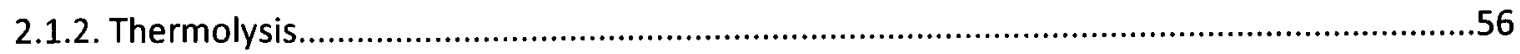

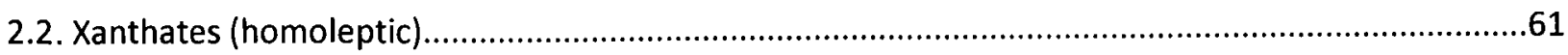

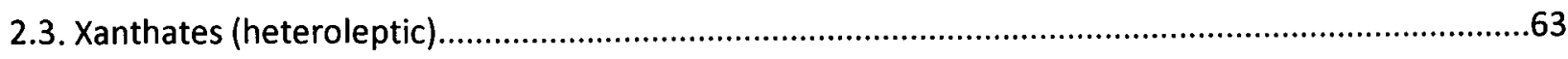


2.4. Conclusions

\section{Silver (I) Complexes}

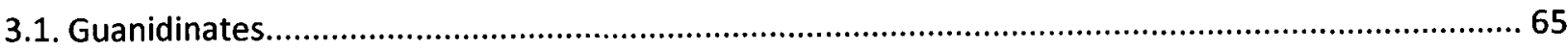

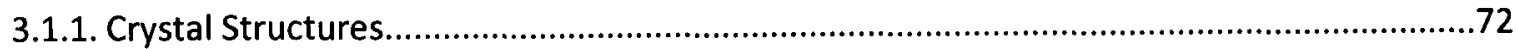

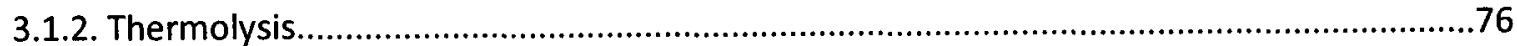

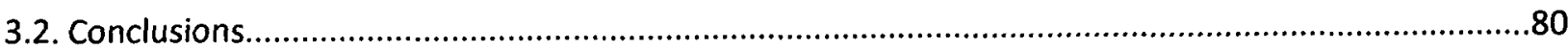

\section{Zinc(II) Guanidinate Complexes}

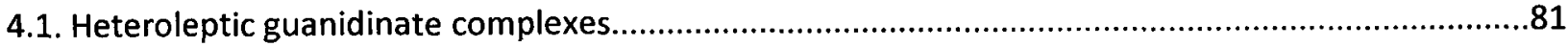

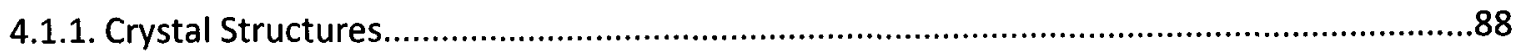

4.2. Conclusions

\section{Gold Metal Photo Deposition}

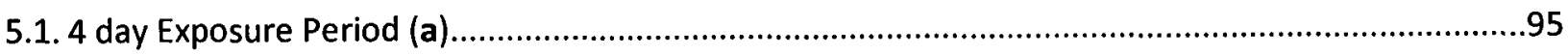

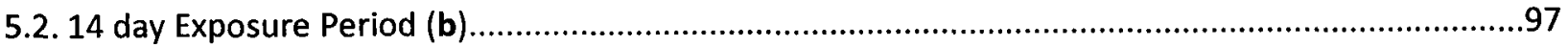

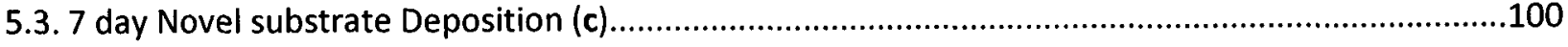

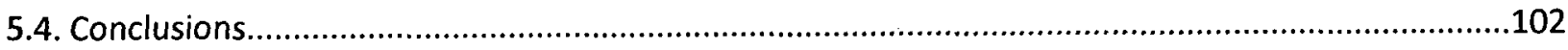

\section{Gold Metal Chemical Vapour Deposition}

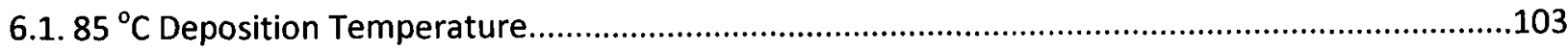

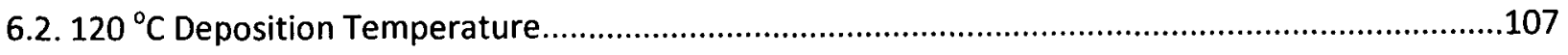

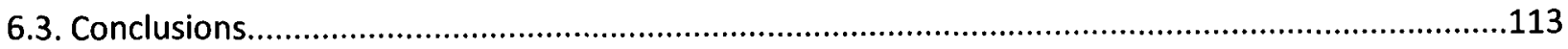

\section{Experimental}

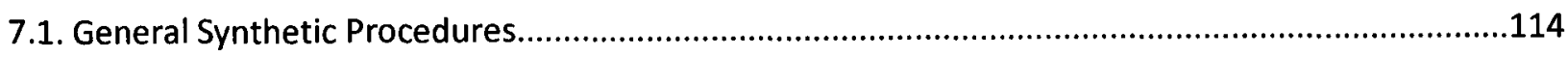

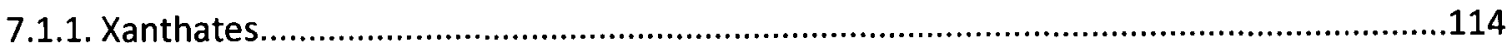

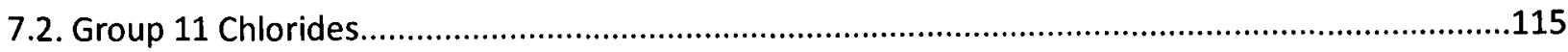

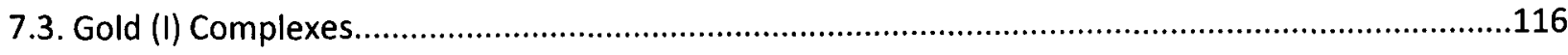

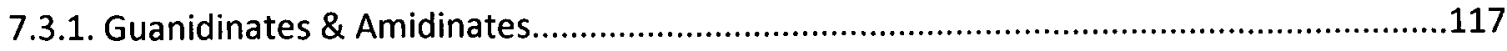

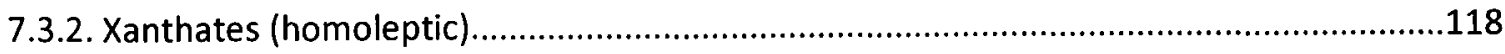




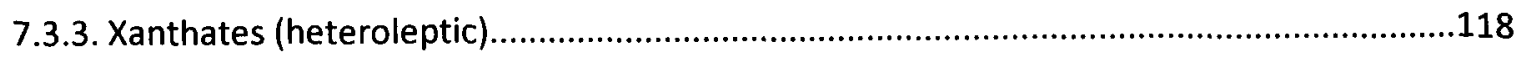

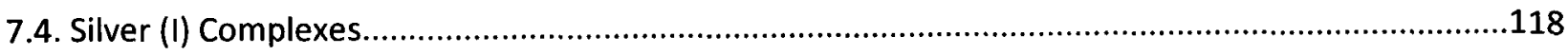

7.4.1. Guanidinates (homoleptic) .................................................................................118

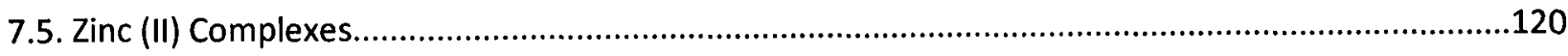

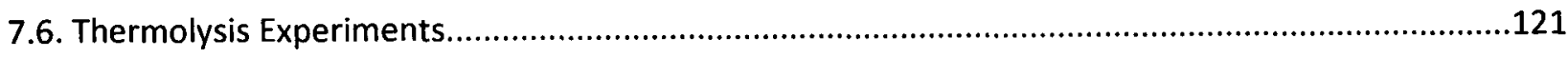

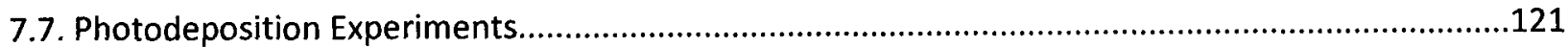

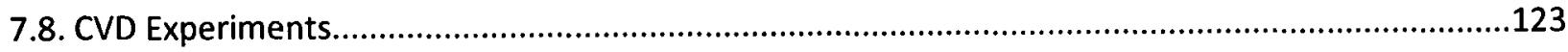

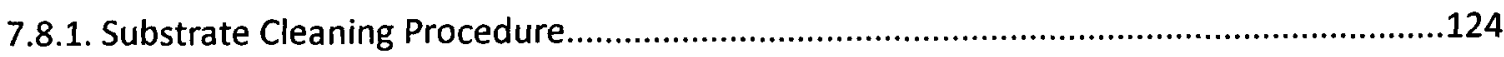

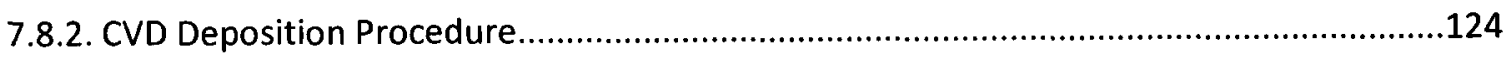

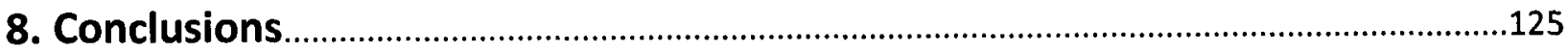

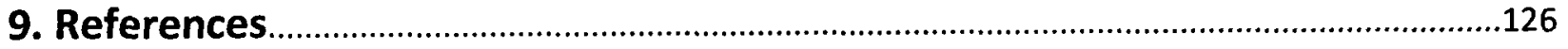

\section{Appendix: Crystallographic Data for Compounds 1, 2, 3, 10, 14, 16}

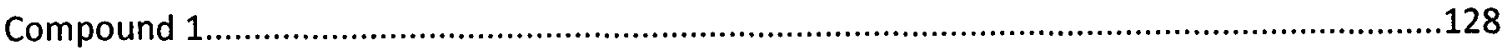

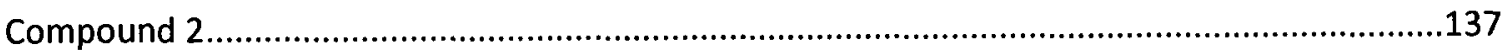

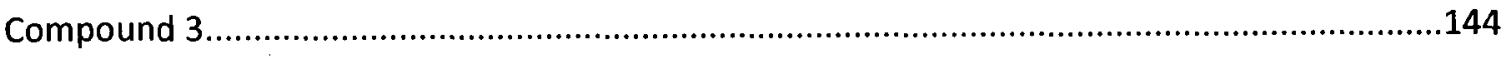

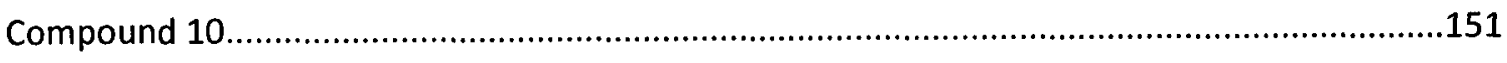

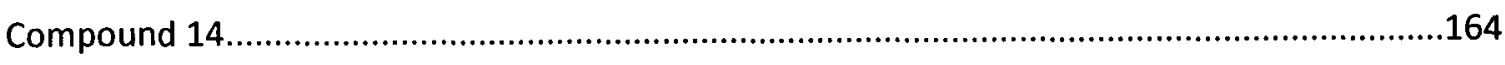

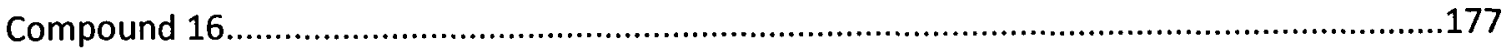




\section{List of Tables}

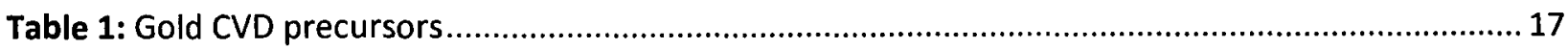

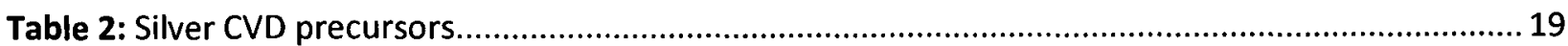

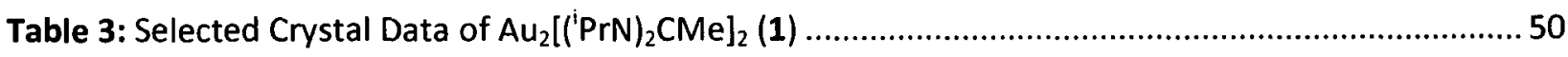

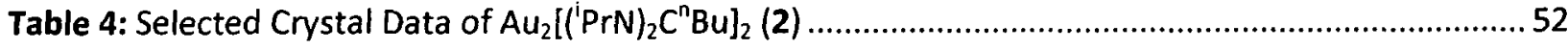

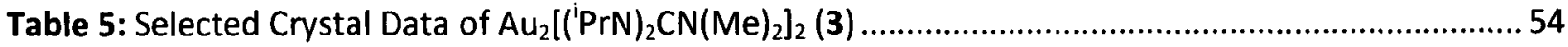

Table 6: Selected Bond Lengths and Angles for gold (I) amidinates/ guanidinates...............................56

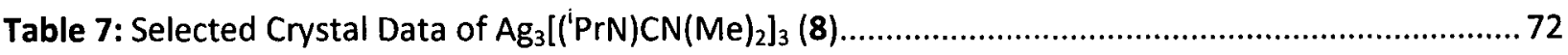

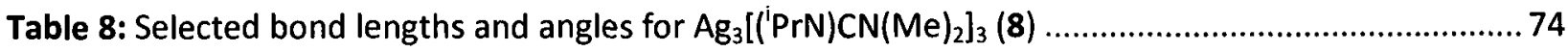

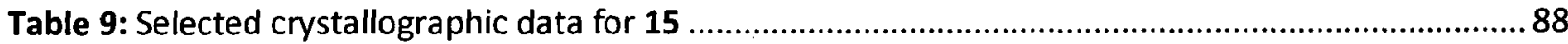

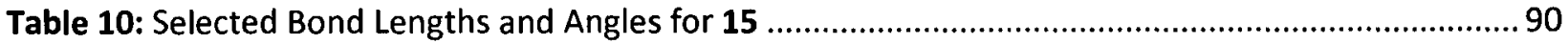

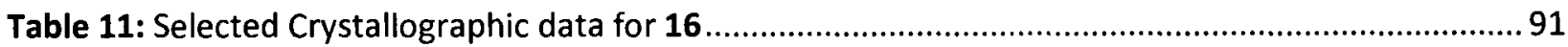

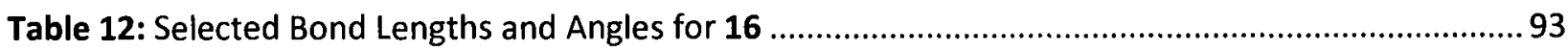




\section{List of Figures}

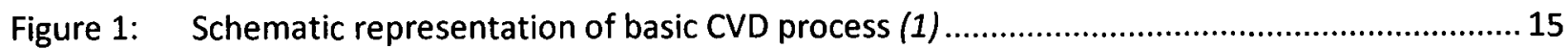

Figure 2: Diimides varying backbone functionality....................................................................... 21

Figure 3: Theoretical bonding of S-alkylisoureas with soft metal centres ......................................... 21

Figure 4: Generalized structures for the diimides ..................................................................... 22

Figure 5: Synthesis routes for amidinate and guanidinate alkali salts ...............................................2 23

Figure 6: Resonance stabilized coordination of metal centres in $\mu-1$ and $\mu-2$ chelation ...................... 24

Figure 7: Monodentate bonding of amidinates and guanidinates ................................................... 24

Figure 8: Resonance structures of the guanidinate ligands........................................................... 25

Figure 9: N'-Isopropyl-N"-isopropylidene-N,N-dialkyl-guanidine ("oxidized guanidine")....................25

Figure 10: Dithiolates, a) dithiocarbamates, b) alkyl dithiolates, c) xanthates. ................................26

Figure 11: Resonance forms of chelating and bridging metal xanthates ........................................ 27

Figure 12: Possible bonding configurations through one sulphur moiety. ...................................... 27

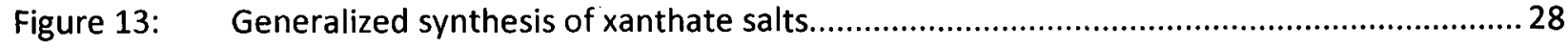

Figure 14: Generalized structures of a) thiophenes, b) phosphines.................................................2 29

Figure 15: $\quad$ a) $A u(I I I)$ reduction by THT, b) Au(III) reduction by TPP, c) THT replacement by

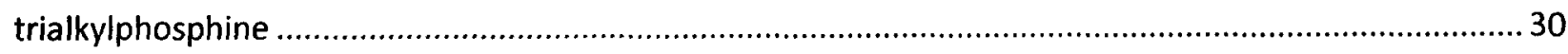

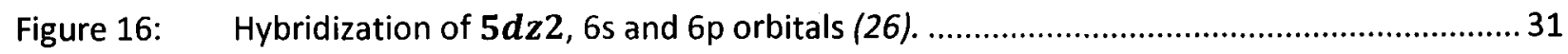

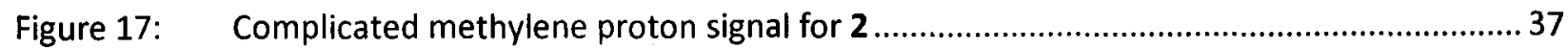

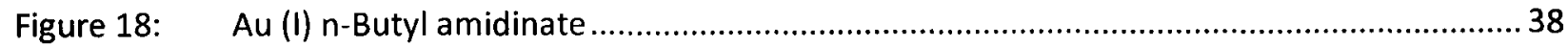

Figure 19: $\quad$ Pathways toward monomeric gold guanidinates \& amidinates...................................... 43

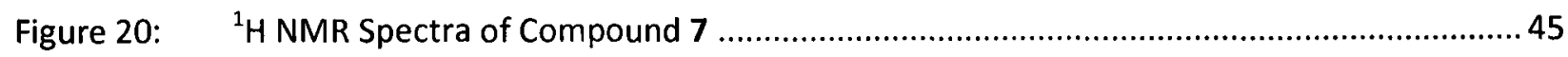

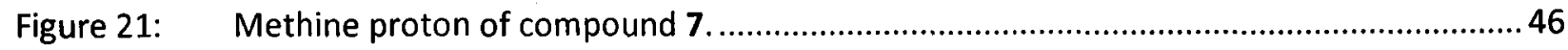

Figure 22: $\quad$ NMR spectra of 7 showing small TMS guanidine impurity ............................................ 47

Figure 23: $\quad$ Schematic of theoretical gold (I) guanidinate / amidinate monomer geometry ............... 48

Figure 24: Torsion angle in amidinates and guanidinates (resonance removed for clarity) .............. 49

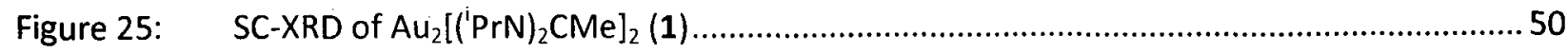

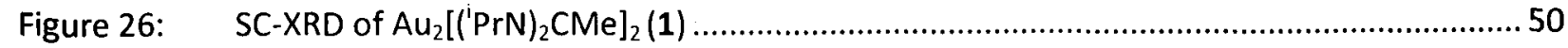

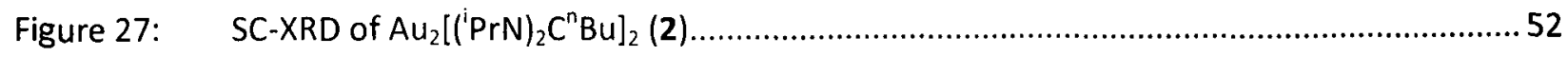

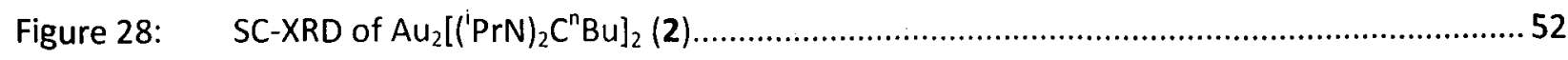




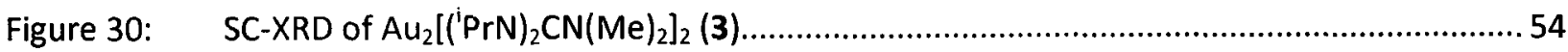

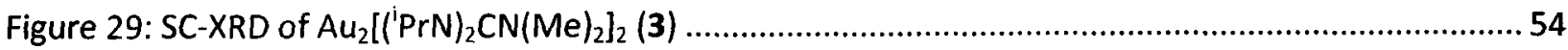

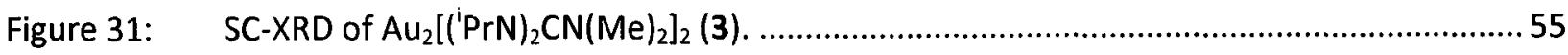

Figure 32: a) $\beta$-Hydride abstraction to produce one equivalent of oxidized guanidine and $b$ ) guanidine formation through a gold hydride intermediate ................................................................... 57

Figure 33: $\quad$ CDI deinsertion to produce gold amide or alkyl gold complex....................................... 57

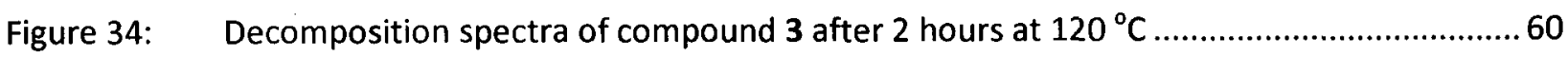

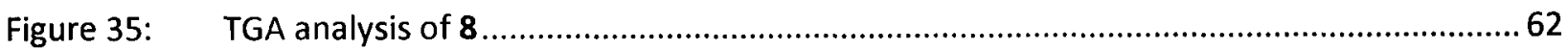

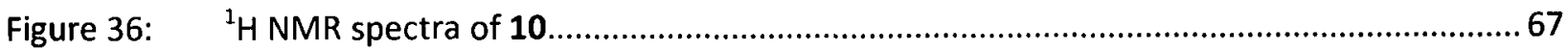

Figure 37: $\quad \mathrm{SC}-\mathrm{XRD}$ of $\mathrm{Ag}_{3}\left[(\mathrm{PrN}) \mathrm{CN}(\mathrm{Me})_{2}\right]_{3}(8)$. Hydrogen ..........................................................72

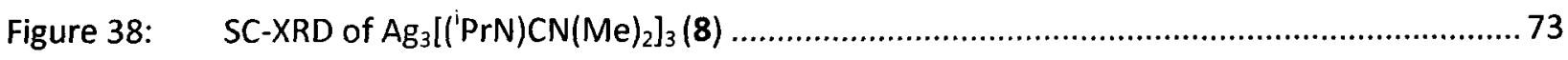

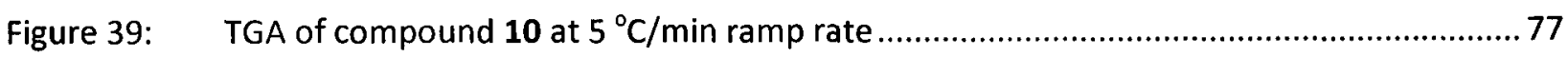

Figure 40: $\quad{ }^{1}$ H NMR showing guanidine as the soluble decomposition product of $10 \ldots \ldots \ldots \ldots \ldots \ldots \ldots . . . . . . . . .78$

Figure 41: Possible polymerization of oxidized guanidine, forming insoluble products................... 79

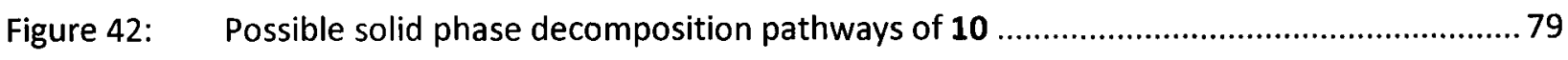

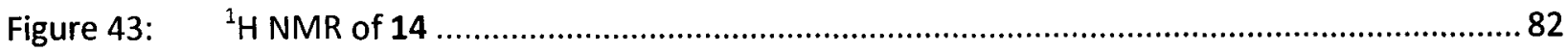

Figure 44: Unlabelled peaks showing new solid formation within liquid compound 14..................83

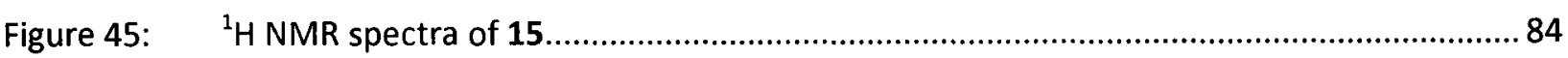

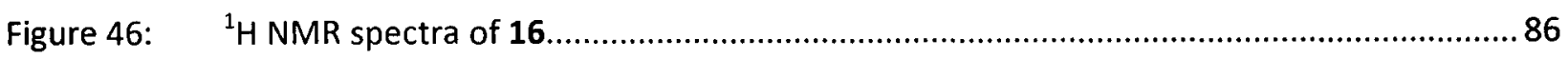

Figure 47: $\quad{ }^{1} \mathrm{H}$ NMR spectra showing possible alternate ethyl environments of compound 16. ........ 87

Figure 48: $\quad$ SC-XRD of compound 15. Hydrogen atoms were ........................................................ 88

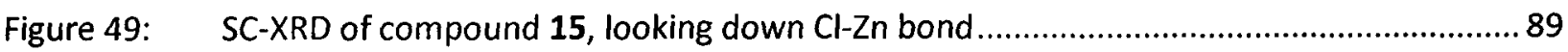

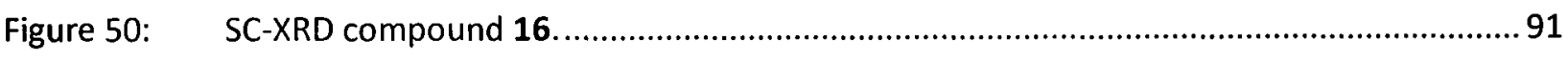

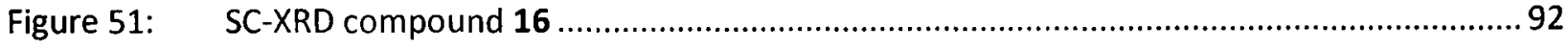

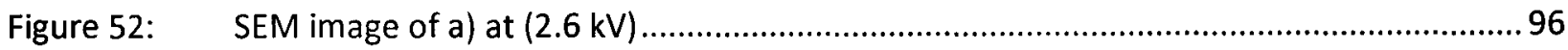

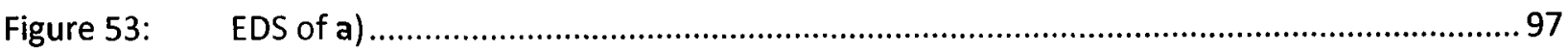

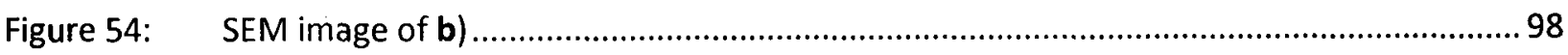

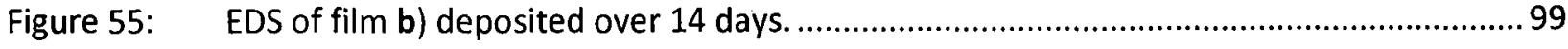

Figure 56: XRD of film $\mathrm{c}$ ) indicating crystalline gold and glass slide substrate. ............................. 100

Figure 57: $\quad$ SEM image of photodeposited gold on a fibre Bragg grating filament $(2.6 \mathrm{kV}) \ldots \ldots \ldots \ldots . . . .101$

Figure 58: Sublimed gold (I) dimethylguanidinate precursor on Si(100) wafer.............................. 104

Figure 59: $\quad$ EDS data of rectangular region seen in Figure 58.................................................... 104 
Figure 60: SEM image of structure from Figure 58, after three days of atmospheric exposure....... 105

Figure 61: Nanoparticle formation ........................................................................................ 106

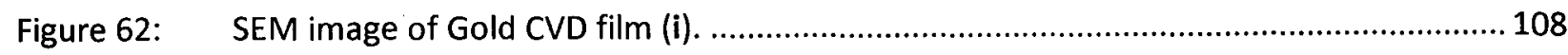

Figure 63: EDS spectra of (i), field seen in Figure 62 ............................................................... 109

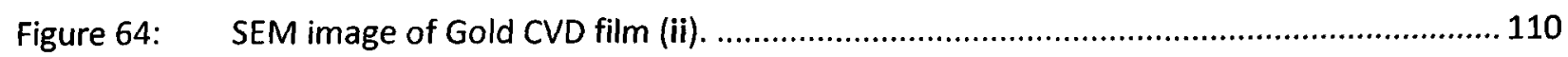

Figure 65: EDS data of (ii) from Figure 64 …........................................................................ 110

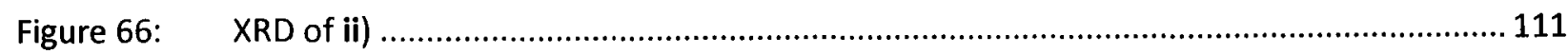

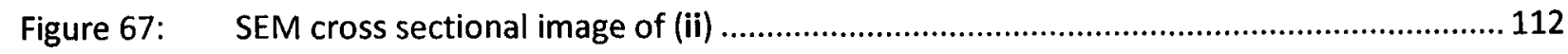

Figure 68: Schematic of photodeposition apparatus ................................................................. 122

Figure 69: Schematic of Fibre Bragg Grating photodeposition apparatus ..................................... 123

Figure 70: Schematic of CVD deposition apparatus ................................................................ 123 


\title{
List of Abbreviations
}

\author{
Acac - Acetylacetonate \\ ALD - Atomic Layer Deposition \\ CDI - diisopropyl Carbo Diimide \\ CVD - Chemical Vapour Deposition \\ DCM - Dichloromethane \\ DSC - Differential Scanning Calorimetry \\ DFT - Density Functional Theory \\ EDS - Energy Dispersive X-ray Spectroscopy \\ FBG - Fibre Bragg Grating \\ NMR - Nuclear Magnetic Resonance \\ SEM - Scanning Electron Microscopy \\ TBP - Tributyl phosphine \\ TGA - Thermogravimetric Analysis \\ THT - Tetra Hydro Thiophene \\ TMS - Trimethylsilane \\ TPP - Triphenyl Phosphine \\ XRD - X-Ray Diffractometry
}




\section{1) Introduction}

\subsection{Chemical Vapour Deposition}

Chemical Vapour Deposition (CVD) is a thin film growth technique used to deposit a variety of thin films. The materials being deposited can range from metals, semiconductors, insulators, superconductors and organic materials. This technique has been applied industrially for microelectronics, and optoelectronics. The resultant films can be polycrystalline, epitaxial or amorphous.

Each CVD process can be broken down into three categories and thus named using these conditions.

i) Film Source: In the past, metal containing precursors tended to be the metal halides(1). Currently metals capped with organic ligands have been found to be more volatile, thus reducing the energy requirements (1). Operating pressures approach atmospheric with the use of organometallic precursors, decreasing system costs. Organometallic ligands also decrease in poisoning of the resultant metal film.

ii) Pressure: Reduced pressure aids in volatilization of the precursor. This can be carried out under Ultra High Vacuum conditions (UHV-CVD), Low Pressure (LPCVD), or even atmospheric pressure (AP-CVD).

iii) Enhancement: Different techniques have been used to increase CVD film growth rates, and film properties (morphology, impurities, conformality). For example a common CVD technique called Plasma Enhanced CVD (PECVD). In this method the precursor while in the gas phase is excited to an ion, radical or neutral excited species. This increases the reactivity of the precursor at the substrate. Photo excitation of the gaseous precursor, physisorbed or chemisorbed precursor on the substrate, or the substrate itself is often used to enhance CVD, and is generally called photo-CVD. 
Desirable precursors should meet certain requirements.

i) Volatility: They should have a significant vapour pressure to be carried via gas flow to the deposition substrate. This is achieved by keeping molecular weight low and limiting intermolecular interaction. Distillable liquids are ideal (due to their specific and reproducible vapour pressure); these can be achieved by frustrating crystalinity via asymmetric ligands and long branched alkyl chains (1).

ii) Reactivity: While in the gas phase the precursor should not react with other precursor molecules. Coordinative saturation of the metal centre will prevent the possibility of oligomerization of the precursor molecules.

iii) Controlled Decomposition: The precursor should decompose to the desired product at the substrate under a reasonable temperature. Decomposition products that are not associated with the target film should be chemically inert to the film as well as volatile so as to not introduce contamination in the target film.

CVD is sometimes used in conjunction with a reactive carrier gas. This initiates the decomposition of the precursor before contact with the substrate. Usually these reactive carrier gases are used to form semiconductor films in the case of metal nitrides, or oxides. This is not always the case as hydrogen can be used to form metallic films. A schematic based on that of C.R. Kleijn best describes this process(1). If no secondary reactive gas is used, reactivity occurs purely at the surface. 


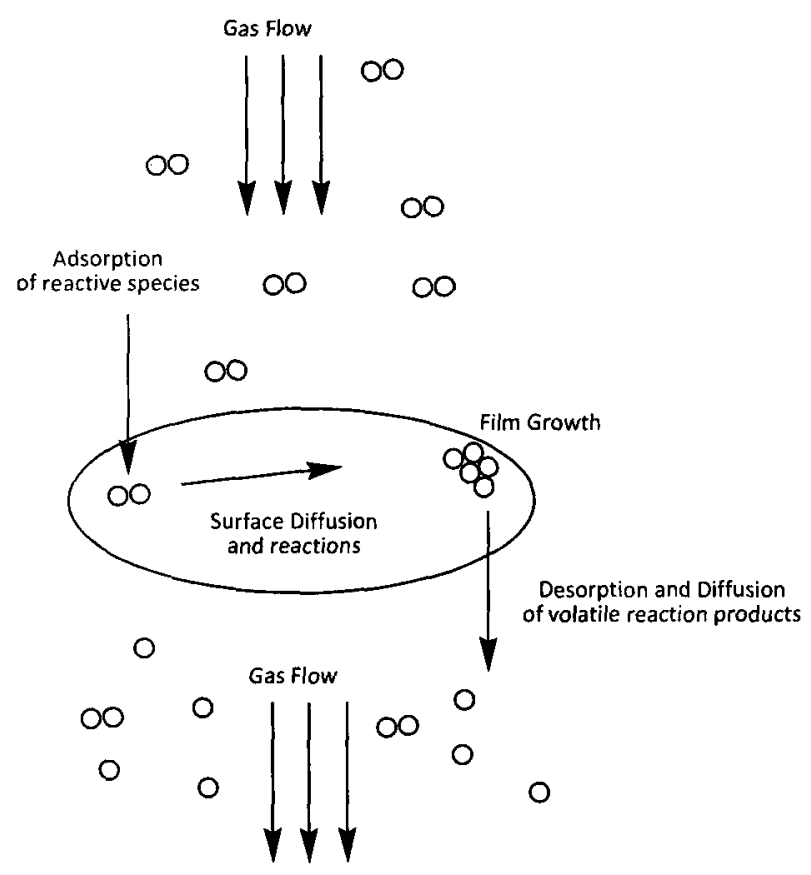

Figure 1: $\quad$ Schematic representation of basic CVD process (1)

The reactive surface sites of the substrate can vary as the substrates vary. Substrates tend to be metal oxides, typically alumina, titania, or silica. The surface oxygens can be occasionally terminated by hydrogen, forming surface hydroxyl sites. The most common substrate is silicon because of its application to microelectronics. Silicon has a native oxide layer at the surface; these can be oxygen atoms bridged between silicons or be hydroxyl sites. The hydroxyl density can be increased by using a variety of chemical and thermal methods that also clean the surface of impurities. These hydroxyl sites are the reactive sites at the surface. In metal film deposition the proton of the hydroxyl sites is lost in volatile reaction products, resulting in a single monolayer where the metal is chemically bound to the Si surface via oxygen. Continued growth proceeds from surface metal sites, without surface hydroxyl sites. Surface sites can also be silicon hydride sites, achieved by baking the surface under hydrogen, removing hydroxyl sites as $\mathrm{H}_{2} \mathrm{O}$. 


\subsubsection{Gold CVD}

Current gold CVD methods utilize gold halides, as well as fluorinated organometallic precursors. Some drawbacks of these types of precursors are the existence destructive byproducts $(\mathrm{HCl}, \mathrm{HF})$ that can etch the film, substrate, as well as damaging vacuum systems. The etching of gold metal films is not really a concern in gold CVD as once the metal layer is formed, it is very resilient, requiring aqua regia to remove. Non-halogenated precursors contain $\mathrm{Au}-\mathrm{C}$ bonds that result in carbon deposits within the film (2). These deposits can make for amorphous structure, poor conductivity and poor film uniformity (2).

Of the precursors in Table 1, i) and ii) are commercially available as CVD precursors.. The complex i) has a melting point of $81-82^{\circ} \mathrm{C}$, and sublimes at $25^{\circ} \mathrm{C}$ with a pressure of $0.01 \mathrm{mmHg}$. The precursor is available from Strem chemicals for $\$ 1,400.00 / 500 \mathrm{mg}$, or $\$ 4,200 / 2 \mathrm{~g}$. Haruta et al. sublimed the precursor at $33^{\circ} \mathrm{C}$ and a substrate temperature of $200^{\circ} \mathrm{C}$ to $500^{\circ} \mathrm{C}$ resulting in varied gold nanoparticle thin films. It was found that gold metal nanoparticles on metal oxide surfaces tend to be very active to oxidation by carbon monoxide at low temperatures (3). 
Table 1: $\quad$ Gold CVD precursors

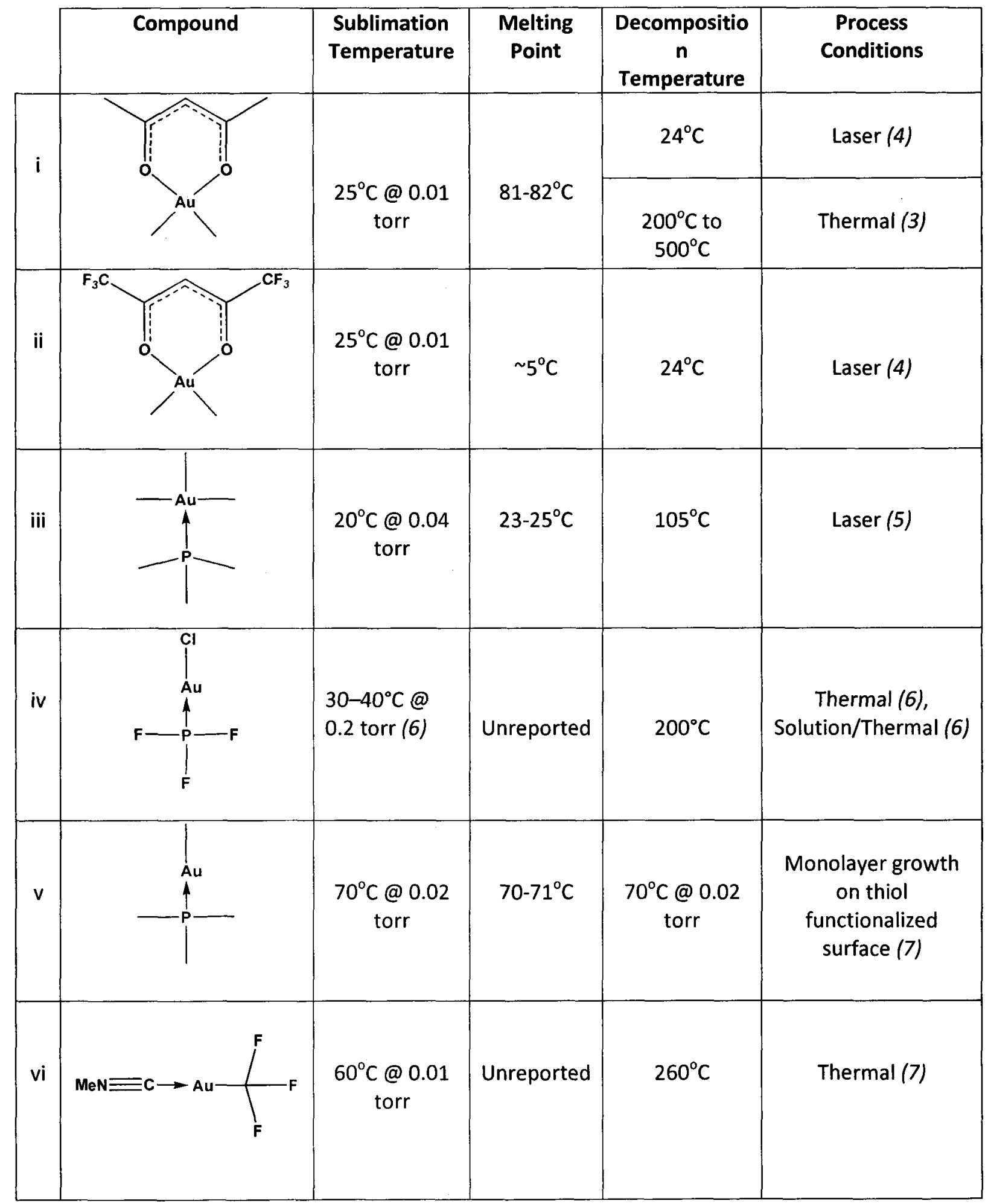




\subsubsection{Silver CVD}

The CVD of silver metal is has received some attention recently. Typically, as film thickness decreases, conduction does as well. In the case of copper it was found that at low film thicknesses $(<100 \mathrm{~nm})$ resistivity increased dramatically (8). However, silver thin films tend not to follow this trend. The high conductivity of bulk silver can be maintained down to feature sizes lower than $100 \mathrm{~nm}$ (9). Thus, silver thin films are of interest as conductive films in microelectronics.

Compounds that result in the best films are those of the silver (I) phosphine acetylacetonate (acac) family. In Table 2, a liquid precursor consisting of a datively bonded vinylsilane can be seen (i). The alkene silver complexes used for CVD are not advantageous as before volatilization they tend to lose alkene and form $\mathrm{Ag}[\mathrm{acac}]_{n}$ which is then subsequently volatilized (10). This behaviour has not been seen for $\mathrm{Ag}(\mathrm{I})$ precursors utilizing phosphine ligands, like that of (iii). 
Table 2: $\quad$ Silver CVo precursors

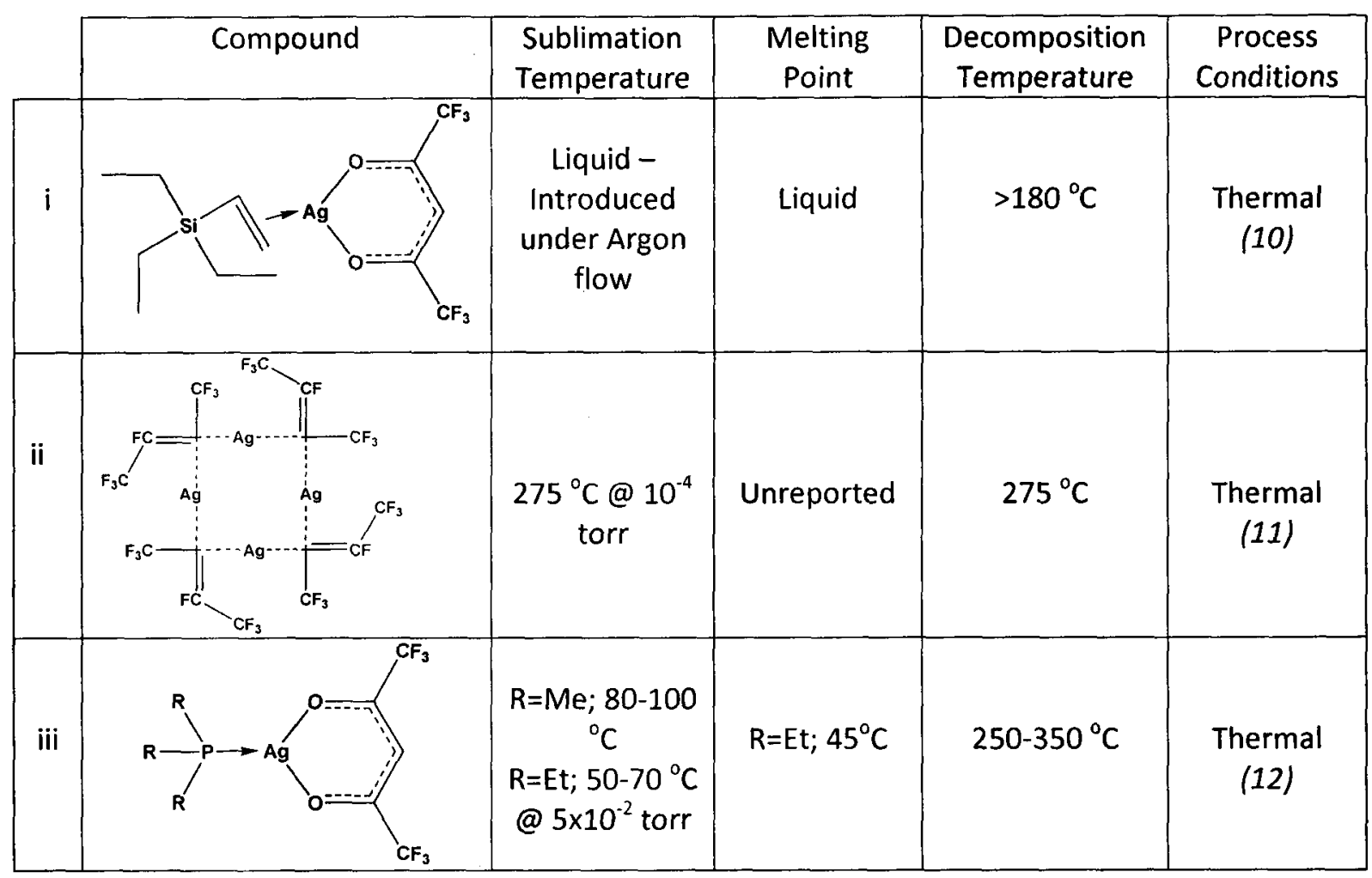




\subsection{Photodeposition}

Much attention has been paid to different photodeposition techniques from solution phase recently $(13,14,15)$. This has been primarily in the nanotechnology field. Photodeposition differs from that of chemical deposition techniques. Instead of utilizing a chemical reaction to initiate decomposition, the decomposition is initiated by absorption of photons.

Light has been used in the past to initiate decomposition of precursors to form uniformly distributed sizes of nanoparticles as well as quantum dots (14). Films have been deposited using photo techniques from solution to deposit organic (15), metallic (16), and ceramic films (13).

The decomposition to form metallic products results in the reduction of a metal containing precursor (14). The decomposition pathways are overall poorly understood (16). 


\subsection{Ligands}

\subsubsection{Amidinates and Guanidinates}

Carbodiimides are a class of compounds that contain a $\mathrm{RN}=\mathrm{C}=\mathrm{NR}$ functionality. These compounds are named via the functionality of the central carbon. When the central carbon is functionalized these compounds share similar structure to that of ureas $\left(\left(\mathrm{NH}_{2}\right)_{2} \mathrm{CO}\right)$ and are named as such. By having alcohols or thiols at the central carbon, O-alkylisoureas and S-alkylisoureas (respectively) can be formed. If an alkyl group is present at this carbon these can be called alkylisoureas, but a more common term is amidine. Similarly if an amine occupies this position it's called a guanidine and not an aminoisourea.

a)<smiles>[R]N=C(N[R])O[R]</smiles>

b)<smiles>[R]N=C(N[R])S[R]</smiles>

c)

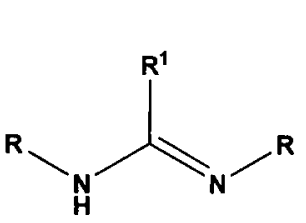

d)<smiles>[R]N=C(N[R])N([R])[R]</smiles>

Figure 2: Dimices varying backbone functionality a) O-alkylisourea, b) 5 alkylisourea, c) amidine, d) guanine.

This document will primarily deal with the chemistry of the amidines and guanidines for silver and gold. The alcohol derivative is shown as a contrast with xanthic acids (see section 1.3.2.). Also the thiol derivative is shown as it was an early candidate for a ligand system in the gold(I) chemistry. It was believed that the ligand would show novel bonding to the gold centre making it a candidate for future work.

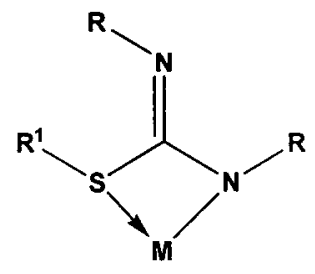

Figure 3: $\quad$ Theorethal bondig of S alkylisoureas with soft metal centres 
However these ligands decompose readily upon heating (17) making for a poor ligand for CVD/ALD applications and were thus taken out of consideration.

The amidinates and guanidinates are dynamic ligands that allow for variations of the alkyl groups on the chelating nitrogens and in the backbone position. In the case of guanidinates the amine in the backbone position can be primary or secondary. This proton resulting from a primary amine synthesis allows for the ligand to be dianionic, when both protons are abstracted (Figure 4). The ligands can be asymmetric. Asymmetric carbodiimides are those which contain different alkyl groups on chelating nitrogens. This thesis will deal with diisopropyl monoanionic amidinates and guanidinates, alkyl groups on chelating nitrogens are isopropyl and in the case of guanidinates equivalent backbone alkyl groups are used.

a)

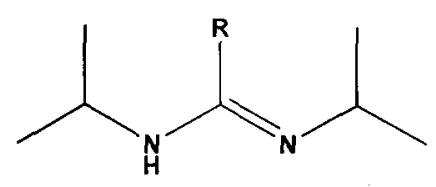

b)

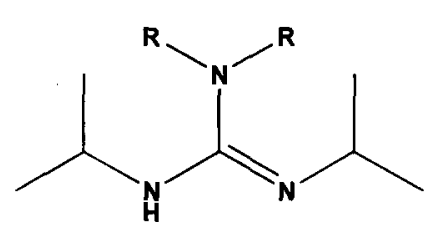

c)

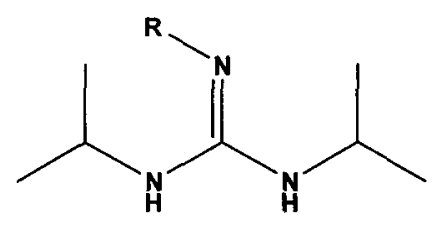

Figure 4: Generalized structures for the dimides a) amidine, b) monoanionic guanidine, c) dianionic guanidine.

The amidinate and guanidinate complexes make for excellent precursors due to their low molecular weight, high steric hindrance, and the existence of a nitrogen-metal bond that helps decrease carbon impurities in the product film. These compounds can be synthesized through a variety of pathways. This document pertains mostly to salt metathesis routes to products. Two general ligand syntheses are shown below. 

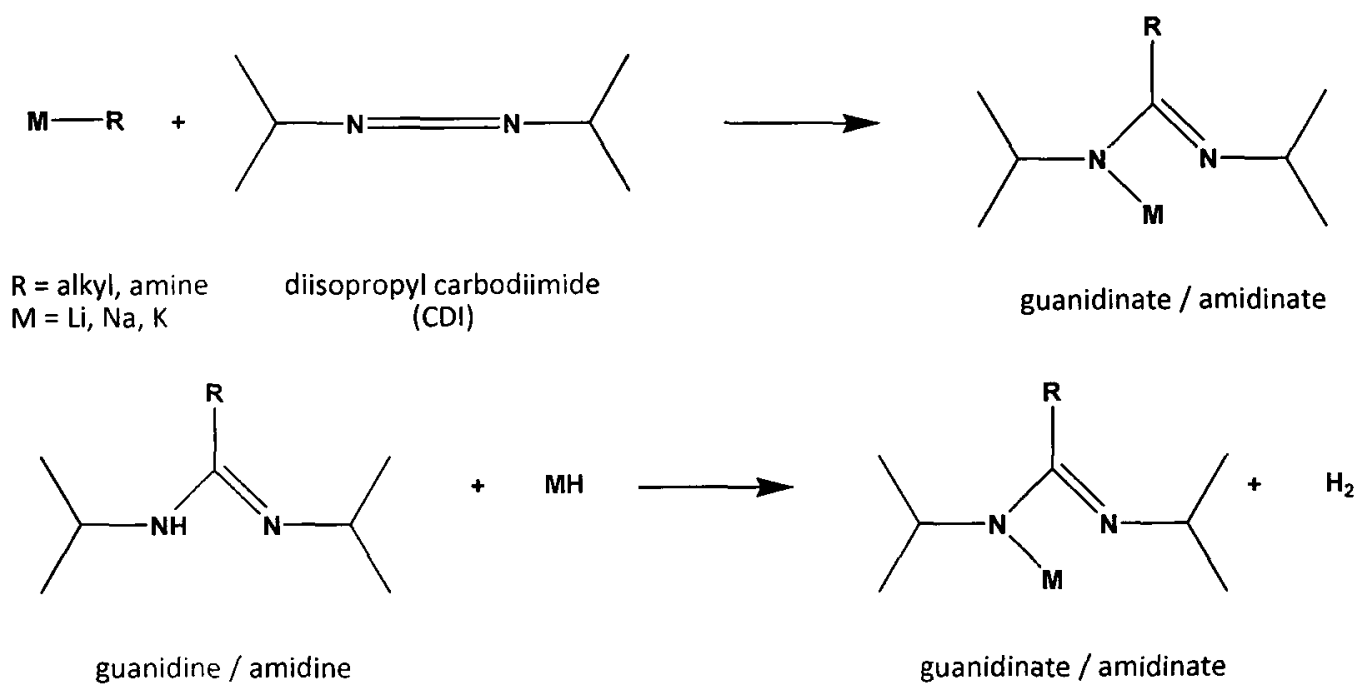

Figure 5: $\quad$ Synthesis routes lor amidinate and guanidinate alkali salts

The parent amidines and guanidines tend to be liquids; this is indicative of their potential to make volatile coordination complexes for CVD applications. They can also chelate the metal centre through both nitrogen groups in the case of the amidinates, or two out of the three in the case of the guanidinates. The chelation can be $\mu-1$ or bridging $\mu-2$ between two metal centres. The resonance stabilization of chelation increases the stability in the compound, hindering decomposition in the gas phase. 

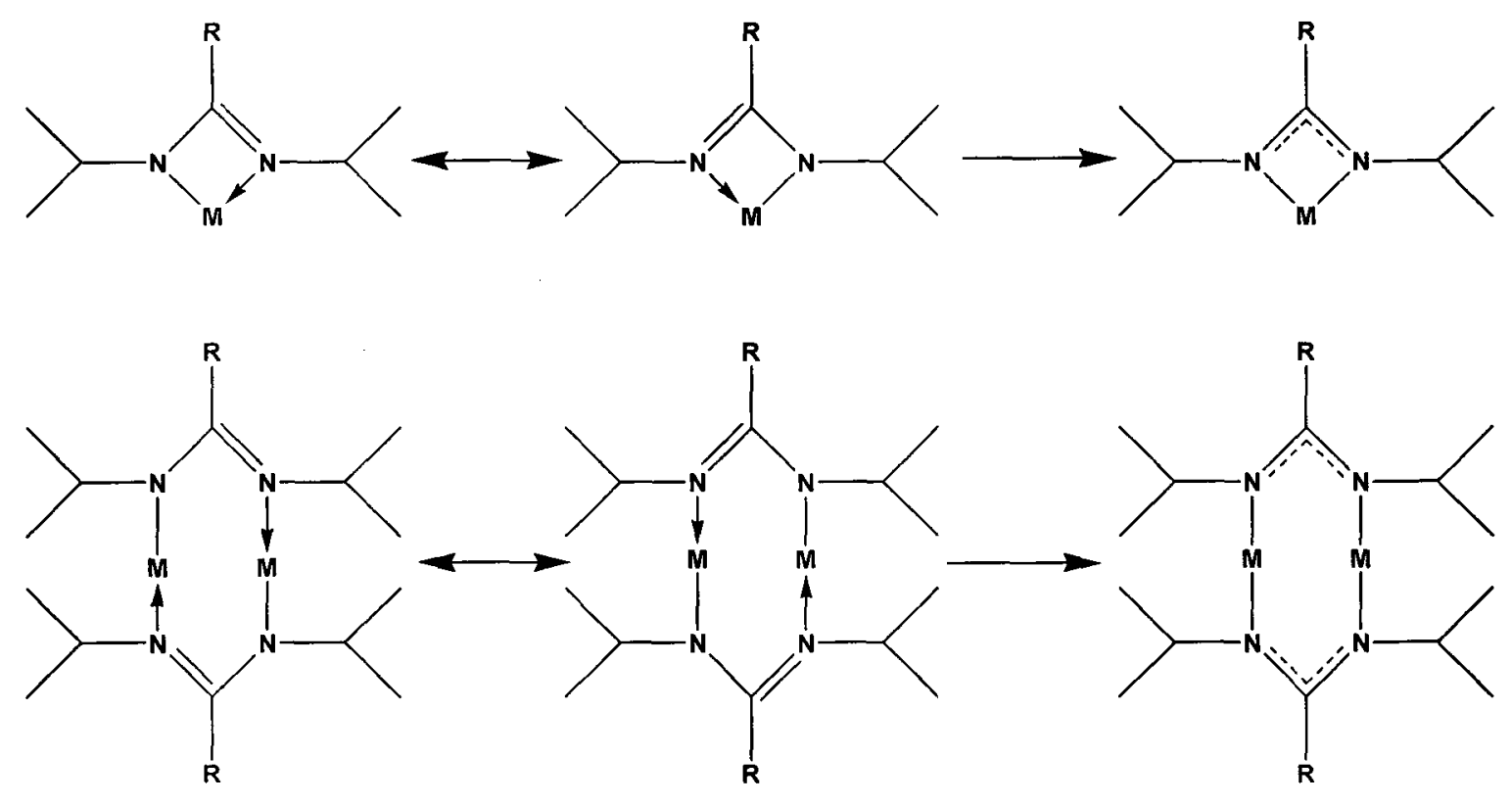

$\mathrm{R}=\mathrm{alkyl}$, amine

Figure 6: $\quad$ Resmance stabilized coordination of metal centres in $\mu-1$ and $\mu-2$ chelation

Both amidinate and guanidinate ligands can bond in a monodentate fashion through one nitrogen. This can be caused by steric hindrance around the metal centre. The metal centre may also have preference for a specific geometry.

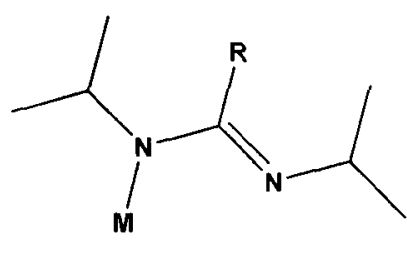

$\mathrm{R}=$ alkyl, amine

Figure 7: $\quad$ Monodentate bonding of amidinates and guanidnates

The decomposition pathways of metal amidinate and guanidinate complexes are not well understood, and thus will be a focus of this thesis. It is generally believed that metal guanidinate species decompose more readily than the amidinate analogues due to the weak $\mathrm{N}-\mathrm{C}$ bond in the exocyclic position resulting in loss of amine and deinsertion of carbodiimide (18). This contrasts with amidinates 
which have a C-C bond in the exocyclic position making the amidinates potentially more thermally stable as the metal nitrogen bonds are more likely to break than the $\mathrm{C}-\mathrm{C}$ bonds.

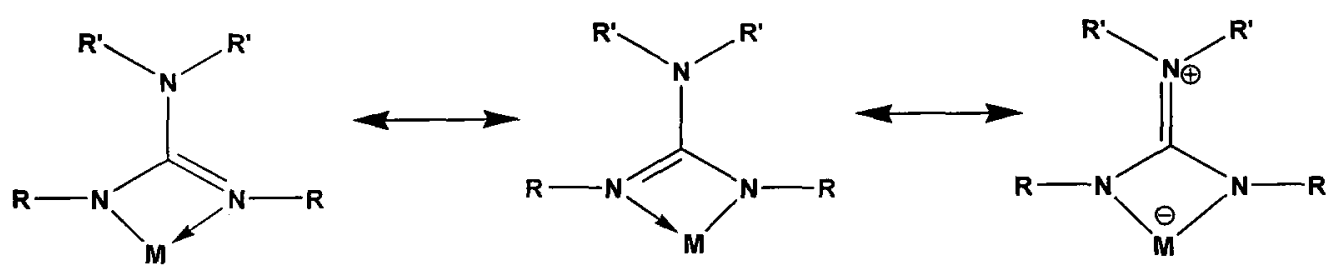

Figure 8: $\quad$ Resciance structures of the guanidinate ligands

The benefit of the guanidinate ligand in precursor chemistry resides in its third resonance structure. The exocyclic amido moiety of the guanidinates participates in the $\pi$ system of the chelate ring, allowing the amides to be slightly pyramidalized frustrating crystal packing giving greater volatility than similar amidinate analogues (19).

It is often stated that amidinates and guanidinates decompose to their analogous amidines and guanidines. However these postulated decomposition mechanisms do not adequately address the necessary proton source. Some groups discuss the possibility of transient water in their reaction as being the proton source (20). Recent findings in dimeric decompositions of guanidinates point toward a pathway where the formation of $\mathrm{N}^{\prime}$-Isopropyl-N"-isopropylidene-N,N-dialkyl-guanidine ("oxidized guanidine") supplies the proton to another ligand and producing the guanidine.

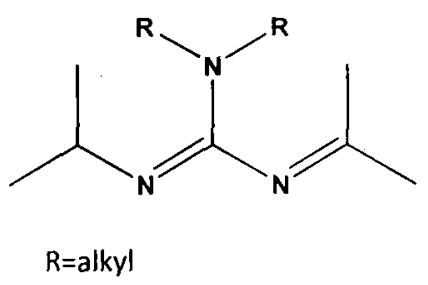

Figure 9: $\quad N$ '-Isopropyl-N"'sopropylidene $N, N$-dialkyl-guandine ("oxidized guanidine") 
It is important to note that this decomposition pathway has only been studied in depth for the case of copper (I) guanidinate dimers. This decomposition can be applied easily to the gold (I) guanidinate dimers as they have similar structures.

\subsubsection{Xanthates}

Dithiolates are a class of compounds derived from carbon disulphide. Dithiolates can be further broken down into classes depending on functional group in the backbone position (similarly to guanidinates and amidinates). Dithiolates are sulphur derivatives of oxylates and are named as such by adding the prefix dithio to the pre-existing oxylate compound. If there is an alkyl group in the backbone position, the ligands are simply alkyl dithiolates. If a primary or secondary amine resides in the backbone position, the ligands are called dithiocarbamates. If an alkoxy moiety exists in the backbone position theses are O-esters of dithiocarbonic acid (they are also the sulphurous derivatives of carbonate esters). These are commonly referred to as xanthates, where an alkoxy group occupies the exocyclic position. If a proton exists on one of the sulphur groups it is called a xanthic acid.
a)
b)
c)
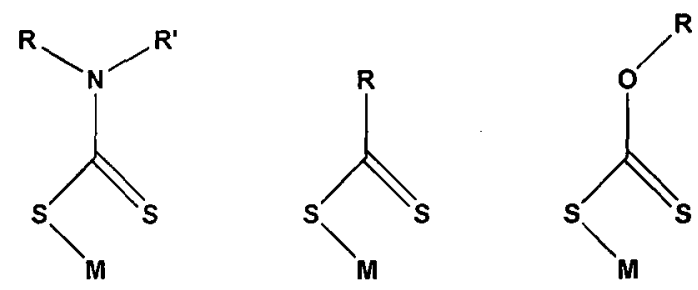

Figure 10: Dithilates, a) dithiocarbamates, b) alkyl dithiclates, cixanthates.

Xanthic acids are liquids, and thus could potentially form volatile CVD precursors when compounded with gold. They can also chelate the metal centre through both sulphur atoms, or to two metal centres in a bridging $\mu$-type bonding. This resonance in chelation allows for greater stability in the compound, hindering decomposition in the gas phase. 

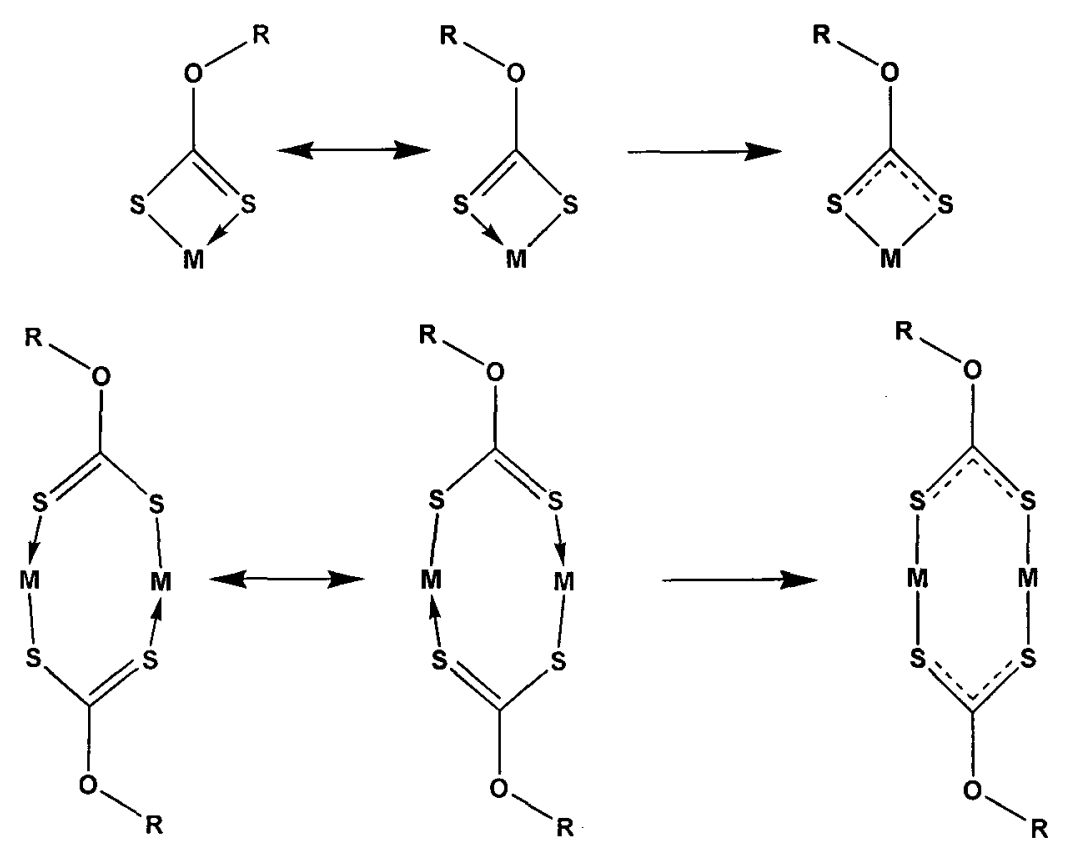

Figure 11: Resonance forms of chelating and bridging metal xanthates

Xanthates can also ligate using only one of the available sulphur groups in a formal manner or in bridging $\mu$-type bonding. Early in this work a third type of coordination was proposed, the possibility of weak coordination with the lone pairs on the oxygen group. However it is obvious that the metal centres used in this chemistry heavily favour sulphur coordination due to their inherent softness. Like guanidinates, xanthates are monoanionic ligands that allow for resonance stabilization when in the chelation coordination mode.
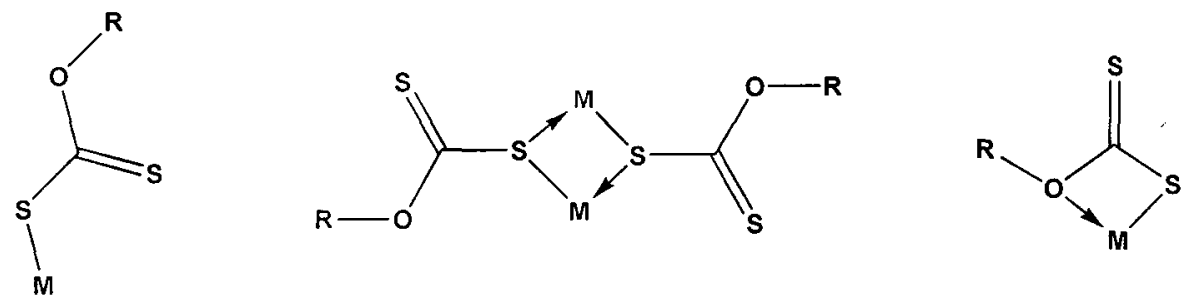

Figure 12: Possible bonding configurations through one sulphu moiety.

Xanthates were chosen as ligands for Au (I) metal centres for a combination of reasons. Firstly they are easily synthesized and purified. Two different synthetic routes can be employed to produce 
xanthate salts, one which can be applied to air sensitive syntheses and the other occurs in an aqueous environment (Figure 13).
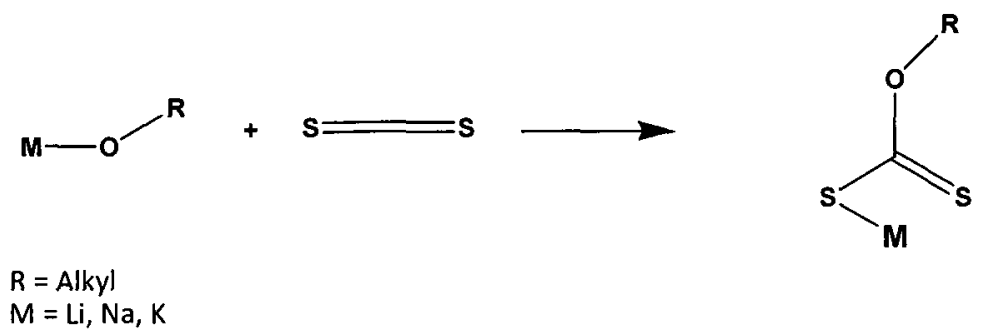

$\mathrm{M}=\mathrm{Li}, \mathrm{Na}, \mathrm{K}$
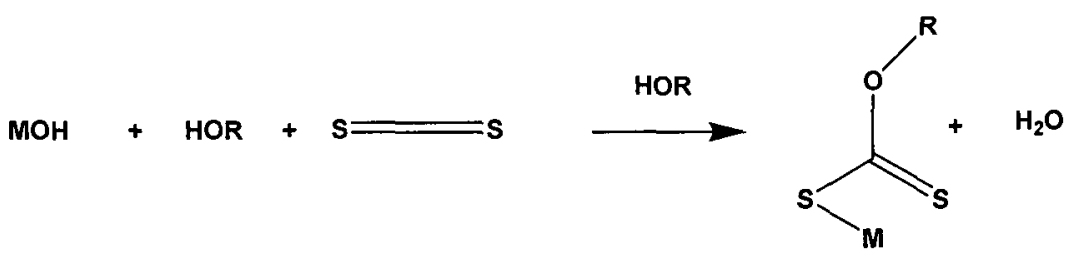

Figure 13: Generalized synthesis of xanthate salts

This simple synthesis allows for easy variation in the alkyl group simply by varying the solvent which is also a reactant in the first reaction pathway. The ligand is inexpensive to synthesize, which is a priority in this research to offset the cost of gold-containing reactants. The ligand is also monoanionic allowing for a coordinatively saturated $\mathrm{Au}(\mathrm{I})$ xanthate.

By far the most important aspect in choosing a ligand is its decomposition products. In CVD/ALD applications, the ligand preferably decomposes cleanly to volatile by products that are unreactive towards the target film. Vreugdenhil et al. found via gas phase IR experiments that metal xanthates of $\mathrm{Cu}$ (I) decomposed to $\mathrm{CS}_{2}, \mathrm{COS}$, and $\mathrm{CO}_{2}$ (21). Previous work done by Fackler et al. found that olefins of the alkyl group were also formed as $\mathrm{Cu}(1)$ xanthates decomposed (22). Similar decomposition studies have not been performed for gold (I) xanthates, but should yield similar results to that of $\mathrm{Cu}(\mathrm{I})$.

Even though gold is a noble metal there is some worry that $\mathrm{Au}_{2} \mathrm{~S}$ could be formed. Although there are no literature examples of this reactivity, it is known that silver xanthates form $\mathrm{Ag}_{2} \mathrm{~S}$ upon decomposition (23). However, these experiments were not performed at reduced pressure, and this 
reactivity occurred with dimeric silver xanthates not heteroleptic compounds as discussed within this thesis. The possibility of gold sulphide formation will be discussed in subsequent chapters.

\subsubsection{Phosphines and Thiophenes}

Phosphines and thiophenes are common neutral ligands employed in main group and transition metal chemistries.

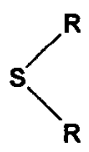

a)

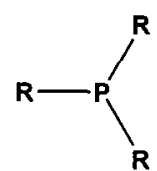

b)

$\mathrm{R}=\mathrm{alkyl}$

Figure 14: Generalized structures of a) thiophenes, b) phosphines, alkyl groups can be equivalent or inequivalent.

Group 11 metals in the +1 oxidation state prefer linear coordination modes to ligands. This is why dimeric structures are formed when using bidentate ligands. Rather than force the metal centre into a coordination mode that may cause instability in the product complex a dative bonding ligand might be used. A neutral dimeric complex might become monomeric if a strong enough dative bond is made to the metal centre, yet not so strong as to result in reduction of the metal centre. Thiophene has been shown to be a good stabilizing datively bonding ligand but has not yet been shown to form monomeric gold complexes (24). Phosphines prove to have similar reactivity to Au (III) as thiophenes. 
a)

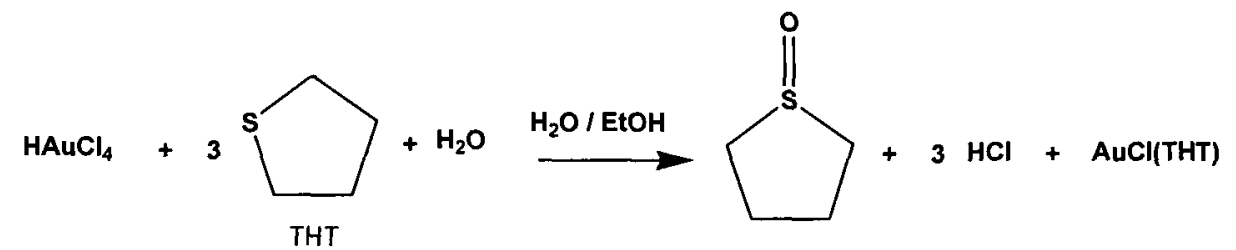

b)

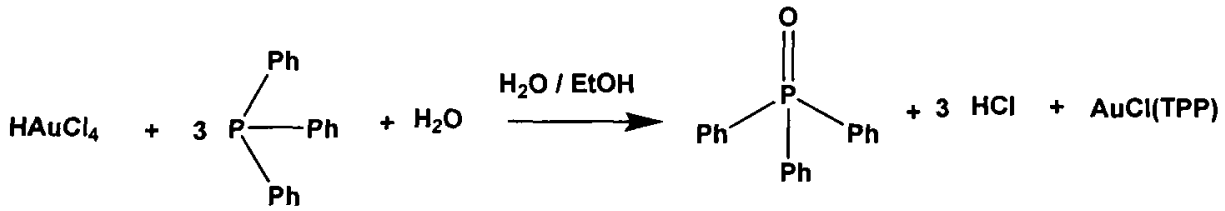

TPP

c)

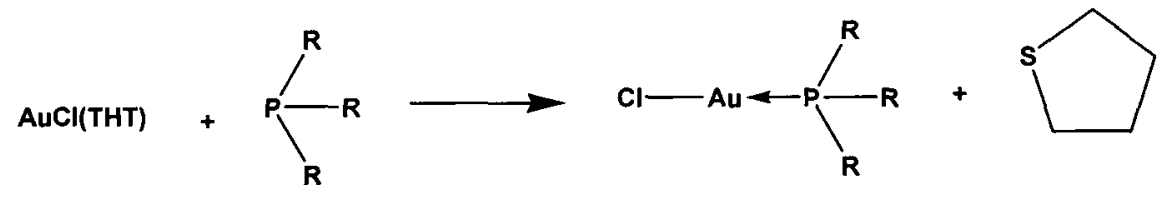
$\mathrm{R}=\mathrm{Alkyl}$

Figure 15:

a) Au(III) reduction by THT, b) Au(III) reduction by TPP, c) THT replacement by trialkylphosphine That is the reduction of $A u(I I)$ to $A u(I)$ complexes stabilized by a thiophene or phosphine yet without reduction to gold metal. The phosphines being stronger datively bonding ligands as they can replace thiophene in thiophene stabilized gold (I) complexes. The use of these in ligand environments with the above chelate ligands will be explored. 


\subsection{Group 11 first oxidation state stereochemistry}

Much theoretical work has been done to explain the trend of coordination number in the coinage metals (25). Generally the first oxidation state of group 11 metals prefer a linear coordination, although other coordination numbers are possible. $\mathrm{Au}(\mathrm{I})$ complexes show the most affinity for two coordinate linear complexes, some trigonal planar complexes are possible such as $\mathrm{AuCl}\left(\mathrm{PPh}_{3}\right)_{2}$, also the tetrahedral complex of $\left[\mathrm{Au}\left(\mathrm{PMe}_{3}\right)_{4}\right]^{+}$have been synthesized but lose phosphine ligands easily, reverting back to the diphosphine linear gold complex. Copper and silver also show a preference for two coordinate linear geometry, however not holding to that rule as stringently as gold. The trend of tendency for linear complexation of the coinage metals is $A u(I)>C u(I)>>A(I)$.

Based on Ligand Field Theory of bonding it may be favourable to hybridize the full $\mathrm{nd}_{\mathrm{z}^{2}}$ orbital with the vacant $6 s$ orbital. This hybridization leads to two orbitals, one with electronic density in the $x y$ plane and the other. In a second order mixing scenario the $\Psi_{2}$ (not the $5 \mathrm{~d}_{\mathrm{z}^{2}}$ directly) hybridizes with the $6 p$ to form two linear hybridized orbitals that result in $\mathrm{Au}(\mathrm{I})$ linear complexes (26).
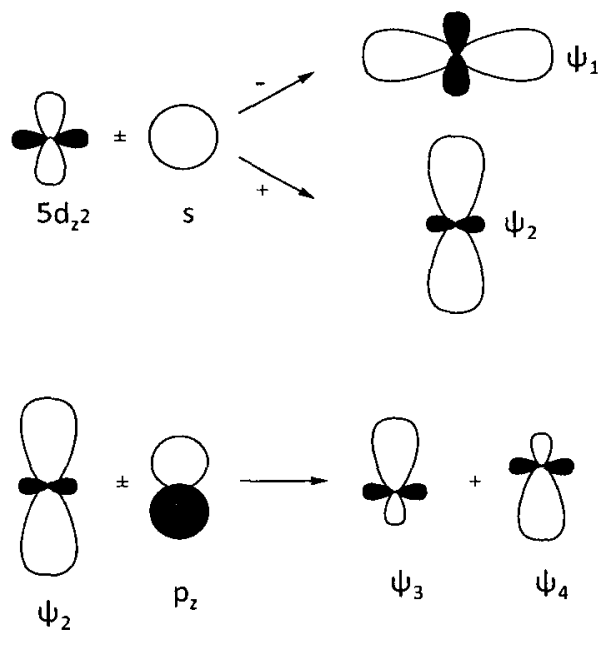

Figure 16: Hybridization of $5 d_{z^{2}}, 6 s$ and $6 p$ orbitals (26). 
Since the valence shell is the $6 s^{1}$ orbital it must be used in the hybridization, as opposed to mixing the $5 \mathrm{~d}_{\mathrm{z}^{2}}$ orbital directly with the $6 \mathrm{p}_{\mathrm{z}}$ orbital which would result in a similar hybridized orbital.

Other theories utilize only $s$ and $p$ orbital mixing to describe the bonding orbitals of the coinage metals (27). This may be accurate for copper and silver but in the case of gold with an entire f-block of electrons it is less likely that the hybridization is as simple as s-p hybrids. Trigonal planar complexes can be adequately described using $\mathrm{sp}_{\mathrm{x}} \mathrm{p}_{\mathrm{y}}$ hybridized orbitals but are of higher energy than that of the linear $\mathrm{sp}_{\mathrm{x}}$ hybridized orbital. The energy gap between the two possible orbitals is least in the case of silver showing that it is more likely than the other coinage metals to make a trigonal planar coordination. 


\section{Results and Discussion}

\section{Gold(I) Complexes}

\subsection{Amidinates and Guanidinates}

Gold guanidinates and amidinates have been previously studied to a small extent as catalysts. Gold oligomers (such as dimers, trimers and tetramers) have been shown to have high catalytic activity for the room temperature oxidation of $\mathrm{CO}$ on $\mathrm{TiO}_{2}$ surfaces. It's believed that the smaller the $\mathrm{Au}-\mathrm{Au}$ distance, the higher the activity (28). These dimeric gold complexes have a high molecular weight, as the ligands contain bulky ring structures in the attempt to use steric bulk to force metal centres closer together (29). Since ring structures tend to $\pi$-stack in the solid phase causing high melting points, and high molecular weights decrease volatility in an idealized manner, the previously studied compounds are not likely CVD/ALD candidates, but are useful for comparison to our results. Surprisingly, no thermal studies of the $\mathrm{Au}(\mathrm{I})$ amidinates or guanidinates have previously been reported. Since low molecular weight guanidinates and amidinates had not been synthesized or studied thermally we decided to determine their potential as CVD precursors by studying their thermal properties via atmospheric TGA, DSC, and MP, as well as sublimation temperatures.

The $\mathrm{Au}(\mathrm{I})$ amidinates and guanidinates proved to be unstable at room temperature, decomposing to metallic gold as well as other insoluble products. The decomposition was faster while in solution of hexanes or pentane and resulted in a gold mirror deposited on vials and flasks accompanied by deep purple / black precipitate. It was found that the $A u(I)$ amidinate and guanidinate complexes were unstable in polar solvents, prompting formation of $A u(0)$ starting as a red solution, turning purple then black; likely indicating the formation and agglomeration of nanostructures. Due to this decomposition, the compounds were stable and soluble in only a handful of solvents: hexanes, pentane and benzene, with a short lifetime unless kept at freezer temperatures $\left(-36^{\circ} \mathrm{C}\right)$. While dissolved in these 
solvents and shielded from light, decomposition occurred slower than when exposed to light. This shows a component of the decomposition is somehow photo assisted. Due the instability of this class of compounds, they were kept in the freezer at $-36{ }^{\circ} \mathrm{C}$ where solutions of the $\mathrm{Au}(1)$ amidinates and guanidinates had a lifetime of a few weeks, but as a solid could be kept indefinitely.

The synthesis of $A u(I)$ amidinates and guanidinates proved to be somewhat touchy. Firstly the reaction had to take place at low temperature $\left(-36^{\circ} \mathrm{C}\right)$. If the ligand salt was made in situ without being isolated as a solid before addition of $\mathrm{AuCl}(\mathrm{THT})$, then decomposition of the gold compound occurred, and greatly reduced yields. The reaction generally resulted in the highest yield when an isolated, solid lithium salt of the ligand was suspended in hexanes and subsequently cooled to $-36{ }^{\circ} \mathrm{C}$, followed by addition of solid $\mathrm{AuCl}(\mathrm{THT})$. Both $\mathrm{AuCl}(\mathrm{THT})$ and the ligand salt reactants were sparingly soluble in hexanes once isolated. This low solubility and low temperature likely limited the kinetics of side reactions that resulted in decomposition. The low solubility control of kinetics is in essence the same as using an extremely dilute reaction of soluble reactants. If the reaction took place at room temperature the reaction goes to the desired product, but decomposition occurred before the desired reaction can go to completion. Therefore the low temperature reduced the kinetics of reaction and maintained the stability of the reaction product until the reaction proceeded to completion.

\section{$\mathrm{Au}_{2}\left[(\operatorname{PrN})_{2} \mathrm{CMe}\right]_{2}(1):$}

The $A u(I)$ acetamidinate was initially synthesized in poor yield $(\sim 25 \%)$. These reactions were done overnight at $-36{ }^{\circ} \mathrm{C}$. Efforts were made to synthesize the sodium and potassium salts of the guanidinates in an effort to increase yield, since it had been reported in literature that lithium salts resulted in $\mathrm{Au}(\mathrm{I})$ reduction side reactions to $\mathrm{Au}(0)$ leading to poor yields(30). The potassium and sodium salts were synthesized by first quenching the lithium acetamidinate salt with water, forming acetamidine. After drying the liquid amidine completely, sodium or potassium hydride was used in a 
hydrogen elimination reaction that resulted in the production of either sodium or potassium amidinate salt, respectively. The combination of quenching by water, drying of the liquid amidine for reintroduction into the drybox and subsequent hydrogen elimination reaction made for an overall low yielding process for the ligand salt due to drying procedures. The synthesis of the sodium and potassium salts became more costly than possible benefits would yield, thus it was abandoned.

It was found that with continued use of the lithium salt the yield increased to acceptable levels (72\%) with careful, concise syntheses, as well as the washing of product mixture with additional warm hexanes. The additional solvent wash dissolved product that was otherwise insoluble at freezer temperature or trapped by the formation of insoluble $\mathrm{LiCl}$.

The ${ }^{1} \mathrm{H}$ NMR of 1 (see experimental) showed one doublet belonging to the methyl groups ( $\delta 1.25$ $\mathrm{ppm}$ ) of the isopropyl moieties bound to the chelating nitrogens. There was also one septet belonging to the methine proton ( $\delta 3.57 \mathrm{ppm}$ ), integrating with the methyl groups in a ratio of 2:12. The methyl groups are all equivalent due to free rotation about the methine-chelating nitrogen bond. Symmetry makes methyl protons on each chelating nitrogen equivalent. The single methine and methyl environments indicate a symmetric structure. A singlet was seen for the remaining methyl group bound to the backbone carbon ( $\delta 1.62 \mathrm{ppm})$ its integration was three.

The ${ }^{13} \mathrm{C}$ NMR showed a weak peak at $\delta 168.49 \mathrm{ppm}$, this is the common shift range of the unsaturated bridgehead carbon. Generally on a $300 \mathrm{MHz} N M R, 500+$ scans were required to resolve this signal. The methyl on the backbone carbon was found at $\delta 50.97 \mathrm{ppm}$ due to its proximity to the NCN resonance, followed by the methine carbons of the isopropyl groups, giving one peak ( $\delta 26.81 \mathrm{ppm})$, and the methyl carbons with one strong peak at $\delta 16.09 \mathrm{ppm}$.

The equivalent isopropyl peaks seen in the ${ }^{1} \mathrm{H}$ and ${ }^{13} \mathrm{C}$ NMR spectra is a common occurrence in the homoleptic monovalent gold and silver guanidinates and amidinates. They are indicative of 
symmetric structures, but does not clarify the extent of oligomerisation as these can also all be highly symmetric with equivalent ligand NMR spectra.

A solid phase experiment to determine the room temperature stability of solid phase gold (I) and silver (I) amidinate/guanidinate complexes was performed. Product was purified by recrystallization, dried and crushed into a powder. The samples were prepared in the drybox and left in vials exposed to ambient light and temperature. When discolouration was seen, this marked the stability of the complex. The longer the onset of discolouration the more stable the complex, this would determine whether a sublimation experiment could be performed, or whether the compound was too thermally unstable. It was found that the acetamidinate gold (I) compound would decompose in less than 12 hrs.

\section{$\mathrm{Au}_{2}\left[\left({ }^{\mathrm{i}} \mathrm{PrN}\right)_{2} \mathrm{C}^{\mathrm{n}} \mathrm{Bu}\right]_{2}(2):$}

Compound $\mathbf{2}$ was always isolated in low yields despite the improved synthetic method discussed for $\mathbf{1}$. The synthesis of $\mathbf{2}$ always resulted in decomposition, identified by the reaction solution going charcoal black and cloudy. This is possibly owing to the high solubility of the lithiated amidinate in hexanes. The long $n$-butyl backbone results in a high concentration of ligand in solution, causing the reaction to proceed too quickly, resulting in partial decomposition. This reaction was attempted under extremely dilute conditions with the same result.

After filtration of the aforementioned black precipitate, decomposition continued even when the supernatant was placed in the freezer. After 24 hours recrystallized product was found within the vial along with more of the black decomposition product, which was removed along with the solvent via pipette. The crystals were good enough for SC XRD analysis, and enough product was available for a ${ }^{1} \mathrm{H}$ and ${ }^{13} \mathrm{C}$ NMR. The reaction had to be repeated to obtain enough product for thermogravimetric analysis. 
The ${ }^{1} \mathrm{H}$ NMR had the typical methine proton septet at $\delta 3.74 \mathrm{ppm}$. An oddly shaped peak was seen at $\delta 2.26 \mathrm{ppm}$ and it integrated to two protons. The peak looked like an overlap of one triplet and two doublets (Figure 17).

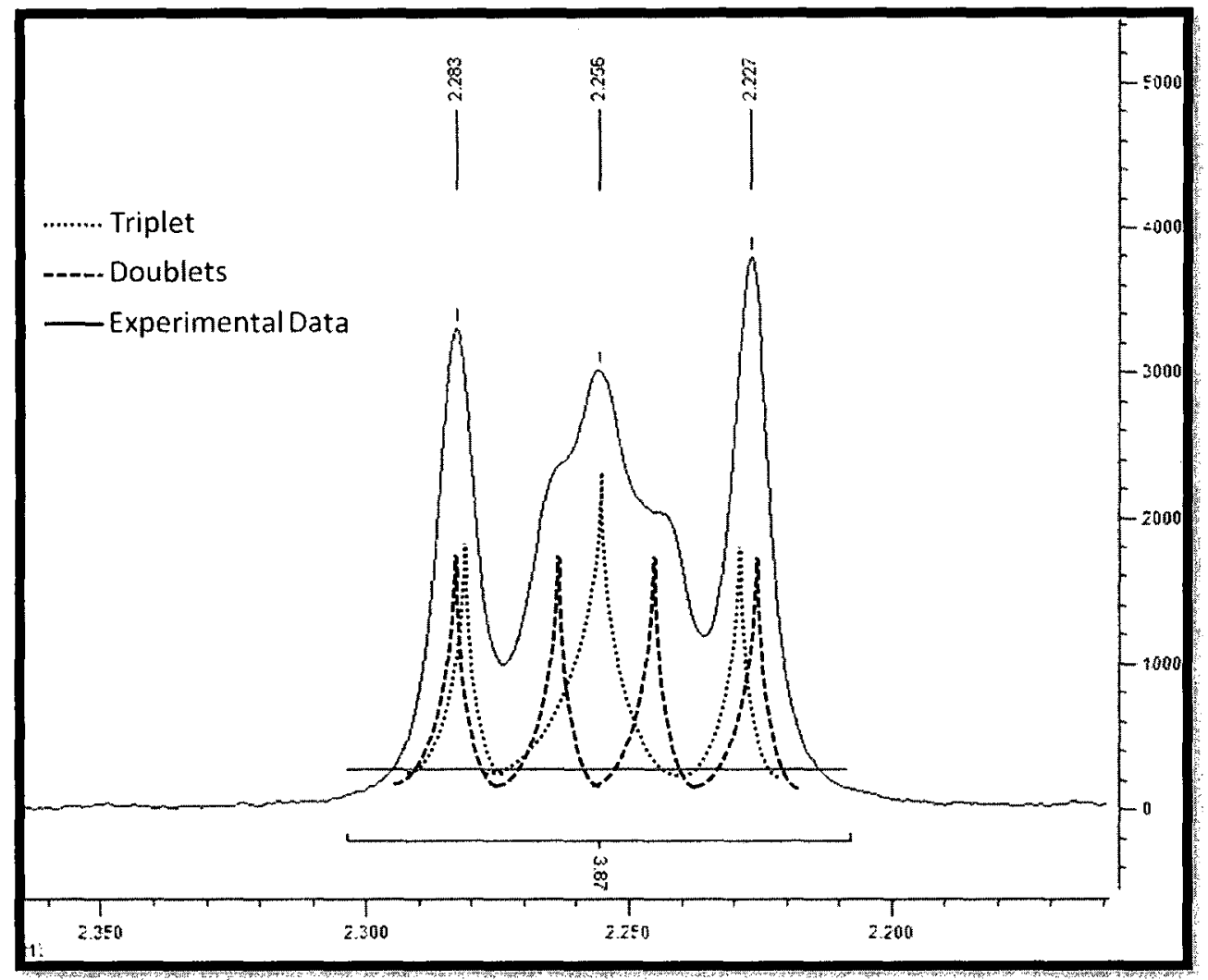

Figure 17: $\quad$ Complicated methylene proton signal for 2

The integration and shift indicated that this was the methylene protons associated with the carbon directly bound to the bridgehead carbon (position 1, Figure 18). Theoretically these protons should have been a triplet, split by neighbouring methylene protons (position 2, Figure 18). However, the rotation around this position was hindered on the time frame of the NMR. 


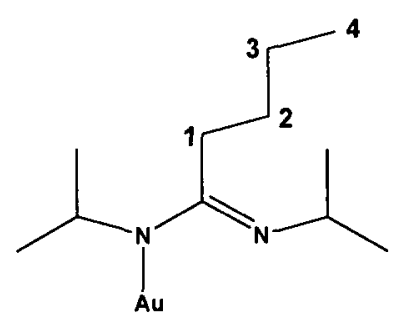

Figure 18: $\quad A u(1) n-B u t y l$ amidinate

The NMR takes snapshots of the proton environments. At one time a population of molecules shows two inequivalent protons on the second methylene carbon position, causing a doublet of doublets formation. A population of the molecules also is in the position where the protons are equivalent causing a triplet formation. These two signals average out to the unique formation seen in Figure 17 . The methylene peaks second from the bridgehead carbon (position 2, Figure 18) were similarly split into a multiplet and integrated to two protons ( $\delta 1.44 \mathrm{ppm})$, which could be two overlapping quintets or similar to the previous example, two quartets and a quintet. A doublet at $\delta 1.33 \mathrm{ppm}$ integrated to 12 protons corresponding to the isopropyl methyl groups. A sextet at $\delta 1.17 \mathrm{ppm}$ corresponded to the methylene protons furthest from the bridgehead carbon and integrated to two protons. Finally the triplet corresponding to the methyl group at the end of the $n$-butyl moiety was seen at $\delta 0.80 \mathrm{ppm}$ and integrated to 3 protons. The ${ }^{13} \mathrm{C}$ NMR was more straightforward with the bridgehead carbon at $\delta 171.55$ $\mathrm{ppm}$, a typical shift. The isopropyl methine was seen at $\delta 50.61 \mathrm{ppm}$ similar to 1 . Two methylene peaks moving away from the bridgehead carbon (position 3, Figure 18) were seen at $\delta 30.73 \mathrm{ppm}$ and $\delta 29.85$ ppm respectively. The isopropyl methyl carbon was seen at $\delta 27.20 \mathrm{ppm}$, the final $\mathrm{n}$-butyl methylene at $\delta 23.06 \mathrm{ppm}$, and the n-butyl methyl at $\delta 13.92 \mathrm{ppm}$, all were of typical NMR shifts. The solid phase ambient conditions experiment (the same as described for 1 ) where a purified powdered sample of 2 was left at ambient light and temperature; resulted in similar longevity as compound 1 . The $n$-butyl acetamidinate was synthesized in the hopes of increasing volatility by increasing the degrees of freedom 
of the ligand. The poor vield of the final product made this a poor choice for a precursor. Therefore a sublimation study was not performed.

\section{$\mathrm{Au}_{2}\left[(\operatorname{PrN})_{2} \mathrm{CN}(\mathrm{Me})_{2}\right]_{2}(3):$}

Compound 3 was isolated in reasonable yields $(71.8 \%)$, benefitting from the improved synthetic method discussed previously for 1 . Crystals were grown from hexanes that were of a quality acceptable for SC XRD.

The ${ }^{1} \mathrm{H}$ NMR was very straight forward. A single methine septet environment was seen at $\delta 3.80$ ppm corresponding to the isopropyl groups and integrated as two protons. Six protons were seen in a singlet at $\delta 2.43 \mathrm{ppm}$, corresponding to the two methyl groups bound to the exocyclic amine. These were equivalent due to free rotation about the bridgehead carbon and exocyclic nitrogen. A doublet at $\delta$ $1.37 \mathrm{ppm}$ belonged to the isopropyl methyl groups and integrated to twelve protons. The ${ }^{13} \mathrm{C}$ NMR showed the bridgehead carbon at $\delta 170.65 \mathrm{ppm}$, methine carbons of the isopropyl groups at $\delta 50.32$ ppm, methyl groups bound to the amine at $\delta 40.89 \mathrm{ppm}$ and the isopropyl methyl carbons at $\delta 27.21$ ppm. These were all standard shifts for these functionalities.

Compound 3 proved to be the only complex that was successfully sublimed. The compound was purified by recrystallization prior to sublimation. Some decomposition was seen in the pot of the sublimation apparatus as the compound was slowly heated. At approximately $60^{\circ} \mathrm{C}, 3$ slowly became off white-grey, then light purple, deep purple and finally black over time. The sublimed product on the cold finger remained white throughout the experiment. The decomposition seen in sublimation was slower than that seen in the melting point determination. This is due to a kinetic component to decomposition. When the compound was heated quickly as in the bench top melting point determination, the decomposition temperature was found to be higher. Yields during sublimation were thus increased dramatically once the sublimation temperature was found. A bench top solid phase experiment (the 
same as that described for 1 ) showed that this compound decomposed over a period of a day by showing a slight purple discolouration.

\section{$\mathrm{Au}_{2}\left[(\operatorname{PrN})_{2} \mathrm{CN}(\mathrm{Et})_{2}\right]_{2}(4):$}

The diethyl $\mathrm{Au}(\mathrm{I})$ derivative was found to be in the lowest yield due to its instability relative to the other Au (I) guanidinates. Similarly to 1, the sodium and potassium salts of the diethyl guanidinate were made from catalytically formed guanidine (31) for the purpose of applying the synthesis to the other $\mathrm{Au}(\mathrm{I})$ and $\mathrm{Ag}(\mathrm{I})$ guanidinates. It was found that the losses incurred during ligand synthesis did not outweigh the losses of gold starting material and was thus abandoned. The synthesis was carried out similarly to that of 3 .

The ${ }^{1} \mathrm{H}$ NMR showed one septet belonging to two methine protons ( $\left.\delta 3.80 \mathrm{ppm}\right)$. A quartet integrating to four protons was seen at a shift of $\delta 2.85 \mathrm{ppm}$, these corresponded to the methylene groups of the ethyl moieties bound to the exocyclic nitrogen. A doublet corresponding to the methyls of the isopropyl groups was seen at $\delta 1.39 \mathrm{ppm}$, integration showed twelve protons. Finally a triplet was seen $(\delta 0.83 \mathrm{ppm})$ corresponding to the methyls of the ethyl group bound to the exocyclic nitrogen, these integrated to six protons. The ${ }^{13} \mathrm{C}$ NMR showed the resonance of the bridgehead carbon to be at a typical shift of $\delta 166.33 \mathrm{ppm}$. At $\delta 50.45 \mathrm{ppm}$ the resonance for the methine carbon corresponding to the isopropyl groups was seen. The following peak was that of the methylene carbon bound to the exocyclic nitrogen ( $\delta 44.19 \mathrm{ppm}$ ). A shift of $\delta 27.13 \mathrm{ppm}$ showed the typical position of the isopropyl methyl carbon. At $\delta 13.30 \mathrm{ppm}$ the methyl carbons of the exocyclic ethyl groups were seen.

The decomposition of the diethyl guanidinate complex $\left(72^{\circ} \mathrm{C}\right)$ was found to occur at a lower temperature than all other gold ( 1 ) guanidinates studied. Compound 4 also proved to be more sensitive to light and temperature during the isolation procedure of the experimental. The solid phase decomposition experiment under ambient conditions (the same as that described for 1) resulted in 
decomposition after 3 hours; the first of all compounds studied to decompose. It was determined that this was the least stable of the Au (I) guanidinates and thus a sublimation experiment wasn't performed as we ruled it out as a precursor.

\section{$\mathrm{Au}_{2}\left[(\operatorname{PrN})_{2} \mathrm{CN}(' \mathrm{Pr})_{2}\right]_{2}(5):$}

The tetraisopropyl guanidinate $\mathrm{Au}$ (I) complex proved to have great overall yield at $91.1 \%$, greatly benefiting from an additional wash of hexanes.

The ${ }^{1} \mathrm{H}$ NMR was a little more complicated than that of the gold (I) guanidinates seen previously. This is due to the existence of two inequivalent isopropyl groups. The isopropyl methine proton shift was seen at $\delta 3.96 \mathrm{ppm}$ corresponded to the chelating nitrogen position. While the methine proton for the exocyclic nitrogen was seen at $\delta 3.26 \mathrm{ppm}$, both integrated to two protons each. Two sets of doublets were seen both integrating to twelve protons each. These corresponded to the methyls of the chelating position ( $\delta 1.39 \mathrm{ppm}$ ) and the exocyclic position ( $\delta 1.06 \mathrm{ppm})$. The ${ }^{13} \mathrm{C}$ NMR showed the bridgehead carbon shift to be $\delta 167.15 \mathrm{ppm}$. The carbons for the methine peaks were seen at $\delta 50.06$ ppm and $\delta 48.48 \mathrm{ppm}$ corresponding to chelating and exocyclic positions respectively. Similarly the peaks for isopropyl methyls were seen at $\delta 27.23 \mathrm{ppm}$ and $\delta 22.55 \mathrm{ppm}$ again corresponding to chelating and exocyclic positions respectively.

The compound was found to have a longer lifetime in the ambient conditions experiment (as described for 1) lasting more than a day, longer than all gold (1) amidinates or guanidinates, excluding compound 6. Unfortunately 5 decomposed prior to sublimation, excluding it as a gold CVD precursor. 


\section{$\mathrm{Au}_{2}\left[(\operatorname{PrN})_{2} \mathrm{CN}(\mathrm{TMS})_{2}\right]_{2}(6):$}

Compound 6 was the only guanidinate in this work that was synthesized from a potassium salt as opposed to a lithium salt. This was for convenience only. The potassium bis trimethylsilylamide was purchased from Aldrich, for curiosities sake it was reacted with diisopropyl carbodiimide to form $\mathrm{K}\left[(\mathrm{PrN})_{2} \mathrm{CN}(\mathrm{TMS})_{2}\right]$. Nothing else in the experimental was changed from that of the other gold (I) guanidinates.

Compound 6 was found to the most resilient to decomposition in the solid phase on the bench top. The white powder changed to slightly grey after a period of a week. Of the gold (1) guanidinates 6 had the highest decomposition temperature $\left(92{ }^{\circ} \mathrm{C}\right)$. Unfortunately the compound contained Si, which acts as a poison for conducting films, thus this material was excluded as a potential precursor and a sublimation study was not done.

The yield was marginally higher for 6 than the other guanidinates. This was most likely due to its higher stability. Once the compound was formed in solution it would take longer to decompose thus all reactants could go towards products before decomposition began, increasing yield. It is unlikely that the potassium guanidinate had any effect as potassium salts had be tried previously in this chemistry and found to increase the yield very minimally.

The ${ }^{1} \mathrm{H}$ NMR spectra contained a septet at $\delta 4.21 \mathrm{ppm}$ corresponding to the two methine protons of the isopropyl groups present on the chelating nitrogens. The isopropyl methyl doublet was seen at $\delta 1.39 \mathrm{ppm}$ and integrated to twelve protons. At $\delta 0.17 \mathrm{ppm}$ a singlet for the methyls of the trimethylsilyl moieties was seen and corresponded to eighteen protons. The ${ }^{13} \mathrm{C}$ NMR showed four carbon environments. The bridgehead carbon had a typical shift at $\delta 165.04 \mathrm{ppm}$. The methine carbons on the isopropyl groups had a shift of $\delta 49.73$, while the methyls had a shift of $\delta 27.46 \mathrm{ppm}$. The TMS carbons were located at $\delta 2.38 \mathrm{ppm}$. 


\section{$\operatorname{Au}\left[(\operatorname{PrN})_{2} \mathrm{CN}(\mathrm{TMS})_{2}\right](\mathrm{TPP})(7):$}

Various attempts were made to synthesize monomeric gold (I) guanidinates and amidinates by utilizing a strong dative ligand to coordinate to gold. Phosphines were chosen since they are a classic example and are of low molecular weight. Two pathways to achieve monomeric complexes were attempted. One method is the coordination of the phosphine to the gold chloride before introduction of amidinate or guanidinate lithium salt. The second route would be adding two equivalents of phosphine to the pre-existing dimeric products.

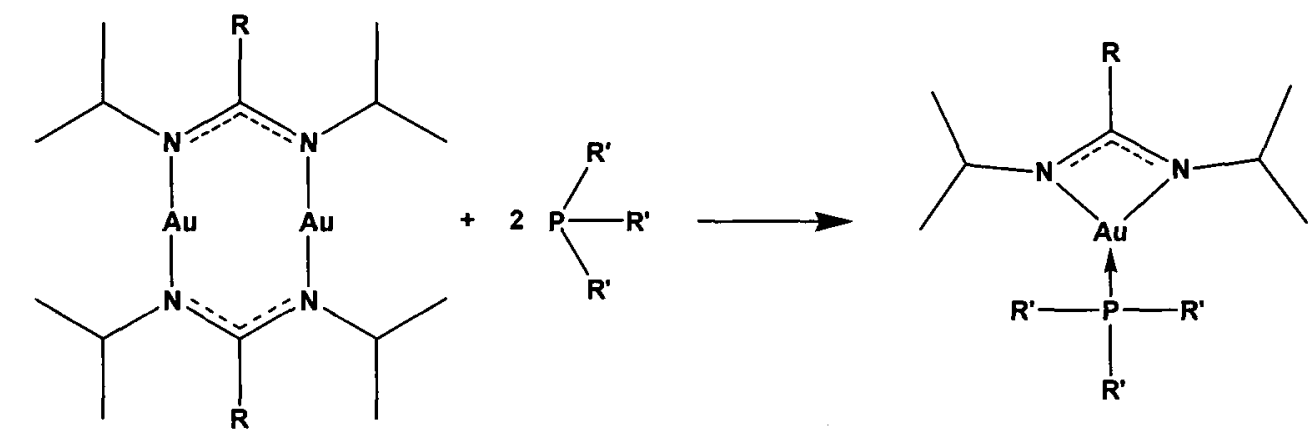<smiles>[R]C(=NC(C)C)N([Al])C(C)C</smiles>

Figure 19: $\quad$ Pathways toward monomeric gold guanidinates \& amidinates

It was found that both pathways proceeded without decomposition to metallic gold, but the desired products of these reactions were short lived and eventually resulted in the formation of an insoluble species. Additionally, it was found that the reaction would only proceed at room temperature in benzene or toluene. No decomposition was seen in the form of black precipitate or gold mirror. After filtration of the $\mathrm{LiCl}$, the solvent was removed under reduced pressure, during this time a white powder 
formed. The white powder proved insoluble in organic solvents, while decomposing to gold metal in coordinative solvents. Attempts to crystallize the product directly from the reaction solution post filtration resulted in an insoluble white precipitate. Interestingly when the bis trimethylsilyl guanidinate was used it had a significant lifetime before becoming an insoluble product. It's believed that these compounds oligomerized as opposed to decomposed as gold metal was not formed.

The proton NMR of 7 proved to be quite complex. Firstly the NMR consisted of two compounds, the heteroleptic compound 7, as well as the bis trimethylsilyl guanidine ligand. The guanidine ligand is a product of decomposition that occurred within the timeframe of preparing the NMR sample and collecting the spectrum. This was further demonstrated after the sample was ejected from the NMR and had a faint white cloudiness that was not there previously; this was the insoluble decomposition product starting to form.

The proton NMR spectra can be seen in Figure 20. The phenyl protons of the triphenyl phosphine were seen far downfield as to be expected of the electron withdrawing phenyl rings. There were two sets of peaks, one was centred at $\delta 7.51 \mathrm{ppm}$. These were the six protons closest to the phosphine centre. The other nine protons are centred about $\delta 6.96 \mathrm{ppm}$. These sets of peaks straddle the benzene NMR solvent peak at $\delta 7.15 \mathrm{ppm}$. The next environment centred at $\delta 5.56 \mathrm{ppm}$ is somewhat complex (see Figure 21). 


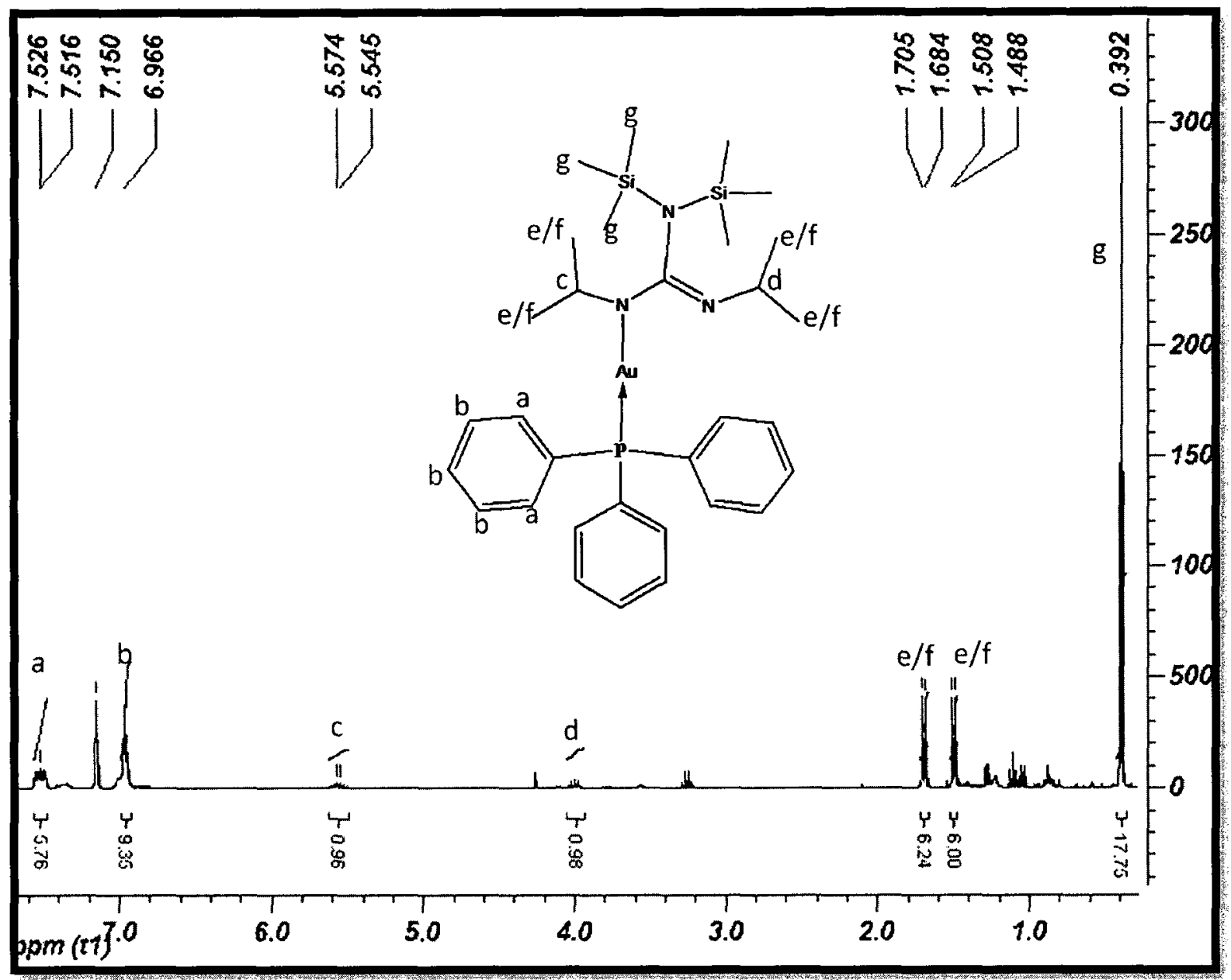

Figure 20: $\quad{ }^{1}$ HNMR Spectra of Compound 7

This is one of the methine protons. It exists as two overlapping septets, this is due to hindered rotation about the $\mathrm{C}-\mathrm{N}$ bond. The hindered rotation is due to sterically bulky exocyclic bis TMS amide. This steric hindrance was not from the TPP moiety as a similar splitting pattern was seen in the guanidine where no TPP is present (see inset of Figure 22, overlapping septets at $4.09 \mathrm{ppm}$ and $4.11 \mathrm{ppm}$ ). The methine proton shift is over $1 \mathrm{ppm}$ farther downfield than generally seen. 


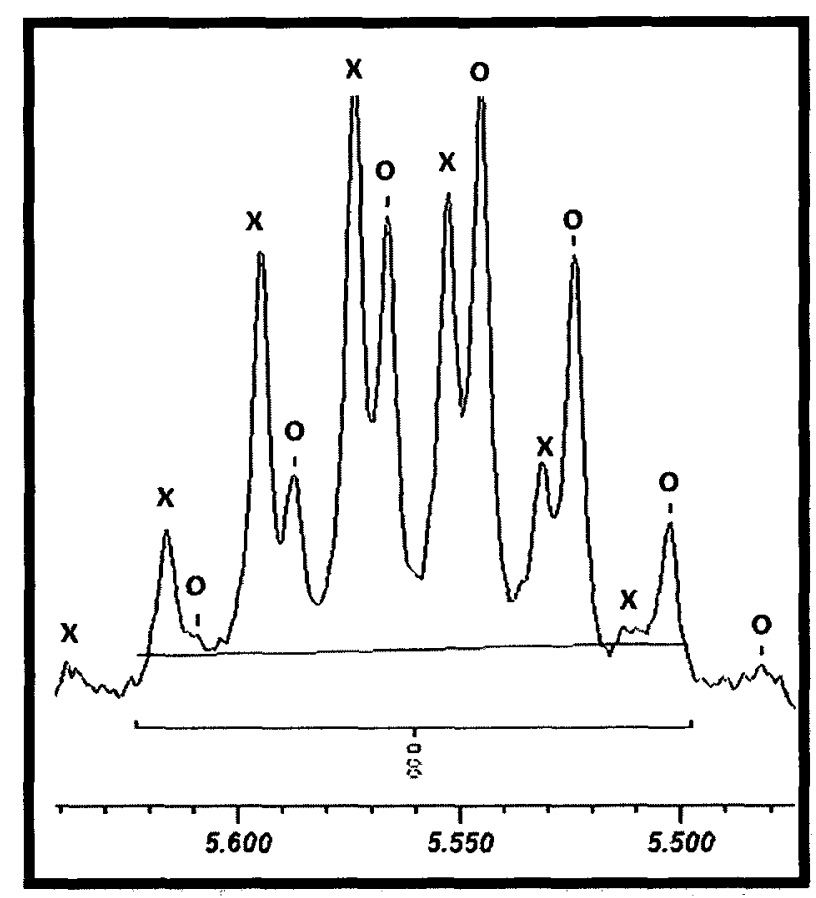

Figure 21: Methine proton of compound 7 showing two separate septets caused by hindered rotation of the isopropyl group.

Another methine proton is seen at $\delta 4.00 \mathrm{ppm}$ corresponding to the other isopropyl group that is unhindered by the exocyclic TMS moiety and was seen as a classic septet. Two doublets were seen at $\delta$ $1.69 \mathrm{ppm}$ and $\delta 1.49 \mathrm{ppm}$, these correspond to the two isopropyl methyl protons and both integrate to six protons each. It was unclear if the doublet which lies farther downfield corresponded to the same isopropyl group as the methine proton with a large downfield shift ( $\delta 5.56 \mathrm{ppm})$ but this was most likely the case. Finally a large singlet at $\delta 0.39 \mathrm{ppm}$ was seen to correspond to the 18 methyl protons of the exocyclic TMS position. 


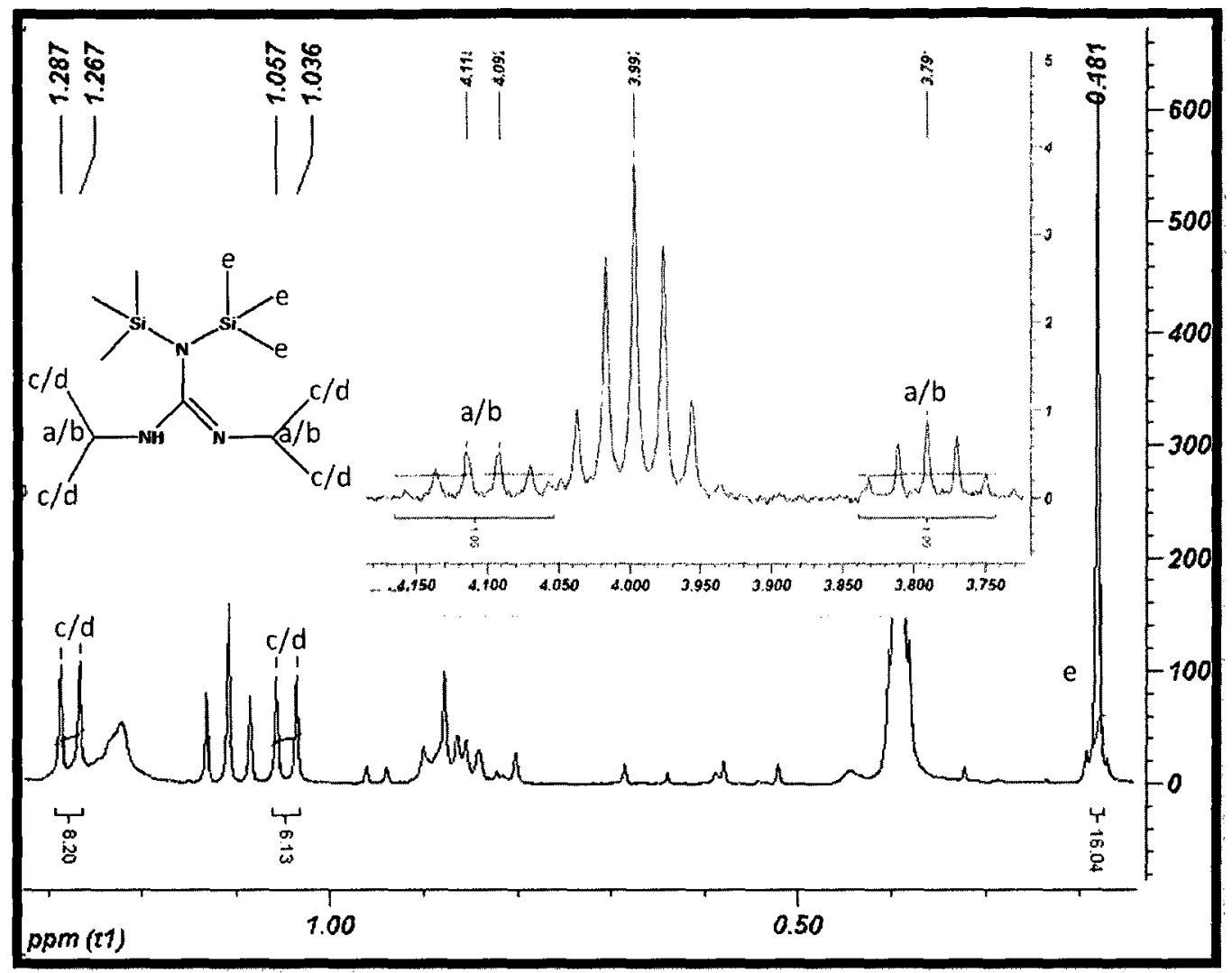

Figure 22: $\quad$ NMR spectra of 7 showing small TMS guanidine impurity, a product of slow decomposition

The existence of two separate methine and methyl environments on the chelating nitrogens suggests that the guanidinate is bonding to the gold centre through one nitrogen in a $k^{1}$ fashion. This behaviour is not unexpected, since Au (I) prefers a two coordinate linear geometry. The question is: why does the bis trimethylsilyl guanidinate ligand have a resistance to oligomerization/polymerization, unlike all other guanidinate and amidinate ligands seen in this thesis that were attempted in these heteroleptic systems? The most straightforward answer is steric bulk: the size of the backbone position decreases the bite angle of the ligand. Au (I) preference for linear geometry forces the compound into a non chelating geometry (Figure 23 a)). In the case of a bulky exocyclic group like bis TMS amide, this could decrease the bite angle of the ligand. This in turn could force the nonchelating nitrogen into a weak 
interaction with the metal centre (Figure $23 \mathrm{~b}$ )). Another possibility is that the guanidinate ligand rotates to a position in which the exocyclic position is partially protecting the metal centre (Figure $23 \mathrm{c})$ ). In this position the larger exocyclic group offers greater protection to the metal centre, thus making the bis TMS amide the more stable of the guanidinates due to its bulk (Figure $23 \mathrm{~d}$ )). However NMR data showed that the isopropyl group closest to the phenyl rings has hindered rotation caused by the bis TMS amide moiety. Thus this makes the geometry seen in Figure 23 b) most likely.

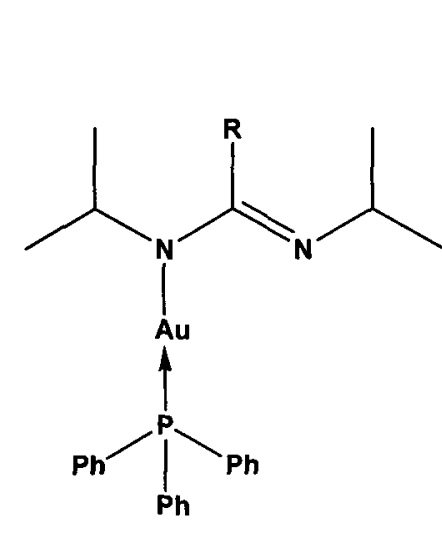

a)

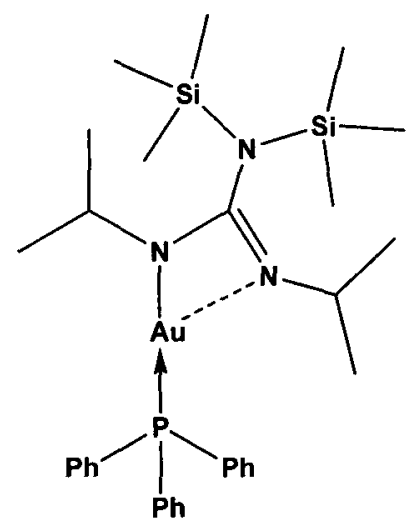

b)

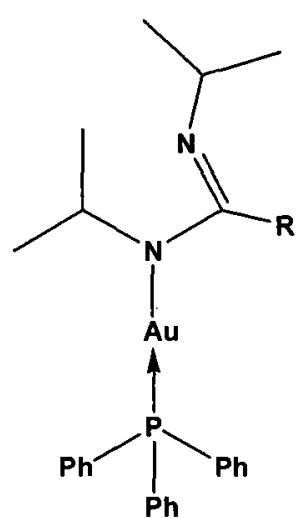

c)

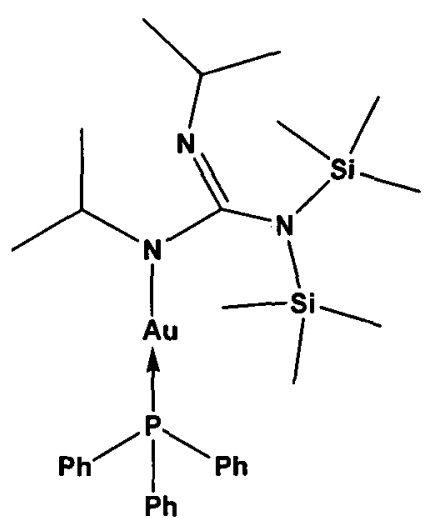

d)

Figure 23: $\quad$ Schematic of theoretical gold (1) guanidinate / amidinate monomer geometry 


\subsubsection{Crystal Structures}

There was concern that the amidinates and guanidinates of gold (I) would form tetramers, as seen in literature for different solvent systems for $\mathrm{Au}(\mathrm{l})$ guanidinates and $\mathrm{Ag}(\mathrm{I})$ guanidinates(29, 32).

The torsion angle is a measure of the planarity of the metallocycle. For gold $(I)$ amidinate and guanidinate dimeric structures, the torsion angle is measured using the chelating nitrogens in the structure in a ' $Z$ ' pattern, measuring the angle between the two ligand planes. If the nitrogens are all in the same plane the angle between ligand planes is $0^{\circ}$. The bite angle is defined as the angle between the chelating nitrogens and the bridgehead carbon.

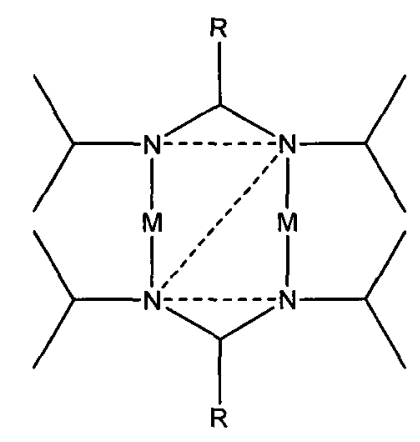

Figure 24: $\quad$ Torsion angle in amidinates and guanidinates (resonance removed for clarity)

The torsion angle can also predict the degree of participation in $\pi$ resonance of the backbone amide moiety. In the case of copper (I) guanidinate dimers there was seen a decrease in planarity (or core twist) between the two ligands as the backbone amide participated in the resonance. $A$ trend between melting point and core twist showed that with increasing backbone amide $\pi$ participation increased core twist and decreased melting point(33). The degree that the backbone amide moiety is participating also corroborates the bond length of the nitrogen with the central or bridgehead carbon. The shorter the bond length the greater the $\pi$ participation, increased core twist and ultimately greater volatility. 


\section{$\mathrm{Au}_{2}\left[(\operatorname{PrN})_{2} \mathrm{CMe}\right]_{2}(1)$}

Table 3: Selected Crystal Data of $\mathrm{Au}_{2}\left[\left({ }^{\mathrm{j}} \mathrm{PrN}\right)_{2} \mathrm{CMe}_{2}(1)\right.$

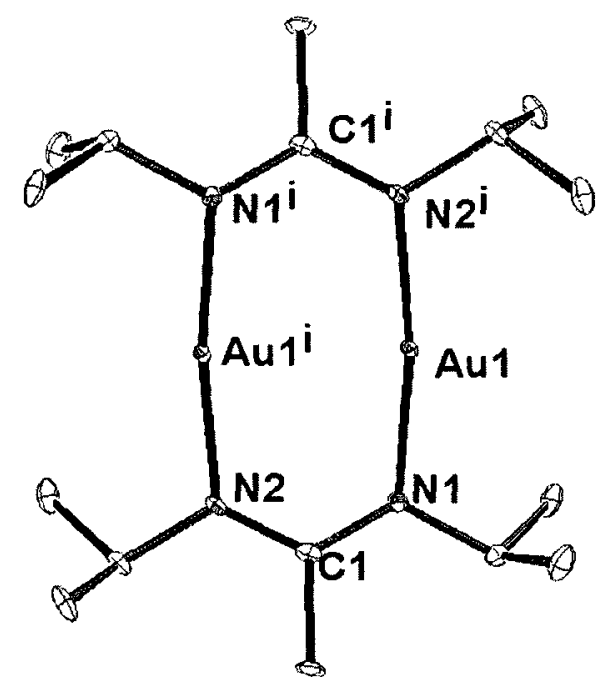

Figure 25: $\quad \mathrm{SC}-\mathrm{XRD}$ of $\mathrm{Au}{ }_{2}\left[\left({ }^{\mathrm{i}} \mathrm{PrN}\right)_{2} \mathrm{CMe}\right]_{2}(1)$.

Hydrogen atoms were omitted for clarity, and the thermal ellipses are shown at $30 \%$.

\begin{tabular}{|c|c|}
\hline Empirical formula & $\mathrm{C}_{16} \mathrm{H}_{34} \mathrm{Au}_{2} \mathrm{~N}_{4}$ \\
\hline fw & 676.40 \\
\hline$T(K)$ & 120 \\
\hline$\lambda(\AA)$ & $0.71073\left(\mathrm{Mo} \mathrm{K}_{\alpha}\right)$ \\
\hline Cryst syst & Monoclinic \\
\hline Space group & $\mathrm{C} 2 / \mathrm{c}$ \\
\hline $\mathrm{a}(\AA)$ & 25.98 \\
\hline $\mathrm{b}(\AA)$ & 11.23 \\
\hline$c(\AA)$ & 17.72 \\
\hline$\alpha(\operatorname{deg})$ & 90.00 \\
\hline$\beta(\operatorname{deg})$ & 131.98 \\
\hline$\gamma(\mathrm{deg})$ & 90.00 \\
\hline$\vee\left(\AA^{3}\right)$ & 4059 \\
\hline$Z$ & 8 \\
\hline$\rho$ (calcd) $\left(\mathrm{Mg} / \mathrm{m}^{3}\right)$ & 2.214 \\
\hline Abs coeff $\left(\mathrm{mm}^{-1}\right)$ & 14.443 \\
\hline Refinement method & $\begin{array}{l}\text { full-matrix least- } \\
\text { squares on F2 }\end{array}$ \\
\hline$R$ indices $[I>2 \sigma(I)]^{a}$ & $\begin{array}{l}R 1=0.0276 \\
w R 2=0.0507\end{array}$ \\
\hline \multicolumn{2}{|c|}{$\begin{array}{l}R 1=\Sigma|| F_{0}|-| F_{c}|| / \Sigma\left|F_{o}\right| \\
W R 2=\left(\Sigma W\left(\left|F_{0}\right|-\left|F_{c}\right|\right)^{2} / \Sigma W\left|F_{0}\right|^{2}\right)^{1 / 2}\end{array}$} \\
\hline
\end{tabular}

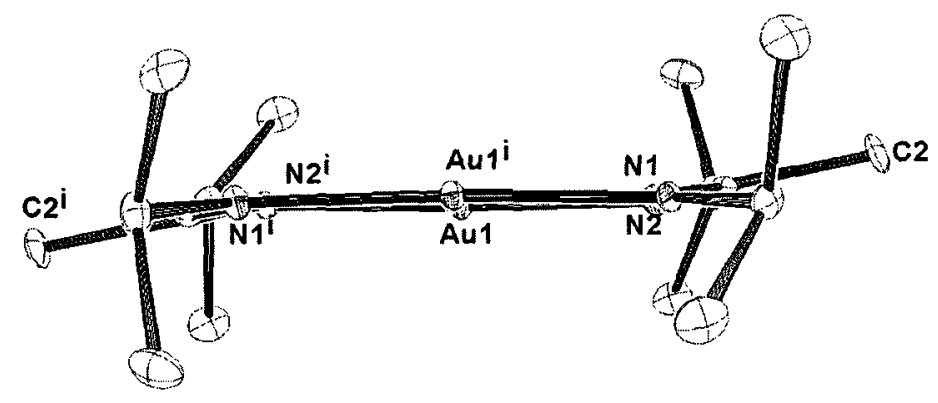

Figure 26: $\quad S C \times R D$ of $\mathrm{Au}_{2}\left[(\operatorname{PrN})_{2} \mathrm{CMe}\right]_{2}$ (1). Hydrogen atoms were omitted for clarity, and the thermal ellipses are shown at $30 \%$.

Crystals of $\mathrm{Au}_{2}\left[\left({ }^{\mathrm{i}} \mathrm{PrN}\right)_{2} \mathrm{CMe}\right]_{2}$ were grown from pentane in at $-30^{\circ} \mathrm{C}$ and underwent single crystal X-ray analysis (Figure 25). 
The central metallocycle that contained all the nitrogen, and gold centres was found to be perfectly planar with a torsion angle of $0^{\circ}$. The bridgehead carbons within the ring structure $\left(\mathrm{C} 1 / \mathrm{C}^{\prime}\right)$ were found to lie above and below the rings plane, offset by $8.7^{\circ}$ from planarity, this also resulted in the methyl groups $\left(\mathrm{C} 2 / \mathrm{C}^{\prime}\right)$ to lie above and below the plane. The isopropyl groups on the chelating nitrogens showed a standard geometry in which the methyl group bonded to the methine carbon bent toward the metal centres while the proton on the methine carbon pointed away from the metal centres. The methine carbon of the isopropyl groups lay within the same plane as the nitrogen and gold centres. The nitrogen centres were found to have a sum of angles around them close to $360^{\circ}$, which indicated their planar geometry, signifying that a $\pi$ resonance existed in the N-C-N moiety. Similar bond distances between the bridgehead carbon of the amidinate and the two chelating nitrogens also the existence of the resonance structure (see Table 6).

There is no reason to believe there is a Au-Au bond in these dimeric structures. As can be seen in Figure 25 , the gold centres were bowed out away from each other, trying to limit interaction, they were held within a close proximity by the amidinate ligands. The gold centres deviated slightly from linear geometry $\left(171.15^{\circ}\right)$, which indicated a further lack of bonding interaction between the gold centres. The Au-Au distance was $2.653 \AA$, shorter than the one other existing gold (1) amidinate dimeric species, $2.712 \AA$ found by Fackler in his formamidinates (34). The bite angle is dependent on metal centres within multi metal centred systems. Larger bite angles are indicative of larger metal centres that have larger $M-M$ distances. The bite angle of the amidinate ligand was found to be $122.37^{\circ}$, larger than those found in previously reported $\mathrm{Cu}$ (I) and $\mathrm{Ag}(\mathrm{I})$ amidinate complexes (20), and smaller than that found in the $\mathrm{Au}$ (I) formamidinate $\left(127.8^{\circ}\right)(34)$. The Au-N bond distances are similar to those seen in the monovalent $\mathrm{Cu}, \mathrm{Ag}$, and $\mathrm{Au}$ amidinate dimer examples (20,34). 


\section{$\mathrm{Au}_{2}\left[\left({ }^{\prime} \mathrm{PrN}\right)_{2} \mathrm{C}^{\mathrm{n}} \mathrm{Bu}\right]_{2}(2)$}

Table 4: Selected Crystal Data of $\mathrm{Au}_{2}\left[\left({ }^{i} \operatorname{PrN}\right)_{2} \mathrm{C}^{n} \mathrm{Bu}\right]_{2}$ (2)

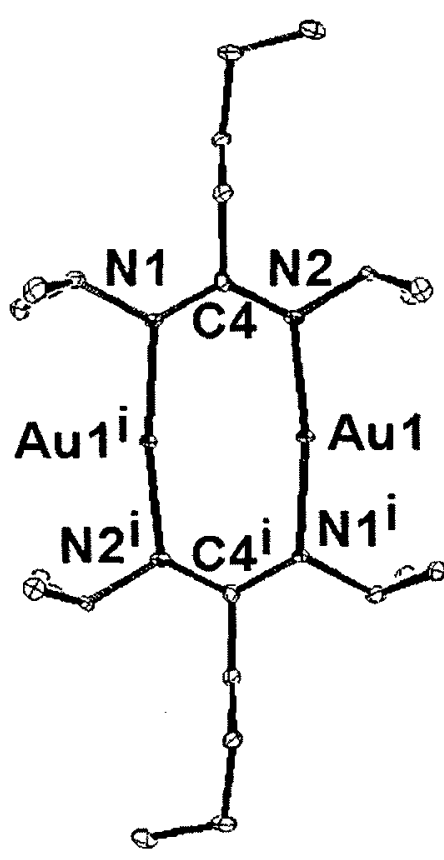

Figure 27: $\quad \mathrm{SC}-\mathrm{XRD}$ of $\mathrm{Au}_{2}\left[(\mathrm{PrN})_{2} \mathrm{C} B \mathrm{Cu}_{2}\right.$ (2). Hydrogen atoms were omitted for clarity, and the thermal ellipses are shown at 30\%.

\begin{tabular}{|c|c|}
\hline Empirical formula & $\mathrm{C}_{22} \mathrm{H}_{46} \mathrm{Au}_{2} \mathrm{~N}_{4}(2)$ \\
\hline$f w$ & 760.56 \\
\hline$T(K)$ & 120 \\
\hline$\lambda(\AA)$ & $0.71073\left(\mathrm{Mo} \mathrm{K}_{\alpha}\right)$ \\
\hline Cryst syst & Triclinic \\
\hline Space group & $P-1$ \\
\hline$a(\AA)$ & 7.851 \\
\hline $\mathrm{b}(\AA)$ & 8.88 \\
\hline$c(\AA)$ & 10.21 \\
\hline$\alpha$ (deg) & 104.22 \\
\hline$\beta$ (deg) & 102.47 \\
\hline$y($ deg $)$ & 105.08 \\
\hline$V\left(\AA^{3}\right)$ & 635 \\
\hline$Z$ & 1 \\
\hline$\rho$ (calcd) $\left(\mathrm{Mg} / \mathrm{m}^{3}\right)$ & 1.987 \\
\hline Abs coeff $\left(\mathrm{mm}^{-1}\right)$ & 11.54 \\
\hline Refinement method & $\begin{array}{l}\text { full-matrix least- } \\
\text { squares on } \mathrm{F} 2\end{array}$ \\
\hline R indices $[I>2 \sigma(l)]^{a}$ & $\begin{array}{l}R 1=0.0325 \\
W R 2=0.0681\end{array}$ \\
\hline \multicolumn{2}{|c|}{$\begin{array}{l}\text { R1 }=\Sigma|| F_{o}|-| F_{c}|| / \Sigma\left|F_{o}\right| \\
w R 2=\left(\Sigma w\left(\left|F_{o}\right|-\left|F_{c}\right|\right)^{2} / \Sigma w\left|F_{o}\right|^{2}\right)^{1 / 2}\end{array}$} \\
\hline
\end{tabular}

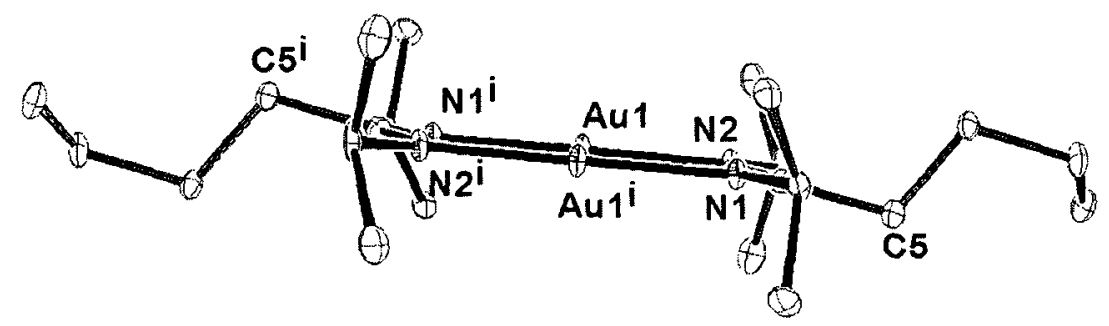

Figure 28: $\quad S C-X R D$ of $A u_{2}\left[(\operatorname{PrN})_{2} C^{n} B\right]_{2}(2)$, looking down the plane of the metallocycle. Hydrogen atoms were omitted for clarity, and the thermal ellipses are shown at $30 \%$. 
The $\mathrm{Au}_{2}\left[\left({ }^{\mathrm{i} P \mathrm{PN}}\right)_{2} \mathrm{C}^{\mathrm{n}} \mathrm{Bu}\right]_{2}$ complex was found to have a general structure similar to that of the $\mathrm{Au}_{2}\left[\left({ }^{\mathrm{P} r N}\right)_{2} \mathrm{CMe}\right]_{2}$. The metallocycle was again found to be planar with a torsion angle of $0^{\circ}$. The bridgehead carbons $\left(\mathrm{C} 4 / \mathrm{C}^{i}\right)$ were found to lie outside of the plane formed by the four nitrogens, lying $4.52^{\circ}$ above and below the plane. The isopropyl groups bound to the chelating nitrogens showed standard geometry as the methine carbons laid within the same plane as the nitrogen and gold centres. The planarity of the nitrogen centres indicated the existence of $\pi$ overlap between the nitrogens; similar bond distances to the metal centres and the bridgehead carbons were also seen. All Au-Au distances were similar in the amidinates and guanidinates where $\mathrm{Au}_{2}\left[\left({ }^{\prime} \mathrm{PrN}\right)_{2} \mathrm{C}^{n} \mathrm{Bu}\right]_{2}$ was the shortest (see Table 6). Shorter $\mathrm{Au}$-Au amidinate bond distances are seen only in Au (II) dimeric complexes. These divalent gold compounds have halides directly bonded to the metal centres. By removing an electron and adding the electron withdrawing halide it's possible to create a smaller Au-Au distance $(24,29)$. Since the Au-Au distance in compound 2 is the shortest of the gold amidinates/guanidinates it's fitting that the bite angle also be the smallest, as is seen (Table 6). 


\section{$\mathrm{Au}_{2}\left[(\operatorname{PrN})_{2} \mathrm{CN}(\mathrm{Me})_{2}\right]_{2}(3)$}

Table 5: Selected Crystal Data of $\mathrm{Au}_{2}\left[(\operatorname{PrN})_{2} \mathrm{CN}(\mathrm{Me})_{2}\right]_{2}(3)$

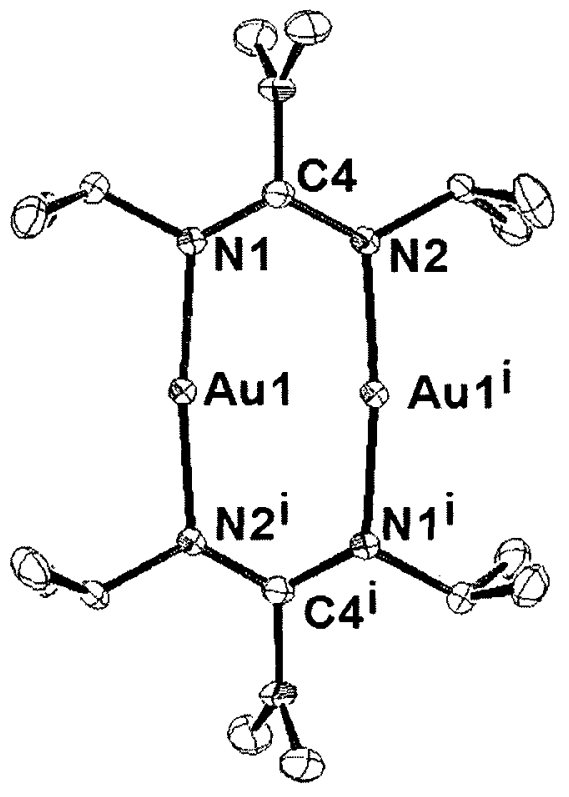

Figure 29: SC-XRD of $\left.\mathrm{Au}_{2} l(\mathrm{PrN})_{2} \mathrm{CN}(\mathrm{Me})_{2}\right]_{2}$

(3).Hydrogen atoms were omitted for clarity, and the thermal ellipses are shown at $30 \%$.

\begin{tabular}{|c|c|}
\hline Empirical formula & $\mathrm{C}_{18} \mathrm{H}_{40} \mathrm{Au}_{2} \mathrm{~N}_{6}$ \\
\hline fw & 734.49 \\
\hline$T(K)$ & 200 \\
\hline$\lambda(\AA)$ & $0.71073\left(\mathrm{Mo} \mathrm{K}_{\alpha}\right)$ \\
\hline Cryst syst & Monoclinic \\
\hline Space group & $\mathrm{C} 2 / \mathrm{c}$ \\
\hline$a(\AA)$ & 19.48 \\
\hline $\mathrm{b}(\AA)$ & 11.35 \\
\hline$c(\AA)$ & 12.08 \\
\hline$\alpha$ (deg) & 90.00 \\
\hline$\beta$ (deg) & 113.21 \\
\hline$\gamma(\mathrm{deg})$ & 90.00 \\
\hline$V\left(\AA^{3}\right)$ & 2454 \\
\hline $\mathbf{Z}$ & 4 \\
\hline$\rho($ calcd $)\left(\mathrm{Mg} / \mathrm{m}^{3}\right)$ & 1.988 \\
\hline Abs coeff $\left(\mathrm{mm}^{-1}\right)$ & 11.96 \\
\hline Refinement method & $\begin{array}{l}\text { full-matrix least- } \\
\text { squares on F2 }\end{array}$ \\
\hline$R$ indices $[1>2 \sigma(I)]^{\mathrm{a}}$ & \\
\hline \multicolumn{2}{|c|}{$\begin{array}{l}\text { R1 }=\Sigma|| F_{0}|-| F_{c}|| / \Sigma\left|F_{o}\right| \\
W R 2=\left(\Sigma W\left(\left|F_{o}\right|-\left|F_{c}\right|\right)^{2} / \Sigma W\left|F_{o}\right|^{2}\right)^{1 / 2}\end{array}$} \\
\hline
\end{tabular}

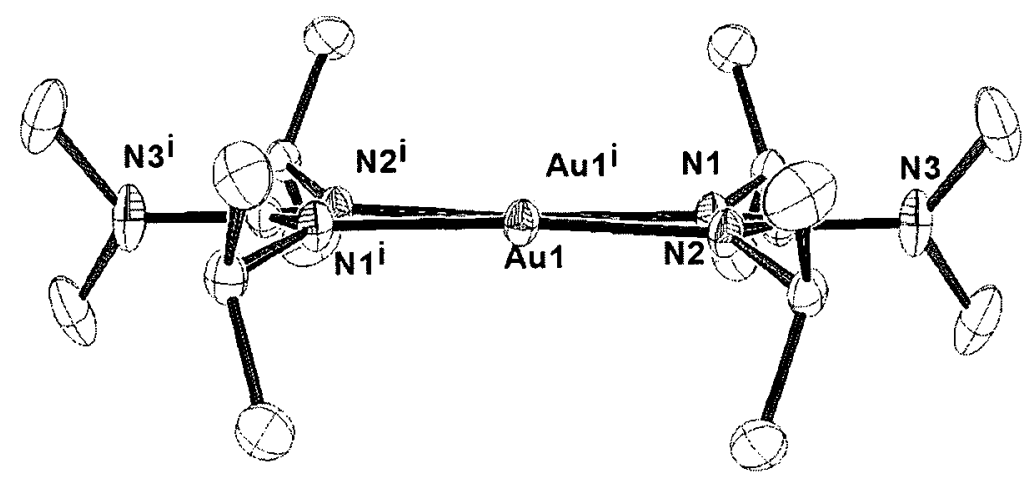

Figure 30: $\quad 5 \mathrm{C} \times \mathrm{XRD}$ of $\mathrm{Au}_{2}\left[\left({ }^{i} \mathrm{PrN}\right)_{2} \mathrm{CN}(\mathrm{Me})_{2}\right]_{2}(3)$, looking down the plane of the metallocycle. Hydrogen atoms were omitted for clarity, and the thermal ellipses are shown at $30 \%$.

It was seen in copper (1) guanidinates that the structure was heavily influenced by the existence of $\pi$ resonance not only within the cyclic nitrogen system but also with the exocyclic nitrogen position. This caused high torsion angles within the metallocycle (33). This was not 
seen in the gold (I) guanidinate. The $\mathrm{Au}_{2}\left[\left({ }^{\mathrm{i}} \mathrm{PrN}\right)_{2} \mathrm{CN}(\mathrm{Me})_{2}\right]_{2}$ complex was found to have similar metallocyclic structure as the previously described $A u(I)$ amidinates.

The methine carbons of the isopropyl groups bound to the chelating nitrogens lay above and below the central plane formed by the metal centres and the chelating nitrogens (see Figure 31). The sum of angles around the chelating nitrogen centres and surrounding bonds was $358.16^{\circ}$ a slight deviation from planar while the sum of angles around the bridgehead carbon was $360.01^{\circ}$. This was indicative of an extended $\pi$ system between the chelating and exocyclic nitrogens with the bridgehead carbon. The bond length of the bridgehead carbon with each of the nitrogens centres indicated by how much $p$ orbital overlap there was with the exocyclic amide. The distance to chelating nitrogens was $1.337 \AA$, while the distance to the exocyclic amide was $1.404 \AA$. The similar bond length to the exocyclic position is indicative that the electron pair spent some time in the exocyclic position. This caused the chelating nitrogens to lose electron density in their $\mathrm{sp}^{2}$ hybridized orbitals. This reduced their trigonal planar shape, and resulted in the methine protons to lie above and below the metallocycle plane.

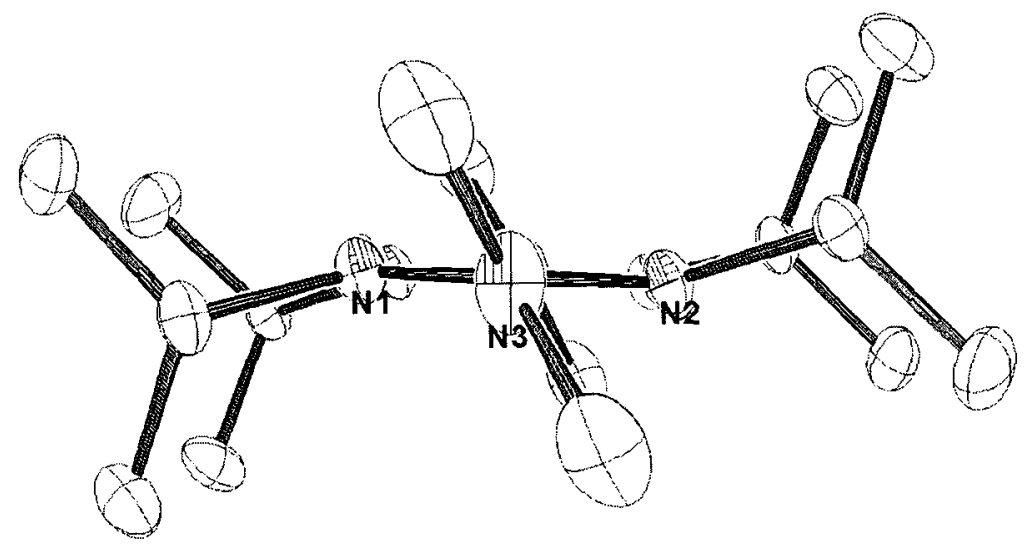

Figure 31: $\quad \mathrm{SC}-\mathrm{XRD}$ of $\left.\mathrm{Au} \mathrm{u}_{2}\left({ }^{\mathrm{PrN}}\right)_{2} \mathrm{CN}(\mathrm{Me})_{2}\right]_{2}(3)$, looking down the plane of the guanidinate ligand. Hydrogen atoms were omitted for clarity, and the thermal ellipses are shown at $30 \%$. 
Table 6: $\quad$ Selected Bond Lengths and Angles for gold (1) amidinates/ guanidinates.

\begin{tabular}{|c|c|c|c|c|c|}
\hline \multicolumn{2}{|c|}{$\mathrm{Au}_{2}\left[\left({ }^{\mathrm{i}} \mathrm{PrN}\right)_{2} \mathrm{CN}(\mathrm{Me})_{2}\right]_{2}$} & \multicolumn{2}{|c|}{$\mathrm{Au}_{2}\left[(\mathrm{PrN})_{2} \mathrm{CMe}\right]_{2}$} & \multicolumn{2}{|c|}{$\mathrm{Au}_{2}\left[\left({ }^{\prime} \mathrm{PrN}\right)_{2} \mathrm{C}^{\mathrm{n}} \mathrm{Bu}\right]_{2}$} \\
\hline \multicolumn{6}{|c|}{ Selected Bond Lengths $(\AA)$} \\
\hline Au1-N1 & $2.041(2)$ & Au1-N1 & $2.044(3)$ & Au1-N1 & $2.044(5)$ \\
\hline Au1-N2 & $2.038(2)$ & Au1-N2 & $2.037(3)$ & Au1-N2 & $2.044(5)$ \\
\hline Au1-Au1 & $2.6559(6)$ & Au1-Au1' & $2.6529(5)$ & Au1-Au1 & $2.6436(6)$ \\
\hline N1-C4 & $1.337(3)$ & $\mathrm{N} 1-\mathrm{C} 1$ & $1.328(5)$ & $\mathrm{N} 1-\mathrm{C} 4$ & $1.339(7)$ \\
\hline $\mathrm{N} 2-\mathrm{C} 4$ & $1.337(4)$ & $\mathrm{N} 2-\mathrm{C} 1$ & $1.346(5)$ & $\mathrm{N} 2-\mathrm{C} 4$ & $1.346(8)$ \\
\hline N3-C4 & $1.404(3)$ & & & & \\
\hline \multicolumn{6}{|c|}{ Selected Bond Angles $\left({ }^{\circ}\right)$} \\
\hline N1-Au1-N2 & $170.64(10)$ & N1-Au1-N2 & $171.15(13)$ & N1-Au1-N2 & $171.63(19)$ \\
\hline $\mathrm{N} 1-\mathrm{C} 4-\mathrm{N} 2$ & $123.8(2)$ & $\mathrm{N} 1-\mathrm{C} 1-\mathrm{N} 2$ & $122.6(4)$ & N1-C4-N2 & $121.8(5)$ \\
\hline \multicolumn{6}{|c|}{ Sum of Angles $\left({ }^{\circ}\right)$} \\
\hline N1 & 358.2 & N1 & 359.3 & N1 & 359.8 \\
\hline N2 & 358.2 & N2 & 359.8 & N2 & 359.6 \\
\hline N3 & 359.9 & & & & \\
\hline \multicolumn{6}{|c|}{ Torsion Angles $\left({ }^{\circ}\right)$} \\
\hline$N 1-N 2-N 1^{i}-N 2^{i}$ & 0 & $\mathrm{~N} 1-\mathrm{N} 2-\mathrm{N} 2^{i}-\mathrm{N} 1^{i}$ & 0 & $\mathrm{~N} 1-\mathrm{N} 2-\mathrm{N} 2^{i}-\mathrm{N} 1^{\mathrm{i}}$ & 0 \\
\hline
\end{tabular}

\subsubsection{Thermolysis}

It was found that the gold (I) amidinates and guanidinates were relatively thermally unstable. In a melting point study all compounds were found to decompose, slowly turning purple then black before melting ranging from $72{ }^{\circ} \mathrm{C}$ for the diethyl guanidinate complex and $96{ }^{\circ} \mathrm{C}$ for the $\mathrm{n}$-butyl amidinate. All of the compounds were also found to decompose before sublimation at 20 mtorr except for the dimethyl guanidinate which sublimes at $\sim 80^{\circ} \mathrm{C}$. Since the dimethyl guanidinate gold (I) complex could be volatilized and showed a low decomposition temperature $\left(83^{\circ} \mathrm{C}\right)$ it was applied to a simple CVD gold film deposition experiment (see Section 6.).

The decomposition of the gold (I) guanidinates and amidinates were studied by NMR (see experimental section 7.6.). The decomposition of both guanidinates and amidinates can proceed 
through two different routes. Firstly the $\beta$-hydride abstraction route that can result in the formation of one equivalent of guanidine / amidine and one equivalent of oxidized guanidine / amidine (Figure 32).

a)

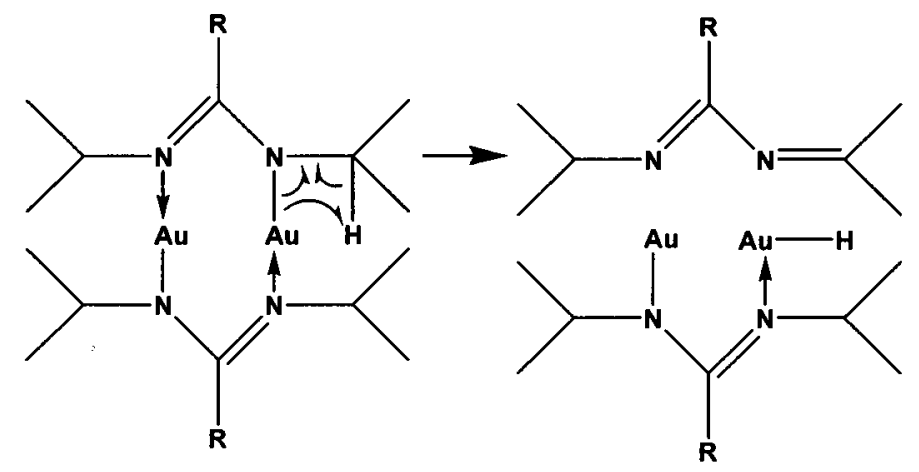

b)

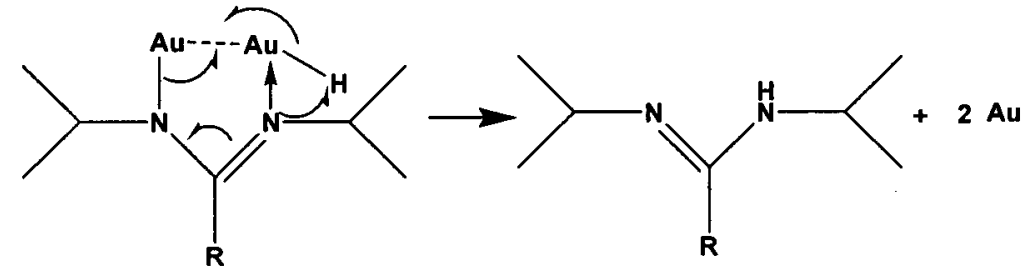

Figure 32: $\quad$ a) B-Hydride abstraction to produce one equivalent of oxidized guanidine and b) guanidine formation through a gold hydride intermediate

The second major pathway is the deinsertion of CDI to produce a metal amide or metal alkyl intermediate that can then disproportionate to gold metal.
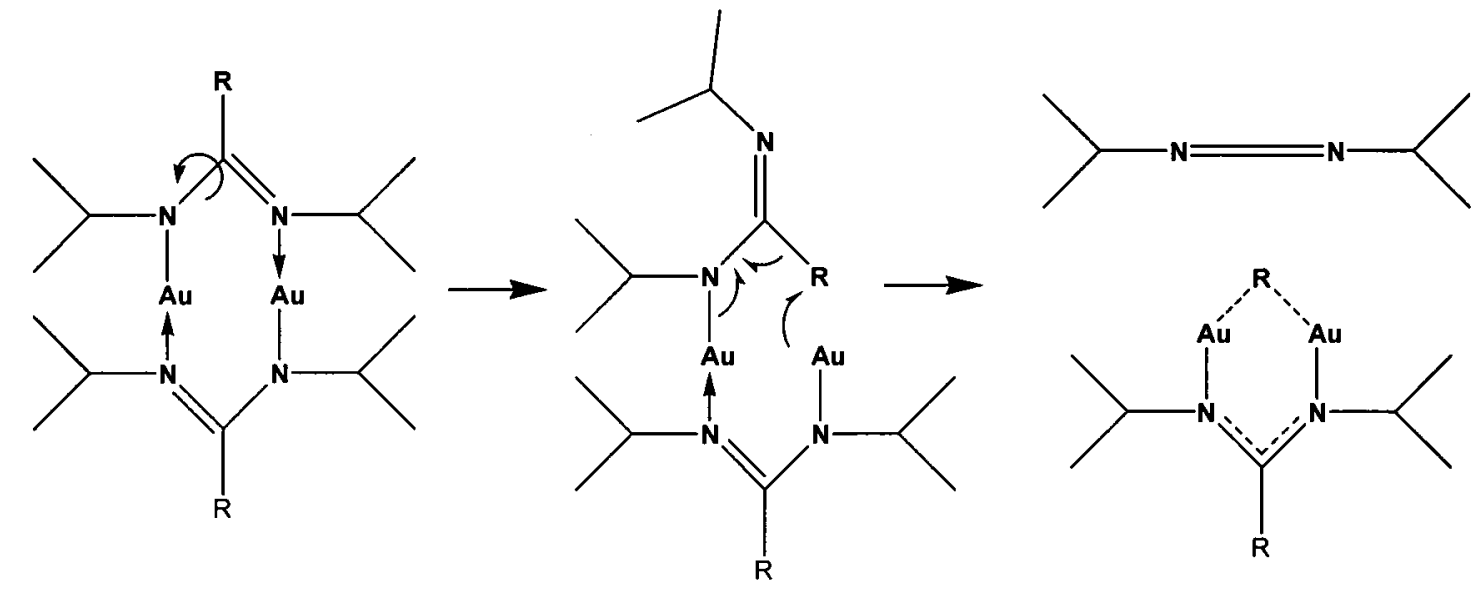

Figure 33: $\quad$ COI deinsertion to produce gold amide or alkyl gold complex 
Since there were two guanidinates or amidinates per molecule it became apparent that the CDI deinsertion pathway would have to occur twice, or the $\beta$-hydride abstraction would occur twice. Finally to make things more complicated an intermediate hydride could form the guanidine or amidine which can further decompose, depending on the temperature, to CDI and amine or alkane.

Decomposition studies for the gold (I) guanidinates showed varying results depending on the alkyl groups on the backbone position. The tetraisopropyl guanidinate was found by NMR to completely decompose at $120^{\circ} \mathrm{C}$ after $2 \mathrm{hrs}$. The product peaks showed numerous isopropyl doublets all within $\delta$ $0.4 \mathrm{ppm}$ range. CDI was seen as the major product in the decomposition spectra with a very distinct doublet shift of $\delta 1.04 \mathrm{ppm}$ with corresponding septet at $\delta 3.33 \mathrm{ppm}$. A spectra of the parent guanidine showed the remaining doublet environments in the decomposition corresponded with the guanidine. However the tetraisopropylguanidine has five isopropyl environments as it exists as two isomers in solution. These peaks could be overlapping other isopropyl environments such as a diisopropyl amine, another possible decomposition product. A separate experiment under the same conditions containing only tetraisopropyl guanidine was performed to determine if the ligand itself would deinsert CDI producing diisopropyl amine. The resulting spectra showed parent guanidine, and again CDI as a major product. Diisopropyl amine was not seen. A spectrum of diisopropyl amine yielded confirmation that the doublet could exist beneath one of the isopropyl doublets of the parent guanidine. Luckily the methine proton of the amine had a characteristic septet shift of $\delta 2.78 \mathrm{ppm}$ which can barely be seen. The low concentration of the diisopropyl amine was most likely due to amine volatility; once the cap on the NMR tube is opened to add solvent, the amine could escape. No oxidized tetraisopropyl guanidine was seen. This complex would have two singlets instead of an isopropyl environment, as well as having lost a methine proton environment. There is a possibility that the singlets could lie beneath the existing mass of doublets. But this is most likely not the case as the electron withdrawing ability of the newly formed 
nitrogen carbon double bond most likely places the singlets farther downfield above $\delta 1.50 \mathrm{ppm}$, beyond the isopropyl doublet region.

The existence of tetraisopropyl guanidine as a major product in the NMR showed that a major decomposition pathway must have been $\beta$-hydride abstraction. The existence of $C D I$ was confusing until it was realized that the guanidine itself would decompose to CDI and amine readily at the experimental conditions. The oxidized guanidine was not seen as a decomposition product, and the diisopropyl amine is seen in minimal quantities. The oxidized guanidine was presumed quite volatile as was the amine and could have escaped upon addition of NMR solvent. The other possibility was that they reacted with each other to produce an unknown complex or possibly insoluble oligomer or polymer.

The dimethyl guanidinate gold (I) complex decomposed via the $\beta$-hydride abstraction route as well. The NMR spectrum consists of free guanidine as the major product, but was absolutely devoid of CDI. In a separate experiment the dimethyl guanidine was found not to decompose under the same conditions. The lack of $\mathrm{CDI}$ gave insight into the decomposition of the previous tetraisopropyl guanidinate gold (I) complex. The deinsertion of CDI must have occurred after the formation of the guanidine, tetraisopropyl guanidine was less thermally stable than that of the dimethyl guanidine due to its steric bulk, thus resulted in amine and $\mathrm{CDI}$ at lower temperatures. The minor peaks of the decomposition spectra were of the most interest. A small isopropyl environment was seen as a doublet at $\delta 1.53 \mathrm{ppm}$ that integrated as 6 protons, to two singlets one upfield at $\delta 1.43 \mathrm{ppm}$, and one downfield at $\delta 1.71 \mathrm{ppm}$, integrated to 3 protons each. Finally a third singlet at $\delta 2.67 \mathrm{ppm}$ integrated to 6 protons. These peaks all revealed that the oxidized guanidine is formed as a decomposition product of the $\beta$ hydride abstraction. Unfortunately integration of the methine proton could not be determined as it overlapped with other environments, its shift was tentatively set at $\delta 3.34 \mathrm{ppm}$ (see inset of Figure 34). 


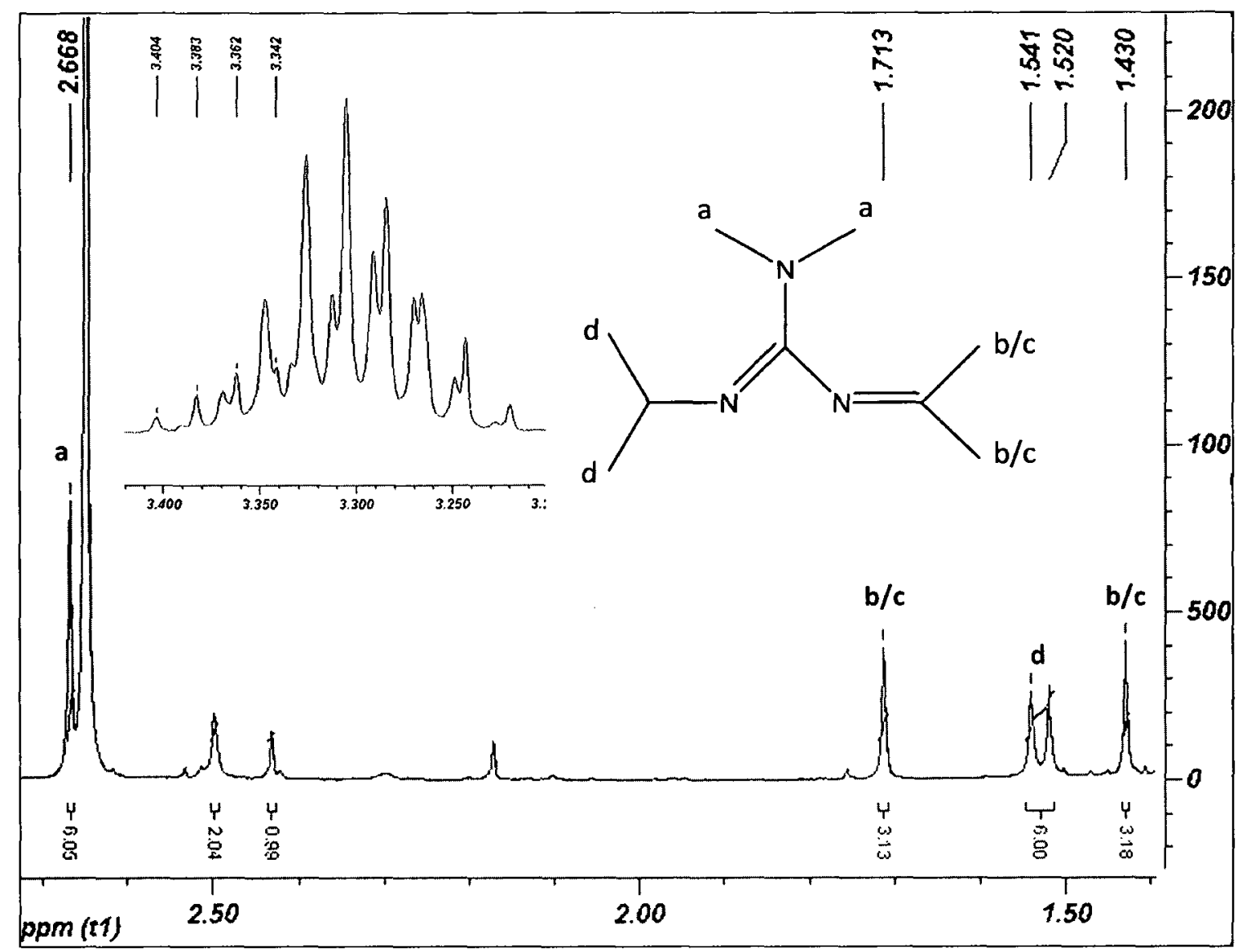

Figure 34: Decomposition spectra of compound 3 after 2 hours at $120^{\circ} \mathrm{C}$

The dimethyl oxidized guanidinate was presumably much more volatile than its parent guanidine due to the lack of hydrogen bonding between molecules. This may have resulted in the loss of some product upon addition of NMR solvent; this was why the oxidized guanidine product was in a ratio of $1: 6$ with the other decomposition product dimethyl guanidine. Theoretically as per Figure 32 , the ratio should be 1:1.

Unfortunately the dimethyl oxidized guanidine has not yet been successfully synthesized, to show comparative spectra to the single decomposition product. This product was hypothesized as a result of theoretical DFT work done by a colleague studying the decomposition of copper (I) guanidinate dimers. 


\subsection{Xanthates (homoleptic)}

\section{$\mathrm{Au}_{2}\left[\mathrm{~S}_{2} \mathrm{CO}^{\mathrm{n}} \mathrm{Bu}\right]_{2}(8):$}

The dimeric structure of $\mathrm{Au}$ (I) n-butyl xanthate has been synthesized previously by Fackler et al(35). However the thermolysis of this species and other analogues has not been studied nor has their applicability as CVD precursors studied. The $n$-butyl xanthate was synthesized to compare with Facklers results.

The synthesis of the compound was straight forward and was done on the bench top. Any alcohol could be used as the solvent; water was used as it was more convenient than methanol and ethanol. Also if methanol or ethanol is used, the solubility of the potassium xanthate salt is reduced, thus would require overnight synthesis as opposed to a couple hours in water. Contrary to gold (I) guanidinate or amidinate synthesis the product gold (I) xanthate is insoluble in the solvent and the potassium chloride is soluble. The yield was found to be quantitative. Unfortunately purification by recrystallization was impossible. The gold (1) homoleptic xanthates were found to be insoluble in most solvents, except for dimethylsulphoxide (DMSO). This made NMR analysis possible, but did not help with purification by recrystallization as the solvation was too strong. 


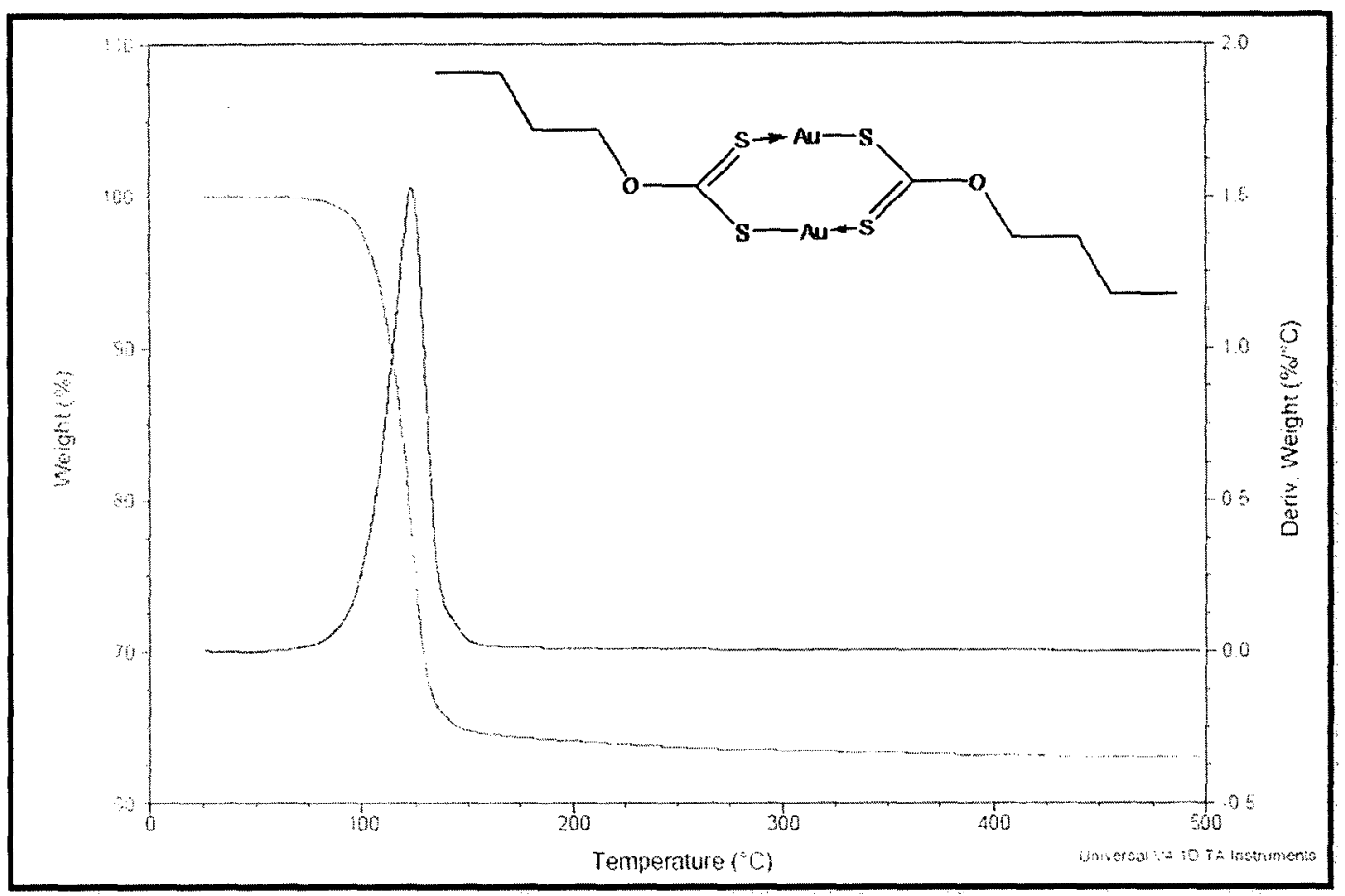

Figure 35: $\quad$ TGA analysis of 8

The TGA data was very compelling. It showed a slow onset of volatility initiating around $75^{\circ} \mathrm{C}$. This slow onset could mean evaporation, whereas a quick onset would have meant rapid decomposition. The $\%$ weight loss was found to equal that of the $n$-butyl xanthate ligand. The derivative curve shows one feature which is indicative of a clean decomposition, a requirement of CVD and ALD. When the sample pan was removed it was coated in gold metal. All of these findings lead us to believe that this could make a viable CVD precursor. However once a sublimation experiment was performed it was evident that the compound decomposed prior to sublimation. The homoleptic Au (I) xanthates were then abandoned as plausible precursors for CVD. 


\subsection{Xanthates (heteroleptic)}

\section{$\mathrm{Au}\left[\mathrm{S}_{2} \mathrm{CO}^{t} \mathrm{Bu}\right](\mathrm{TPP})_{2}(9):$}

Compound 9 was air stable thus synthesis was carried out on the bench top. AuCl(TPP) was dissolved in benzene while the ligand was added as a solution dropwise. The reaction yielded two immiscible liquids. $\mathrm{KCl}$ was dissolved in the aqueous phase while 9 was dissolved in the benzene. Attempts to grow SC XRD quality crystals resulted in failure.

The product was found to be pure by NMR once isolated. The proton NMR showed a multiplet at $\delta 7.41 \mathrm{ppm}$ and corresponded to the twelve proton environments on the phenyl rings closest to the phosphine. At $\delta 6.94 \mathrm{ppm}$ the other eighteen phenyl proton environments were seen as a multiplet. The methyl proton environments were seen at $\delta 1.66 \mathrm{ppm}$ and corresponded to the t-butyl group of the xanthate ligand. The integration was nine protons.

${ }^{13} \mathrm{C}$ spectrum gave the typical triphenyl phosphine carbon splitting pattern showing six separate environments. These were seen at $\delta 134.50 \mathrm{ppm}, \delta 134.29 \mathrm{ppm}, \delta 130.46 \mathrm{ppm}, \delta 130.44 \mathrm{ppm}, \delta 129.06$ ppm, $\delta 128.92 \mathrm{ppm}$. The methyl carbon of the xanthate moiety yielded a peak at $\delta 28.20 \mathrm{ppm}$. The carbon bound between the sulphur groups of the xanthate was not seen as previously discussed.

Compound 9 was found to melt at $120^{\circ} \mathrm{C}$ before decomposing. This prompted a sublimation experiment that resulted in melting at $120^{\circ} \mathrm{C}$ followed by decomposition at $135^{\circ} \mathrm{C}$ prior to sublimation. 


\subsection{Conclusions}

\subsubsection{Amidinates and Guanidinates}

The synthesis of all compounds was found to be good yield (>71\%) excluding that of compounds 2 and 7. The amidinates and guanidinates were found to be unstable in the presence of light, decomposing to metallic gold. Decomposition rates were increased when the compounds were dissolved in solution. The production of guanidine upon decomposition was found to be indicative of a $\beta$ hydride abstraction decomposition mechanism. The tetraisopropyl guanidine was found to decompose under the experimental conditions of $120^{\circ} \mathrm{C} .3$ was the only compound found to be sublimable. The crystal structures of compounds $\mathbf{1}, \mathbf{2}$, and $\mathbf{3}$ showed these compounds to be dimeric, it was assumed that the compounds without crystals would have also been dimeric, excluding 7.

\subsubsection{Xanthates (homoleptic)}

The work of Fackler et al. was recreated (35), in order to study the possibility of homoleptic xanthates as CVD precursors. It was found that these compounds decompose cleanly to metallic gold in a TGA experiment. However attempts to sublime (a requirement of vapour deposition techniques) 8 resulted in decomposition prior to sublimation.

\subsubsection{Xanthates (heteroleptic)}

With the introduction of ligand bearing sulphur in conjunction with two datively bonding phosphine ligands a compound stable under ambient conditions was prepared. 9 also proved stable enough to form a liquid at $120{ }^{\circ} \mathrm{C}$ but decomposed prior to sublimation at $135^{\circ} \mathrm{C}$. For the purposes of CVD or ALD this novel compound was seen as promising. Gold (1) xanthates utilizing low molecular weight phosphines have been shown to be distillable liquids, but never applied to the CVD or ALD field. 


\section{Silver (I) Complexes}

\subsection{Guanidinates}

Silver (I) guanidinate chemistry has not been very well studied. The only published data on the subject that could be found pertains to a hexanuclear bimetallic $A g(I), A u(I I)$ guanidinate complex in

which the gold centres bear the ligand and silvers bridge the gold centres(36). $\mathrm{Ag}(\mathrm{I})$ amidinate complexes have been synthesized by Gordon et al(20). These proved to be a mixture of dimeric and trimeric structures. The trimer differs from other homoleptic amidinate or guanidinate complexes of the +1 oxidation state group 13 metals, as these tend toward dimeric or tetrameric oligomers $(24,29,32-34$, $37,38)$. Our driving force for studying the guanidinates of $\mathrm{Ag}(\mathrm{I})$ was that the third resonance structure where the exocyclic group adopts an $\mathrm{N}=\mathrm{C}$ bond (see introduction) could force the silver centres to adhere to a dimeric conformation. It has been shown that the dimers of group 13 metals are volatile enough to prove useful in the formation of metal thin films via CVD (33).

The synthesis of the silver guanidinates was done in hexanes at room temperature. Like the gold (I) guanidinates, it was found that these compounds were sensitive to light and thus had to be wrapped in foil during synthesis. Unlike their gold counterparts the silver guanidinates did not form from the addition of $\mathrm{AgCl}$ to a suspension of the previously isolated guanidinate lithium salt. An in situ synthesis of the ligand at lower temperatures $\left(-36^{\circ} \mathrm{C}\right)$ also did not result in the formation of silver guanidinate without significant decomposition. Only upon addition of $\mathrm{AgCl}$ to a room temperature solution of ligand generated in situ could silver guanidinate be formed. It is likely that, upon drying, the ligand salt forms an insoluble oligomer that does not break upon re-suspension in hexanes (39). The reaction of silver chloride with the lithiade ligand in this case is less favourable than breaking the oligomer. Another possibility may be that, without a coordinating solvent, the alkali salts of the guanidinates and amidinates oligomerize into insoluble units larger than dimers. This conclusion is supported by the fact that all single crystal XRD of alkali guanidinate and amidinate dimers have a solvent of crystallization in 
the unit cell, all of which are polar $(39,40)$. The silver (I) guanidinates were also found to be pure by ${ }^{1} \mathrm{H}$ NMR without recrystallization. This was beneficial as the compounds did not have considerable lifetimes in solution during attempts to recrystallize them. These compounds were considerably less stable than their gold counterparts and couldn't be stored in the solid phase for more than a couple weeks. Decomposition was then seen as grey discolouration of the white solid.

\section{$\mathrm{Ag}_{3}\left[(\operatorname{PrN})_{2} \mathrm{CN}(\mathrm{Me})_{2}\right]_{3}(10):$}

Compound $\mathbf{1 0}$ was synthesized in hexanes by first forming the lithium salt in hexanes and rather than isolating the ligand product, $\mathrm{AgCl}$ was added. The reaction was done in the absence of light, as was the isolation process (see Section 7.4.). Crude yields were high (85\%) and the crude product was very pure by NMR, recrystallization resulted in considerably reduced yields (45\%). This was due to further handling of the unstable product to achieve slow crystal formation for high purity and for SC XRD quality crystals.

It was important to isolate crude product and perform a ${ }^{1} \mathrm{H}$ NMR analysis to determine if a mixture of dimer or trimer existed in solution, while crystallization may preferentially crystallize out one of the isomers. The crude NMR can be seen in Figure 36. One product was seen, and was very pure excluding the residual ether (from BuLi) and hexanes, the reaction solvent. 


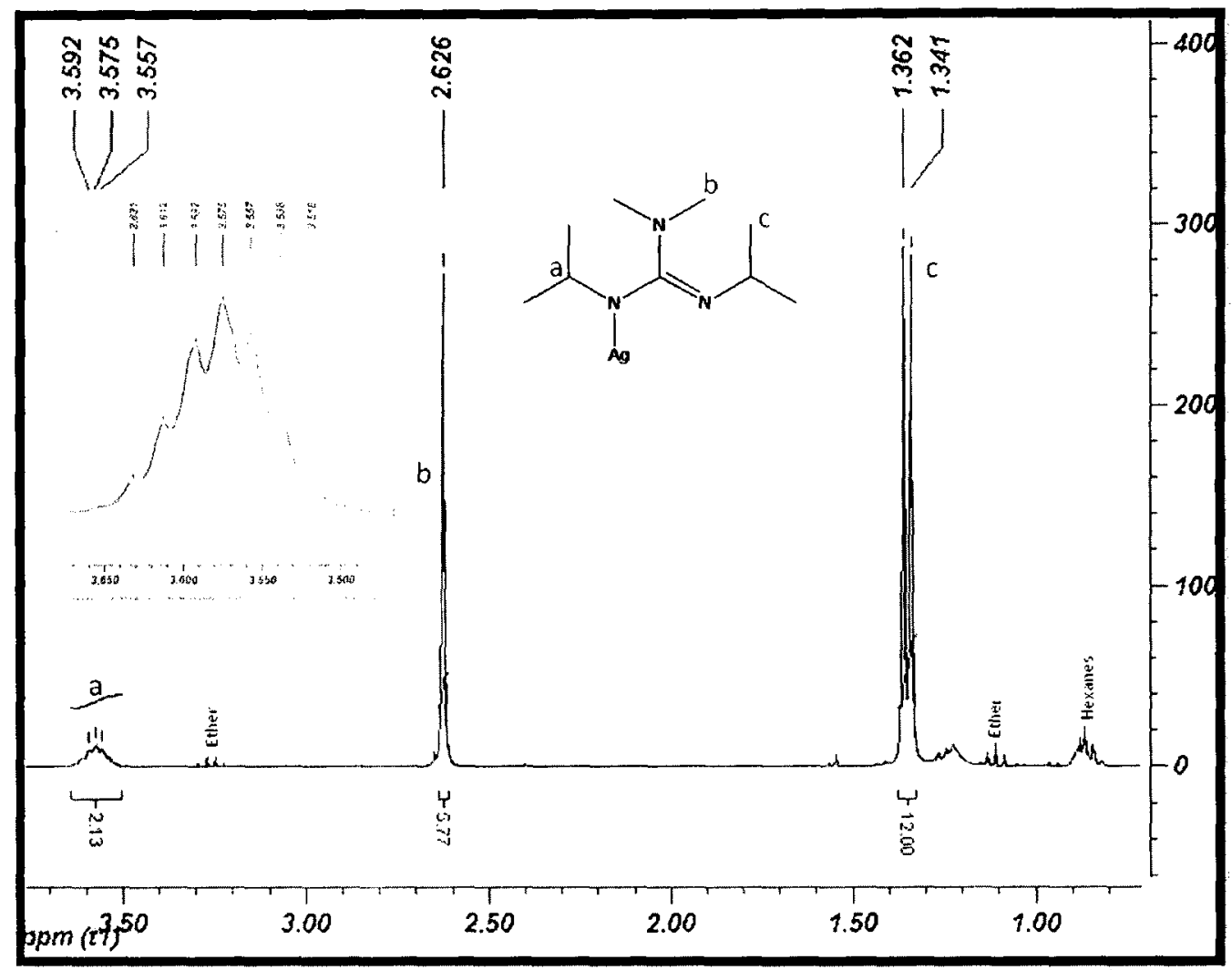

Figure 36: "HThR spectra of $\cdots$

Interestingly, the methine proton septet $(\delta 5.58 \mathrm{ppm})$ that corresponds to the chelating isopropyl positions was seen to be broadened (Figure 36), this was present in the recrystallized NMR as well (Figure 36 inset). This could have been indicative of almost equivalent methine protons overlapping. This broadening could be indicative of a more complex structure, most likely a trimeric species. The peak broadening wasn't seen in the methyl doublet $(\delta 1.35 \mathrm{ppm})$, corresponding to the twelve protons also on the isopropyl group. The exocyclic methyl protons bound to the amide were seen to have a shift of $\delta$ $2.63 \mathrm{ppm}$, and corresponded to six protons. 


\section{$\mathrm{Ag}_{3}\left[(\operatorname{PrN})_{2} \mathrm{CN}(\mathrm{Et})_{2}\right]_{3}(11):$}

The silver (I) diethyl guanidinate proved to be in poor vield (36.4\%). This was due to the unstable nature of compound 11. Synthesis was carried out by the same synthesis that the other silver (I) guanidinates were. However it was found when removing the solvent under vacuum that the result was a mixture of guanidine (liquid) and compound 11, making a viscous liquid. The silver complex could be isolated by recrystallization: a minimum of hexanes was used to dissolve the liquid then allowed to cool to $-36{ }^{\circ} \mathrm{C}$. The resulting solid was shown to be pure by NMR. Interestingly, it decomposed in the NMR solvent over the period of extended carbon scan durations owing to its instability. Similarly the diethylguanidinate complex of gold (1) (compound 4) was found to be the least thermally stable.

The ${ }^{1} \mathrm{H}$ NMR showed the typical isopropyl methine septet at $\delta 3.65 \mathrm{ppm}$, corresponding to two protons. The broadening of this peak was seen but was not as pronounced as in 10. A quartet integrating to four protons was seen at $\delta 3.01 \mathrm{ppm}$. These protons were from the methylene groups bound directly to the nitrogen in the exocyclic position. Twelve protons were found to correspond to a doublet found at $\delta 1.36 \mathrm{ppm}$. These were the methyl protons of the isopropyl groups bound to the chelating nitrogen positions. The final peak seen was at $\delta 0.95 \mathrm{ppm}$, a triplet of six protons corresponding to the methyl groups of the ethyl moieties bound to the exocyclic nitrogen.

The ${ }^{13} \mathrm{C}$ NMR spectrum shows five environments. The bridgehead carbon is seen at $\delta 168.40$ $\mathrm{ppm}$, similar to that seen for the other $\mathrm{Ag}(\mathrm{I})$ guanidinates. The next signal was seen at $\delta 48.62 \mathrm{ppm}$ corresponded to that of the methine carbons bound to the chelating nitrogen positions. At $\delta 43.91 \mathrm{ppm}$ the methylene carbons of the exocyclic positions were seen. The isopropyl methyls showed a signal at $\delta$ $27.85 \mathrm{ppm}$ while the methyl carbons on the ethyl moieties of the exocyclic position showed a signal at $\delta$ $13.44 \mathrm{ppm}$. 


\section{$\mathrm{Ag}_{3}\left[(' \mathrm{PrN})_{2} \mathrm{CN}(\mathrm{Pr})_{2}\right]_{3}(12):$}

The tetraisopropyl guanidinate silver (I) complex experimental differs from that of the other guanidinates (see Section 7.4.1.). The reaction was carried out at freezer temperature $\left(-36{ }^{\circ} \mathrm{C}\right)$ whereas the other compounds were able to be synthesized at room temperature. This was due to the increased solubility of the lithiated tetraisopropyl guanidinate in hexanes. At the concentrations used in the synthesis the ligand was completely dissolved at room temperature, upon addition of $\mathrm{AgCl}$ the reaction proceeded too quickly and instantly turned black. By cooling the ligand solution to $-36{ }^{\circ} \mathrm{C}$ the concentration of the lithiated ligand salt was decreased in solution. Upon addition of the $\mathrm{AgCl}$ the reaction proceeded slower with less concentration of ligand, thus being less exothermic. Once the synthesis was performed in the freezer the yields were found to be similar to those of the other silver (I) guanidinates (70\%).

The ${ }^{1} \mathrm{H}$ NMR spectra showed two methine protons at $\delta 3.85 \mathrm{ppm}$ and two at $\delta 3.46 \mathrm{ppm}$ as septets. These protons corresponded to methine groups of the chelating isopropyl positions and exocyclic positions respectively. The septet at $\delta 3.85 \mathrm{ppm}$ showed similar broadening that was seen for 10 in the inset of Figure 36. This broadening could be indicative of a more complex structure, most likely a trimeric species similar to that found for compound 10 . The broadening would be due to more than one partially overlapping septets. Two doublets were seen, also corresponding to both chelating and exocyclic methyl positions ( $\delta 1.34 \mathrm{ppm}, \delta 1.21 \mathrm{ppm}$ ). The peaks both integrated to twelve protons each.

The ${ }^{13} \mathrm{C}$ NMR showed a typical bridgehead carbon shift of $\delta 167.28 \mathrm{ppm}$. There were two separate carbon environments seen at $\delta 49.13 \mathrm{ppm}$, and $\delta 47.98 \mathrm{ppm}$. These corresponded to the methine isopropyl carbons in the chelating and exocyclic positions respectively. The methyl carbons of the chelating isopropyl group showed a shift of $\delta 27.60 \mathrm{ppm}$, with the exocyclic methyl carbon environment at $\delta 23.44 \mathrm{ppm}$. 


\section{$\mathrm{Ag}_{3}\left[(\operatorname{PrN})_{2} \mathrm{CN}(\mathrm{TMS})_{2}\right]_{3}(13):$}

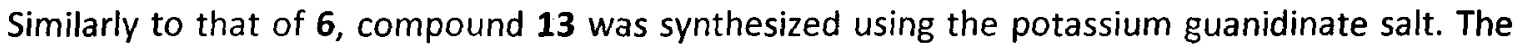
synthesis differed from the gold (I) TMS derivative in the same way as the other silver guanidinates. The ligand was made in situ by addition of $C D I$ to a suspension of potassium bis trimethylsilyl amide. The guanidinate was not isolated, prior to metal halide introduction. The addition of potassium instead of lithium did not seem to hurt the yield $(69.9 \%$ crude) or rate of reactivity of the reaction when compared to the other $\mathrm{Ag}(\mathrm{I})$ guanidinates. The final compound was able to be recrystallized and yielded a purified yield of $41.6 \%$

The recrystallized product yielded a ${ }^{1} \mathrm{H}$ NMR consisting of a methine environment at $\delta 3.76 \mathrm{ppm}$, corresponding to the isopropyl environments bound to chelating nitrogens. Integration was seen as two protons. The doublet for the methyl protons on the isopropyl groups was seen at $\delta 1.11 \mathrm{ppm}$, and showed an integration of twelve protons. The methyl protons bound to the silicon of the exocyclic trimethylsiliylamide moiety was seen at $\delta 0.29 \mathrm{ppm}$, and corresponded to eighteen protons. The ${ }^{13} \mathrm{C}$ NMR gave a bridgehead carbon shift of $\delta 157.92 \mathrm{ppm}$. The isopropyl methine carbon environments yielded a shift of $46.66 \mathrm{ppm}$, with the isopropyl methyls at $\delta 28.00 \mathrm{ppm}$. The TMS methyl carbons had a shift of $\delta 3.00 \mathrm{ppm}$.

The single crystal $x$-ray structure of silver (I) dimethyl guanidinate combined with NMR data leads us to believe that all the silver (I) guanidinates studied form trimeric complexes. Gordon et al(20) found that the amidinates of silver (I) formed a 1:1 mixture of dimer to trimer (as shown by NMR) but also forms a 1:2 dimer/trimer equilibrium in the solid phase seen by SCXRD. The acetamidinate silver (I) was also found to sublime at $80{ }^{\circ} \mathrm{C}$ and 40 mtorr. It's likely that the silver amidinate sublimed as a monomeric or dimeric species, then formed 1:2 trimer/dimer equilibrium in the solid phase and a 1:1 
equilibrium in NMR solvent. It was also found that the acetamidinate silver ( 1 ) melted at $95^{\circ} \mathrm{C}$ without decomposition.

The silver (I) dimethyl guanidinate complex was found to have only one product set of environments via NMR spectra. The SC XRD spectra showed that the compound exists as a trimer in the solid phase and not as a mixture of dimer to trimer. Gordon found two separate sets of environments in NMR spectra, one being the dimer and one the trimer. In the solid phase he found an increase in trimer concentration. The fact that we see one set of peaks in the NMR and one structure in the solid phase could mean that the trimer exists in the liquid and solid phase. It could also mean that the compound is dimeric in solution and converts completely to a trimeric structure in the solid phase, although this explanation is needlessly complicated.

\section{Amidinate / Guanidinate Heteroleptic Complexes}

An issue with bidentate ligands and monovalent metal centres is that they can form dimeric, trimeric, or complexes with a higher number of metal centres. As the units in the oligomer (and thus, the molecular weight) increases, the volatility of these complexes decreases, making poor precursors for CVD. In the effort of creating volatile CVD precursors, trialkyl phosphines have been used in conjunction with amidinates and guanidinates to promote monomer formation. Silver (I) metal centres are the best candidates of the group 11 monovalent metals for adduction, as they are the most likely to form tricoordinate species (26).

Using tributyl phosphine as the dative bonding ligand with silver ( 1 ) chloride yields a liquid silver halide that is stable at room temperature and ambient conditions (41). The halide was added to a solution of hexanes and pre-isolated guanidinate or amidinate lithium salt. It was found that after short reaction times (3-6 hours.), followed by filtration of the $\mathrm{LiCl}$, and removal of the solvent under reduced pressure yielded a viscous liquid. This liquid was extremely sensitive to oxygen and water. The liquid 
decomposed in a matter of minutes even within the drybox if left uncapped. In the freezer, this species had a lifetime of a day but never actually froze. Unfortunately the NMR spectra were extremely hard to discern. This is due to overlapping environments of the n-butyl phosphine ligand obscuring or overlapping with the xanthate alkyl environment. We were able to determine that the chloro silver phosphine, as well as guanidine (a decomposition product) was present in the NMR. Attempts to distill were unsuccessful due to the compound's reactive nature. If the reaction is done over an extended period, the result is the homoleptic silver (I) guanidinates. When attempts were made to crystallize the product as a softer method of isolation, the homoleptic silver compound recrystallized leaving $n$-butyl phosphine in the mother liquor.

\subsubsection{Crystal Structures}

\section{$\mathrm{Ag}_{3}\left[(\mathrm{PrN})_{2} \mathrm{CN}(\mathrm{Me})_{2}\right]_{3}(8)$}

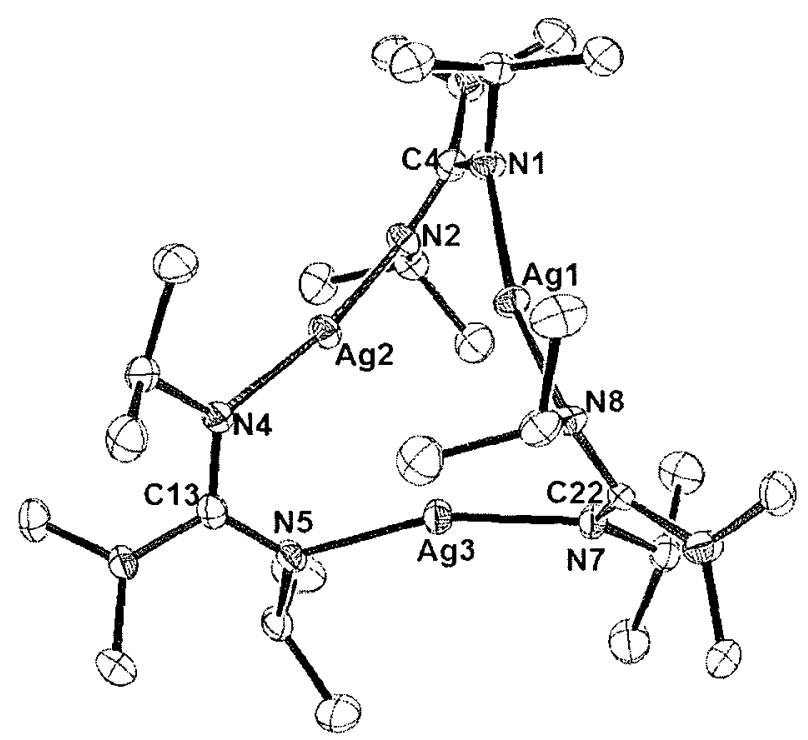

Figure 37: SC XRD of $\mathrm{Ag}_{3}\left[(\mathrm{PrN}) \mathrm{CN}(\mathrm{Me})_{2}\right]_{3}(8)$. Hydrogen atoms were omitted for clarity, and the thermal ellipses are shown at $30 \%$
Table 7: Selected Crystal Data of Ag $\left.3(\operatorname{PrN}) \mathrm{CN}(\mathrm{Me})_{2}\right]_{3}(8)$

\begin{tabular}{|c|c|}
\hline Empirical formula & $\mathrm{C}_{27} \mathrm{H}_{60} \mathrm{Ag}_{3} \mathrm{~N}_{9}$ \\
\hline$f w$ & 834.45 \\
\hline$T(K)$ & 200 \\
\hline$\lambda(\AA)$ & $0.71073\left(\mathrm{Mo} \mathrm{K}_{\alpha}\right)$ \\
\hline Cryst syst & Triclinic \\
\hline Space group & $P-1$ \\
\hline$a(\AA)$ & 10.36 \\
\hline $\mathrm{b}(\AA)$ & 11.86 \\
\hline$c(\AA)$ & 15.30 \\
\hline$\alpha(\mathrm{deg})$ & 98.86 \\
\hline$\beta$ (deg) & 91.26 \\
\hline$y(\operatorname{deg})$ & 105.5 \\
\hline$V\left(\AA^{3}\right)$ & 1786 \\
\hline$Z$ & 2 \\
\hline$\rho($ calcd $)\left(\mathrm{Mg} / \mathrm{m}^{3}\right)$ & 1.552 \\
\hline Abs coeff $\left(\mathrm{mm}^{-1}\right)$ & 1.658 \\
\hline Refinement method & $\begin{array}{l}\text { full-matrix least- } \\
\text { squares on F2 }\end{array}$ \\
\hline$R$ indices $[I>2 \sigma(I)]^{a}$ & $\begin{array}{l}R 1=0.0505 \\
W R 2=0.0741\end{array}$ \\
\hline \multicolumn{2}{|c|}{$\begin{array}{l}{ }^{B} 1=\Sigma|| F_{o}|-| F_{c}|| / \Sigma\left|F_{o}\right| ; \\
W R 2=\left(\Sigma w\left(\left|F_{o}\right|-\left|F_{c}\right|\right)^{2} / \Sigma w\left|F_{o}\right|^{2}\right)^{1 / 2}\end{array}$} \\
\hline
\end{tabular}


It was found that $\mathbf{8}$ existed as a trimer in the solid phase. The structure of $\mathbf{8}$ was best described by imagining a plane formed by the three silver metal centres (Figure 37). Carbon C22 is the only other atom that lies within this plane (within approx. $6^{\circ}$ ). If one imagines each ligand forming a plane via two chelating nitrogens and the bridgehead carbon, the ligand containing C22 crosses that of the metal centres at an angle of $67.5^{\circ}$. Of the two other ligand planes, one lay above the silver plane, the other laid below it (see Figure 38).

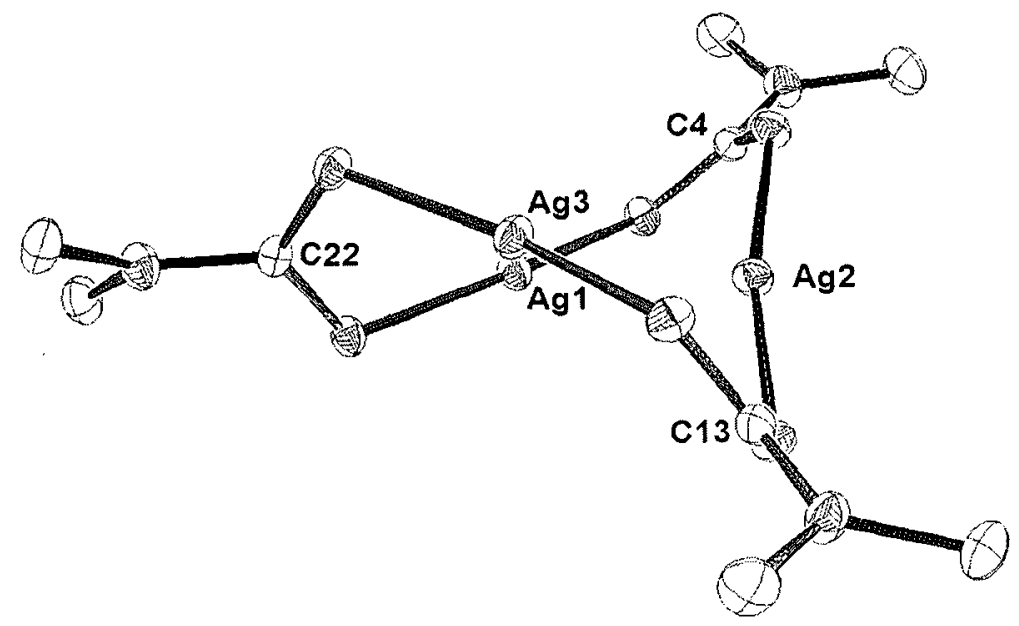

Figure 38: $\quad$ SC-XRD of $\mathrm{Ag}_{3}\left[(\operatorname{PrN}) \mathrm{CN}(\mathrm{Me})_{2}\right]_{3}(8)$. Hydrogen atoms were omitted for clarity, as were isopropyl groups. Thermal ellipses are shown at $30 \%$.

The three silver centres were each seen to be in a semi-linear, two coordinate geometry. The bond angles of the metal centres deviated from linearity as much as $16.92^{\circ}$, whereas the gold (I) dimeric structures deviated from linearity by $9.36^{\circ}$ at their maximum. The bond angles of Ag1 and Ag3 were similar while $\mathrm{Ag} 2$ was larger by almost $6^{\circ}$. The metallocycle was not planar as was the case with the gold (I) amidinates and guanidinates studied. This was due to monovalent silver's lessened tendency towards linear geometries, as well as the guanidinates increased flexibility to allow the chelate nitrogens to pyramidalize, compared to the amidinates. The bite angles of the ligands were decreased compared to the gold structures even though the silver metal centres were larger. This was due to the non planar 
metallocycle conformation, and the distance between metal centres is increased by moving out of the plane of the ligand, instead of bowing outward within the plane as the case was with gold.

Table 8: $\quad$ Selected bond lengths and angles for $\mathrm{Ag}_{3}\left[(\operatorname{PrN}) \mathrm{CN}(\mathrm{Me})_{2}\right]_{3}(8)$

\begin{tabular}{|c|c|c|c|}
\hline \multicolumn{4}{|c|}{ Selected Bond Lengths $(\AA)$} \\
\hline Ag1-N1 & $2.098(3)$ & $\mathrm{Ag} 2-\mathrm{N} 4$ & $2.091(3)$ \\
\hline Ag1-N8 & $2.094(3)$ & Ag3-N5 & $2.102(2)$ \\
\hline Ag2-N2 & $2.084(3)$ & Ag3-N7 & $2.117(2)$ \\
\hline Ag1-Ag2 & $2.9545(5)$ & Ag3-Ag1 & $3.2173(5)$ \\
\hline Ag2-Ag3 & $2.9896(5)$ & & \\
\hline $\mathrm{N} 1-\mathrm{C} 4$ & $1.338(4)$ & $\mathrm{N} 6-\mathrm{C} 13$ & $1.393(4)$ \\
\hline $\mathrm{N} 2-\mathrm{C} 4$ & $1.336(4)$ & $\mathrm{N} 7-\mathrm{C} 22$ & $1.316(4)$ \\
\hline N3-C4 & $1.402(4)$ & $\mathrm{N} 8-\mathrm{C} 22$ & $1.353(4)$ \\
\hline $\mathrm{N} 4-\mathrm{C} 13$ & $1.329(4)$ & N9-C22 & $1.385(4)$ \\
\hline $\mathrm{N} 5-\mathrm{C} 13$ & $1.338(4)$ & & \\
\hline \multicolumn{4}{|c|}{ Selected Bond Angles $\left({ }^{\circ}\right)$} \\
\hline N1-Ag1-N8 & $164.41(10)$ & $\mathrm{N} 1-\mathrm{C} 4-\mathrm{N} 2$ & $120.4(3)$ \\
\hline N2-Ag2-N4 & $168.87(10)$ & N4-C13-N5 & $120.3(3)$ \\
\hline N5-Ag3-N7 & $163.08(10)$ & $\mathrm{N} 7-\mathrm{C} 22-\mathrm{N} 8$ & $118.8(3)$ \\
\hline \multicolumn{4}{|c|}{ Sum of Angles $\left(^{\circ}\right)$} \\
\hline N1 & 359.2 & N6 & 359.6 \\
\hline $\mathrm{N} 2$ & 359.8 & N7 & 359.9 \\
\hline N3 & 359.8 & N8 & 359.8 \\
\hline N4 & 359.9 & N9 & 360.0 \\
\hline N5 & 359.3 & & \\
\hline \multicolumn{4}{|c|}{ Torsion Angles $\left({ }^{\circ}\right)$} \\
\hline Ag2-N4-N5-Ag3 & 44.9 & Ag3-N7-N8-Ag1 & 62.7 \\
\hline Ag1-N1-N2-Ag2 & 41.8 & & \\
\hline
\end{tabular}

A few questions arose from Gordon's work with silver (1) amidinates (20), as well as the work presented here with silver (I) guanidinates. Firstly why of the group 11 monovalent metals does silver differ so dramatically, while copper and gold are so similar? Secondly, why was it possible to form silver dimers of amidinates but not guanidinates? 
As shown in Section 1.3.4. silver (I) had the least tendency toward two coordinate linear structures of group 11.

It can be seen in Table 8 that the metal centres are two coordinate and semi linear coordination. However the close proximity of other silver metal centres could be indicative of some $\mathrm{sp}_{\mathrm{x}} \mathrm{p}_{\mathrm{y}}$ hybrid orbital character forming a distorted trigonal planar geometry around each metal centre. It has been shown that silver (I) has a stronger affinity for trigonal planar geometry than the other coinage metals (26). This is reasonable, considering that silver has the highest ionic radius of the group 11 compounds.

The amidinate ligand in silver ( 1 ) amidinate dimers allow for $\pi$ stabilization to exist between the chelating nitrogens only. This causes purely trigonal planar geometry around the $\mathrm{sp}^{2}$ hybridized chelating nitrogens, making for a rigid ligand that has a limited bite angle range. Guanidinates on the other hand have an exocyclic amide group that can participate marginally in the $\pi$ resonance of the chelating nitrogens. This allows for "flex" within the ligand as the nitrogens are not rigidly bound to trigonal planar geometry. The guanidinate allows for the trimer to exist while being flexible enough to minimize steric interactions between ligands. 


\subsubsection{Thermolysis}

A sublimation study found that none of the guanidinates could be successfully sublimed prior to decomposition. The decomposition result was deposition of a silver mirror on the sublimation apparatus sidewalls in the heating zone with no deposition seen on the cold finger. This occurred even when the sublimation apparatus was shielded from light.

Thermogravimetric analysis (TGA) of 10 (Figure 39) found that there was a weight loss of one equivalent of ligand while one equivalent of silver metal was left in the pan, which was obvious on inspection of the pan after the experiments were completed. This is consistent with the stoichiometry of these compounds, although the source of protons to produce free ligand is unknown. The TGA was further broken down to show that there was a weight loss of approximately two ligands (when considering trimeric 10 ) corresponding to $40 \%$ of the weight loss. At this point a second feature was seen, corresponding to a less volatile decomposition product, possibly the dimethyl guanidine. 


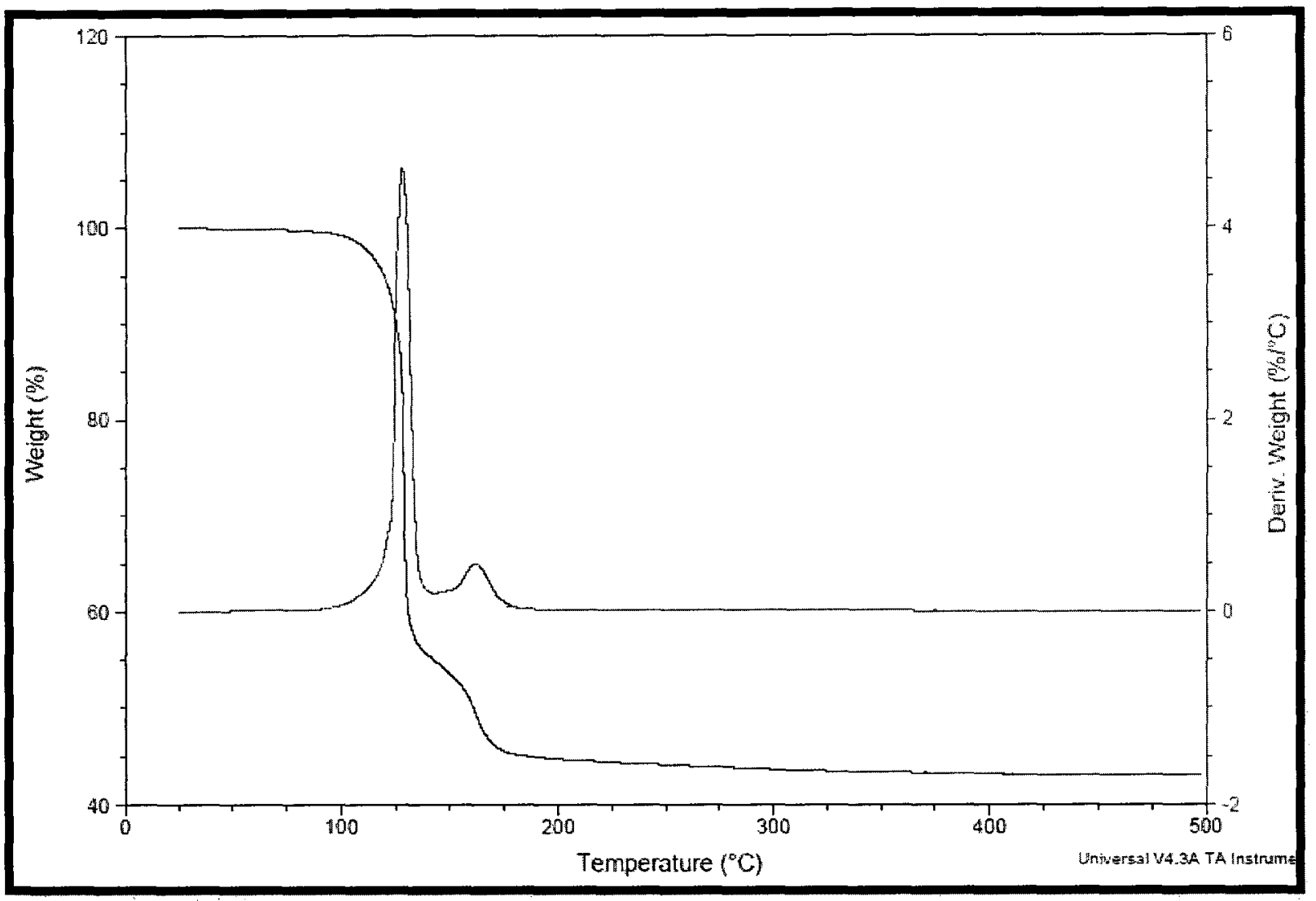

Figure 39: $\quad$ TGA of compound 10 at $5^{\circ} \mathrm{C} / \mathrm{min}$ ramp rate

An NMR study to determine the decomposition products of thermolysis of silver dimethylguanidinate (10) was undertaken. A screw cap NMR tube was charged with the compound and then heated to $120{ }^{\circ} \mathrm{C}$ for $4 \mathrm{hrs}$. The tube was chilled in liquid nitrogen and NMR solvent added to determine the decomposition products. The ${ }^{1} \mathrm{H}$ NMR spectrum of the decomposition was surprisingly clean and consisted of one major product, dimethyl guanidine. 


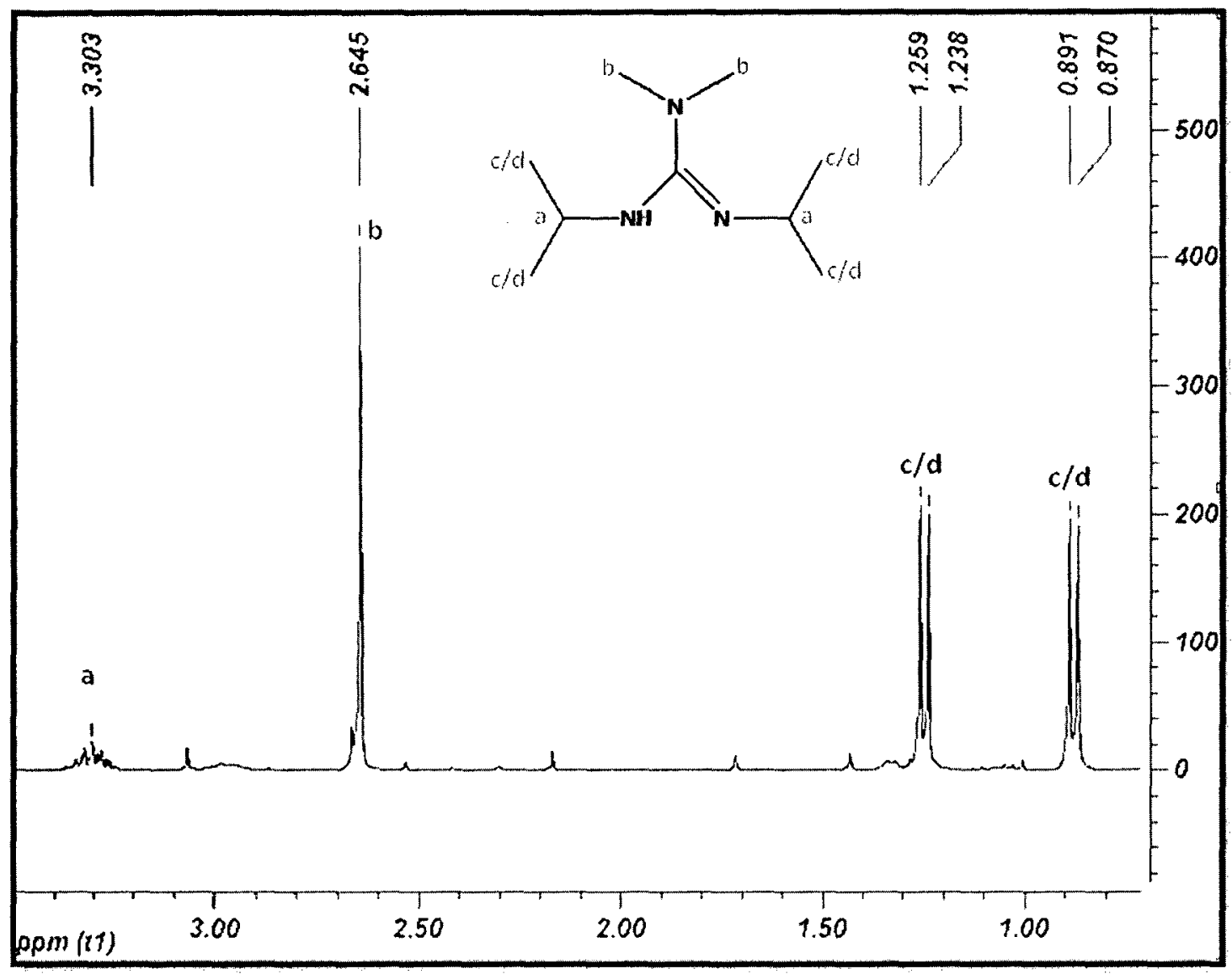

Figure 40: $\quad{ }^{\mathrm{I}} \mathrm{H}$ NMR showing guanidine as the soluble decomposition product of 10

The presence of the guanidine suggests a $\beta$-hydride abstraction mechanism (Figure 40) as the proton source. However, the necessary equivalent of oxidized dimethyl guanidine was not seen. This could be a situation like that of the gold (1) dimethyl guanidinate decomposition (section 2.1.2.) where the ratio of guanidine to oxidized guanidine is not as predicted (1:1) due to losses of volatile products when adding NMR solvent to the tube. The loss of two ligands at temperatures lower than that of the boiling point of the guanidine further solidified this theory.

It was shown in the gold (I) dimethyl guanidinate (section 2.1.2.) that under the conditions of the NMR decomposition experiment; the guanidine does not decompose to amine and CDI. Looking at Figure 40 , it can be seen that there are a couple broadened doublets. This is indicative of partially soluble products, possibly a polymer. It has been discussed previously in the gold (I) guanidinate decomposition 
that the pathway of $\beta$-hydride abstraction results in the production of an oxidized guanidine (see Figure 32).

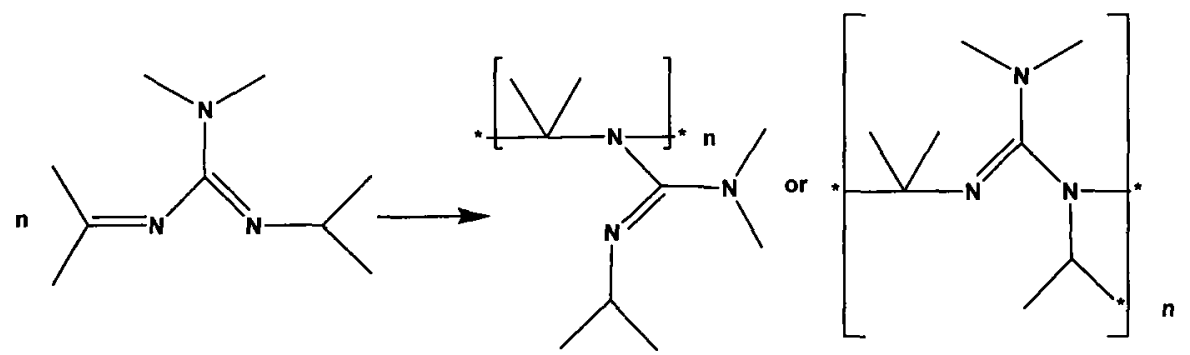

Figure 41: Possible polymerization of oxidized guanidine, forming insoluble products.

The oxidized guanidine is relatively reactive as it contains two unsaturated carbon sites that can react with another oxidized guanidine in a polymerization reaction forming chains of oxidized guanidine. The reactive unsaturated carbon sites of the oxidized guanidine can react intermolecular manner to form a metal organic insoluble macromolecule. The oxidized guanidine can also react with a metal hydride forming the insoluble product seen.

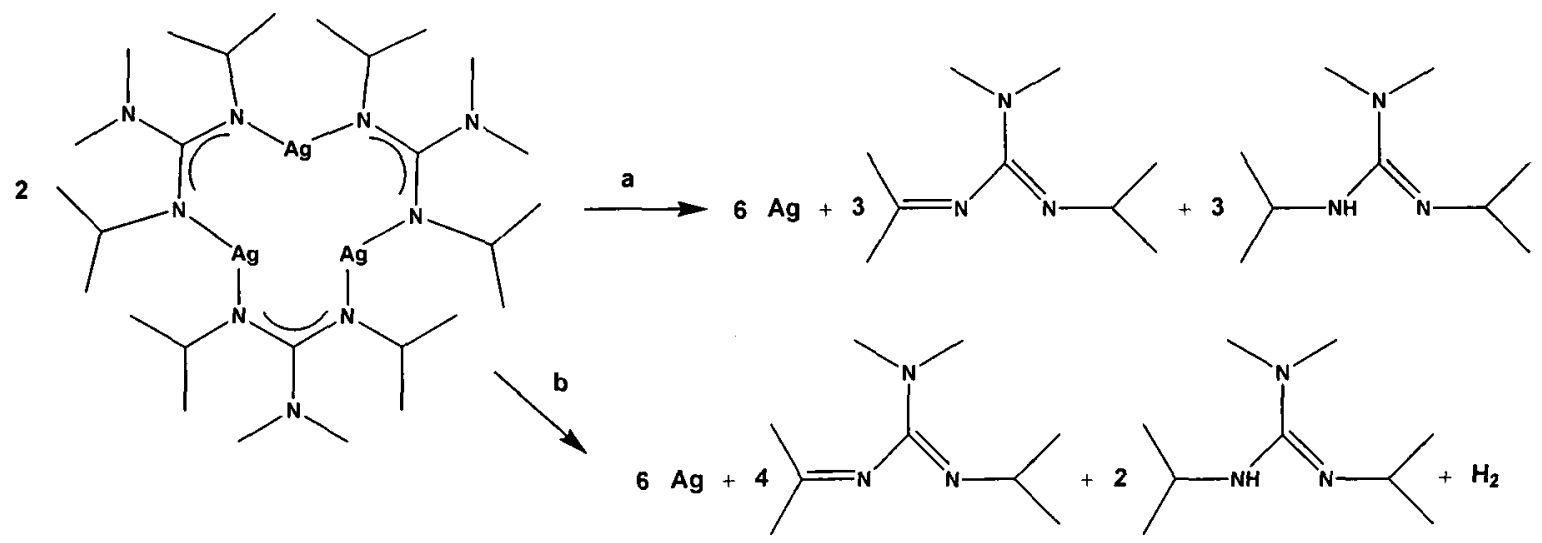

Figure 42: $\quad$ Possible solid phase decomposition pathways of 10

The TGA of 10 indicates a 2:1 oxidized guanidine to guanidine ratio through decomposition. This pathway would differ in products only by the expulsion of hydrogen gas (see Figure 42). 


\subsection{Conclusions}

The silver (I) guanidinates were found to decompose in light and over time to a greater extent than the analogous gold compounds. The silver (I) dimethylguanidinate (8) was found to form a trimeric species, not dimeric species as the analogous copper (33) and gold compounds. It was believed that the other $\mathrm{Ag}$ (I) guanidinates also form trimers. TGA study of the silver (I) dimethylguanidinate showed a weight loss corresponding to loss of ligand while leaving silver in the pan, beginning at $95{ }^{\circ} \mathrm{C}$. Sublimation attempts of the same compound resulted in decomposition prior to sublimation even in the absence of light. Since this class of compounds seems to decompose before becoming a gas; the silver (I) guanidinates could not be applicable as CVD precursors. There is however the possibility for solution phase photo deposition that can be explored further since these compounds are photo unstable. Solution phase decomposition studies showed guanidine formation as well as an insoluble side product while forming a silver mirror. The decomposition pathway seems identical to that seen in the gas phase. 


\section{Zinc (II) Guanidinate Complexes}

We managed to isolate a number of different zinc compounds serendipitously through the use of zinc metal in the reduction of $\mathrm{Ti}$ (IV) to $\mathrm{Ti}$ (III). In some cases these compounds were isolated and recrystallized to yield SCXRD quality crystals. This work began by attempting to recreate the serendipitous synthesis of $\mathbf{1 5}$ under controlled conditions to better understand the complex chemistry of $\mathrm{Zn}(\mathrm{II})$.

\subsection{Zn (II) Triisopropyl Guanidinate Complexes}

$\mathrm{Zn}\left[(\mathrm{PrN})_{2} \mathrm{CN}(\mathrm{iPr})\right]_{2}(14):$

Compound 14 was synthesized by either salt metathesis or alkane elimination; alkane elimination having the greatest yield. The compound was found to be a clear liquid with a viscosity similar to honey. The liquid was pure by NMR without the need for distillation (see Figure 43).

The ${ }^{1} \mathrm{H}$ NMR spectra showed a multiplet of two overlapping methine environments that integrated for one proton at $\delta 3.76 \mathrm{ppm}$, this corresponded to the exocyclic isopropyl methine. The amine proton participated in the unusual splitting pattern. The methine proton was split into a septet by the six neighbouring methyl protons, this septet was then split again by the amine proton into a doublet of septets. A septet for another methine proton of an isopropyl environment was seen at $\delta 3.62 \mathrm{ppm}$. This corresponded to the isopropyl environments bound to the chelating positions. The methine proton peaks can be seen in the inset of Figure $43 . \mathrm{A}$ broad doublet was seen next to the methine environments, generally the amine proton was not seen due to its broadness, but the splitting (by the exocyclic methine proton) and integration indicated that this was the amine proton on the exocyclic position. The methyl protons of the chelating isopropyl positions showed a shift of $\delta 1.37 \mathrm{ppm}$. This environment was a doublet that 
corresponded to twelve protons. The exocyclic methyl protons were seen at $\delta 1.08 \mathrm{ppm}$ also as a doublet and corresponded to six protons.

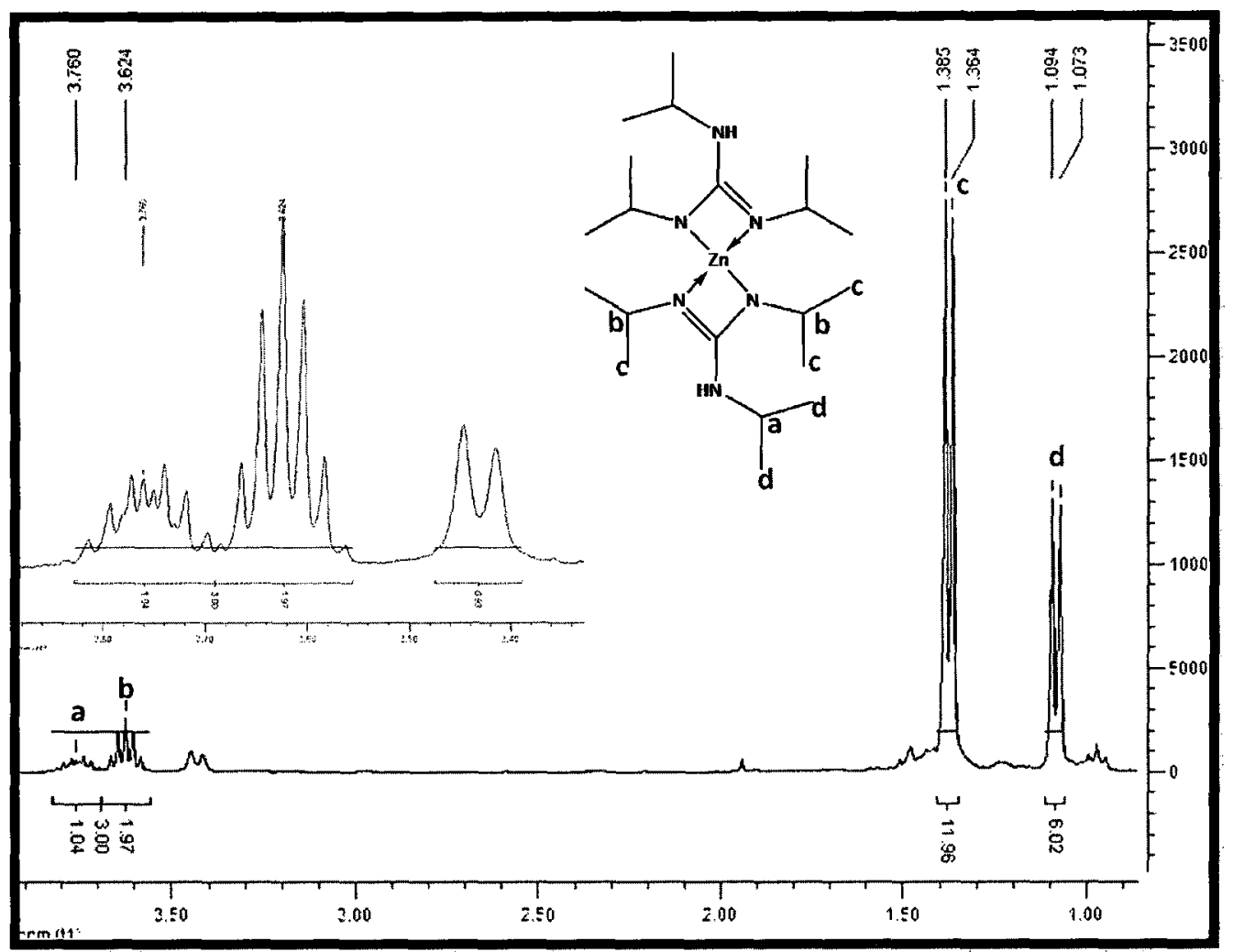

Figure 43: $\quad{ }^{1}$ H NMR of 14

Given that this product formed from salt metathesis (from zinc dichloride) and by alkane elimination (from diethyl zinc), the homoleptic formulation in Figure 43 is the most likely structure of this compound. This was supported by the proton NMR, as well as the ${ }^{13} \mathrm{CNMR}$.

The ${ }^{13} \mathrm{C}$ NMR showed the bridgehead carbon peak at $\delta 164.35 \mathrm{ppm}$, there were two methine carbon peaks at $\delta 45.77 \mathrm{ppm}$, and $\delta 45.33 \mathrm{ppm}$ corresponding to the chelating and exocyclic isopropyl groups respectively. Similarly the methyl carbon environments were seen at $\delta 26.31 \mathrm{ppm}$ and $\delta 23.78 \mathrm{ppm}$, corresponding to chelating and exocyclic positions. 
Over a period of a few weeks the isolated liquid product formed crystallites. This was likely due to the slow formation of a larger oligomer, possibly a dimeric species that was no longer a liquid at room temperature. This new compound showed a distinctively different NMR and can be seen "growing in" a spectrum of the original liquid compound (see Figure 44).

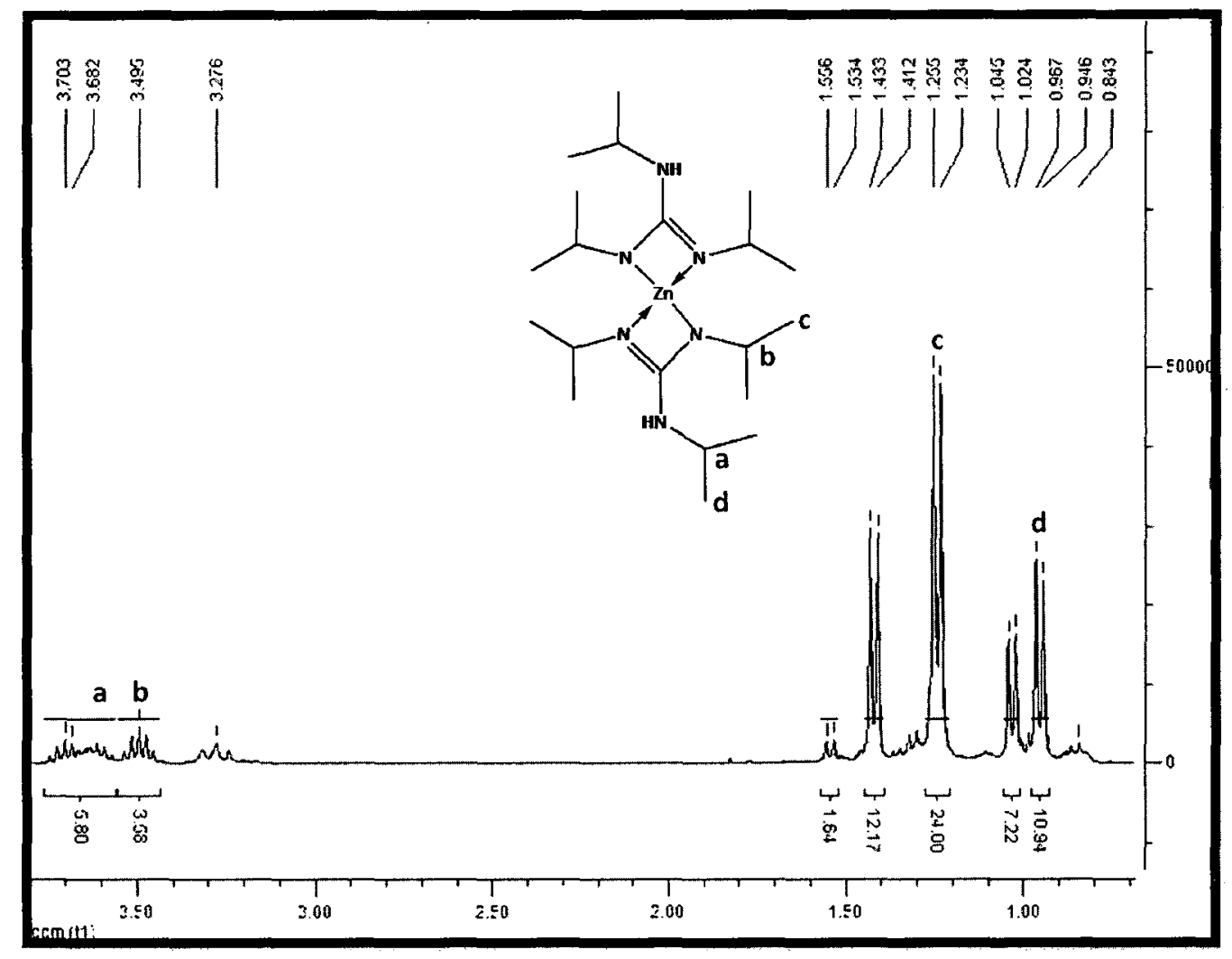

Figure 44: Unlabelled peaks showing new solid formation within liquid compound 14.

All attempts to synthesize this compound directly by heating or using a more coordinating solvent such as diethyl ether failed. Attempts to recrystallize the compound failed as it powdered out of solution. 


\section{$\mathrm{Zn}_{2} \mathrm{Cl}\left[(\mathrm{PrN})_{2} \mathrm{CNH}(\mathrm{Pr})\right]_{3}(15):$}

This compound was isolated serendipitously. The complex was thus made by a rationale synthesis from a reaction of 3:2 molar ratio of lithiated monoanionic triisopropyl guanidinate and $\mathrm{ZnCl}_{2} \cdot \mathrm{THF}$ respectively. The product was recrystallized and SC XRD obtained. The crystal structure was exactly the same as that which was achieved serendipitously (see Figure 48). The crystal structure was necessary to understand the structure, as the ${ }^{1} H$ NMR proved to be quite complex and difficult to interpret.

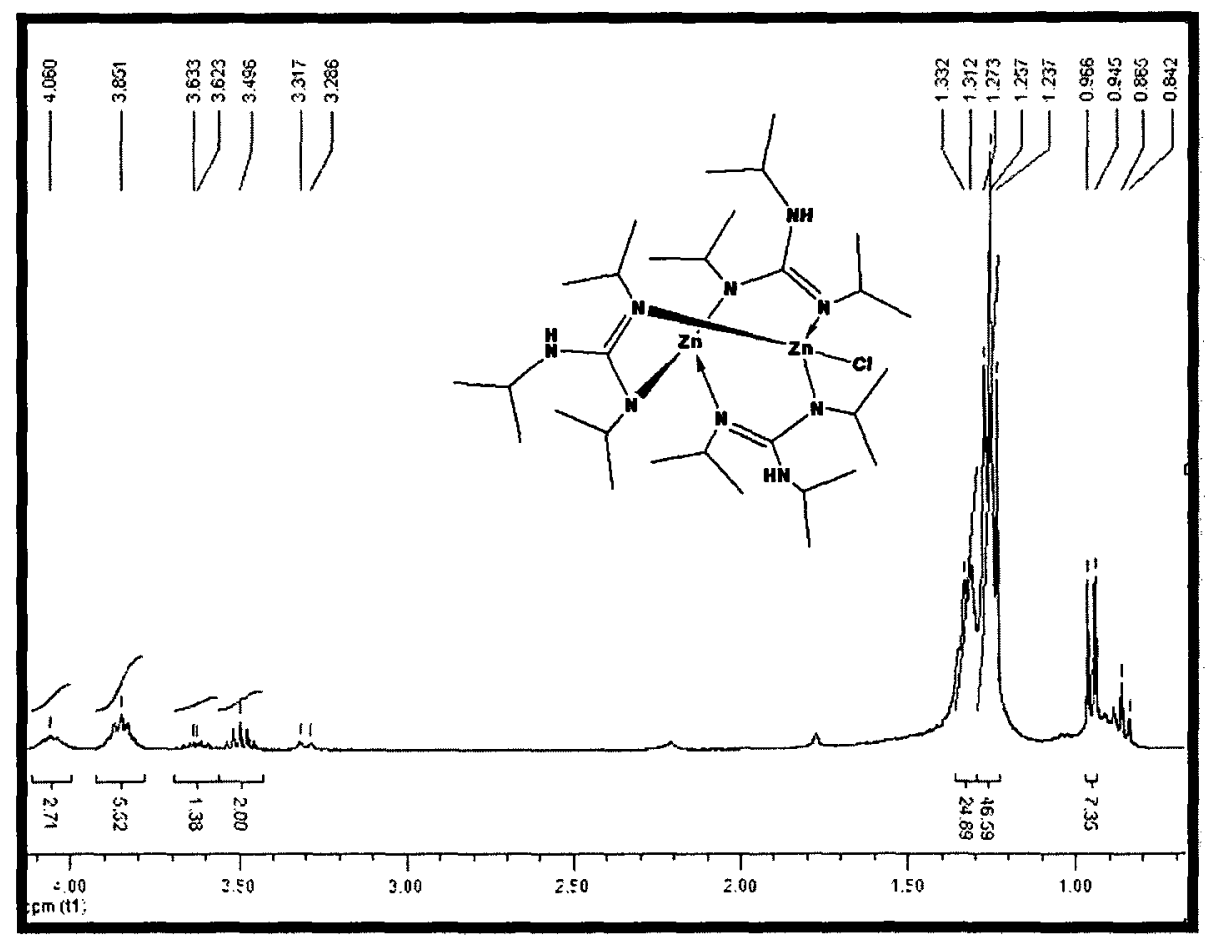

Figure 45: ${ }^{1}$ HNMR spectra of 15

The ${ }^{1} \mathrm{H}$ NMR seen in Figure 45 was collected from the same batch as the crystal structure in Figure 48. Four separate methine environments can be seen. The first septet seen at $\delta 4.06 \mathrm{ppm}$ integrated to three protons, due to its integration compared to that of the other methine protons, this is most likely a methine proton existing on an exocyclic amine position. The next methine peak corresponded to six protons; twice that of the previous methine proton; 
most likely being the isopropyl groups of the chelating positions on the same ligand. Interestingly the next two methine environments correspond exactly to those found for compound 14. The corresponding methyl peaks can also be seen. This leads us to believe that in solution the compound exists as two complexes, the bis complex already characterized as well as a chloride-containing compound. The chloride containing compound was most likely partially soluble and caused broadening of its signals, this caused the integration to be overestimated. This is why the proton NMR was very difficult to interpret.

\section{$\mathrm{Zn}_{4} \mathrm{Et}_{4}\left[\left({ }^{\mathrm{P}} \mathrm{PrN}\right)_{2} \mathrm{CN}\left({ }^{\mathrm{P} P r}\right)\right]_{2}(16):$}

When a 1:1 molar ratio of triisopropyl guanidine was reacted with diethyl zinc, the recrystallized product was that of the spectrum seen in Figure 46 . The spectra lead us to believe this compound consisted of one ethyl group and one guanidinate per metal centre. However the SC XRD structure (Figure 50) showed a ratio of one guanidinate per two ethyl groups. This forced us to re-examine the NMR, in an effort to explain how the other ethyl moiety was represented in the spectrum. 


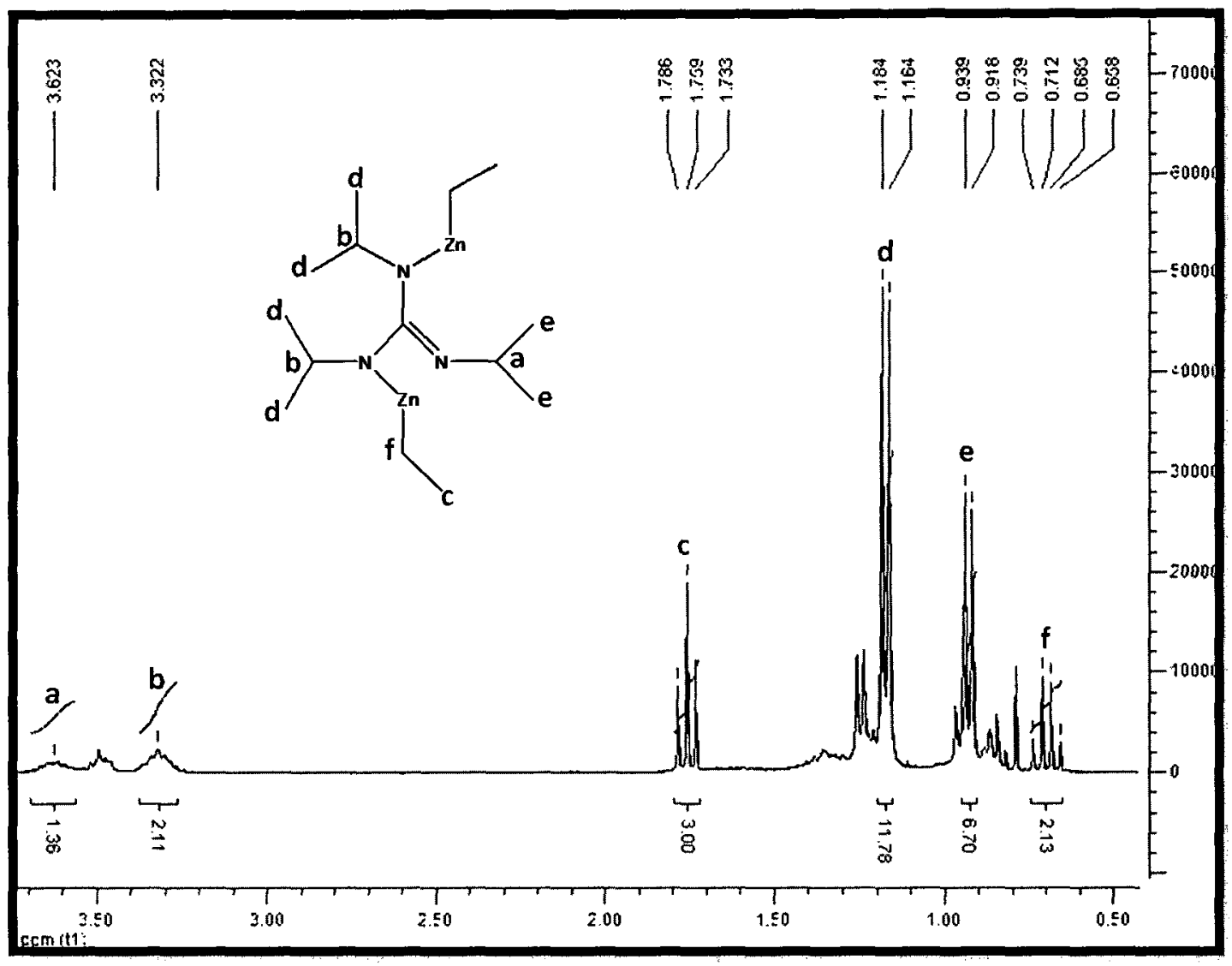

Figure A6: $\quad{ }^{1}$ HNMR spectra of 16

it was not clear where the other ethyl moiety lay. It is possible that sterics cause some unexpected splitting patterns that mask the remaining five protons. The most likely answer is seen in Figure 47. The signals $\mathbf{g}$ and $\mathrm{h}$ are those of previously unassigned peaks that closely match the integration requirements, and theoretical shift of the structure found by SC XRD. Sterics could cause the triplet to be seen as a doublet $(\mathrm{g})$, as well the misshapen quartet $(\mathrm{h})$ is most likely the unassigned methyl protons. This, like compound $\mathbf{1 6}$ would benefit from a variable temperature NMR. 


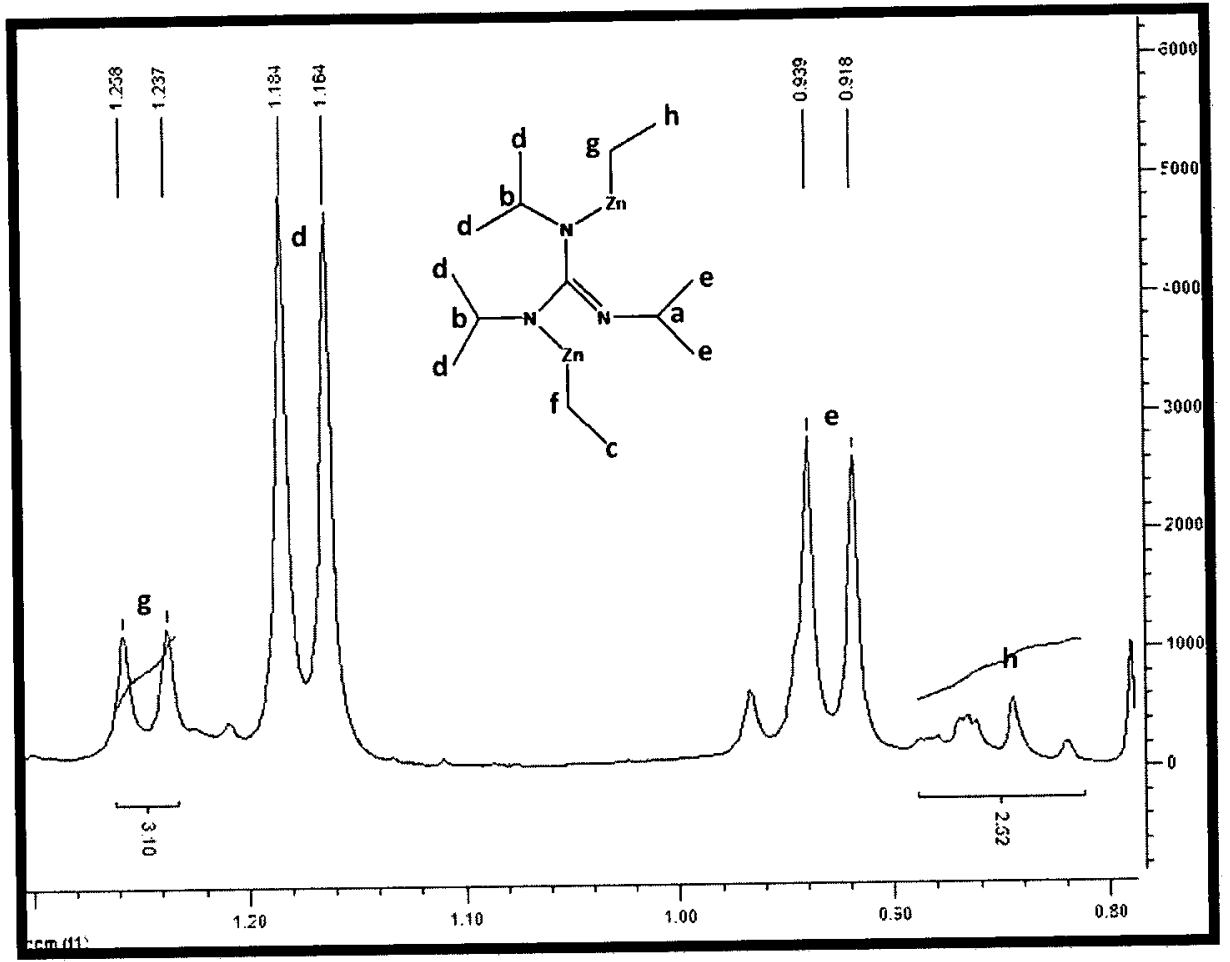

Figure 47: $\quad{ }^{1} \mathrm{H} N M R$ spectra showing possible alternate ethyl environments of compound 16. 


\subsection{Crystal Structures}

\section{$\mathrm{Zn}_{2} \mathrm{Cl}\left[\left({ }^{\prime} \mathrm{PrN}\right)_{2} \mathrm{CNH}\left({ }^{\prime} \mathrm{Pr}\right)\right]_{3}$}

Table 9: Selected crystallographic data for 15

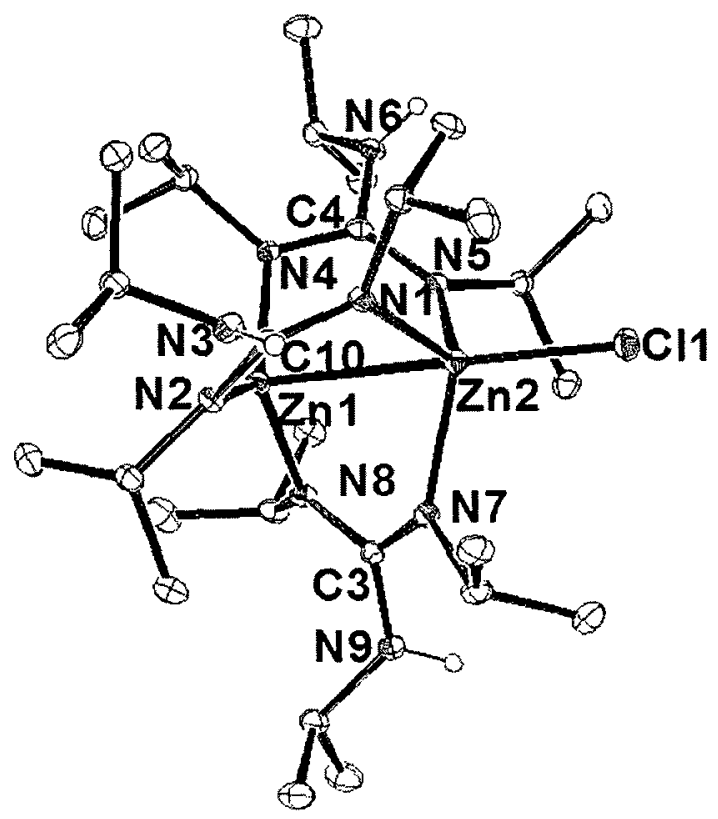

Figure 48: SC-XRD of compound 15. Hydrogen atoms were omitted for clarity, excluding those bound to nitrogen, the thermal ellipses are shown at $30 \%$.

The crystal structure of 16 can be seen in

\begin{tabular}{|c|c|}
\hline Empirical formula & $\mathrm{C}_{30} \mathrm{H}_{66} \mathrm{Zn}_{2} \mathrm{~N}_{9} \mathrm{Cl}$ \\
\hline$f w$ & 719.14 \\
\hline$T(K)$ & $120(2)$ \\
\hline$\lambda(\AA)$ & $0.71073\left(\mathrm{Mo} \mathrm{K}_{\alpha}\right)$ \\
\hline Cryst syst & Monoclinic \\
\hline Space group & P $123 / c 1$ \\
\hline$a(\AA)$ & 10.725 \\
\hline $\mathrm{b}(\AA)$ & 34.697 \\
\hline$c(A)$ & 10.581 \\
\hline$\alpha(\mathrm{deg})$ & 90.00 \\
\hline$\beta$ (deg) & 104.21 \\
\hline$\gamma($ deg $)$ & 90.00 \\
\hline$V\left(\AA^{3}\right)$ & 3817 \\
\hline Z & 4 \\
\hline$\rho($ calcd $)\left(\mathrm{Mg} / \mathrm{m}^{3}\right)$ & 1.251 \\
\hline Abs coeff $\left(\mathrm{mm}^{-1}\right)$ & 1.358 \\
\hline Refinement method & $\begin{array}{l}\text { full-matrix least- } \\
\text { squares on F2 }\end{array}$ \\
\hline$R$ indices $[1>2 \sigma(I)]^{a}$ & $\begin{array}{l}R 1=0.0614 \\
w R 2=0.1135\end{array}$ \\
\hline $\begin{array}{l}{ }^{R} 1=\Sigma|| F_{o}|-| F_{c}|| / \Sigma \\
W R 2=\left(\Sigma W\left(\left|F_{o}\right|-\left|F_{c}\right|\right)\right.\end{array}$ & $\begin{array}{l}\Sigma\left|F_{0}\right| ; \\
\left.)^{2} / \Sigma w\left|F_{0}\right|^{2}\right)^{1 / 2}\end{array}$ \\
\hline
\end{tabular}

Figure 48. The structure was a "lantern" dimer. The two metal centres are bridged by three triisopropyl guanidinate ligands that bonded in a $k^{1}$ fashion to each of the zinc centre. The distance between the zinc centres was $2.709 \AA$, larger than the $2.34 \AA$ found in a $\mathrm{Zn}$ - $\mathrm{Zn}$ bond (42). $\mathrm{Zn} 2$ was found to be tetracoordinate with a chloride bound to one face. $\mathrm{Zn} 2$ was seen to be very close to tetrahedral with bond angles ranging from $\sim 107^{\circ}-112^{\circ}$. In contrast, $\mathrm{Zn} 1$ was found to be tricoordinate. The sum of angles around $\mathrm{Zn} 1$ was $359.83^{\circ}$, very near planar, thus a trigonal planar bonding geometry to the guanidinate ligands. The large $\mathrm{Zn}$ - $\mathrm{Zn}$ distance was believed to be caused by the existence of the electron withdrawing chloride that minimized the 
interaction between zinc centres. This resulted in a large guanidinate bite angle not expected of first row transition metals.

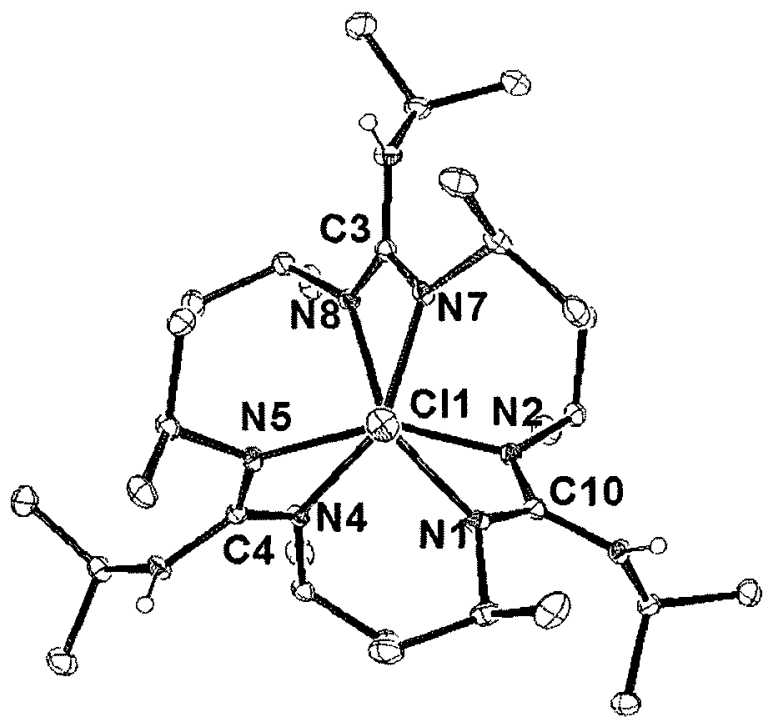

Figure 49: $\quad$ SC-XPD of compound 25, looking down Cl Zn bond. Hydrogen atoms were omitted for clarity excluding those bound to nitrogen; thermal ellipses are shown at $30 \%$.

The bond distance between the exocyclic nitrogen and the bridgehead carbon of all the guanidinates was found to be considerably less than the bond lengths of the bridgehead carbon to the chelating nitrogen positions. This indicates that the $\pi$ resonance has a greater contribution from the exocyclic position. Each of the nine nitrogens in the structure were found to be $\mathrm{sp}^{2}$ hybridized as they all deviated by no more than $0.5^{\circ}$ from planarity, the bridgehead carbons also showed the same character. 
Table 10: $\quad$ Selected Bond Lengths and Angles for 15

\begin{tabular}{|c|c|c|c|c|c|c|}
\hline \multicolumn{7}{|c|}{ Selected Bond Lengths (Å) } \\
\hline \multicolumn{2}{|c|}{$\operatorname{Zn} 1-\operatorname{Zn} 2$} & 2.709 & \multicolumn{2}{|c|}{$\mathrm{Zn} 2-\mathrm{Cl} 1$} & \multicolumn{2}{|c|}{2.288} \\
\hline \multicolumn{2}{|c|}{$\mathrm{Zn} 1-\mathrm{N} 4$} & 1.928 & \multicolumn{2}{|c|}{$\mathrm{Zn} 2-\mathrm{N} 1$} & \multicolumn{2}{|c|}{2.040} \\
\hline \multicolumn{2}{|c|}{$\mathrm{Zn} 1-\mathrm{N} 2$} & 1.932 & \multicolumn{2}{|c|}{$\mathrm{Zn} 2-\mathrm{N} 5$} & \multicolumn{2}{|c|}{2.038} \\
\hline \multicolumn{2}{|c|}{$\mathrm{Zn1-N8}$} & 1.931 & \multicolumn{2}{|c|}{ Zn2-N7 } & \multicolumn{2}{|c|}{2.055} \\
\hline \multicolumn{2}{|c|}{ C3-N7 } & C4-N4 & 1.337 & \multicolumn{2}{|c|}{ C10-N1 } & 1.338 \\
\hline C3-N8 & 1.333 & C4-N5 & 1.347 & \multicolumn{2}{|c|}{$\mathrm{C} 10-\mathrm{N} 2$} & 1.335 \\
\hline C3-N9 & 1.394 & C4-N6 & 1.383 & \multicolumn{2}{|c|}{ C10-N3 } & 1.385 \\
\hline \multicolumn{7}{|c|}{ Selected Bond Angles $\left({ }^{\circ}\right)$} \\
\hline \multicolumn{2}{|c|}{$\mathrm{Zn} 1-\mathrm{Zn} 2-\mathrm{Cl} 1$} & 179.29 & \multicolumn{3}{|c|}{ N1-Zn2-N5 } & 110.22 \\
\hline \multicolumn{2}{|c|}{ N2-Zn1-N4 } & 119.43 & & $\mathrm{Zn}$ & N7 & 112.63 \\
\hline $\mathrm{N} 4-\mathrm{Zn}$ & LN8 & 120.45 & & $\mathrm{Zn}$ & $\mathrm{N} 1$ & 110.36 \\
\hline $\mathrm{N} 8-\mathrm{Zn}$ & $-\mathrm{N} 2$ & 119.95 & & $\mathrm{C} 3$ & & 119.41 \\
\hline $\mathrm{N} 4-\mathrm{C} 4$ & N5 & 118.95 & & C1 & N2 & 119.22 \\
\hline & & & of Ang & & & \\
\hline $\mathrm{Zn} 1$ & 359.83 & N4 & 359.3 & & N9 & 360.00 \\
\hline $\mathrm{Zn} 2$ & 384.01 & N5 & 360.4 & & $\mathrm{C} 3$ & 359.99 \\
\hline N1 & 359.81 & N6 & 360.0 & & $\mathrm{C} 4$ & 359.98 \\
\hline N2 & 359.50 & N7 & 359.8 & & C10 & 360.00 \\
\hline N3 & 360.00 & N8 & 359.6 & & & \\
\hline
\end{tabular}




\section{$\mathrm{Zn}_{4} \mathrm{Et}_{4}\left[(\operatorname{PrN})_{2} \mathrm{CN}\left({ }^{\prime} \mathrm{Pr}\right)\right]_{2}$}

Table 11: Selected Crystallographic data for 16

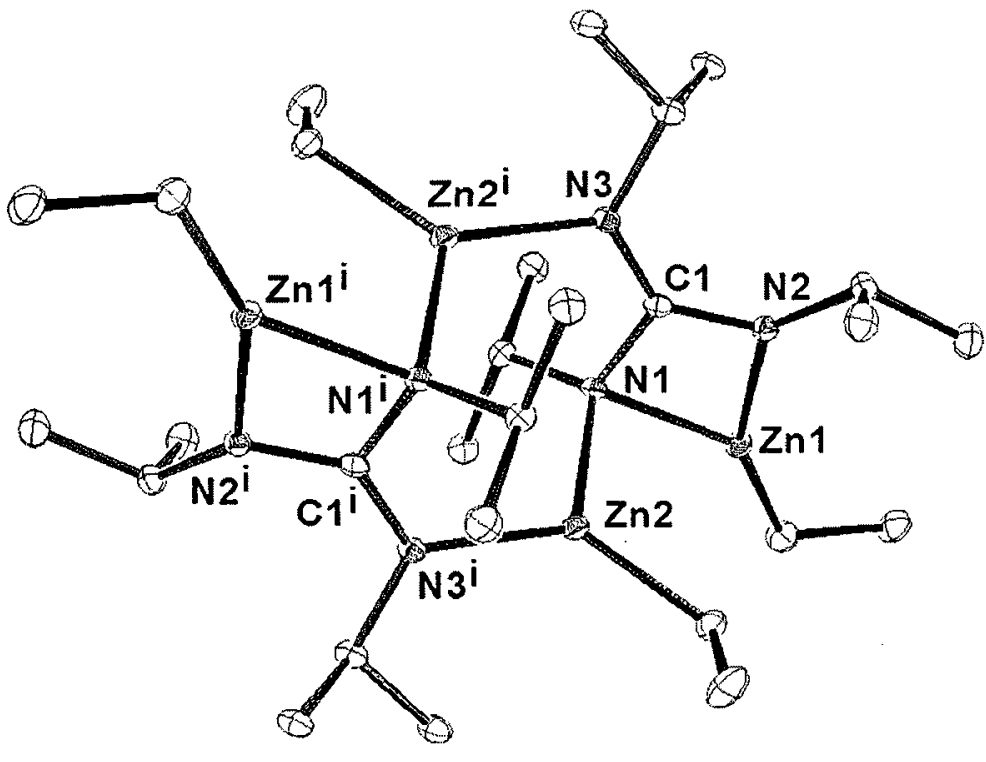

Figure 50: SC-XRD compound 16. Hydrogen atoms were omitted for clarity; thermal ellipses are shown at 30\%.

The crystal structure of compound 16 consisted

\begin{tabular}{|c|c|}
\hline Empirical formula & $\mathrm{C}_{28} \mathrm{H}_{60} \mathrm{Zn}_{4} \mathrm{~N}_{6}$ \\
\hline fw & 738.22 \\
\hline $\mathrm{T}(\mathrm{K})$ & $120(2)$ \\
\hline$\lambda(\AA)$ & $0.71073\left\langle\mathrm{Mo} \mathrm{K}_{\alpha}\right\rangle$ \\
\hline Cryst syst & Monoclinic \\
\hline Space group & $P 121 / \mathrm{C} 1$ \\
\hline$a(\AA)$ & 10.276 \\
\hline $\mathrm{b}(\AA)$ & 9.897 \\
\hline$c(\AA)$ & 17.350 \\
\hline$\alpha$ (deg) & 90.00 \\
\hline$\beta$ (deg) & 95.34 \\
\hline$y(\mathrm{deg})$ & 90.00 \\
\hline$V\left(\AA^{3}\right)$ & 1757 \\
\hline$Z$ & 2 \\
\hline$\rho$ (calcd) $\left(\mathrm{Mg} / \mathrm{m}^{3}\right)$ & 1.403 \\
\hline Abs coeff $\left(\mathrm{mm}^{-1}\right)$ & 2.723 \\
\hline \multicolumn{2}{|c|}{$\begin{array}{c}\text { Refinement method full-matrix least- } \\
\text { squares on F2 }\end{array}$} \\
\hline$R$ indices $[I>2 \sigma(I)]^{\mathrm{E}}$ & $\begin{array}{l}R 1=0.0412 \\
W R 2=0.0838\end{array}$ \\
\hline $\begin{array}{l}\left.\mathrm{R} 1=\Sigma|| F_{0}|-| F_{c}||\right) \\
W R 2=\left(\sum w\left(\left|F_{o}\right|-\left|F_{c}\right|\right.\right.\end{array}$ & $\begin{array}{l}\Sigma\left|F_{0}\right| ; \\
\mid)^{2} /\left.\Sigma w\left|F_{o}\right|^{2}\right|^{1 / 2}\end{array}$ \\
\hline
\end{tabular}

of four zinc centres each of which was bound to a single ethyl group. Each zinc centre was tricoordinate. Two of the zinc centres participated in a central eight member metallocycle ( $\mathrm{Zn} 2$ and $\left.\mathrm{Zn} 2^{\prime}\right)$. The metallocyclic zinc centres acted as bridges between the two equivalent units within the unit cell bridging to $\mathrm{N} 1$ and $N 1^{i}$ respectively. The metallocycle formed a distorted chair conformation (see Figure 51). The zinc centres $\mathrm{Zn} 2$ and $\mathrm{Zn2}{ }^{i}$, along with $\mathrm{N} 1$ and $\mathrm{N} 1^{\mathrm{i}}$, formed a planar centre with a torsion angle of $0^{\circ}$ (see Table 12$)$. The remaining centres $(\mathrm{Zn} 2, \mathrm{~N} 3, \mathrm{~N} 1$, C1) participating in the ring formed two semi planar structures (see Table 12). The other two zinc centres $\left(\mathrm{Zn} 1\right.$ and $\left.\mathrm{Zn} 1^{i}\right)$ were bound within chelating pockets of the each of the guanidinate moieties bonded in a $\mathrm{k}^{2}$ coordination. 


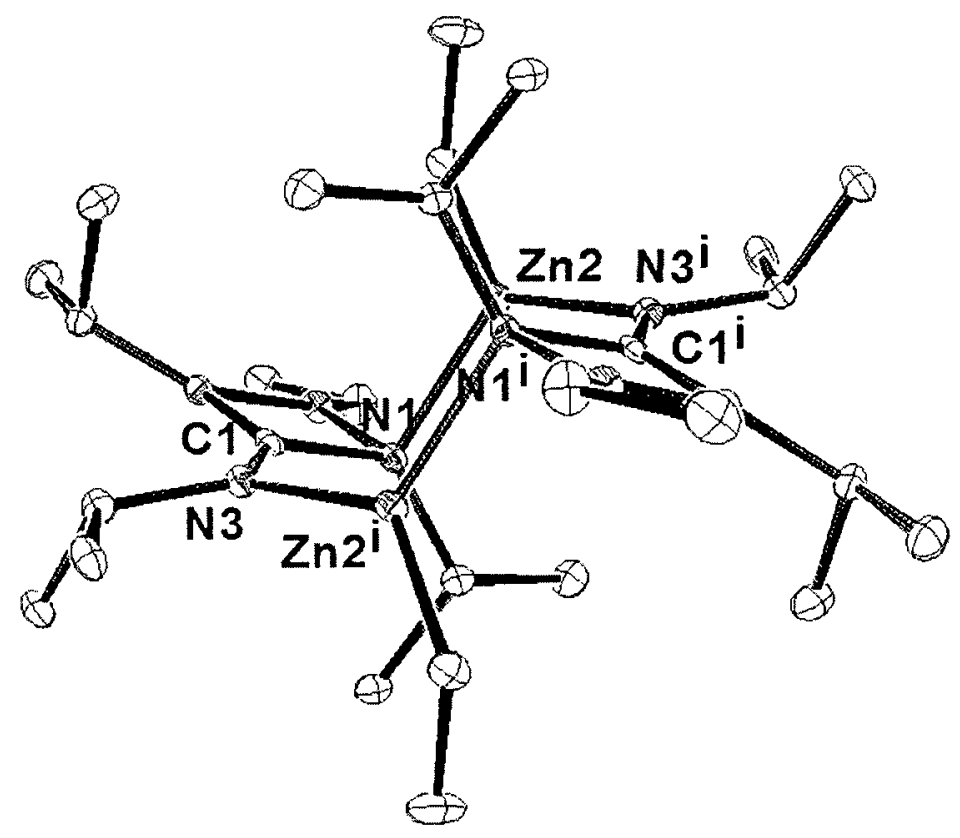

Figure 51: $\quad$ SC-XRD compound 16. Hydrogen atoms were omitted for clarity; thermal ellipses are shown at $30 \%$.

Bond lengths around N1 were considerably shortened as it formed a tetracoordinated geometry linking the two equivalent units. The tetrahedral coordination indicates that $\mathrm{N} 1$ was $\mathrm{sp}^{3}$ hybridized. The planarity of the other nitrogen centres (N3 and N2) indicates that they are $\mathrm{sp}^{2}$. The bite angle of the guanidinate chelating $\mathrm{Zn} 1$ and $\mathrm{Zn} 1^{\prime}$ was found to be considerably smaller than other bite angles given in this thesis. This is due to chelation of one metal centre (M-M repulsion forces aren't an issue) as well as there is a smaller ionic radii of zinc. 
Table 12: Selected Bond Lengths and Angles for 16

\begin{tabular}{|c|c|c|c|}
\hline \multicolumn{4}{|c|}{ Selected Bond Lengths (Å) } \\
\hline Zn1-N1 & 2.124 & Zn2-N1 & 2.056 \\
\hline $\mathrm{Zn} 1-\mathrm{N} 2$ & 1.959 & $\mathrm{Zn} 2-\mathrm{N} 3$ & 1.980 \\
\hline $\mathrm{Zn1-C13}$ & 1.951 & $\mathrm{Zn} 2-\mathrm{C} 5$ & 1.985 \\
\hline N1-C1 & 1.420 & N3-C1 & 1.340 \\
\hline $\mathrm{N} 2-\mathrm{C} 1$ & 1.340 & & \\
\hline \multicolumn{4}{|c|}{ Selected Bond Angles $\left({ }^{\circ}\right)$} \\
\hline $\mathrm{N} 1-\mathrm{C} 1-\mathrm{N} 2$ & 108.64 & N1-Zn2-N3 & 111.68 \\
\hline \multicolumn{4}{|c|}{ Sum of Angles $\left({ }^{\circ}\right)$} \\
\hline N1 & 418.02 & $\mathrm{Zn} 1$ & 359.90 \\
\hline N2 & 358.26 & $\mathrm{Zn} 2$ & 359.30 \\
\hline N3 & 359.99 & $\mathrm{C} 1$ & 359.99 \\
\hline \multicolumn{4}{|c|}{ Torsion Angles $\left({ }^{\circ}\right)$} \\
\hline \multicolumn{2}{|c|}{$\mathrm{Zn} 2-\mathrm{N} 1^{\mathrm{i}}-\mathrm{N} 1-\mathrm{Zn} 2^{\mathrm{i}}$} & \multicolumn{2}{|c|}{0} \\
\hline \multicolumn{2}{|c|}{$\mathrm{Zn} 2-\mathrm{N} 3^{\mathrm{i}}-\mathrm{N} 1^{\mathrm{i}}-\mathrm{C} 1^{\mathrm{i}}$} & \multicolumn{2}{|c|}{18.64} \\
\hline \multicolumn{2}{|c|}{ Zn2-N3-N1-C1 } & \multicolumn{2}{|c|}{18.64} \\
\hline
\end{tabular}

\subsection{Conclusions}

A liquid bis triisopropyl guanidinate zinc complex was created (14). It was found over an extended period of time (weeks) to oligomerize into a solid product. The NMR spectrum of the new compound was obtained, growth of SC XRD quality crystals for structural analysis failed. The "lantern" dimeric compound $\mathbf{1 5}$ was successfully recreated using a 2:3 ratio of THF stabilized zinc (II) chloride and triisopropyl lithium guanidinate. It was found to form compound $\mathbf{1 4}$ in solution phase NMR. A tetrameric compound was also synthesized (16) and a SC XRD structure obtained. The structure showed each guanidine bonding to two zinc centres. 


\section{Gold Metal Photo Deposition}

Early in the synthesis of the gold (I) amidinates it became evident that the compounds were unstable at room temperature. In solution as the compounds decomposed they resulted in the deposition of a gold mirror on sample vials and flasks. It was found that in the absence of light, a solution of hexanes and completely solvated gold (I) acetamidinate dimer would decompose at a much slower rate. The light exposed sample decomposed in a matter of hours while the vial shielded from light would begin to decompose after a few days; a dramatically different time scale.

Since the eventual goal of the gold (1) amidinate research was to develop a process of depositing gold metal films, the photodeposition of gold (I) acetamidinate was studied further. The hope of these experiments was to develop a method of controlling the film thickness as an alternative to CVD.

The acetamidinate gold (I) complex was chosen as it was in the highest yield, thus limiting financial losses in synthesis. Gold (I) n-butylamidinate has greater solubility in organic solvents than that of the acetamidinate. This increased solubility of the ligand made for poor yields of the gold (I) nbutylamidinate (see Section 7.3.1.).

Film depositions were conducted in pentane (higher purity than hexanes) in the drybox as the precursor was air sensitive. The precursor was purified by recrystallization prior to use. The concentration of the gold (I) acetamidinate dimer was kept constant throughout all experiments by obtaining a supersaturated solution at room temperature in pentane. The product was allowed to recrystallize in the freezer where it could be stored for long periods of time. When conducting an experiment, a volume of mother liquor was pipetted from the vial to a deposition vial. The mother liquor would remain at the same concentration provided that the freezer remained at the same temperature throughout experimentation. Also when new precursor was synthesized it would be easy to obtain the exact same concentration as previously used. 
The experiments were simple in their design. Vials were charged with the supersaturated solution from the freezer, left for varied amounts of time (4, 14 days) in ambient light then the films deposited were studied via SEM, EDS, and XRD.

\subsection{4 day Exposure Period (a)}

A short exposure experiment was conducted in order to determine a lower limit of deposition. The period of the experiment was determined via visual inspection. When colour could be seen within the photodeposition apparatus the experiment was halted. This period was found to be four days. After which time the deposition substrate was studied via SEM, EDS, and XRD.

Scanning electron microscopy of films consisting of short deposition times were difficult to obtain due to the insulating nature of glass, which limits the drain of the electrons causing a charging effect at the substrate surface (Figure 52). This requires lowering the potential making for images of poor contrast to minimize the charging effect around the images. A general procedure when imaging a material that insulates is to coat it in gold utilizing a physical vapour technique. This would give false EDS measurements and thus was not done. Deposition on silicon wafers would have been optimal however they are opaque, thus limiting photodeposition. The SEM image seen in Figure 52 was of the edge of the slide. This SEM shows some small crystallite growth along the edges of the glass slide, most likely on defect sites created when the glass slide was cut. These small crystallites running along the edge seem like they have grown out of the surface, showing that decomposition of the precursor molecules could have been originating at the surface. Other larger crystallites were seen to be sitting on the surface (as opposed to growing out of it) as if placed there. This may have shown a different decomposition pathway, one that does not include surface decomposition. 


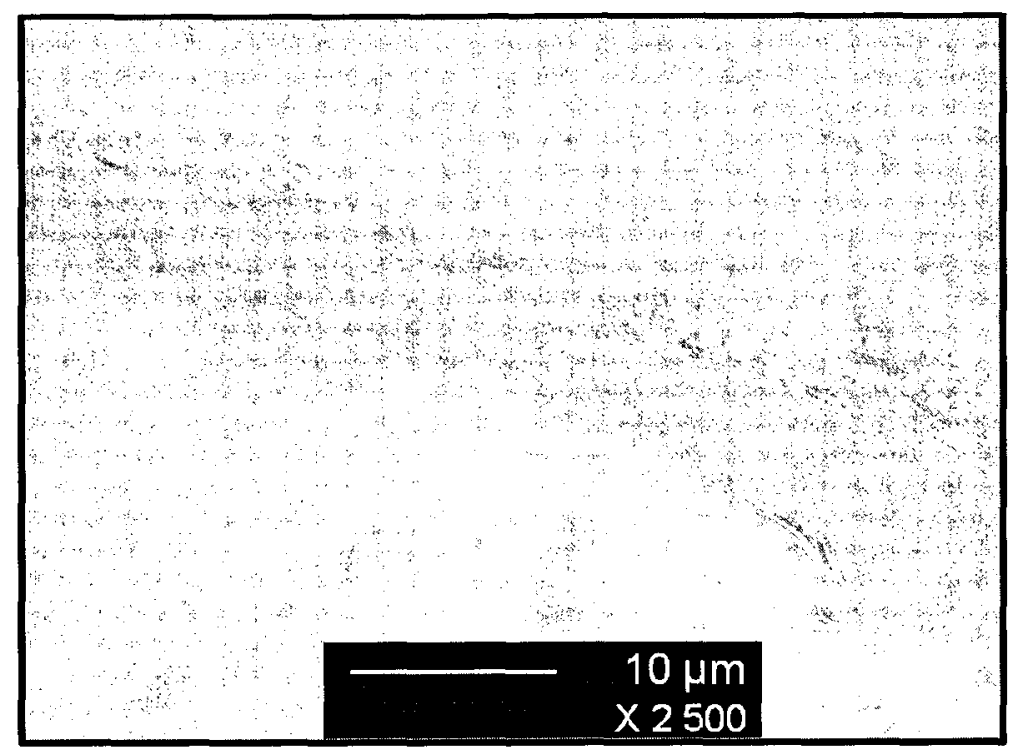

Figure 52: SEM image of a) at $(2.6 \mathrm{kV})$

The deposition done for 4 days was halted upon initial visual evidence of deposition. This resulted in a glass slide that had a uniform cloudy purple tinge to it. The film was determined to be gold metal as was seen by EDS (see Figure 53).

The EDS spectra showed the existence of gold metal (Figure 53). The signal was found to be very weak due to the short exposure time resulting in minimal deposition. This peak can be seen in the inset of Figure 53. The other peaks seen are associated with the glass substrate that contained traces of calcium, sodium, and potassium. The strongest peak belonged to that of silicon. 


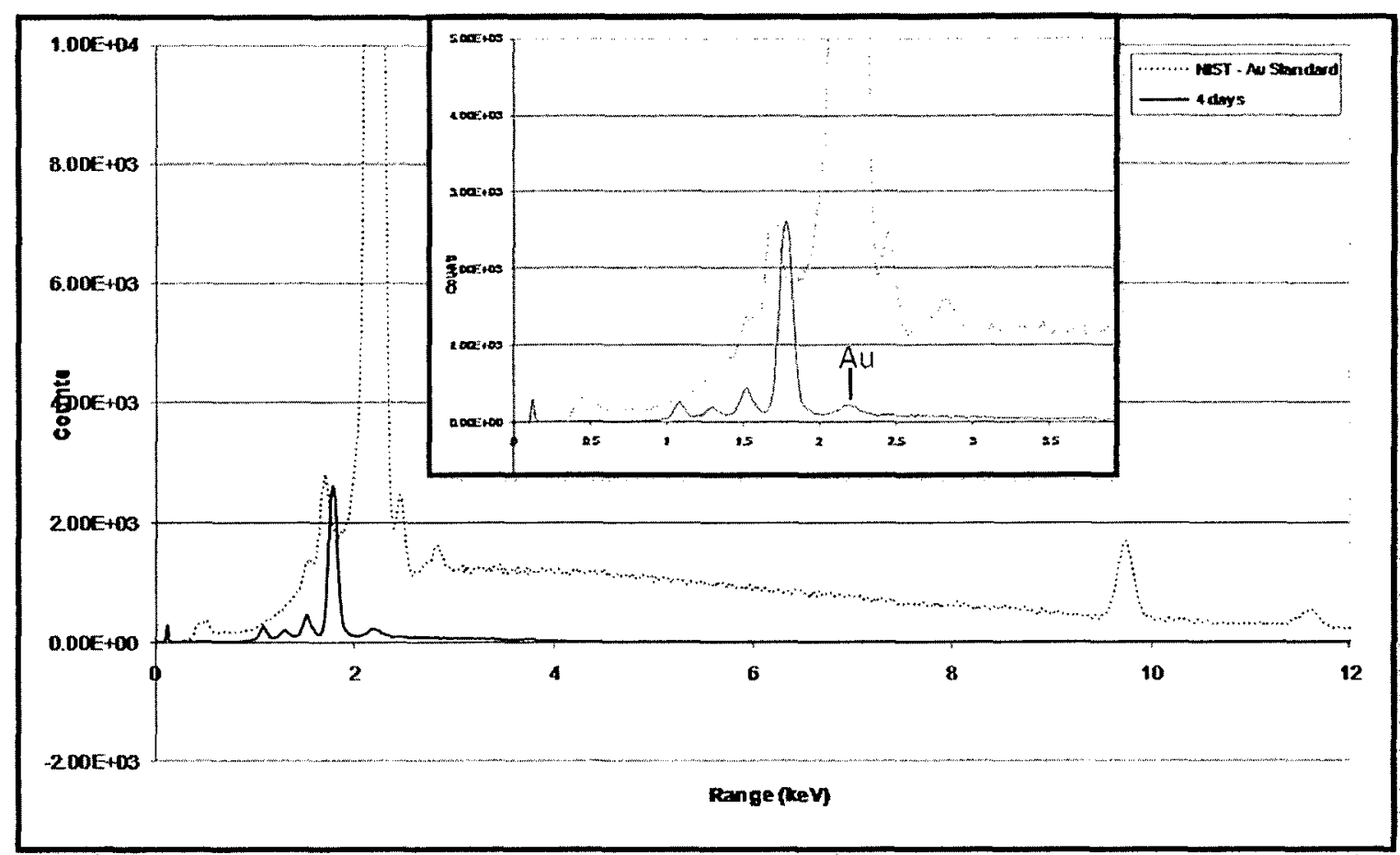

Figure 53:

EDS of a)

Due to the short deposition time resulting in minimal gold sample deposited, XRD micrograph did not yield any gold crystalline phases and instead showed only the broad $\mathrm{SiO}_{2}(101)$ crystalline face.

\subsection{4 day Exposure Period (b)}

A long exposure experiment was conducted in order to determine an upper limit of deposition as well as to obtain insights into surface structure and a growth mechanism. The period of two weeks was set arbitrarily. After this period the glass slide was found to be opaque and have the golden lustre of gold metal. The film was via SEM, EDS, and XRD. 


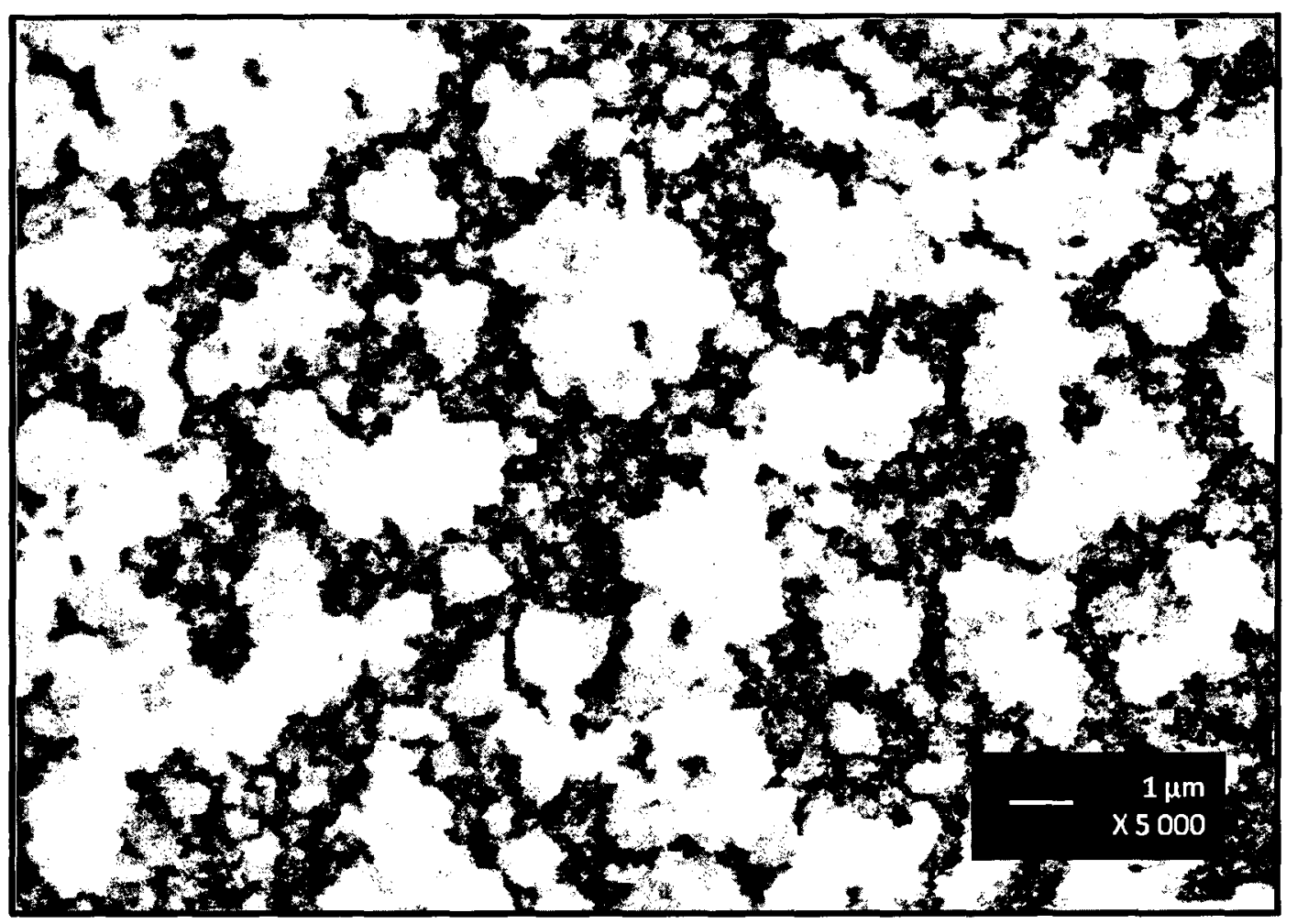

Figure 58: SEM image of 10 )

The film was found to have complete coverage over the glass slide (Figure 54). This was beneficial as a larger potential was used due to a lack of charging effects. The film was found to consist of large particulates $(>1 \mu \mathrm{m})$. The particles were arranged in a random manner. The structure did not seem to indicate uniform growth originating at the surface as there did not seem to be a regularity to the structure as would indicate surface decomposition and growth. Rather the SEM seemed to indicate that the decomposition of the precursor did not occur at the surface but rather in the solution where agglomerates formed then adhered themselves to the surface.

An EDS analysis of the film showed that the film did indeed consist of gold (see Figure 55). The EDS was compared to that of a gold standard and found to correspond nicely. The only peaks that were found to differ was that of the substrate Si and a small peak that could have 
been labelled as either $\mathrm{Mg}$ or $\mathrm{Li}$. Since lithiated ligands were used in the synthesis of the precursor molecules this was determined to be the most likely impurity.

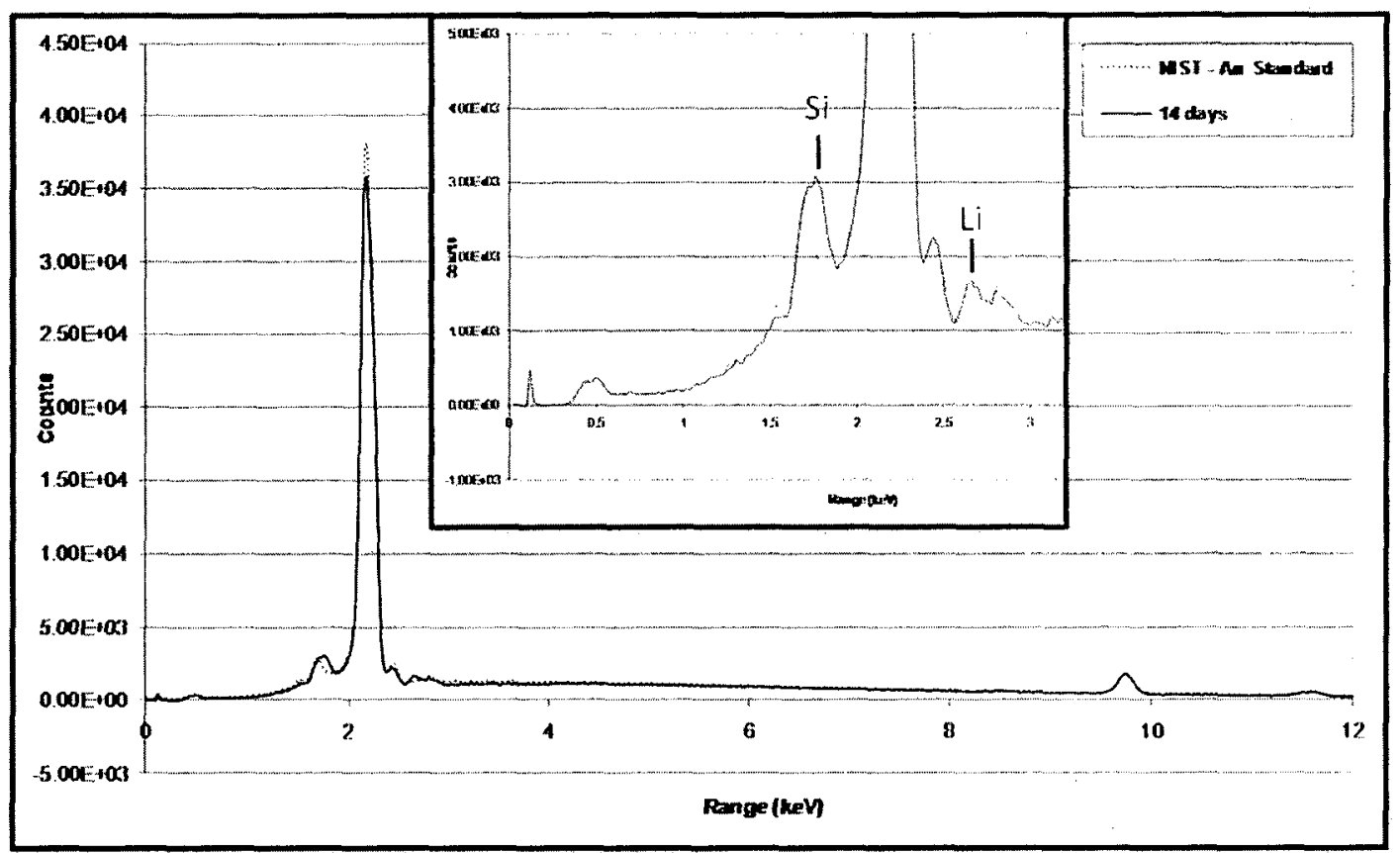

Figure 55: $\quad$ EDS of film b) deposited over 14 days.

A XRD study of the film showed that the deposited gold film was crystalline. All the typical Au crystalline faces could be seen. 


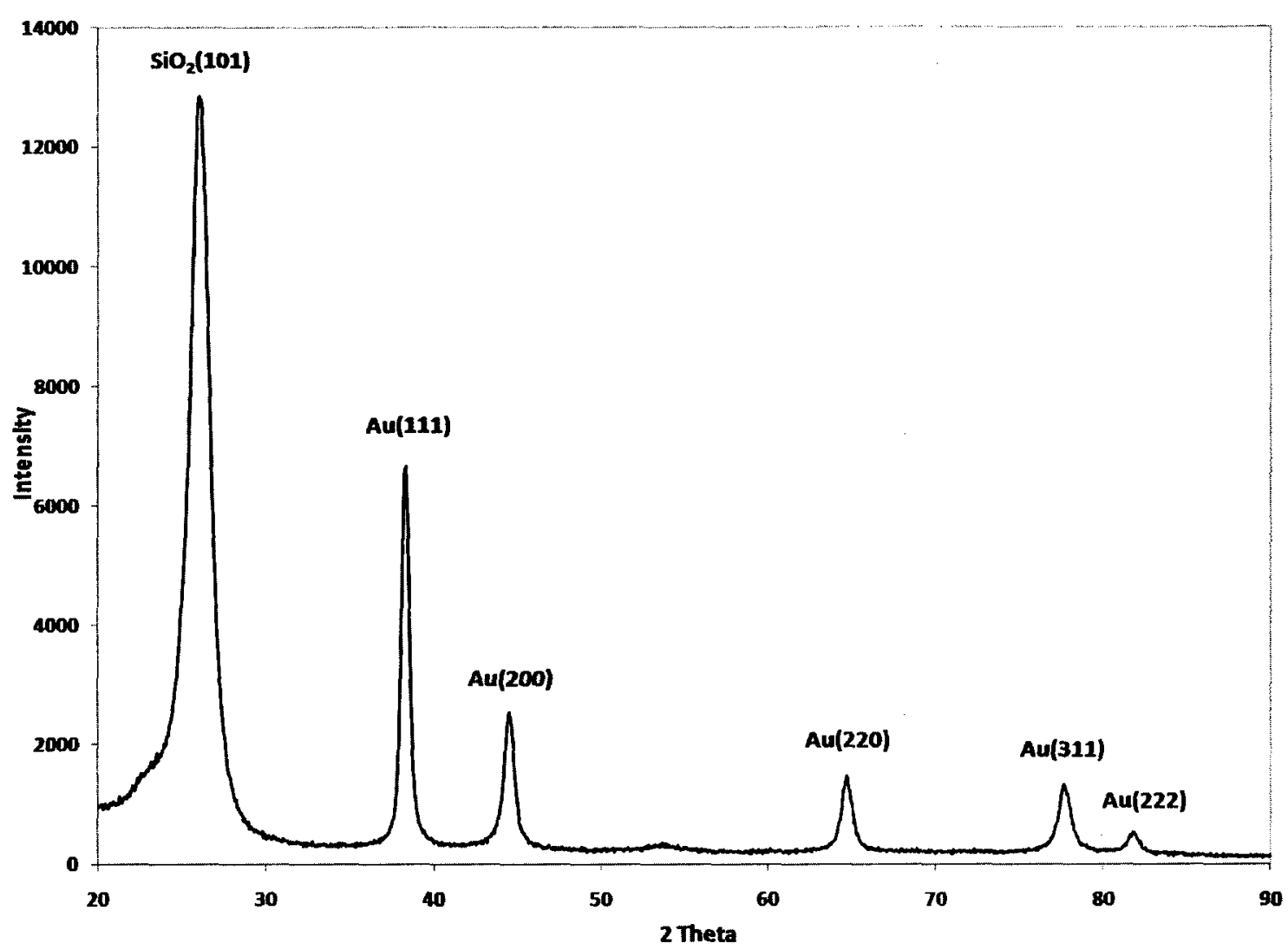

Figure 56: $\quad$ XRO of film $c$ ) indicating crystalline gold and glass slide substrate.

\subsection{7 day Novel substrate Deposition (c)}

An interesting side experiment was conducted in trying to tune the decomposition to occur at the surface of the substrate as opposed to decomposition within solution. It occurred to us that if the light source (the decomposition initiator) could be confined within the substrate, that this might promote decomposition at the substrate surface as opposed to within the solution. The logic behind this was that the light path would not have to travel through the precursor solution possibly initiating solution phase decomposition as was seen in a) and b) experiments before coming in contact with the substrate.

Therefore an optically clear substrate that could confine light within it was required. We decided to use a fibre Bragg grating filament to act as a substrate as well as the light source. 
Fibre Bragg grating filaments differ from normal fibre optics in that light can escape out the sidewalls of the fibre optic as well as the end of the filament whereas in the case of normal fibre optics the light would only escape out the end. However most of the light still escapes out of the end of the fibre Bragg grating making it the most likely point on the fibre for gold deposition. A description of the experiment can be seen in section 7.7 .

The SEM images of the fibre Bragg grating filament after deposition (Figure 57) showed what looked to small crystalline deposits along the sidewall of the filament. It could not be determined conclusively if this was gold deposited by surface decomposition pathway or from an in solution decomposition. A SEM image of the end of the filament was taken (Figure 57 inset) and showed what looked like crystalline growth originating at the surface. The deposits were found to differ dramatically from the large agglomerations seen in Figure 54 and thus must deposit via a different pathway.

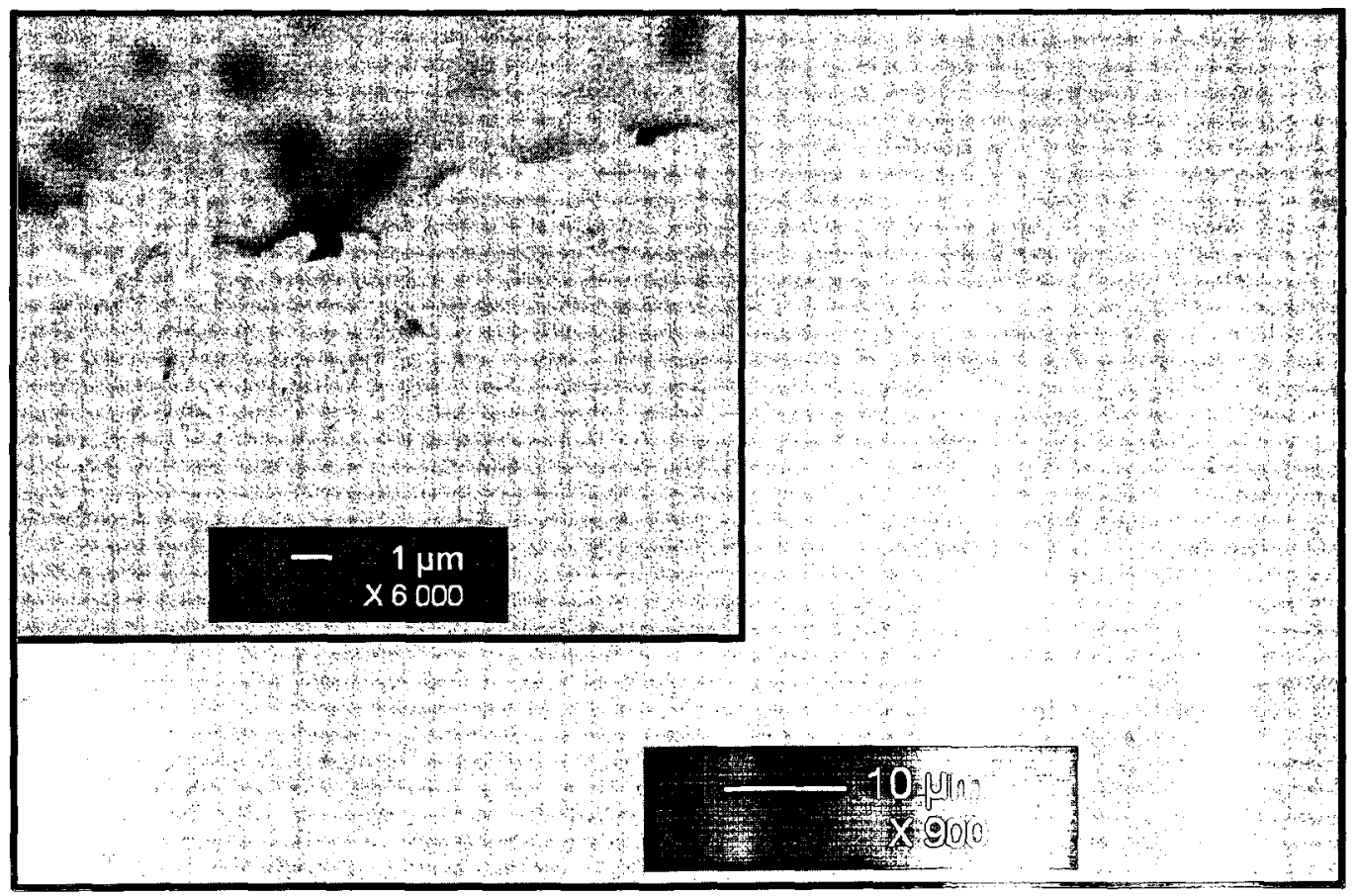

Figure 53: $\quad$ SEM image of photodeposited gold on a fibre Bragg gratim hilament $(2.6 \%$ 


\subsection{Conclusions}

The gold films proved to be weakly adhered to the glass surface. The deposited gold films failed the scotch tape test, and could be removed by acetone, but not dilute acid, water or alkanes. This weak interaction indicates that a photo excited acetamidinate gold (1) precursor molecule is not decomposing at a hydroxyl site and resulting in a chemically bound gold site. More likely a photo excited precursor molecule is physisorbed at the surface and undergoes decomposition and acts as a site for further decomposition to occur on. Since the hydroxyl density in untreated glass vials is relatively low; increasing them using different chemical methods may result in stronger film adhesion to the glass.

Decomposition was not limited to the vial walls. Upon removal of the pentane solution post deposition it was evident that some microparticilate gold was being formed. These particles ranged from red to purple to black in colour, indicating a range of sizes from nanoparticle to microparticle while still being suspended in solution. It's postulated that this solution phase decomposition was most likely that which created the film seen in Figure 54 . This film was most

likely the result of gold particulates that became too large to remain suspended in solution and deposited electrostatically on the substrate surface.

A fibre Bragg grating fibre optic was used in an attempt to confine the decomposition to the substrate surface by having the substrate double as the light source. 


\section{Gold Metal Chemical Vapour Deposition}

Compound $\mathbf{3}$ was shown to have a small window between sublimation and decomposition. For this reason Heating Zone \#1 (see Figure 70 in Experimental Section) was always kept at $85 \pm 2{ }^{\circ} \mathrm{C}$. The temperature of the deposition zone (Heating Zone $\# 2$ ) was varied to determine the limits of the gold CVD process. Gold CVD experiments were performed on Si(100) wafers only.

\section{1. $85^{\circ} \mathrm{C}$ Deposition Temperature}

It was found that with the sublimation and decomposition of the gold (I) dimethyl guanidinate occurring at almost identical temperatures $\left(83^{\circ} \mathrm{C}\right.$, and $85{ }^{\circ} \mathrm{C}$ respectively) that the entire deposition reactor could be heated to $85^{\circ} \mathrm{C}$ and result gold CVD. Long exposure times were used to ensure kinetic decomposition of the precursor once physically adsorbed to the substrate surface.

Experiments done with an exposure time of $8 \mathrm{hrs}$ showed that $85^{\circ} \mathrm{C}$ was not a sufficient temperature to completely decompose the precursor at the surface. Some sublimation component was seen that did not result in complete precursor decomposition, but rather grew crystal islands (Figure 58) of precursor within a field of gold nanocrystals (Figure 61). 


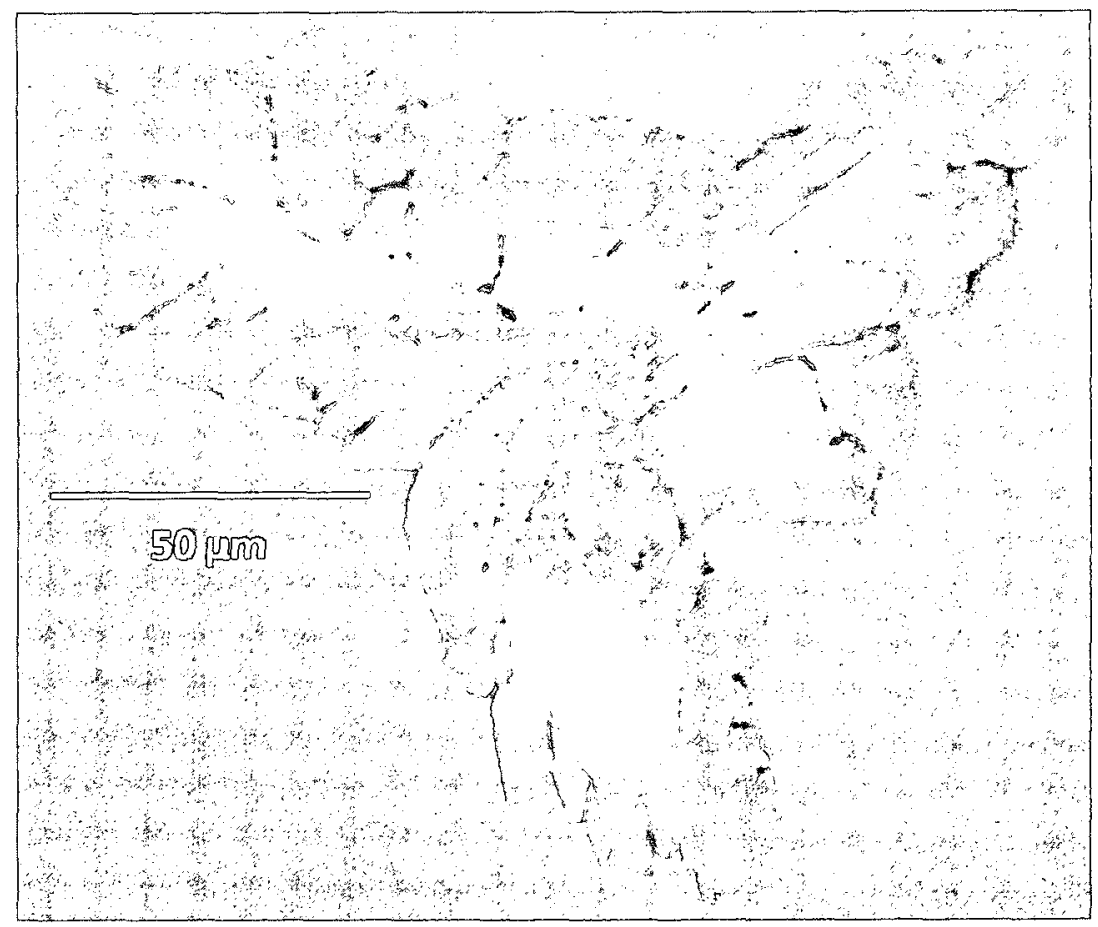

Figure 58: $\quad$ Sublimed gold (1) dimethylguanidinate preursor on sillow wa kectangular area represents an area of prolonged electron expasure.

The first indication that these islands were not gold metal was that they appeared as though they were charging. Charging occurs when the electrons do not escape from the surface, a characteristic of non conducting films or even substrates (seen in Section 5). The EDS confirmed that there was a high level of carbon and nitrogen within the islands (see figure 59).

\begin{tabular}{ccc}
\hline & & \\
\hline C & 31.14 & 37.96 \\
N & 12.11 & 18.23 \\
Au & 56.75 & 43.81 \\
Toial & 100.00 & 100.00
\end{tabular}

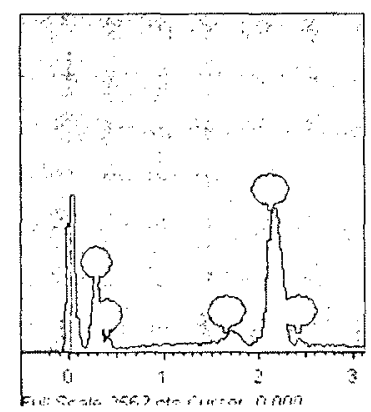

Figure 59: $\quad$ EDS data of rectangular region seen in Figure 58. 
A comparison was made between the theoretical weight percentages of compound 3 , the precursor that was used in the CVD experiments with the found value from the EDS taken of the island seen in Figure 58. The results showed a very good correlation. The experiment seemed to overestimate the quantity of gold centres and underestimate the amount of nitrogen and carbon centres. This is most likely due to partial decomposition within the condensed precursor. This could be caused simply by exposure to atmosphere prior to SEM analysis or simply thermal decomposition as was the goal of the experiment. The electron beam of the microscope also helped to decompose the compound as can be seen in Figure 58. The dark square area was a portion of sample that had been imaged for extended periods. The electron beam would have etched away organic ligands leaving the gold centres behind.

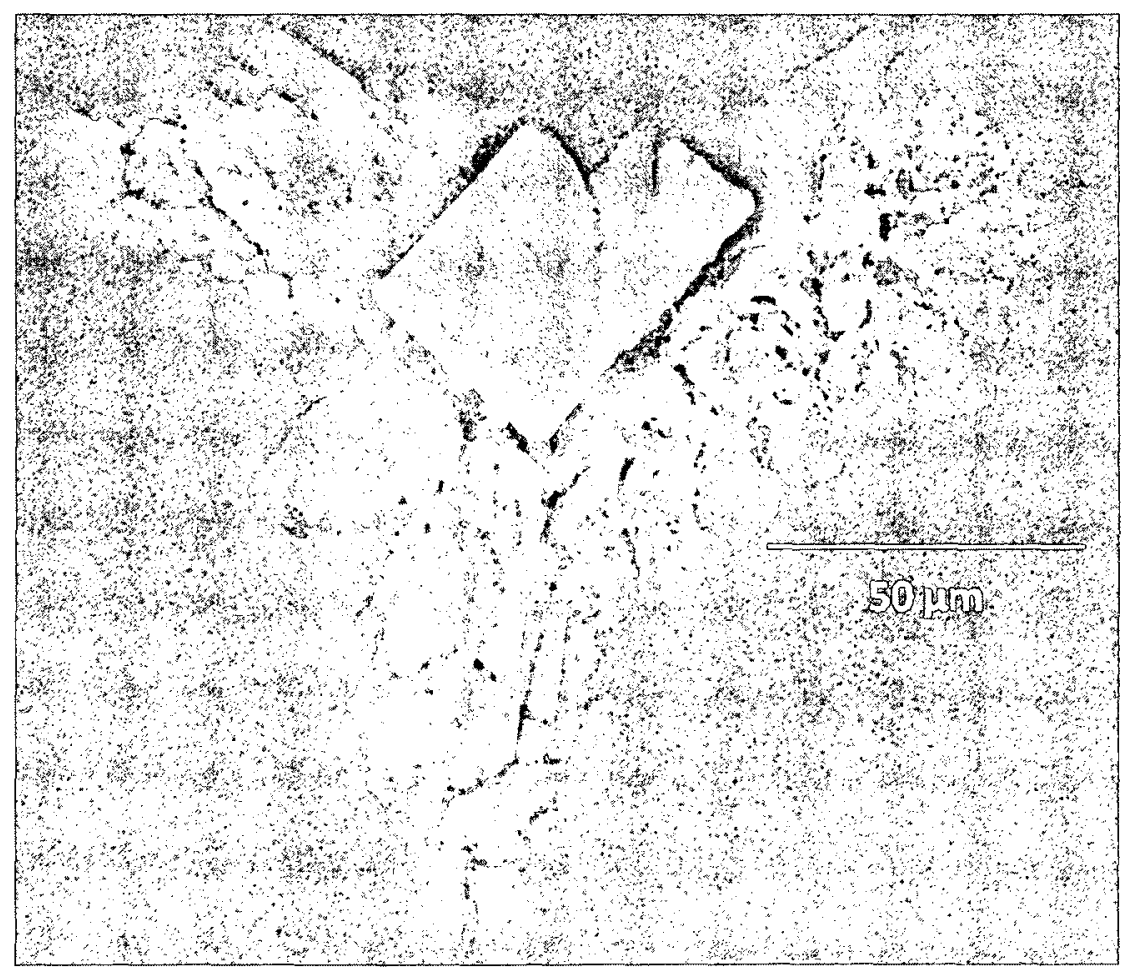

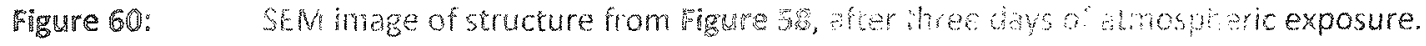

The structure was then imaged three days later after being allowed to sit at ambient conditions exposed to air. The results were a partially decomposed structure, which consisted of 
large cracks and fissures. Interestingly the most well preserved area was that which was exposed to the SEM electrons for an extended period. This was attributed to a higher density of gold centres in the area, as the electron beam had already removed a percentage of ligand from the surface. Effectively decomposing the area before it could undergo decomposition under ambient conditions.

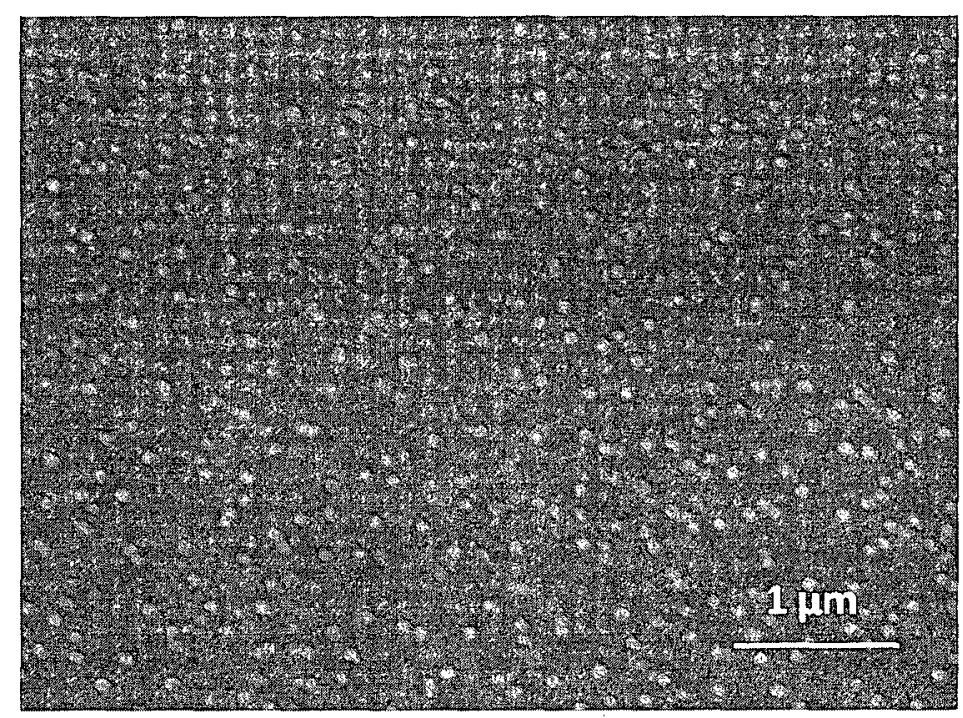

Figure 61: Nanoparticle formation

These islands were found to be a rare occurrence. The remainder of the slide consisted of gold nanoparticles (see Figure 61). EDS showed gold metal with little impurities. This showed that the decomposition is occurring at the surface but not completely. A higher temperature is required for complete decomposition. The islands found also showed that there is physical adsorption happening at the surface. It concentration of condensed precursor in only these islands showed a high mobility of physically adsorbed precursor on the surface. 


\section{2. $120^{\circ} \mathrm{C}$ Deposition Temperature}

This deposition temperature was chosen as thermolysis experiments (see Section 2.1.2.) showed the complete decomposition of compound $\mathbf{3}$ under these conditions. Substrates were cleaned as per the procedure found in section 7.8.1.

\subsubsection{Exposure experiments}

The exposure time was varied in order to obtain variable thicknesses of gold films. The overall goal of these experiments was to obtain a film thickness vs exposure time plot. This would yield a growth rate for this process that could result in a predictable process.

\section{Film 1 (i):}

The first experiment conducted was that for a $2 \mathrm{hr}$ exposure time, the Si(100) wafers exhibited a gold lustre with a mirror-like quality when visually inspected. The films were then inspected via SEM and EDS. 


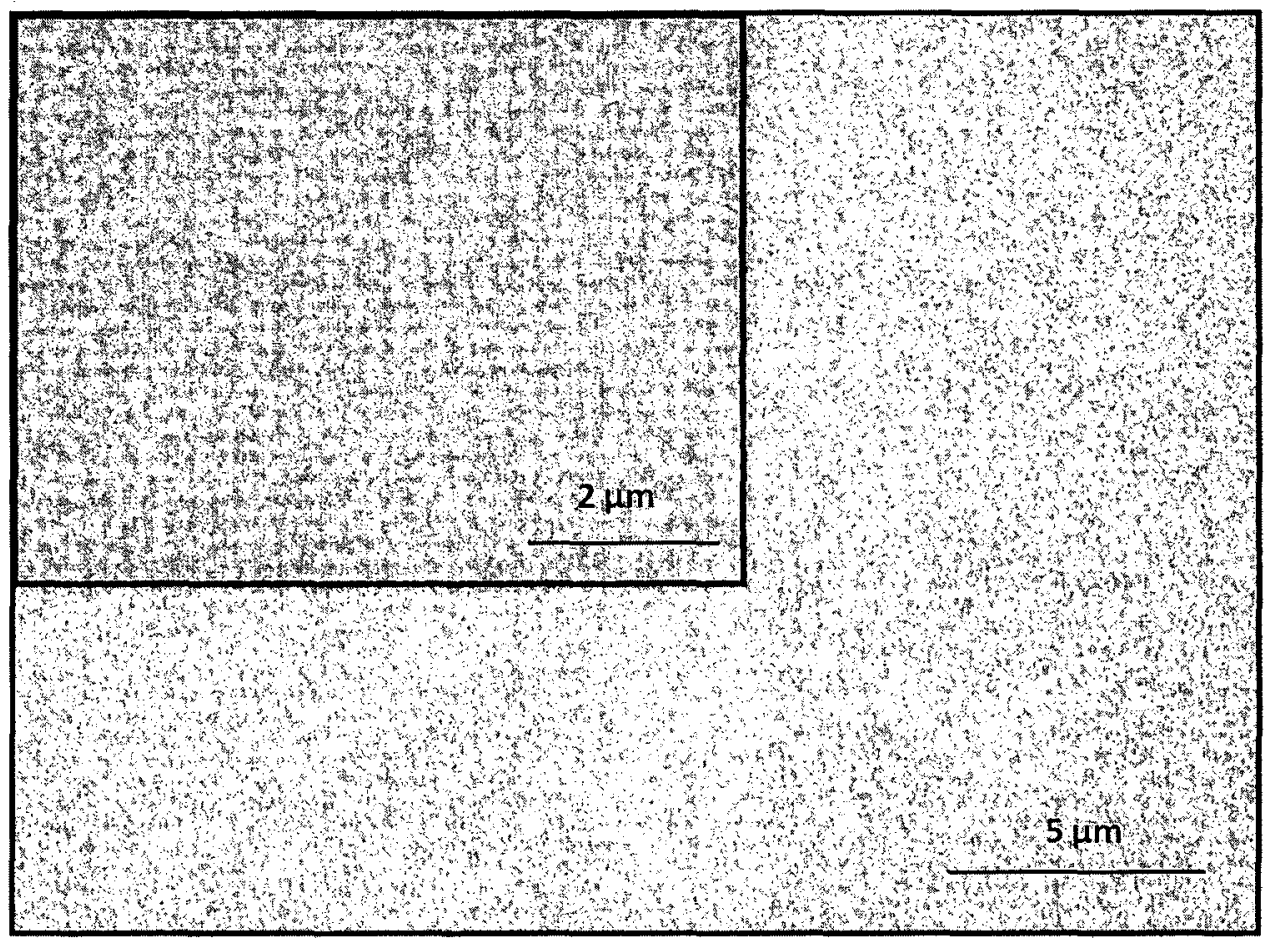

Figure 62: $\quad$ SEM image of Gold CVD film (i).

The SEM images showed a field of white conduction on a black field. The white areas are gold metal which is of higher conduction than that of the silicon surface, seen as the black spaces between particles. The films were found to consist of a conformal thickness throughout. (i) was found to resemble the film deposited at $85{ }^{\circ} \mathrm{C}$; in that they were composed of nanoparticles. The film was more extensive than that shown at lower temperatures (see Figure 61). 


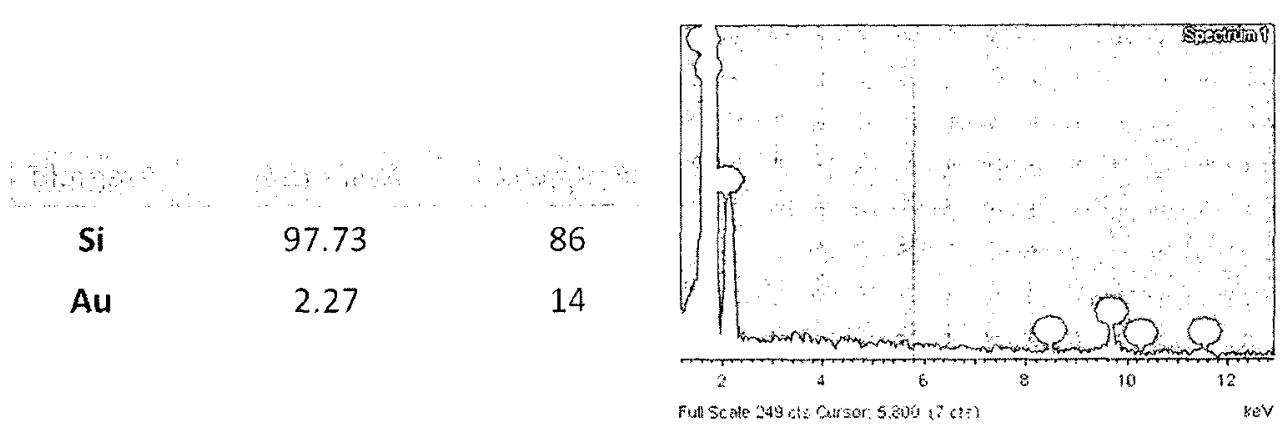

Figure 63: $\quad$ EDS spectra of (i), field seen in Figure 63

The EDS found that the film was composed of gold metal, the substrate was the major signal in the spectra due to the thinness of the film. The lack of carbon seen in the film is inconclusive as there may not have been enough sample to register a carbon signal.

A cross sectional SEM did not yield images of the film. This is indicative of a film less than $10 \mathrm{~nm}$ thick, the limit of the SEM used.

\section{Film 2 (ii):}

In order to achieve a film thick enough to obtain a cross sectional thickness measurement, the exposure time was increased to $6 \mathrm{hrs}$. The film had a gold lustre but was considerably less reflective than that of (i). The lack of reflectivity was indicative of the thickness of the gold film, the reflective nature of the $\mathrm{Si}(100)$ was not be seen as the film obscured it. 


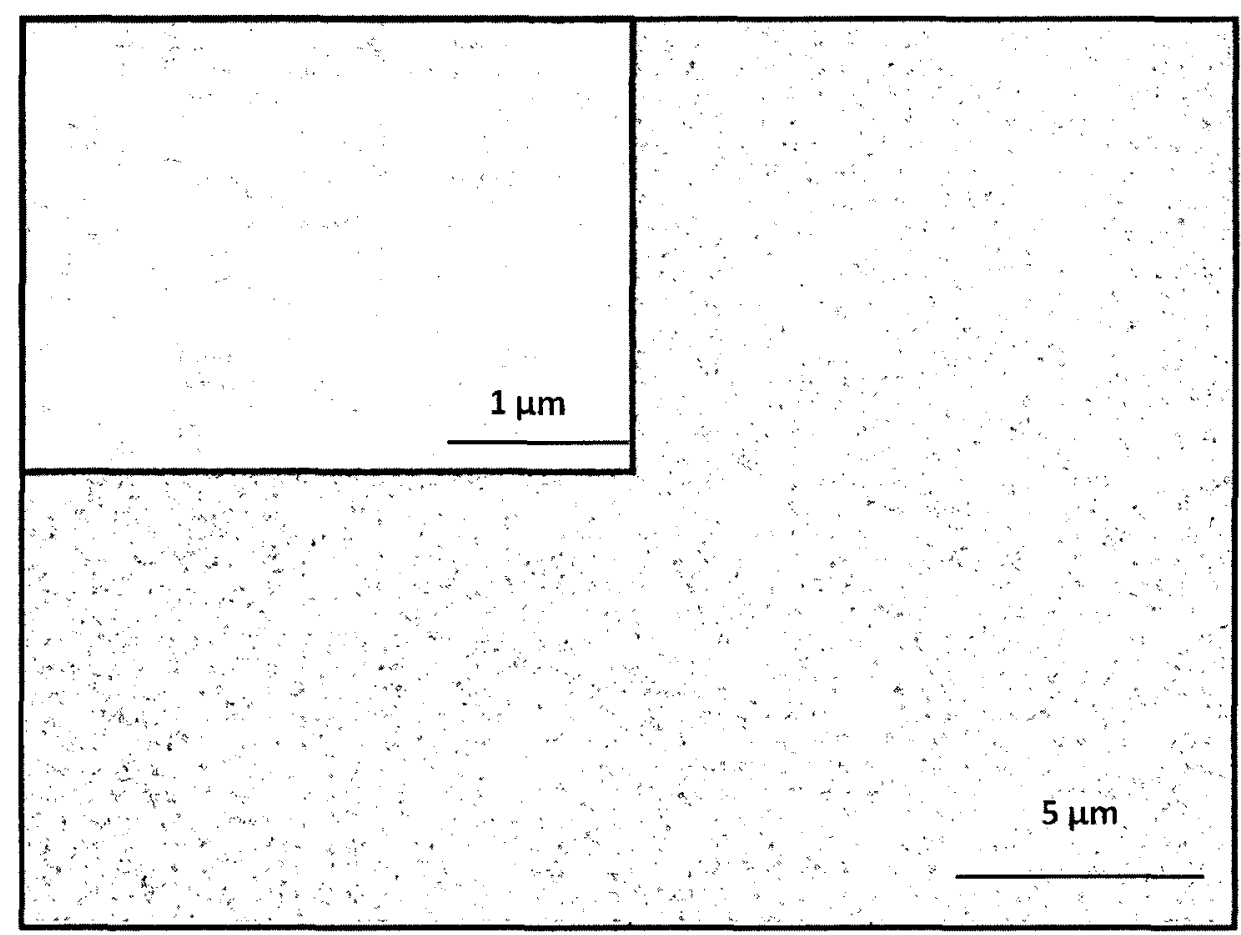

Figure 64: SEM image of Gold CVD film (ii).

The film was found to consist of small prism shaped crystallites stacked on top of each other, the high crystalline growth is indicative of a slow rate of deposition. The crystallites were more tightly packed than that seen for (i) indicative of complete coverage. The substrate could not be seen between the crystallites.

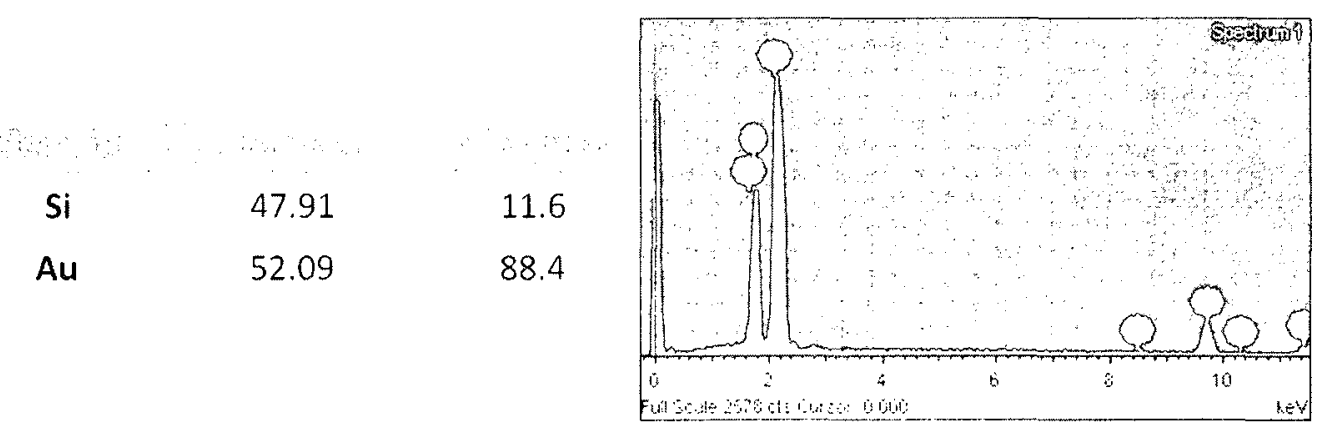

Figure 65: $\quad$ EDS data of (iii from Figure 64

An EDS (Figure 65) of the field seen in Figure 64 showed a significant increase in gold content when compared to (i). The Au peaks in the spectrum were seen to obscure the peaks for 
the Si surface. The atomic and weight percentages confirm that gold is the major surface material. Carbon values were not significant in this film, indicating that our precursor is decomposing cleanly once coming into contact at the surface.

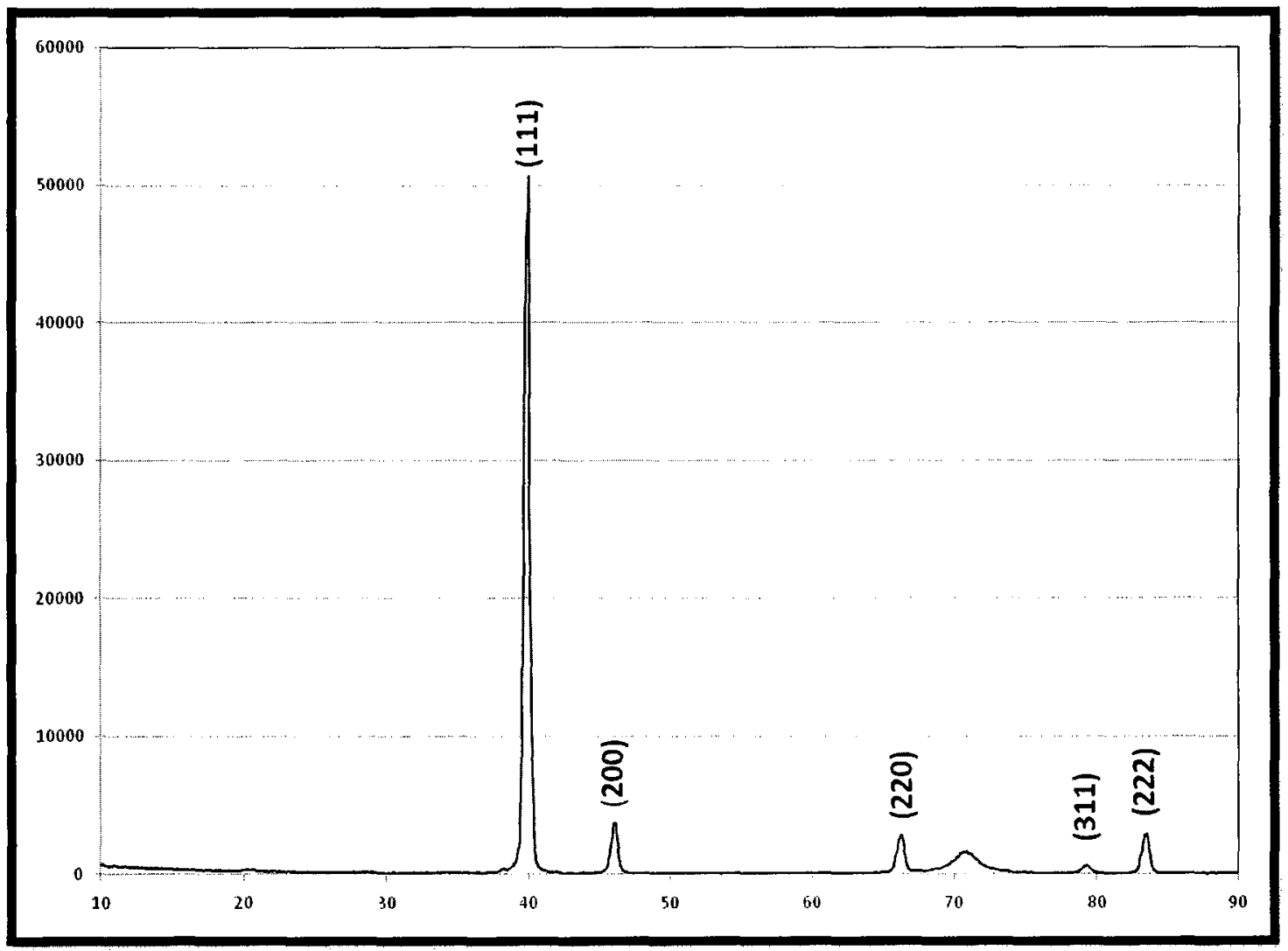

Figure 66: $\quad X R D$ of ii)

The XRD of ii was found to be highly crystalline with the (111) face in preference. Compared to the photodeposited gold XRD (Figure 56) the CVD deposited film was found to be of higher crystalinity. 


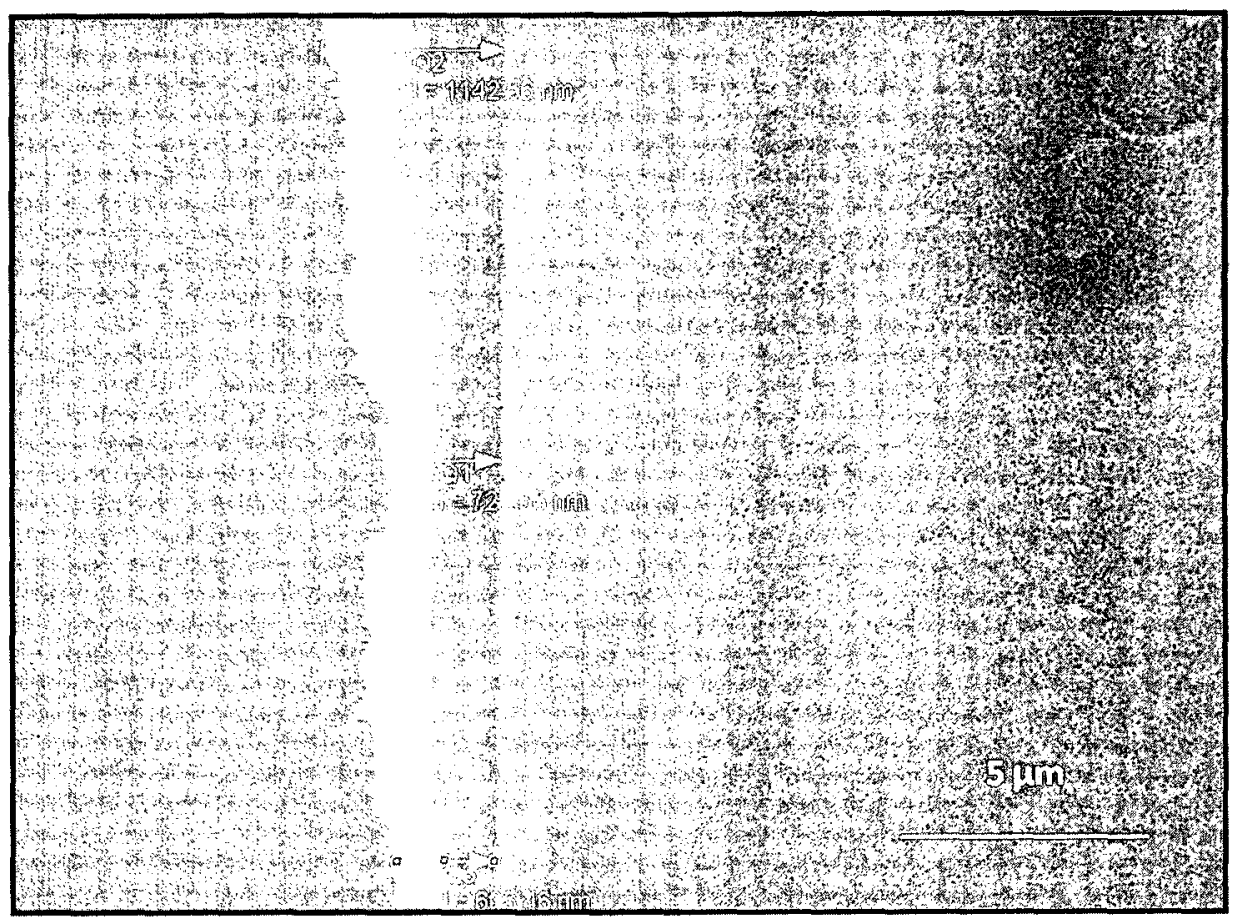

Figure 67: $\quad$ SEM cross sectional image of (ii)

The wafer was broken to achieve a cross sectional thickness measurement. The SEM images of the cross section can be seen in Figure 67. The bright area on the left side of the figure indicates the gold film while the black area on the right is the substrate. It was found that the film varied in thickness from $600-1150 \mathrm{~nm}$. This variance is higher than expected for a process that showed high conformality over thinner films (see previous two examples). The darkened areas in Figure 65 where the areas meet the surface could be indicative of the film lifting from the surface. This is the more likely case. 


\subsection{Conclusions}

Gold metal films were grown on glass from solution by the photoreduction of a $\mathrm{Au}$ (I) acetamidinate precursor. These films were found to be highly crystalline by XRD but lacked conformality. These films stood up to the tape test.

Gold metal nanoparticles were grown by thermal CVD on Si(100) wafers at $85{ }^{\circ} \mathrm{C}$ from $\mathrm{Au}(1)$ dimethyl guanidinate as a single source precursor. This was found to be by far the lowest thermal CVD deposition reported. Gold films were found to form at temperatures of $120{ }^{\circ} \mathrm{C}$ by changing only the temperature of the process yet still at lower temperatures than that found in literature. These films failed the tape test indicating decomposition at the surface without chemically reacting with surface hydroxyl sites. 


\section{Experimental}

\subsection{General Synthetic Procedures}

General Considerations. All manipulations were performed in an MBraun Unilab inert atmosphere drybox, unless otherwise stated. Drybox solvents were degassed and dried on an MBraun solvent purification system. These were stored over activated $4 \mathrm{~A}$ sieves. The chemicals: 1,3-diisopropyl carbodiimide, diethyl amine, diisopropyl amine, butyl lithium (2.5 M in hexanes), methyl lithium ( $1.6 \mathrm{M}$ in diethyl ether), silver(I) chloride, lithium dimethyl amide, carbon disulphide, sodium t-butoxide and potassium bistrimethylsilylamide were purchased from Aldrich Chemical Co. and used as received. The gold(I) starting material AuCl-THT was synthesised by literature methods(43) as was AuCl-TPP, these syntheses were adapted for AgCl-TPP and AgCl-TBP. AuCl was an isolated decomposition product of failed sublimation of $\mathrm{HAuCl}_{4} \cdot \mathrm{XH}_{2} \mathrm{O}$. The compounds $\mathrm{Li}\left[\left({ }^{(} \mathrm{PrN}\right)_{2} \mathrm{CN}\left({ }^{\mathrm{i}} \mathrm{Pr}\right)_{2}\right], \mathrm{Li}\left[(\operatorname{PrN})_{2} \mathrm{CNH}\left({ }^{\prime} \mathrm{Pr}\right)\right]$,

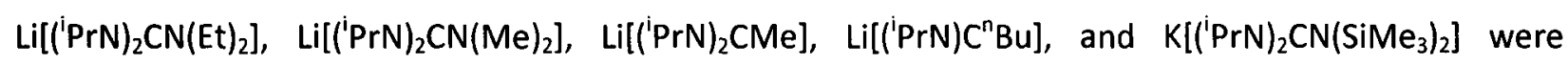
prepared by literature methods $(44,45)$.

\subsubsection{Xanthates}

Xanthate ligands followed literature methods as described for $\mathrm{K}\left[\mathrm{S}_{2} \mathrm{CO}^{n} \mathrm{Bu}\right](35)$, followed by the isolation and drying of the ligand salt in order to determine ${ }^{1} \mathrm{H}$ and ${ }^{13} \mathrm{C}$ NMR spectra. Synthesis of $\mathrm{Na}\left[\mathrm{S}_{2} \mathrm{CO}^{t} \mathrm{Bu}\right]$ was prepared by alternate methods due to the potassium salt derivative's hygroscopic nature.

$\mathrm{Na}\left[\mathrm{S}_{2} \mathrm{CO}^{\mathrm{t}} \mathrm{Bu}\right]:$ In a $250 \mathrm{~mL}$ flask on schlenk lines, $\left(5 \mathrm{~g}, 8.91 \times 10^{-2} \mathrm{~mol}\right)$ sodium t-butoxide was suspended in hexanes. $\left(6.78 \mathrm{~g}, 5.38 \mathrm{~mL}, 8.91 \times 10^{-2} \mathrm{~mol}\right)$ of $\mathrm{CS}_{2}$ was added to the solution dropwise at a rate of 2 drops/s. The reaction was allowed to progress for $1 \mathrm{hr}$. The white powdered sodium xanthate salt precipitate was then filtered and washed with $30 \mathrm{~mL}$ of ethanol followed by $30 \mathrm{~mL}$ of ether; dried under vacuum. $\left(8.91 \times 10^{-2} \mathrm{~mol}, 15.7 \mathrm{~g}, 100 \%\right){ }^{1} \mathrm{H} \mathrm{NMR}\left(300 \mathrm{MHz},\left(\mathrm{CD}_{3}\right)_{2} \mathrm{SO}\right)$ : 1.55 (s, 9H, C(CH3) $\left.)_{3}\right) .{ }^{13} \mathrm{C}\left\{{ }^{1} \mathrm{H}\right\}$ NMR (300 MHz, CD $\left.)_{2} \mathrm{SO}\right): 28.39\left(3 \mathrm{C}, \mathrm{C}\left(\mathrm{CH}_{3}\right)_{3}\right)$.

$\mathrm{K}\left[\mathrm{S}_{2} \mathrm{CO}^{\mathrm{n}} \mathrm{Bu}\right]$ : In a $250 \mathrm{~mL}$ flask on schlenk lines, $\left(5 \mathrm{~g}, 8.91 \times 10^{-2} \mathrm{~mol}\right)$ crushed, dried $\mathrm{KOH}$ was dissolved in $100 \mathrm{~mL}$ of $\mathrm{n}$-butanol. $\left(6.78 \mathrm{~g}, 5.38 \mathrm{~mL}, 8.91 \times 10^{-2} \mathrm{~mol}\right)$ of $\mathrm{CS}_{2}$ was added to the reaction mixture dropwise at a rate of $2 \mathrm{drops} / \mathrm{s}$. The reaction was allowed to progress for $1 \mathrm{hr}$. The white powdered potassium xanthate salt precipitate was then filtered and washed with $30 \mathrm{~mL}$ of ethanol followed by $30 \mathrm{~mL}$ of ether; dried under vacuum. $\left(8.91 \times 10^{-2} \mathrm{~mol}, 15.7 \mathrm{~g}, 100 \%\right) .{ }^{1} \mathrm{H}$ NMR 
(300 MHz, $\left(\mathrm{CD}_{3}\right)_{2} \mathrm{SO}$ ): 4.18 (t, $2 \mathrm{H}, \mathrm{CH}_{3} \mathrm{CH}_{2} \mathrm{CH}_{2} \mathrm{CH}_{2}$ ), 1.56 (pen, $2 \mathrm{H}, \mathrm{CH}_{3} \mathrm{CH}_{2} \mathrm{CH}_{2} \mathrm{CH}_{2}$ ), 1.32 (sex, 2H,

$\mathrm{CH}_{3} \mathrm{CH}_{2} \mathrm{CH}_{2} \mathrm{CH}_{2}$ ), 0.89 (t, $\left.3 \mathrm{H}, \mathrm{CH}_{3} \mathrm{CH}_{2} \mathrm{CH}_{2} \mathrm{CH}_{2}\right) .{ }^{13} \mathrm{C}\left\{{ }^{1} \mathrm{H}\right\} \quad \mathrm{NMR}$ (300 $\left.\mathrm{MHz}, \mathrm{CD}_{3}\right)_{2} \mathrm{SO}$ ): 70.14 $\left(\mathrm{CH}_{3} \mathrm{CH}_{2} \mathrm{CH}_{2} \mathrm{CH}_{2}\right), 30.61\left(\mathrm{CH}_{3} \mathrm{CH}_{2} \mathrm{CH}_{2} \mathrm{CH}_{2}\right), 18.88\left(\mathrm{CH}_{3} \mathrm{CH}_{2} \mathrm{CH}_{2} \mathrm{CH}_{2}\right), 13.71\left(\mathrm{CH}_{3} \mathrm{CH}_{2} \mathrm{CH}_{2} \mathrm{CH}_{2}\right)$.

\subsection{Group 11 Chlorides}

AuCl(TPP): In a $200 \mathrm{~mL}$ flask $100 \mathrm{~mL}$ anhydrous acetone, $\left(8.13 \mathrm{~g}, 2.54 \times 10^{-2} \mathrm{~mol}\right) \mathrm{AuCl}(\mathrm{THT})$ was suspended. $\left(6.65 \mathrm{~g}, 2.54 \times 10^{-2} \mathrm{~mol}\right)$ triphenylphosphine was added. The reaction was allowed to stir for $3 \mathrm{hrs}$. Under reduced pressure THT was removed. The solution was placed in the freezer to recrystallize. The product was collected as white crystals $\left(11.46 \mathrm{~g}, 2.32 \times 10^{-2} \mathrm{~mol}, 91.3 \%\right) .{ }^{1} \mathrm{H}$ NMR (300 MHz, $\left.\mathrm{C}_{6} \mathrm{D}_{6}\right): 7.14,(\mathrm{~m}, 12 \mathrm{H}, \mathrm{PPh}) 6.90\left(\mathrm{~m}, 18 \mathrm{H}, \mathrm{PPh} \mathrm{h}_{3}\right) .{ }^{13} \mathrm{C}\left\{{ }^{1} \mathrm{H}\right\} \mathrm{NMR}\left(300 \mathrm{MHz}, \mathrm{C}_{6} \mathrm{D}_{6}\right)$ : 134.35, 134.16, 131.28, 131.25, 129.21, $129.06\left(\mathrm{PPh}_{3}\right)$

$\mathrm{AuCl}(\mathrm{TPP})_{2}$ : In a $100 \mathrm{~mL}$ flask, $50 \mathrm{~mL}$ of reaction grade acetone was added. Crude AuCl $(0.33 \mathrm{~g}$, $1.42 \mathrm{mmol})$ was suspended in the acetone. TPP $(0.37 \mathrm{~g}, 1.42 \mathrm{mmol})$ was added in excess. The reaction was allowed to proceed overnight. Unreacted Au was filtered off, and the volume of the reaction solution reduced to $25 \mathrm{~mL}$ under reduced pressure. The flask was then placed at - 36 ${ }^{\circ} \mathrm{C}$ for recrystallization ( $\left.0.49 \mathrm{~g}, 0.65 \mathrm{mmol}, 45.7 \%\right) .{ }^{1} \mathrm{H}$ NMR $\left(300 \mathrm{MHz}, \mathrm{C}_{6} \mathrm{D}_{6}\right): 7.21,(\mathrm{~m}, 12 \mathrm{H}$, $\left.P P h_{3}\right) 6.93\left(\mathrm{~m}, 18 \mathrm{H}, \mathrm{PPh} h_{3}\right) .{ }^{13} \mathrm{C}\left\{{ }^{1} \mathrm{H}\right\}$ NMR $\left(300 \mathrm{MHz}, \mathrm{C}_{6} \mathrm{D}_{6}\right): 134.35,134.16,131.28,131.25,129.21$, $129.06\left(\mathrm{PPh}_{3}\right)$

AuCl(TBP): On the benchtop in $50 \mathrm{~mL}$ acetone, $(2.04 \mathrm{~g}, 6.36 \mathrm{mmol}) \mathrm{AuCl}(\mathrm{THT})$ was suspended. $(1.38 \mathrm{~g}, 1.68 \mathrm{~mL}, 6.36 \mathrm{~mol})$ tributylphosphine was added. The reaction was allowed to stir for $3 \mathrm{hrs}$. Under reduced pressure THT and solvent was removed. The product was collected as a yellow oil (2.71 g, $6.24 \mathrm{mmol}, 98.1 \%)$. ${ }^{1} \mathrm{H}$ NMR (300 MHz, $\left.\mathrm{C}_{6} \mathrm{D}_{6}\right): 1.19\left(\mathrm{~m}, 18 \mathrm{H}, \mathrm{CH}_{2} \mathrm{CH}_{2} \mathrm{CH}_{2} \mathrm{CH}_{3}\right)$, $0.77\left(\mathrm{t}, 9 \mathrm{H}, \mathrm{CH}_{2} \mathrm{CH}_{2} \mathrm{CH}_{2} \mathrm{CH}_{3}\right) .{ }^{13} \mathrm{C}\left\{{ }^{1} \mathrm{H}\right\} \quad \mathrm{NMR}\left(300 \mathrm{MHz}, \mathrm{C}_{6} \mathrm{D}_{6}\right): 27.36\left(\mathrm{PCH}_{2} \mathrm{CH}_{2} \mathrm{CH}_{2} \mathrm{CH}_{3}\right), 25.64$ $\left(\mathrm{PCH}_{2} \mathrm{CH}_{2} \mathrm{CH}_{2} \mathrm{CH}_{3}\right), 25.18\left(\mathrm{PCH}_{2} \mathrm{CH}_{2} \mathrm{CH}_{2} \mathrm{CH}_{3}\right), 24.34\left(\mathrm{PCH}_{2} \mathrm{CH}_{2} \mathrm{CH}_{2} \mathrm{CH}_{3}\right), 24.14\left(\mathrm{PCH}_{2} \mathrm{CH}_{2} \mathrm{CH}_{2} \mathrm{CH}_{3}\right)$, 13.80 $\left(\mathrm{PCH}_{2} \mathrm{CH}_{2} \mathrm{CH}_{2} \mathrm{CH}_{3}\right)$.

AgCl(TPP): See Ref. (23)

AgCl(TBP) : See Ref. (23) 


\subsection{Gold (I) Complexes}

\subsubsection{Guanidinates \& Amidinates}

$\mathrm{Au}_{2}\left[(\operatorname{PrN})_{2} \mathrm{CMe}\right]_{2}$ (1): In a $100 \mathrm{~mL}$ round bottomed flask, AuCl.THT $(0.57 \mathrm{~g}, 1.78 \mathrm{mmol})$ suspended in $50 \mathrm{~mL}$ of hexanes. The slurry was cooled to $-36{ }^{\circ} \mathrm{C}$. Solid Li[('PrN $\left.)_{2} \mathrm{CCH}_{3}\right](0.27 \mathrm{~g}$, $1.78 \mathrm{mmol}$ ) was added to the solution and allowed to react at $-36^{\circ} \mathrm{C}$ overnight. The reaction was then warmed to room temperature and immediately filtered, and the $\mathrm{LiCl}$ was washed with an additional $50 \mathrm{~mL}$ of hexanes. The solution was concentrated under reduced atmosphere and returned to the freezer for 24 hours. A white precipitate of 1 formed $(0.43 \mathrm{~g}, 1.28 \mathrm{mmol}, 71.8$ \%). m.p. $79{ }^{\circ} \mathrm{C}$ (dec). Anal. Calcd for $\mathrm{C}_{16} \mathrm{H}_{34} \mathrm{Au}_{2} \mathrm{~N}_{4}$ : C, 28.41; $\mathrm{H}, 5.07 ; \mathrm{N}, 8.28 .{ }^{1} \mathrm{H} \mathrm{NMR}$ (300 MHz, $\mathrm{C}_{6} \mathrm{D}_{6}$ ): 3.57 (sept, $\left.4 \mathrm{H},\left(\mathrm{CH}_{3}\right)_{2} \mathrm{CHN}\right), 1.62$ (s, 6H, $\left(\mathrm{NCCH}_{3} \mathrm{~N}\right), 1.25\left(\mathrm{~d}, 24 \mathrm{H},\left(\mathrm{CH}_{3} \mathrm{CHN}\right){ }^{13} \mathrm{C}\left\{{ }^{1} \mathrm{H}\right\} \mathrm{NMR}\right.$ (300 MHz, $\left.\mathrm{C}_{6} \mathrm{D}_{6}\right): 168.49(\mathrm{NCN}), 50.97\left(\mathrm{CH}_{3} \mathrm{CHN}\right), 26.81\left(\left(\mathrm{CH}_{3}\right)_{2} \mathrm{CHN}\right), 16.09\left(\mathrm{CH}_{3} \mathrm{CNCH}\left(\mathrm{CH}_{3}\right)_{2}\right)$

$\mathrm{Au}_{2}\left[(\operatorname{PrN})_{2} \mathrm{C}^{\mathrm{n}} \mathrm{Bu}\right]_{2}$ (2): Compound $\mathbf{2}$ was prepared in a analogous manner as compound $\mathbf{1}$ substituting: AuCl.THT (1.01 g, $3.15 \mathrm{mmol}) \mathrm{Li}\left[\left({ }^{\mathrm{P} P N}\right)_{2} \mathrm{C}^{\mathrm{n}} \mathrm{Bu}\right)(0.60 \mathrm{~g}, 3.15 \mathrm{mmol}) ; 2$ was isolated by recrystallisation $\left(0.30 \mathrm{~g}, 0.79 \mathrm{mmol}, 25.0 \%\right.$ ). m.p. $96{ }^{\circ} \mathrm{C}$ (dec). Anal. Calcd for $\mathrm{C}_{22} \mathrm{H}_{26} \mathrm{Au}_{2} \mathrm{~N}_{4}: \mathrm{C}$, 34.74; $\mathrm{H}, 6.10 ; \mathrm{N}, 7.37 .{ }^{1} \mathrm{H}$ NMR $\left(300 \mathrm{MHz}, \mathrm{C}_{6} \mathrm{D}_{6}\right): 3.74$ (sept, $\left.4 \mathrm{H},\left(\mathrm{CH}_{3}\right)_{2} \mathrm{CHN}\right), 2.26$ (t, $4 \mathrm{H}$, $\left(\mathrm{CH}_{3} \mathrm{CH}_{2} \mathrm{CH}_{2} \mathrm{CH}_{2}\right), 1.44$ (q, $4 \mathrm{H} \quad\left(\mathrm{CH}_{3} \mathrm{CH}_{2} \mathrm{CH}_{2} \mathrm{CH}_{2}\right), 1.33$ (d, 24H, $\left(\mathrm{CH}_{3} \mathrm{CHN}\right.$ ), 1.17 (sex, $4 \mathrm{H},\left(\mathrm{CH}_{3} \mathrm{CH}_{2} \mathrm{CH}_{2} \mathrm{CH}_{2}\right) ; 0.80\left(\mathrm{t}, 6 \mathrm{H},\left(\mathrm{CH}_{3} \mathrm{CH}_{2} \mathrm{CH}_{2} \mathrm{CH}_{2}\right)\right){ }^{13} \mathrm{C}\left\{{ }^{1} \mathrm{H}\right\}$ NMR (300 MHz, $\left.\mathrm{C}_{6} \mathrm{D}_{6}\right): 171.55$ (NCN), $50.61\left(\mathrm{CH}_{3} \mathrm{CHN}\right), \quad 30.73\left(\mathrm{CCH}_{2} \mathrm{CH}_{2} \mathrm{CH}_{2} \mathrm{CH}_{3}\right), 29.85\left(\mathrm{CCH}_{2} \mathrm{CH}_{2} \mathrm{CH}_{2} \mathrm{CH}_{3}\right) 27.20\left(\left(\mathrm{CH}_{3}\right)_{2} \mathrm{CHN}\right), 23.06$ $\left(\mathrm{CCH}_{2} \mathrm{CH}_{2} \mathrm{CH}_{2} \mathrm{CH}_{3}\right), 13.92\left(\mathrm{CCH}_{2} \mathrm{CH}_{2} \mathrm{CH}_{2} \mathrm{CH}_{3}\right)$

$\mathrm{Au}_{2}\left[(\operatorname{PrN})_{2} \mathrm{CN}(\mathrm{Me})_{2}\right]_{2}$ (3): Compound 3 was prepared in a analogous manner as compound 1 substituting: AuCl-THT (0.99 g, $3.09 \mathrm{mmol})$, Li[('PrN $\left.)_{2} \mathrm{CN}(\mathrm{Me})_{2}\right](0.548 \mathrm{~g}, 3.09 \mathrm{mmol})$. Compound 10 was isolated by recrystallization $(0.99 \mathrm{~g}, 2.70 \mathrm{mmol}, 87.4 \%)$ m.p. $83^{\circ} \mathrm{C}(\mathrm{dec})$. Anal. Calcd for $\mathrm{C}_{18} \mathrm{H}_{40} \mathrm{Au}_{2} \mathrm{~N}_{6}: \mathrm{C}, 29.43 ; \mathrm{H}, 5.49 ; \mathrm{N}, 11.44 .{ }^{1} \mathrm{H} \mathrm{NMR}\left(300 \mathrm{MHz}, \mathrm{C}_{6} \mathrm{D}_{6}\right): 3.80$ (sept, $4 \mathrm{H},\left(\mathrm{CH}_{3}\right)_{2} \mathrm{CHN}$ ), $2.43\left(\mathrm{~s}, 12 \mathrm{H},\left(\mathrm{CH}_{3}\right)_{2} \mathrm{~N}\right), 1.37\left(\mathrm{~d}, 24 \mathrm{H}\left(\mathrm{CH}_{3}\right)_{2} \mathrm{CHN}\right) ;{ }^{13} \mathrm{C}\left\{{ }^{1} \mathrm{H}\right\} \quad \mathrm{NMR}\left(300 \mathrm{MHz}, \mathrm{C}_{6} \mathrm{D}_{6}\right): 170.65(\mathrm{NCN})$, $50.32\left(\left(\mathrm{CH}_{3}\right)_{2} \mathrm{CHN}\right), 40.89\left(\left(\mathrm{CH}_{3}\right)_{2} \mathrm{~N}\right), 27.21\left(\left(\mathrm{CH}_{3}\right)_{2} \mathrm{CHN}\right)$.

$\mathrm{Au}_{2}\left[(\operatorname{PrN})_{2} \mathrm{CN}(\mathrm{Et})_{2}\right]_{2}(4)$ : Compound 4 was prepared in a analogous manner as compound 1 substituting: AuCl.THT $(0.71 \mathrm{~g}, 2.23 \mathrm{mmol})$, Li[('PrN $\left.)_{2} \mathrm{CN}(\mathrm{Et})_{2}\right](0.46 \mathrm{~g}, 2.23 \mathrm{mmol})$. Compound 9 was isolated by reduced pressure $\left(0.71 \mathrm{~g}, 1.80 \mathrm{mmol}, 80.6 \%\right.$ ) crude yield. m.p. $72{ }^{\circ} \mathrm{C}(\mathrm{dec})$. Anal. Calcd for $\mathrm{C}_{22} \mathrm{H}_{48} \mathrm{Au}_{2} \mathrm{~N}_{6}: \mathrm{C}, 33.42 ; \mathrm{H}, 6.12 ; \mathrm{N}, 10.63 .{ }^{1} \mathrm{H}$ NMR (300 MHz, $\mathrm{C}_{6} \mathrm{D}_{6}$ ): 3.80 (sept, 4H, $\left.\left(\mathrm{CH}_{3}\right)_{2} \mathrm{CHN}\right), 2.85\left(\mathrm{q}, 8 \mathrm{H},\left(\mathrm{CH}_{3} \mathrm{CH}_{2}\right)_{2} \mathrm{~N}\right), 1.39\left(\mathrm{~d}, 24 \mathrm{H}\left(\mathrm{CH}_{3}\right)_{2} \mathrm{CHN}\right), 0.83\left(\mathrm{t}, 12 \mathrm{H},\left(\mathrm{CH}_{3} \mathrm{CH}_{2}\right)_{2} \mathrm{~N}\right) ;{ }^{13} \mathrm{C}\left\{{ }^{1} \mathrm{H}\right\}$ 
NMR (300 MHz, $\left.\mathrm{C}_{6} \mathrm{D}_{6}\right): 166.33(\mathrm{NCN}), 50.45\left(\left(\mathrm{CH}_{3}\right)_{2} \mathrm{CHN}\right), 44.19\left(\left(\mathrm{CH}_{3} \mathrm{CH}_{2}\right)_{2} \mathrm{~N}\right), 27.13\left(\left(\mathrm{CH}_{3}\right)_{2} \mathrm{CHN}\right)$, $13.30\left(\left(\mathrm{CH}_{3} \mathrm{CH}_{2}\right)_{2} \mathrm{~N}\right)$.

$\mathrm{Au}_{2}\left[\left({ }^{\prime} \mathrm{PrN}\right)_{2} \mathrm{CN}\left({ }^{\mathrm{P} r}\right)_{2}\right]_{2}$ (5): Compound 5 was prepared in a analogous manner as compound 1 substituting: AuCl-THT (0.85 g, $2.64 \mathrm{mmol}), \mathrm{Li}\left[\left({ }^{i} \mathrm{PrN}\right)_{2} \mathrm{CN}\left({ }^{\mathrm{P}} \mathrm{Pr}\right)_{2}\right](0.62 \mathrm{~g}, 2.64 \mathrm{mmol})$ Compound 10 was isolated by recrystallization $(1.02 \mathrm{~g}, 2.41 \mathrm{mmol}, 91.1 \%)$ m.p. $87^{\circ} \mathrm{C}$ (dec). Anal. Calcd for $\mathrm{C}_{26} \mathrm{H}_{56} \mathrm{Au}_{2} \mathrm{~N}_{6}: \mathrm{C}, 36.88 ; \mathrm{H}, 6.67 ; \mathrm{N}, 9.93 .{ }^{1} \mathrm{H}$ NMR $\left(300 \mathrm{MHz}, \mathrm{C}_{6} \mathrm{D}_{6}\right): 3.96$ (sept, $\left.4 \mathrm{H},\left(\mathrm{CH}_{3}\right)_{2} \mathrm{CHN}\right), 3.26$ (sept, $\left.4 \mathrm{H},\left(\mathrm{CH}_{3}\right)_{2} \mathrm{CHNCH}\left(\mathrm{CH}_{3}\right)_{2}\right), 1.39$ (d, 24H, $\left.\left(\mathrm{CH}_{3}\right)_{2} \mathrm{CHN}\right), 1.06$ (d, 24H, $\left.\left(\mathrm{CH}_{3}\right)_{2} \mathrm{CHNCH}\left(\mathrm{CH}_{3}\right)_{2}\right)$; ${ }^{13} \mathrm{C}\left\{{ }^{1} \mathrm{H}\right\}$ NMR $\left(300 \mathrm{MHz}, \mathrm{C}_{6} \mathrm{D}_{6}\right): 167.15(\mathrm{NCN}), 50.06\left(\left(\mathrm{CH}_{3}\right)_{2} \mathrm{CHN}\right), 48.48\left(\left(\mathrm{CH}_{3}\right)_{2} \mathrm{CHNCH}\left(\mathrm{CH}_{3}\right)_{2}\right)$, $27.23\left(\left(\mathrm{CH}_{3}\right)_{2} \mathrm{CHN}\right), 22.55\left(\left(\mathrm{CH}_{3}\right)_{2} \mathrm{CHNCH}\left(\mathrm{CH}_{3}\right)_{2}\right)$.

$\mathrm{Au}_{2}\left[(\operatorname{PrN})_{2} \mathrm{CN}(\mathrm{TMS})_{2}\right]_{2}(6):$ In a $100 \mathrm{~mL}$ round bottomed flask, AUCl.THT $(0.542,1.69 \mathrm{mmol})$ was suspended in $50 \mathrm{~mL}$ of hexanes. $\mathrm{K}\left[\left({ }^{\mathrm{i}} \mathrm{PrN}\right)_{2} \mathrm{CN}\left(\mathrm{SiMe}_{3}\right)_{2}\right](0.551 \mathrm{~g}, 1.69 \mathrm{mmol})$ was added to the solution and allowed to react for $3 \mathrm{~h}$, then immediately filtered. The remaining solution was concentrated under reduced atmosphere and placed in the freezer at $-35^{\circ} \mathrm{C}$ for 24 hours. A white precipitate of 13 was isolated $(0.824 \mathrm{~g}, 1.69 \mathrm{mmol}, 100.0 \%)$. m.p. $92{ }^{\circ} \mathrm{C}(\mathrm{dec})$. Anal. Calcd for $\mathrm{C}_{26} \mathrm{H}_{64} \mathrm{Au}_{2} \mathrm{~N}_{6} \mathrm{Si}_{4}: \mathrm{C}, 32.29 ; \mathrm{H}, 6.67 ; \mathrm{N}, 8.69 .{ }^{1} \mathrm{H} \mathrm{NMR}$ (300 $\mathrm{MHz}, \mathrm{C}_{6} \mathrm{D}_{6}$ ): 4.21 (sept, $4 \mathrm{H}$, $\left.\left(\mathrm{CH}_{3}\right)_{2} \mathrm{CHN}\right), 1.39\left(\mathrm{~d}, 24 \mathrm{H},\left(\mathrm{CH}_{3}\right)_{2} \mathrm{CHN}\right), 0.17\left(\mathrm{~s}, 36 \mathrm{H}, \mathrm{Si}\left(\mathrm{CH}_{3}\right)_{3}\right) ;{ }^{13} \mathrm{C}\left\{{ }^{1} \mathrm{H}\right\}$ NMR (300 MHz, $\left.\mathrm{C}_{6} \mathrm{D}_{6}\right)$ : $165.04(\mathrm{NCN}), 49.73\left(\left(\mathrm{CH}_{3}\right)_{2} \mathrm{CHN}\right), 27.46\left(\left(\mathrm{CH}_{3}\right)_{2} \mathrm{CHN}\right), 2.38\left(\mathrm{Si}\left(\mathrm{CH}_{3}\right)_{3}\right)$.

Au[('PrN) $\left.{ }_{2} \mathrm{CN}(\mathrm{TMS})_{2}\right]$ (TPP) (7): In a $100 \mathrm{~mL}$ round bottomed flask, AuCl.TPP (0.166 g, $0.33 \mathrm{mmol}$ ) was suspended in $50 \mathrm{~mL}$ of hexanes. $\left.\mathrm{K}\left[{ }^{\mathrm{i}} \mathrm{PrN}\right)_{2} \mathrm{CN}\left(\mathrm{SiMe}_{3}\right)_{2}\right](0.109 \mathrm{~g}, 0.33 \mathrm{mmol})$ was added slowly over a period of $15 \mathrm{~min}$. The reaction was allowed to proceed overnight. $\mathrm{KCl}$ was filtered and the hexanes removed under reduced pressure to yield a white powdered product. $(0.104 \mathrm{~g}$, 0.14 mmol, 42 \%). m.p. $68{ }^{\circ} \mathrm{C} ;{ }^{1} \mathrm{H}$ NMR (300 MHz, $\left.\mathrm{C}_{6} \mathrm{D}_{6}\right): 7.51\left(\mathrm{~m}, 6 \mathrm{H}, \mathrm{P}(P h)_{3}\right), 6.96(\mathrm{~m}, 9 \mathrm{H}$, $\left.\mathrm{P}(P h)_{3}\right), 5.56$ (sept, $1 \mathrm{H}, \mathrm{NCHCH}_{3}$ ), 4.00 (sept, $1 \mathrm{H}, \mathrm{NCHCH}_{3}$ ), 1.69 (d, 6H, $\mathrm{NCHCH}_{3}$ ), 1.49 (d, $\left.\left.6 \mathrm{H}, \mathrm{NCHCH} \mathrm{H}_{3}\right), 0.39\left(\mathrm{~s}, 18 \mathrm{H}, \mathrm{N}\left(\mathrm{Si}\left(\mathrm{CH}_{3}\right)_{3}\right)_{2}\right) ;{ }^{13} \mathrm{C}^{1}{ }^{1} \mathrm{H}\right\} \quad \mathrm{NMR}\left(300 \mathrm{MHz}, \mathrm{C}_{6} \mathrm{D}_{6}\right): 195.29$ (NCN) 134.41, 134.23, 131.36, 131.32, 129.14, $128.99\left(\mathrm{PPh}_{3}\right), 49.04,48.25\left(\mathrm{NCH}\left(\mathrm{CH}_{3}\right)_{2}\right), 27.29,26.85$ $\left(\mathrm{NCH}\left(\mathrm{CH}_{3}\right)_{2}\right), 3.31\left(\mathrm{~N}\left(\mathrm{Si}\left(\mathrm{CH}_{3}\right)_{3}\right)_{2}\right)$.

\subsubsection{Xanthates (homoleptic)}

$\mathrm{Au}_{2}\left[\mathrm{~S}_{2} \mathrm{CO}^{\mathrm{n} B u}\right]_{2}(8)$ : See Ref. (35)

\subsubsection{Xanthates (heteroleptic)}


$\mathrm{Au}\left[\mathrm{S}_{2} \mathrm{CO}^{\mathrm{t}} \mathrm{Bu}\right](\mathrm{TPP})_{2}$ (9): On the bench top a $100 \mathrm{~mL}$ flask was charged with $50 \mathrm{~mL}$ of benzene. $\operatorname{AuCl}(T P P)_{2}(0.24,0.28 \mathrm{mmol})$ was dissolved in the benzene. A $10 \mathrm{~mL}$ solution of $\mathrm{K}\left[\mathrm{S}_{2} \mathrm{CO}^{\mathrm{t}} \mathrm{Bu}\right]$ $(0.05 \mathrm{~g}, 0.28 \mathrm{mmol})$ was added and the solution allowed to stir over night. $\mathrm{KCl}$ was removed by removing the aqueous phase; 9 was isolated by removal of benzene under reduced pressure (0.27 mmol, 0.23g, 98\%) Mp: $120{ }^{\circ} \mathrm{C}$, dec.: $135{ }^{\circ} \mathrm{C} .{ }^{1} \mathrm{H}$ NMR (300 MHz, $\left(\mathrm{C}_{6} \mathrm{D}_{6}\right): 7.41\left(\mathrm{~m}, 12 \mathrm{H}, \mathrm{PPh}{ }_{3}\right)$, $6.94\left(\mathrm{~m}, 18 \mathrm{H}, \mathrm{PPh} \mathrm{h}_{3}\right), 1.66\left(\mathrm{~s}, 9 \mathrm{H}, \mathrm{C}\left(\mathrm{CH}_{3}\right)_{3}\right) .{ }^{13} \mathrm{C}\left\{{ }^{1} \mathrm{H}\right\} \mathrm{NMR}\left(300 \mathrm{MHz}, \mathrm{C}_{6} \mathrm{D}_{6}\right): 134.50,134.29,130.46$, $130.44,129.06,128.92\left(\mathrm{PPh}_{3}\right), 28.20\left(\mathrm{C}\left(\mathrm{CH}_{3}\right)_{3}\right)$.

\subsection{Silver (I) Complexes}

\subsubsection{Guanidinates (homoleptic)}

$\mathrm{Ag}_{3}\left[(\operatorname{PrN})_{2} \mathrm{CN}(\mathrm{Me})_{2}\right]_{3}(10)$ : In a $50 \mathrm{~mL}$ flask, lithium dimethylamide $(0.189 \mathrm{~g}, 3.70 \mathrm{mmol})$ was suspended in $30 \mathrm{~mL}$ of hexanes. Diisopropylcarbodiimide $(0.467 \mathrm{~g}, 3.70 \mathrm{mmol})$ was diluted with $8 \mathrm{~mL}$ of hexanes and added dropwise to the suspension of $\mathrm{LiNMe}_{2}$ at $-30^{\circ} \mathrm{C}$. The cloudy, pale

yellow suspension cleared to a homogeneous pale yellow solution over $2 \mathrm{~h}$ of stirring at room temperature. Owing to the photosensitivity of silver (I) chloride, the reaction was carried out with protection against light from this point on. Silver (I) chloride $(0.530 \mathrm{~g}, 3.70 \mathrm{mmol})$ was added to the ligand suspension, and the mixture was stirred overnight, after which a light brown solid was filtered to afford a colorless solution. The volatiles were removed under reduced pressure to afford white solid $4(0.85 \mathrm{~g}, 3.15 \mathrm{mmol}, 85.0 \%$ crude yield). This was dissolved in a minimal volume of hexanes and was kept at $-35{ }^{\circ} \mathrm{C}$ overnight. Compound 4 was collected as white crystals (0.45 g, $1.62 \mathrm{mmol}, 45 \%$ ). m.p. $78{ }^{\circ} \mathrm{C}$ (dec). Anal. Calcd for $\mathrm{C}_{27} \mathrm{H}_{60} \mathrm{Ag}_{3} \mathrm{~N}_{9}$ : C, 38.86; $\mathrm{H}, 7.25 ; \mathrm{N}, 15.11 .{ }^{1} \mathrm{H}$ NMR $\left(300 \mathrm{MHz}, \mathrm{C}_{6} \mathrm{D}_{6}\right): 3.57$ (sept, $\left.4 \mathrm{H}, \mathrm{NCH}\left(\mathrm{CH}_{3}\right)_{2}\right), 2.62\left(\mathrm{~s}, 12 \mathrm{H}, \mathrm{N}\left(\mathrm{CH}_{3}\right)_{2}\right)$, $1.34\left(\mathrm{~d}, 24 \mathrm{H} \mathrm{NCH}\left(\mathrm{CH}_{3}\right)_{2} .{ }^{13} \mathrm{C}\{1 \mathrm{H}\}\right.$ NMR $\left(75 \mathrm{MHz}, \mathrm{C}_{6} \mathrm{D}_{6}\right): 169.38$ (NCN), $48.19\left(\left(\mathrm{CH}_{3}\right)_{2} \mathrm{CHN}\right), 40.83$ $\left(\left(\mathrm{CH}_{3}\right)_{2} \mathrm{~N}\right), 27.76\left(\left(\mathrm{CH}_{3}\right)_{2} \mathrm{CHN}\right)$.

$\mathrm{Ag}_{3}\left[(\operatorname{PrN})_{2} \mathrm{CN}(\mathrm{Et})_{2}\right]_{3}$ (11): Compound 11 was prepared in a analogous manner as compound 10 substituting: Diethylamine $(0.523 \mathrm{~g}, 7.20 \mathrm{mmol})$, Meli (11.4 $\mathrm{mL}, 7.20 \mathrm{mmol})$, diisopropylcarbodiimide $(0.442 \mathrm{~g}, 7.20 \mathrm{mmol})$, and silver(l) chloride $(1.03 \mathrm{~g}, 7.20 \mathrm{mmol})$. Compound 6 was collected as white crystals $\left(0.82 \mathrm{~g}, 2.62 \mathrm{mmol}, 36.4 \%\right.$ crude yield). m.p. $65^{\circ} \mathrm{C}$ (dec). Anal. Calcd for $\mathrm{C}_{33} \mathrm{H}_{72} \mathrm{Ag}_{3} \mathrm{~N}_{9}: \mathrm{C}, 43.15 ; \mathrm{H}, 7.90 ; \mathrm{N}, 13.72 .{ }^{1} \mathrm{H} \mathrm{NMR}$ (300 MHz, $\mathrm{C}_{6} \mathrm{D}_{6}: 3.65$ (sept, $\left.4 \mathrm{H}, \mathrm{NCH}\left(\mathrm{CH}_{3}\right)_{2}\right), 3.01$ (q, $\left.8 \mathrm{H}, \mathrm{N}\left(\mathrm{CH}_{2} \mathrm{CH}_{3}\right)_{2}\right), 1.36$ (d, $24 \mathrm{H} \mathrm{NCH}\left(\mathrm{CH}_{3}\right)_{2}, 0.95$ (t, $12 \mathrm{H}$, 
$\left.\mathrm{N}\left(\mathrm{CH}_{2} \mathrm{CH}_{3}\right)_{2}\right) .{ }^{13} \mathrm{C}\{1 \mathrm{H}\} \quad \mathrm{NMR}\left(75 \mathrm{MHz}, \mathrm{C}_{6} \mathrm{D}_{6}\right): 168.40(\mathrm{NCN}), 48.62\left(\left(\mathrm{CH}_{3}\right)_{2} \mathrm{CHN}\right), 43.91\left(\mathrm{~N}\left(\mathrm{CH}_{2} \mathrm{CH}_{3}\right)_{2}\right)$, $27.85\left(\left(\mathrm{CH}_{3}\right)_{2} \mathrm{CHN}\right), 13.44\left(\mathrm{~N}\left(\mathrm{CH}_{2} \mathrm{CH}_{3}\right)_{2}\right)$.

$\mathrm{Ag}_{3}\left[(\operatorname{PrN})_{2} \mathrm{CN}\left(\mathrm{Pr}_{2}\right]_{3}\right.$ (12): In a $100 \mathrm{~mL}$ flask, diisopropylamine $(0.354 \mathrm{~g}, 3.50 \mathrm{mmol})$ was dissolved in $40 \mathrm{~mL}$ of hexanes at $-30{ }^{\circ} \mathrm{C}$ and MeLi $(2.19 \mathrm{~mL}, 3.50 \mathrm{mmol})$ was added dropwise to give white suspension after stirring for 2 hours. Diisopropylcarbodiimide $(0.442 \mathrm{~g}, 3.50 \mathrm{mmol})$ was diluted with $10 \mathrm{~mL}$ of hexanes and added dropwise to the suspension of the lithiated amine at $-36{ }^{\circ} \mathrm{C}$. Owing to the photosensitivity of silver $(1)$ chloride, the reaction was carried out with protection against light from this point on. Silver(I) chloride $(0.50 \mathrm{~g}, 3.50 \mathrm{mmol})$ was added, and the mixture was stirred overnight, after which a dark brown/grey solid was filtered to afford pale yellow solution. The volatiles were removed under reduced pressure to afford white solid 5 $(0.819 \mathrm{~g}, 2.45 \mathrm{mmol}, 70.0 \%$ crude yield). The solid was dissolved in a minimal volume of hexanes and was kept at $-35{ }^{\circ} \mathrm{C}$ overnight. Compound 5 was collected as white crystals $(0.29 \mathrm{~g}$, $0.87 \mathrm{mmol}, 24.9$ \%). m.p. $73{ }^{\circ} \mathrm{C}(\mathrm{dec})$. Anal. Calcd for $\mathrm{C}_{39} \mathrm{H}_{84} \mathrm{Ag}_{3} \mathrm{~N}_{9}: \mathrm{C}, 46.71 ; \mathrm{H}, 8.44 ; \mathrm{N}, 12.57 .{ }^{1} \mathrm{H}$ NMR $\left(300 \mathrm{MHz}, \mathrm{C}_{6} \mathrm{D}_{6}: 3.85\right.$ (sept, $\left.4 \mathrm{H}, \mathrm{NCH}\left(\mathrm{CH}_{3}\right)_{2}\right), 3.46$ [sept, $4 \mathrm{H}, \mathrm{N}\left(\mathrm{CH}\left(\mathrm{CH}_{3}\right)_{2}\right)$ ], 1.33 [d, $24 \mathrm{H}$ $\mathrm{NCH}\left(\mathrm{CH}_{3}\right)_{2}$, $\left.1.20\left(\mathrm{~d}, 24 \mathrm{H} \mathrm{N}\left(\mathrm{CH}\left(\mathrm{CH}_{3}\right)_{2}\right)_{2}\right) .{ }^{13} \mathrm{C}^{1} \mathrm{H}\right\} \quad \mathrm{NMR}\left(75 \mathrm{MHz}, \mathrm{C}_{6} \mathrm{D}_{6}\right): 167.28$ (NCN),49.13 $\left(\mathrm{NCH}\left(\mathrm{CH}_{3}\right)_{2}, 47.98\left(\mathrm{~N}\left(\mathrm{CH}\left(\mathrm{CH}_{3}\right)_{2}\right)_{2}\right), 27.60\left(\mathrm{NCH}\left(\mathrm{CH}_{3}\right)_{2}\right), 23.44\left(\mathrm{~N}\left(\mathrm{CH}\left(\mathrm{CH}_{3}\right)_{2}\right)_{2}\right)\right.$.

$\mathrm{Ag}_{3}\left[(\operatorname{PrN})_{2} \mathrm{CN}(\mathrm{TMS})_{2}\right]_{3}(13):$ In a $50 \mathrm{~mL}$ flask, $\mathrm{KN}(\mathrm{TMS})_{2}(0.542 \mathrm{~g} ; 2.71 \mathrm{mmol})$ was suspended in $30 \mathrm{~mL}$ of hexanes. Diisopropylcarbodiimide $(0.342 \mathrm{~g}, 2.71 \mathrm{mmol})$ was added dropwise and the homogeneous pale yellow solution turned cloudy, pale yellow over $2 \mathrm{~h}$ of stirring. Owing to the photosensitivity of silver (I) chloride, the reaction was carried out with protection against light from this point on. Silver ( 1 ) chloride $(0.389 \mathrm{~g}, 2.71 \mathrm{mmol})$ was added, and the mixture was stirred overnight, after which a light brown/grey solid was filtered to afford colorless solution. Volatiles were removed under reduced pressure to afford white solid $7(0.747 \mathrm{~g}, 1.89 \mathrm{mmol}$, $69.9 \%$ crude yield). The solid was dissolved in a minimal volume of hexanes and was kept at -35 ${ }^{\circ} \mathrm{C}$ overnight. Compound 7 was collected as white microcrystalline material $(0.445 \mathrm{~g}, 1.13 \mathrm{mmol}$, $41.6 \%$ ). m.p. $106{ }^{\circ} \mathrm{C}$ (dec). Anal. Calcd for $\mathrm{C}_{39} \mathrm{H}_{96} \mathrm{Ag}_{3} \mathrm{~N}_{9} \mathrm{Si}_{6}: \mathrm{C}, 39.58 ; \mathrm{H}, 8.18 ; \mathrm{N}, 10.65 .{ }^{1} \mathrm{H}$ NMR (300 MHz, $\mathrm{C}_{6} \mathrm{D}_{6}: 3.76$ [sept, $\left.4 \mathrm{H}, \mathrm{NCH}\left(\mathrm{CH}_{3}\right)_{2}\right], 1.11$ [d, $\left.24 \mathrm{H} \mathrm{NCH}\left(\mathrm{CH}_{3}\right)_{2}\right] .0 .29\left[\mathrm{~s}, 36 \mathrm{H} \mathrm{Si}\left(\mathrm{CH}_{3}\right)_{3}\right]$. ${ }^{13} \mathrm{C}\left\{{ }^{1} \mathrm{H}\right\} \quad \mathrm{NMR}\left(75 \mathrm{MHz}, \mathrm{C}_{6} \mathrm{D}_{6}\right): 157.92(\mathrm{NCN}), 46.66\left[\mathrm{NCH}\left(\mathrm{CH}_{3}\right)_{2}\right], 28.00\left[\mathrm{NCH}\left(\mathrm{CH}_{3}\right)_{2}\right], 3.00$ $\left[\mathrm{Si}\left(\mathrm{CH}_{3}\right)_{3}\right]$. 


\subsection{Zinc (II) Complexes}

$\left[{ }^{\mathrm{i}} \mathrm{PrNC}\left(\mathrm{N}^{\mathrm{i} P r}\right)_{2}\right]_{2} \mathrm{Zn}(\mathbf{1 4})$

- Salt metathesis

In a $100 \mathrm{~mL}$ round bottom flask, lithiated isopropyl guanidinate $(0.549 \mathrm{~g}, 3.01 \mathrm{mmol})$ was dissolved in Hexanes or Pentane $(30 \mathrm{~mL})$. Zinc Chloride.THF $(0.315 \mathrm{~g}, 1.51 \mathrm{mmol})$ was added while the solution was stirred rapidly. The solution remained colourless with undisolved $\mathrm{ZnCl}_{2}$. The solution was left to stir for $12 \mathrm{~h}$. The mixture became cloudy white with the precipitation of $\mathrm{LiCl}$. The solution was filtered. Excess solvent was removed via a vacuum pump. A colourless resin was isolated which did not solidify at $-30^{\circ} \mathrm{C}$. (0.561g, $\left.1.29 \mathrm{mmol}, 85 \%\right) .{ }^{1} \mathrm{H} \mathrm{NMR}(300 \mathrm{MHz}$, $\mathrm{C}_{6} \mathrm{D}_{6}$ ): 3.63 (sept, $2 \mathrm{H}, \mathrm{CH}\left(\mathrm{Me}_{2}\right)$ ), 3.49 (sept, $4 \mathrm{H}, \mathrm{CH}\left(\mathrm{Me}_{2}\right)$ ), 1.24 (d, $\left.24 \mathrm{H}, \mathrm{CH}\left(\mathrm{CH}_{3}\right)_{2}\right), 0.95$ (d, 12H, $\left.\mathrm{CH}\left(\mathrm{CH}_{3}\right)_{2}\right) .{ }^{13} \mathrm{C}\left\{{ }^{1} \mathrm{H}\right\}$ NMR $\left(75 \mathrm{MHz}, \mathrm{C}_{6} \mathrm{D}_{6}\right): 164.35 \mathrm{NC}\left(\mathrm{NMe}_{2}\right) \mathrm{N}, 45.77 \mathrm{CH}\left(\mathrm{Me}_{2}\right), 45.33 \mathrm{CH}\left(\mathrm{Me}_{2}\right)$, $26.31\left(\mathrm{CH}\left(\mathrm{CH}_{3}\right)_{2}\right), 23.78\left(\mathrm{CH}\left(\mathrm{CH}_{3}\right)_{2}\right)$.

- Alkane elimination

In a $100 \mathrm{~mL}$ round bottom flask, Isopropyl Guanidine $(0.0 .615 \mathrm{~g}, 3.37 \mathrm{mmol})$ was dissolved in Hexanes or Pentane $(30 \mathrm{~mL})$. Diethylzinc $(1.0 \mathrm{M}$ in hexane, $1.69 \mathrm{~mL}, 1.69 \mathrm{mmol})$ was added dropwise over $15 \mathrm{~min}$ while the solution was stirred rapidly and left to stir for $12 \mathrm{~h}$. The mixture remained colourless. Excess solvent was removed via a vacuum pump. A colourless resin was isolated which did not solidify at $-36^{\circ} \mathrm{C} .(0.647 \mathrm{~g}, 1.49 \mathrm{mmol}, 88 \%) .{ }^{1} \mathrm{H} \mathrm{NMR}\left(300 \mathrm{MHz}, \mathrm{C}_{6} \mathrm{D}_{6}\right): 3.63$ (sept, 2H, $\mathrm{CH}\left(\mathrm{Me}_{2}\right)$ ), 3.50 (sept; $\left.4 \mathrm{H}, \mathrm{CH}\left(\mathrm{Me}_{2}\right)\right), 1.24$ (d, 24H, $\left.\mathrm{CH}\left(\mathrm{CH}_{3}\right)_{2}\right), 0.95$ (d, 12H, $\left.\mathrm{CH}\left(\mathrm{CH}_{3}\right)_{2}\right)$. ${ }^{13} \mathrm{C}\left\{{ }^{1} \mathrm{H}\right\} \quad \mathrm{NMR}\left(75 \mathrm{MHz}, \mathrm{C}_{6} \mathrm{D}_{6}\right): 164.34 \mathrm{NC}\left(\mathrm{NMe}_{2}\right) \mathrm{N}, 45.76 \mathrm{CH}\left(\mathrm{Me}_{2}\right), 45.32 \mathrm{CH}\left(\mathrm{Me}_{2}\right), 26.30$ $\left(\mathrm{CH}\left(\mathrm{CH}_{3}\right)_{2}\right), 23.76\left(\mathrm{CH}\left(\mathrm{CH}_{3}\right)_{2}\right)$.

\section{$\left[{ }^{\prime} \mathrm{PrNC}\left(\mathrm{N}^{\mathrm{i}} \mathrm{Pr}\right)_{2}\right]_{3} \mathrm{Zn}{ }_{2} \mathrm{Cl}(15)$}

A $100 \mathrm{~mL}$ flask, was charged with $30 \mathrm{~mL}$ of diethyl ether $(0.386 \mathrm{~g}, 2.02 \mathrm{mmol})$ of lithium triisopropyl guanidinate was added. $\mathrm{ZnCl} \cdot \mathrm{THF}(0.237 \mathrm{~g}, 1.37 \mathrm{mmol})$ was added to the suspension and allowed to stir overnight. LiCl was filtered, and ether removed under reduced pressure, yielding a white powder. 15 was isolated as by recrystallization in ether as clear colourless plates (0.396g, $0.55 \mathrm{mmol})$. 


\section{$\left[\mathrm{PrHNC}\left(\mathrm{N}^{\mathrm{P} P r}\right)_{2}\right]_{2}(\mathrm{ZnEt})_{4}(16)$}

In a $100 \mathrm{~mL}$ round bottom flask, Isopropyl Guanidine $(0.538 \mathrm{~g}, 2.95 \mathrm{mmol}$ ) was dissolved in Hexanes $(30 \mathrm{~mL})$. Diethylzinc $(1.0 \mathrm{M}$ in hexane, $2.95 \mathrm{~mL}, 2.95 \mathrm{mmol})$ was added dropwise over $15 \mathrm{~min}$ while the solution was stirred rapidly. The solution remained colourless. The solution was left to stir for $12 \mathrm{~h}$. The mixture remained colourless. Excess solvent was removed under reduced pressure. Clear platy crystals were precipitated at $-30^{\circ} \mathrm{C}$ then recrystallized in hexanes $(0.507 \mathrm{~g}$, $0.69 \mathrm{mmol}, 47 \%) .{ }^{1} \mathrm{H}$ NMR $\left(300 \mathrm{MHz}, \mathrm{C}_{6} \mathrm{D}_{6}\right): 3.63$ (sept, $1 \mathrm{H}, \mathrm{CH}\left(\mathrm{Me}_{2}\right)$ ), 3.32 (sept, 2H, $\mathrm{CH}\left(\mathrm{Me}_{2}\right)$ ), $1.75\left(\mathrm{t}, 3 \mathrm{H}, \mathrm{CH}_{2} \mathrm{CH}_{3}\right), 1.17$ (d, $\left.12 \mathrm{H}, \mathrm{CH}\left(\mathrm{CH}_{3}\right)_{2}\right), 0.93\left(\mathrm{~d}, 6 \mathrm{H}, \mathrm{CH}\left(\mathrm{CH}_{3}\right)_{2}\right), 0.69\left(\mathrm{q}, 2 \mathrm{H}, \mathrm{CH}_{2} \mathrm{CH}_{3}\right) .{ }^{13} \mathrm{C}\left\{{ }^{1} \mathrm{H}\right\}$ NMR $\left(75 \mathrm{MHz}, \mathrm{C}_{6} \mathrm{D}_{6}\right): 162.20(\mathrm{NCN}), 46.92 \mathrm{CH}\left(\mathrm{Me}_{2}\right), 44.98 \mathrm{CH}\left(\mathrm{Me}_{2}\right), 25.06\left(\mathrm{CH}\left(\mathrm{CH}_{3}\right)_{2}\right), 24.57$ $\left(\mathrm{CH}\left(\mathrm{CH}_{3}\right)_{2}\right), 14.65\left(\mathrm{CH}_{2} \mathrm{CH}_{3}\right), 3.23\left(\mathrm{CH}_{2} \mathrm{CH}_{3}\right)$.

\subsection{Thermolysis Experiments:}

A screw cap NMR tube was charged with enough compound for an NMR experiment, typically a few milligrams. The bottom portion of the tube containing the compound was placed in an oil bath at $120^{\circ} \mathrm{C}$ for 2 hours with no solvent present. The sample tube was then cooled in liquid nitrogen $\left(-196^{\circ} \mathrm{C}\right)$ to trap any volatile byproducts, then $\mathrm{C}_{6} \mathrm{D}_{6}$ was added and a ${ }^{1} \mathrm{H} N \mathrm{NM}$ was collected.

\subsection{Photodeposition Experiments}

All experiments done in a nitrogen atmosphere drybox.

\subsubsection{Film deposition on glass vials:}

Recrystallized $\mathrm{Au}_{2}\left[\left({ }^{\prime} \mathrm{PrN}\right)_{2} \mathrm{CMe}\right]_{2}$ was dissolved in a volume of pentane in a $20 \mathrm{~mL}$ glass vial until a supersaturated solution was achieved. The solution was placed in a freezer at $-36{ }^{\circ} \mathrm{C}$ for a minimum of $12 \mathrm{hrs}$. A glass microscope slide was cut to $1 \mathrm{~cm}^{2}$ and sonicated in acetone for 30 min then rinsed with distilled water dried and pumped into the drybox overnight then added to a $20 \mathrm{~mL}$ vial. A volume of the mother liquor from the $\mathrm{Au}_{2}\left[\left({ }^{\prime} \mathrm{PrN}\right)_{2} \mathrm{CMe}\right]_{2}$ recrystallization was transferred to the slide containing glass vial at room temperature. The vial was placed on a stainless steel shelf and left for a period of time ranging from a) 4 days, b) 7 days, c) 14 days. The remaining pentane was removed and the films rinsed with hexanes to remove any loosely bound particulates. The slides were then removed and characterized. Vials were also cut with a diamond tipped pen to be characterized. 


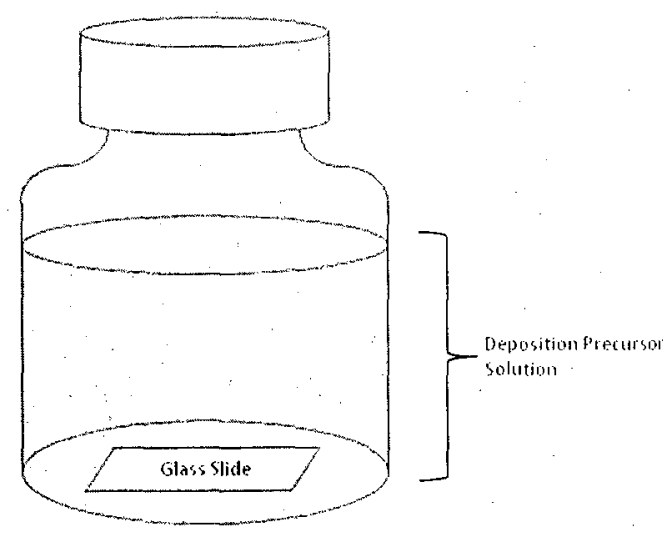

Figure 68: Schenatic of photodepositon apparatus

\subsubsection{Deposition on Fibre Bragg Gratings (FBG):}

A fibre Bragg grating (FBG) filament was sonicated for $30 \mathrm{~min}$ in acetone to remove the polymeric protective jacket. The FBG filament mount was adhered to a hole in a $20 \mathrm{~mL}$ vial cap. The filament was then mounted within the lid assembly. The vial was filled to the top with precursor pentane solution (as prepared in 7.7.1.). The filament-lid assembly was screwed to the top of the filled vial, making sure that the entire filament was submerged. The vial was then wrapped in aluminum foil to ensure no ambient light penetrated the vial. The FBG filament was plugged into a white light source via fibre optic cable and allowed to run for 7 days. The FBG filament was then removed from the apparatus and the source, rinsed in pentane and characterized via optical microscopy as well as SEM. 


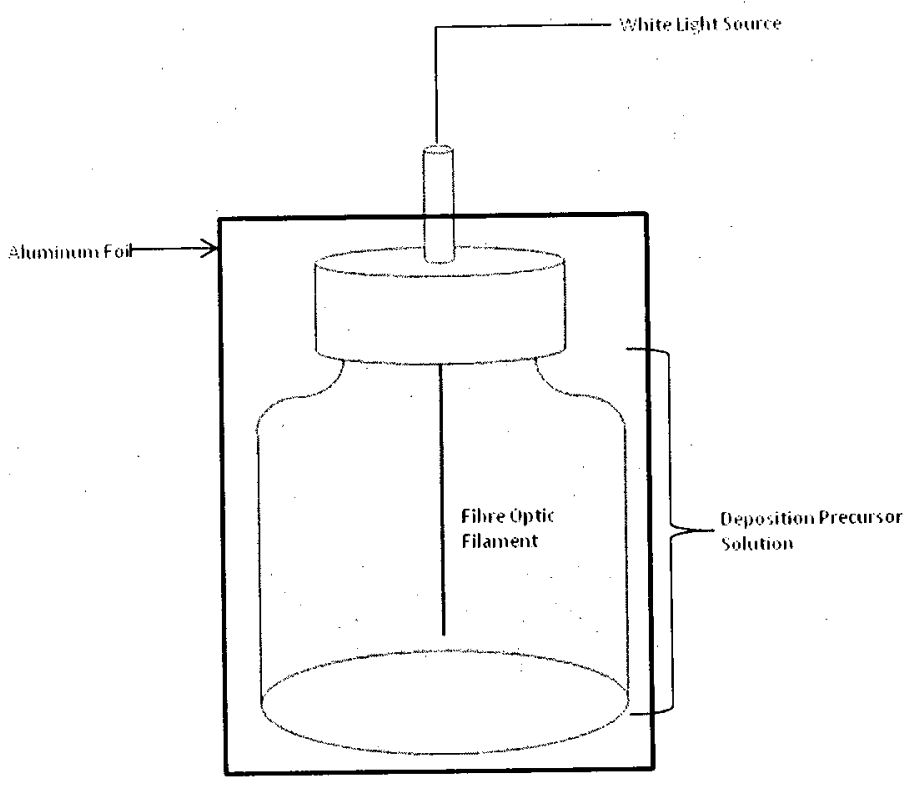

Figure 69: Schematic of Fore Bnge Grotng whotopostion apparas

\subsection{CVD Experiments}

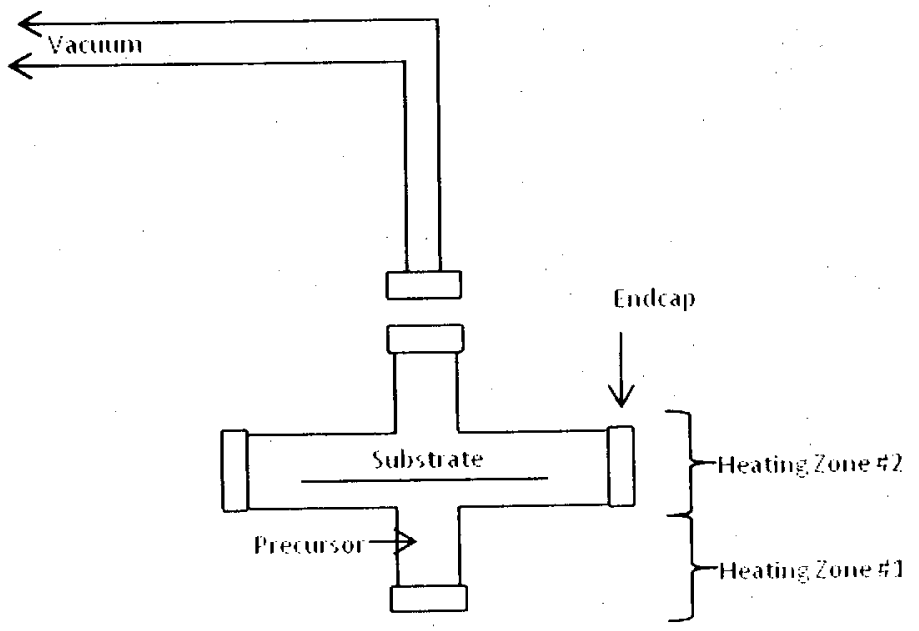

Figure 70: $\quad$ Schematic of Cvodepostion appatatus 


\subsubsection{Substrate Cleaning Procedure}

The following steps were undertaken to clean the Si(100) substrates

i) Sonicated for 20 minutes at highest power level in acetone

ii) Rinsed with distilled water

iii) Placed in a freshly prepared mixture of concentrated 10:10:1 ratio of $\mathrm{H}_{2} \mathrm{O}: \mathrm{H}_{2} \mathrm{SO}_{4}: \mathrm{H}_{2} \mathrm{O}_{2}$ for 30 minutes then rinsed with distilled water.

iv) Sonicated for $\mathbf{1 0}$ minutes at highest power level in distilled water

v) Placed in a freshly prepared mixture of $\mathrm{H}_{2} \mathrm{SO}_{4}: \mathrm{H}_{2} \mathrm{O}_{2}$ in a ratio of $4: 1$ for 10 minutes then rinsed with distilled water.

vi) Placed in freshly prepared 1:1:6 ratio of $\mathrm{NH}_{4} \mathrm{OH}: \mathrm{H}_{2} \mathrm{O}_{2}: \mathrm{H}_{2} \mathrm{O}$ for 10 minutes, then rinsed with distilled water.

vii) Dried with a kim wipe and placed under a UV Ozone lamp for 30 seconds.

\subsubsection{CVD Deposition Procedure}

For all depositions $\mathrm{Si}(100)$ was used as the substrate. The substrate was placed so as to have the (100) face down so as to incur a "line of site" type CVD film. All depositions occurred using approximately $1 \mathrm{~g}$ of purified then powdered $\mathrm{Au}_{2}\left[\left({ }^{\prime} \mathrm{PrN}\right)_{2} \mathrm{CN}(\mathrm{Me})_{2}\right]_{2}$ as the gold source.

Heating zones $\# 1$ and $\# 2$ were heated to the desired temperatures using heating tape, then precursor introduced via the endcap into the lower portion of the apparatus. The substrate was then placed polished side down facing the precursor. The endcap was replaced and dynamic vacuum applied via roughing pump (20 mtorr). The experiment was allowed to proceed from a period of 2-12 hours. 


\section{Conclusions}

Novel monovalent gold complexes of amidinates and guanidinates were synthesized in order study their thermal chemistry for the purposes of application as CVD precursors. These compounds were $\left[R C\left(N^{i} P r\right)_{2}\right]_{2} \mathrm{Au}_{2}$ where $\mathrm{R}={ }^{n} \mathrm{Bu}, \mathrm{Me}, \mathrm{NMe}_{2}, \mathrm{NEt}_{2}, \mathrm{~N}^{i} \mathrm{Pr}_{2}$ and $\mathrm{N}(T M S)_{2}$. It was found that these compounds decomposed to metallic gold in the presence of light. This resulted in the solution phase deposition of gold metal films using the $R=M e$ derivative as the gold source. The films were characterized by SEM, EDS, and XRD.

Gold (I) dimethyl guanidinate $\left(\mathrm{R}=\mathrm{NMe}_{2}\right)$ proved to be the only sublimable compound. For this reason it was used as a single source precursor in the deposition of gold metal films by thermal CVD. This was obtained at lower operating temperatures than those previously reported in literature. The films were studied by SEM and EDS.

Monovalent silver guanidinates were synthesized for the same purposes as the gold analogues. These were found to be too unstable to reach the vapour phase and made for poor CVD precursors. The crystal structure of silver (I) dimethyl guanidinate proved to be a trimeric complex.

Novel zinc (II) triisopropyl structures showed interesting geometry and helped to better understand the chemistry behind alkane elimination reactions. The complex NMR data showed that the zinc (II) lantern structure exists as a dimer in solution as well as another chloride containing zinc (II) guanidinate complex. 


\section{References}

1. C.R. Kleijn, in , 2001), pp. 119, vol. 55.

2. J. Crowella, J. Vac. Sci. Technol. A 21, s88 (2003).

3. M. Okumura, S. Nakamura, M. Haruta, Catalysis Letters, 53 (1998).

4. T. H. Baum, Journal of the Electrochemical Society 134, 2616 (1987).

5. J. Messelhäuser, E. Flint, H. Suhr, Applied Surface Science, 64 (1992).

6. P. Tran, P. Doppelt, Journal of the Electrochemical Society 154, D520 (2007).

7. N. Dryden, J. Shapter, L. Coatsworth, P. Norton, R. Puddephatt, Chem. Mater. 2, 979 (1992).

8. R. Manepalli, F. Stepniak, S. A. Bidstrup-Allen, P. Kohl, IEEE Trans. Adv. Pack. 22, 4 (1999).

9. M. Hauder, W. Hansch, J. Gstottner, D. Schmitt-Landsiedel, Appl. Phys. Lett. 78, 838 (2001).

10. L. Gao, A. Wiltner, D. Schmitt-Landsiedel, Microelectronic Engineering 82, 296 (2005).

11. P. Jeffries, S. Wilson, S. Girolami, Journal of Organometallic Chemistry 449, 203 (1993).

12. N. Dryden, J. Vittal, R. Puddephatt, Chem. Mater. 5, 765 (1993).

13. T. P. Niesen, M. R. De Guire, Journal of Electroceramics 6, 169 (2001).

14. F. Kim, H. J. Song, P. Yang, J. Am. Chem. Soc. 124, 14316 (2002).

15. K. Shimizua, H. Imai, H. Hirashimab, K. Tsukuma, Thin Solid Films, 220 (1999).

16. M. Matsushita, M. Sano, Y. Hayakawa, H. Honjo, Y. Sawada, Phys. Rev. Lett. 53, 286 (1984).

17. M. Mikolajczyk, P. Kielbasinski, Tetrahedron 37, 233 (1981).

18. J. Decamsa, L. Hubert-Pfalzgrafa, J. Vaissermannb, Polyhedron, 2885 (1999).

19. A. P. Kenney, G. P. A. Yap, D. S. Richeson, S. T. Barry, Inorg. Chem. 44, 2926 (2005).

20. S. B. Lim, A. Rahtu, J. Park, R. G. Gordon, Inorganic Chemistry 42, 7951 (2003).

21. A. J. Vreugdenhil, S. Brienne, I. S. Butler, J. A. Finch, R. D. Markwell, Specrochimica Acta Part A 53, 2139 (1997).

22. J. P. J. Fackler, C. Seidel, Chemical Communications, 1133 (1969). 
23. R. F. Makens, Journal of the American Chemical Society 57, 405 (1935).

24. J. John P. Fackler, H. E. Abdou, A. A. Mohamed, Inorg. Chem. 44, 166 (2005).

25. F. A. Cotton, G. Wilkinson, Advanced Inorganic Chemistry (John Wiley and Sons, New York, 1988).

26. J. E. Huheey, Ed., Inorganic Chemistry (Harper and Row, London, 1975), pp. 372.

27. R. S. Nyholm, Proc. Chem. Soc., 273 (1961).

28. T. V. Choudhary et al., J. Catal. 297, 247 (2002).

29. J. John P. Fackler, M. D. Irwin, H. E. Abdou, Chem. Commun., 2882 (2003).

30. M. Laguna, M. Bardaji, P. Jones, A. Laguna, Organometallics 14, 1310 (1995).

31. C. N. Rowley, T. Ong, J. Priem, T. K. Woo, D. S. Richeson, Inorganic Chemistry 47, 9660 (2008).

32. J. John P. Fackler, A. A. Mohamed, A. P. Mayer, Inorg. Chem. 46, 11165 (2007).

33. J. P. Coyle, W. H. Monillas, Y. P. A. Glenn, S. T. Barry, Inorganic Chemistry 47, 683 (2008).

34. J. John P. Fackler, H. E. Abdou, A. A. Mohamed, Inorg. Chem. 46, 141 (2007).

35. J. John P. Fackler, A. A. Mohamed, I. Kani, O. A. Ramirez, Inorg. Chem. 43, 3833 (2004).

36. A. A. Mohamed, H. E. Abdou, A. Mayer, J. P. J. Fackler, J Clust Sci 19, 551 (2008).

37. J. John P. Fackler, A. A. Mohamed, H. E. Abdou, Inorg, Chem 45, 11 (2006).

38. J. John P. Fackler, H. E. Abdou, A. A. Mohamed, Inorg. Chem. 46, 9692 (2007).

39. G. R. Giesbrecht, A. Shafir, J. Arnold, Dalton Transactions, 3601 (1999).

40. L. Yun-Jie, Y. Ying-Ming, Z. Yong, S. Qi, Chinese Journal of Chemistry 25, 562 (2007).

41. P. Gordon, S. T. Barry, "Synthesis, Kinetics and Reactivity of Dimerized 1,3-diisopropyl Carbodiimide," (2006).

42. Y. Liu et al., Organometallics Note xxx, xxx (2009).

43. R. Uson et al., in Inorganic Syntheses (Wiley, , 2007), vol. 26.

44. A. P. Kenney, G. P. A. Yap, D. S. Richeson, S. T. Barry, Inorg. Chem. 44, 2926 (2005).

45. F. Fiel, S. Harder, Eur. J. Inorg. Chem., 4438 (2005). 


\section{Appendices}

\section{Crystallographic Data}

Compound 1

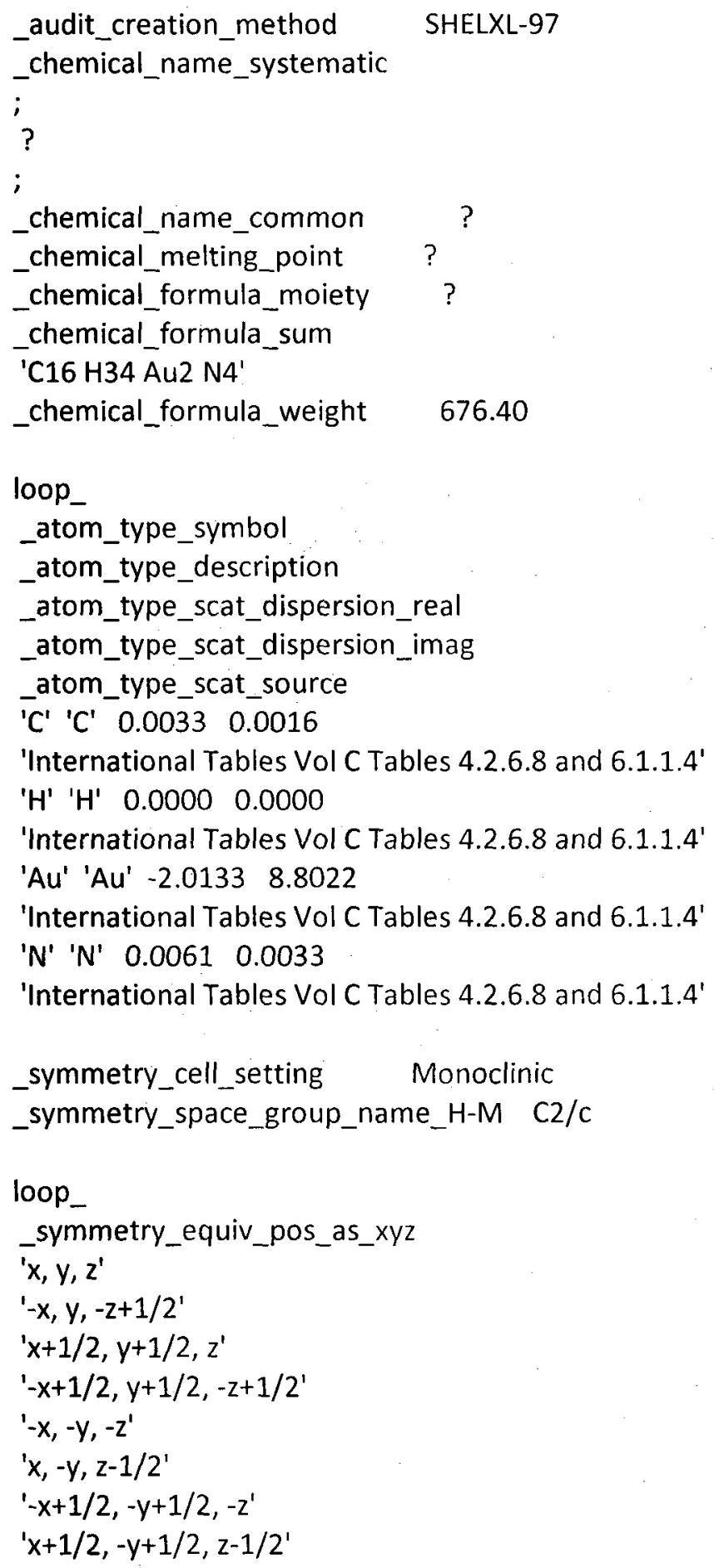




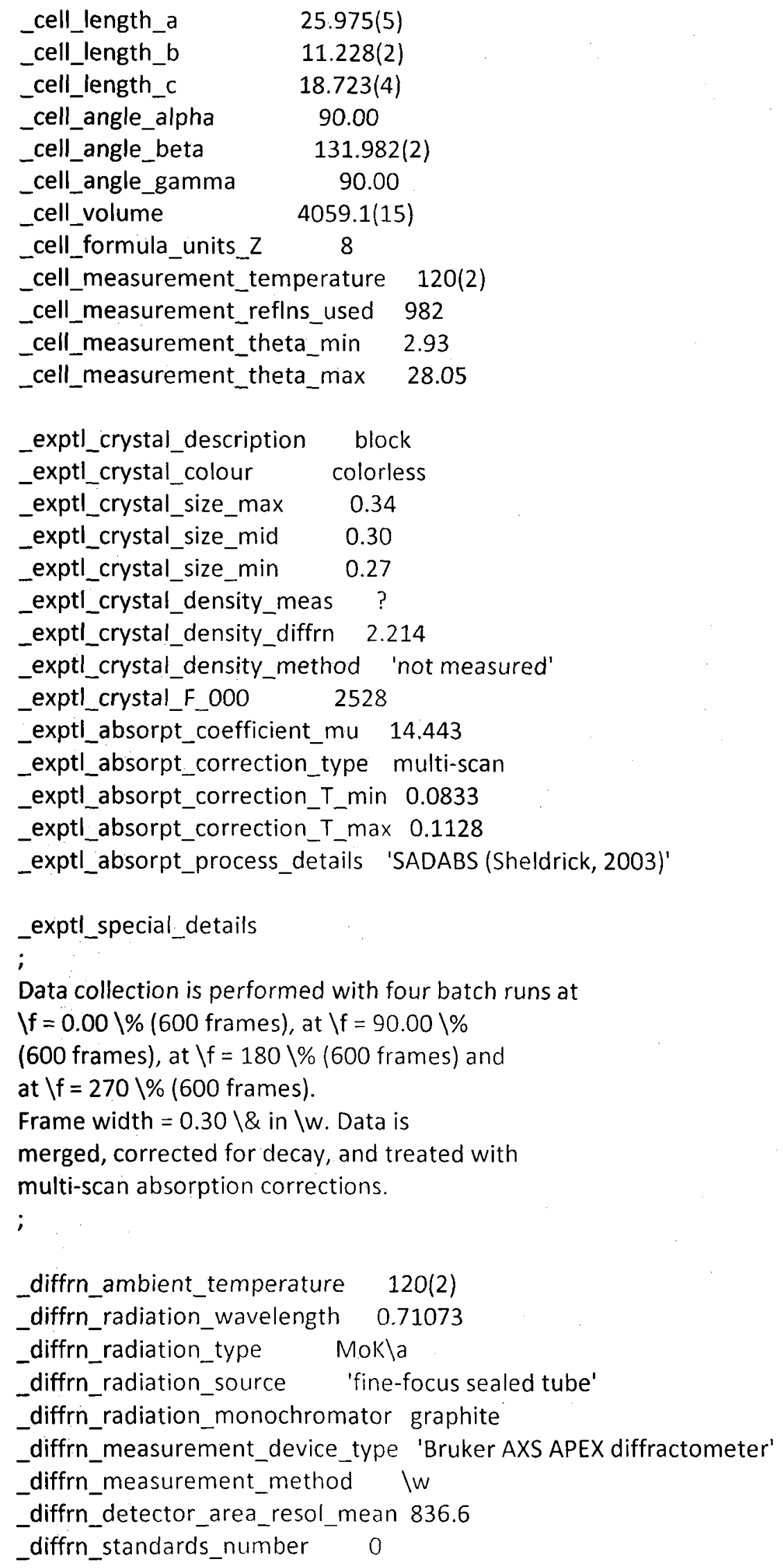




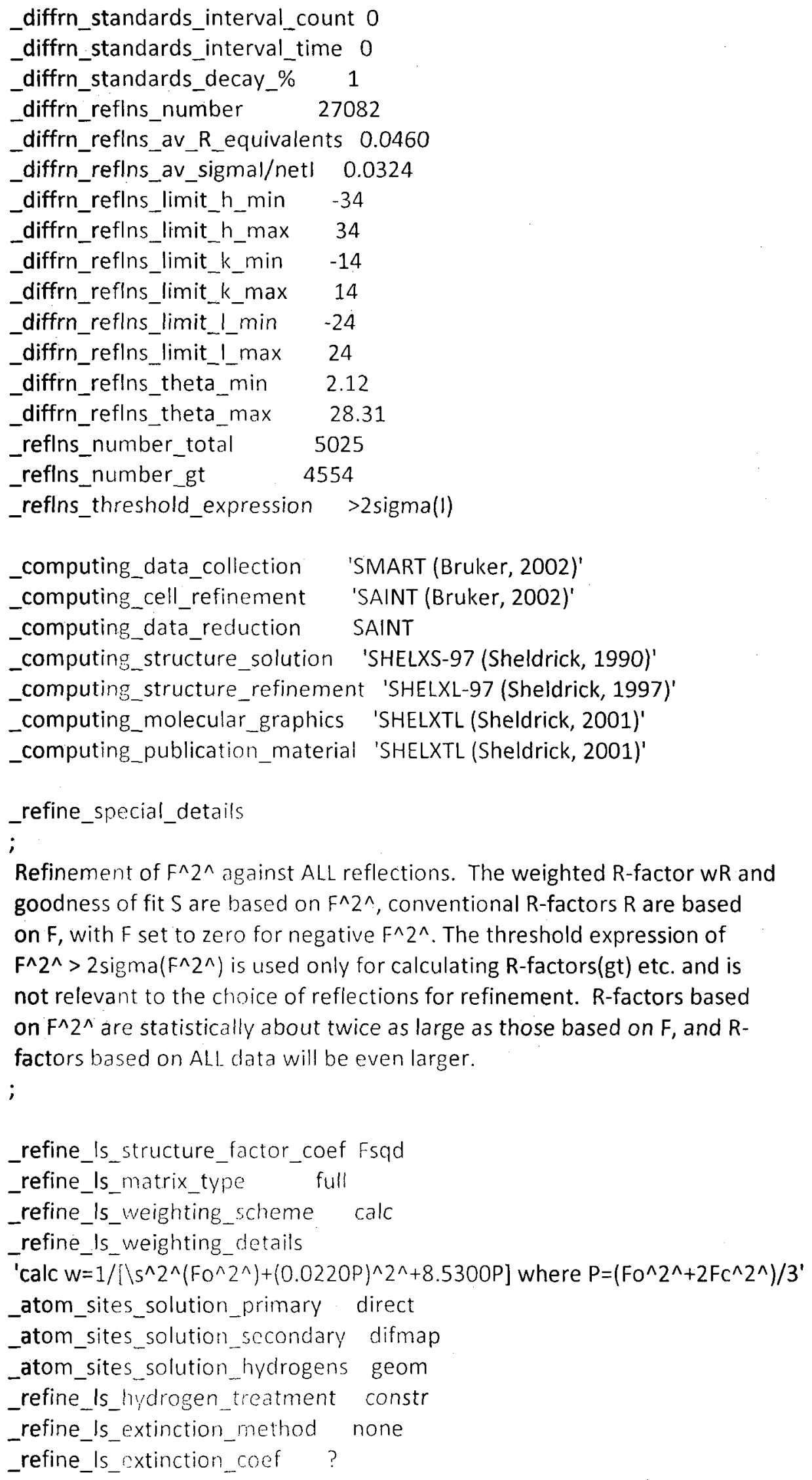




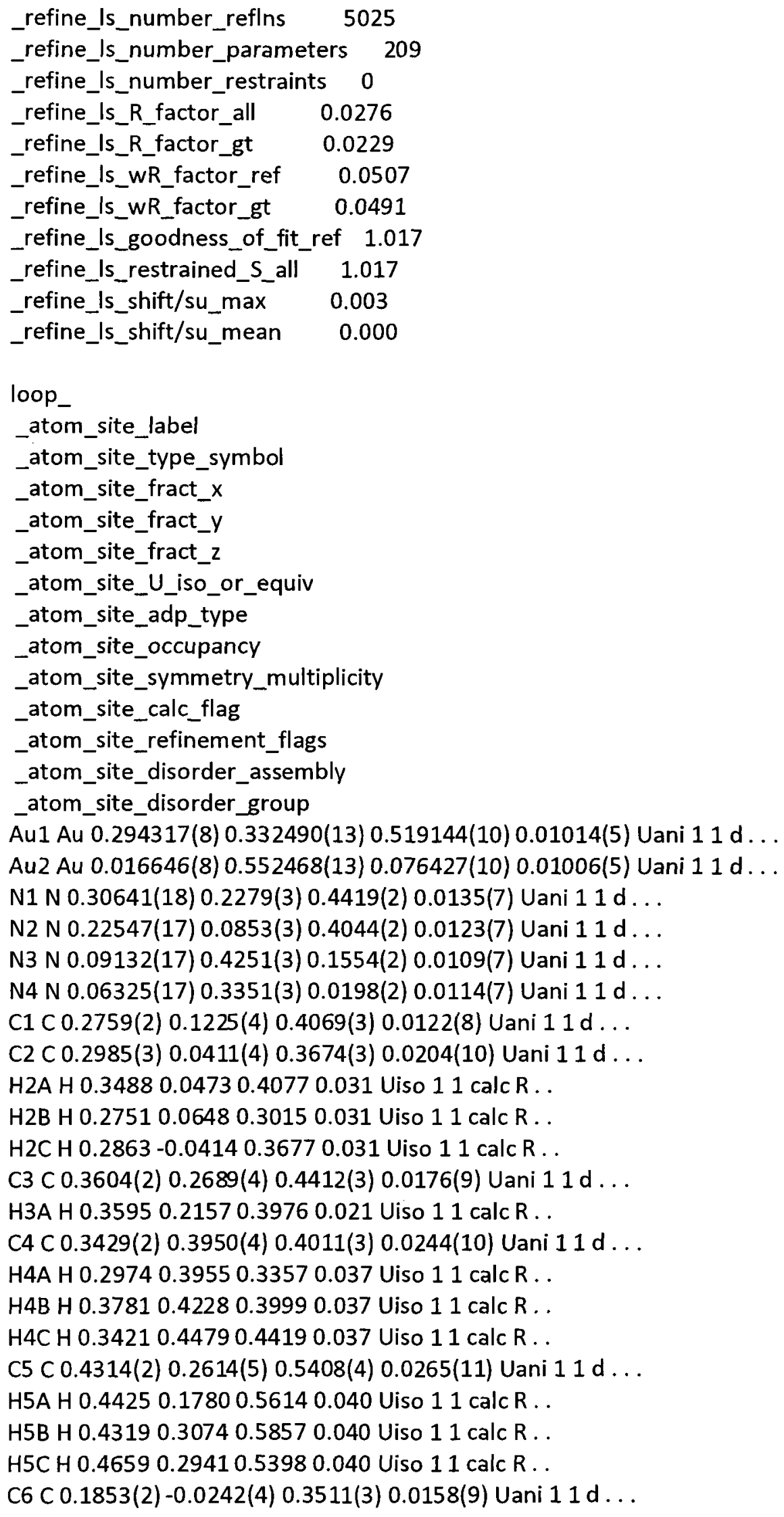


H6A H $0.1874-0.03930 .30040 .019$ Uiso 11 calc $R$. .

C7 C $0.2153(3)-0.1318(4) 0.4177(3) 0.0261(11)$ Uani $11 \mathrm{~d}$. . . H7A H $0.2639-0.14250 .44880 .039$ Uiso 11 calc $R$. . H7B H $0.1889-0.20320 .38040 .039$ Uiso 11 calc R . . H7C H $0.2125-0.11900 .46680 .039$ Uiso 11 calc $R$. . C8 C 0.1101(2) -0.0060 (5) $0.3026(3) 0.0266$ (11) Uani $11 \mathrm{~d}$... H8A H 0.09040 .05990 .25660 .040 Uiso 11 calc R . . H8B H 0.10750 .01280 .35120 .040 Uiso 11 calc R. . H8C H $0.0838-0.07900 .26860 .040$ Uiso 11 calc $R$. . C9 C $0.09833(19) 0.3371$ (3) $0.1146(3) 0.0103$ (8) Uani $11 \mathrm{~d} \ldots$ C10 C 0.1481 (2) $0.2354(4) 0.1772(3) 0.0171$ (9) Uani $11 \mathrm{~d} \ldots$ H10A H 0.14840 .22020 .22900 .026 Uiso 11 calc R . . H10B H 0.19480 .25720 .20480 .026 Uiso 11 calc R . . H10C H 0.13310 .16350 .13790 .026 Uiso 11 calc R . . C11 C $0.1318(2) 0.4267(4) 0.2603(3) 0.0152$ (9) Uani $11 \mathrm{~d} \ldots$ H11A H 0.17230 .37180 .29280 .018 Uiso 11 calc R . . C12 C 0.0869 (2) $0.3844(5) 0.2806$ (3) 0.0254 (11) Uani $11 d$. . H12A H 0.07180 .30240 .25770 .038 Uiso 11 calc $R$. . H12B H 0.04630 .43630 .24720 .038 Uiso 11 calc $R$. . H12C H 0.11380 .38740 .34990 .038 Uiso 11 calc R . . C13 C 0.1584(2) 0.5524(4) 0.2990(3) 0.0235(10) Uani $11 \mathrm{~d} \ldots$ H13A H 0.18700 .57850 .28520 .035 Uiso 11 calc $R$. . H13B H 0.18630 .55280 .36860 .035 Uiso 11 calc R. . $\mathrm{H} 13 \mathrm{CH} 0.11900 .60670 .26810 .035$ Uiso 11 calc $R$. . C14 C $0.0768(2) 0.2420(4)-0.0215$ (3) $0.0207(10)$ Uani $11 \mathrm{~d} \ldots$ H14A H 0.12490 .21130 .03040 .025 Uiso 11 calc $R$. .

C15 C $0.0719(3)$ 0.2944(6) $-0.1004(4) 0.0389(15)$ Uani $11 \mathrm{~d}$. . H15A H $0.10560 .3591-0.07410 .058$ Uiso 11 calc R . . H15B H $0.02510 .3257-0.15160 .058$ Uiso 11 calc R . . $\mathrm{H} 15 \mathrm{CH} 0.08170 .2324-0.12670 .058$ Uiso 11 calc $\mathrm{R}$. . C16 C $0.0263(3) 0.1391(4)-0.0585(4) 0.0322(13)$ Uani $11 \mathrm{~d} \ldots$ H16A H $0.03480 .1006-0.00450 .048$ Uiso 11 calc R . . H16B H $0.03290 .0810-0.09090 .048$ Uiso 11 calc $R$. . H16C H $-0.02130 .1694-0.10410 .048$ Uiso 11 calc $R$. .

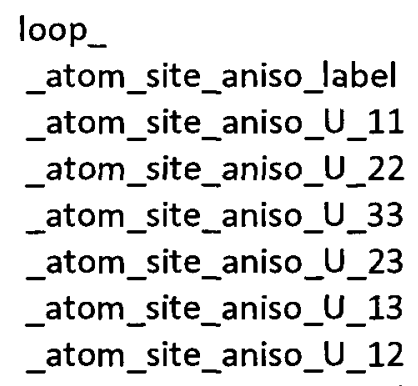

Au1 $0.01231(8) 0.00713(8) 0.01258(8)-0.00136(5) 0.00898(7)-0.00139(5)$ Au2 $0.01098(8) 0.00953(8) 0.00772(7) 0.00051(5) 0.00544(6) 0.00255(6)$ N1 $0.0189(18) 0.0091(17) 0.0196(18) 0.0008(14) 0.0158(16)-0.0006(14)$ N2 $0.0158(17) 0.0071(17) 0.0133(17)-0.0019(13) 0.0095(15)-0.0007(13)$ N3 $0.0099(16) 0.0126(17) 0.0066(15) 0.0023(13) 0.0040(14) 0.0016(13)$ 
N4 $0.0099(16) 0.0117(18) 0.0104(16) 0.0012(13) 0.0059(14) 0.0028(13)$

C1 0.0133(19) $0.010(2) 0.0084(18) 0.0029(15) 0.0053(17) 0.0053(16)$

C2 $0.030(3) 0.010(2) 0.031(3)-0.0016(18) 0.025(2) 0.0045(18)$

C3 $0.021(2) 0.017(2) 0.023(2)-0.0022(18) 0.018(2)-0.0018(18)$

C4 $0.022(2) 0.030(3) 0.025(2) 0.006(2) 0.018(2)-0.005(2)$

C5 $0.016(2) 0.029(3) 0.034(3) 0.010(2) 0.016(2) 0.0037(19)$

C6 0.021(2) $0.010(2) 0.014(2)-0.0036(16) 0.0103(19)-0.0033(17)$

C7 0.034(3) $0.010(2) 0.028(3)-0.0023(19) 0.018(2)-0.008(2)$

C8 $0.020(2) 0.026(3) 0.022(2)-0.006(2) 0.009(2)-0.011(2)$

C9 $0.0075(18) 0.010(2) 0.0112(19)-0.0012(15) 0.0055(16)-0.0018(15)$

C10 0.021(2) 0.009 (2) $0.015(2) 0.0034(16) 0.0098(19) 0.0058(17)$

C11 0.014(2) $0.019(2) 0.0081(19) 0.0010(16) 0.0054(17) 0.0047(17)$

C12 0.030(3) $0.033(3) 0.020(2) 0.007(2) 0.019(2) 0.005(2)$

C13 $0.025(2) 0.025(3) 0.015(2)-0.0054(19) 0.011(2)-0.004(2)$

C14 0.019(2) $0.023(2) 0.016(2)-0.0010(18) 0.0095(19) 0.0106(18)$

C15 $0.043(3) 0.057(4) 0.027(3) 0.014(3) 0.028(3) 0.031(3)$

C16 0.027(3) $0.019(3) 0.027(3)-0.010(2) 0.009(2) 0.006(2)$

_geom_special_details

;

All esds (except the esd in the dihedral angle between two I.s. planes) are estimated using the full covariance matrix. The cell esds are taken into account individually in the estimation of esds in distances, angles and torsion angles; correlations between esds in cell parameters are only used when they are defined by crystal symmetry. An approximate (isotropic) treatment of cell esds is used for estimating esds involving l.s. planes.

;

loop

_geom_bond_atom_site_label_1

_geom_bond_atom_site_label_2

_geom_bond_distance

_geom_bond_site_symmetry_2

_geom_bond_publ_flag

Au1 N2 2.037(3) 7_556?

Au1 N1 2.044(3) . ?

Au1 Au1 2.6529(5) 7_556?

Au2 N4 2.036(3) 5_565?

Au2 N3 2.039(3) . ?

Au2 Au2 2.6486(6) 5_565?

N1 C1 1.328(5) . ?

N1 C3 1.483(5) . ?

N2 C1 1.346(5) . ?

N2 C6 1.485(5) . ?

N2 Au1 2.037(3) 7_556?

N3 C9 1.334(5) . ?

N3 C11 1.483(5) . ?

N4 C9 1.349(5) . ? 


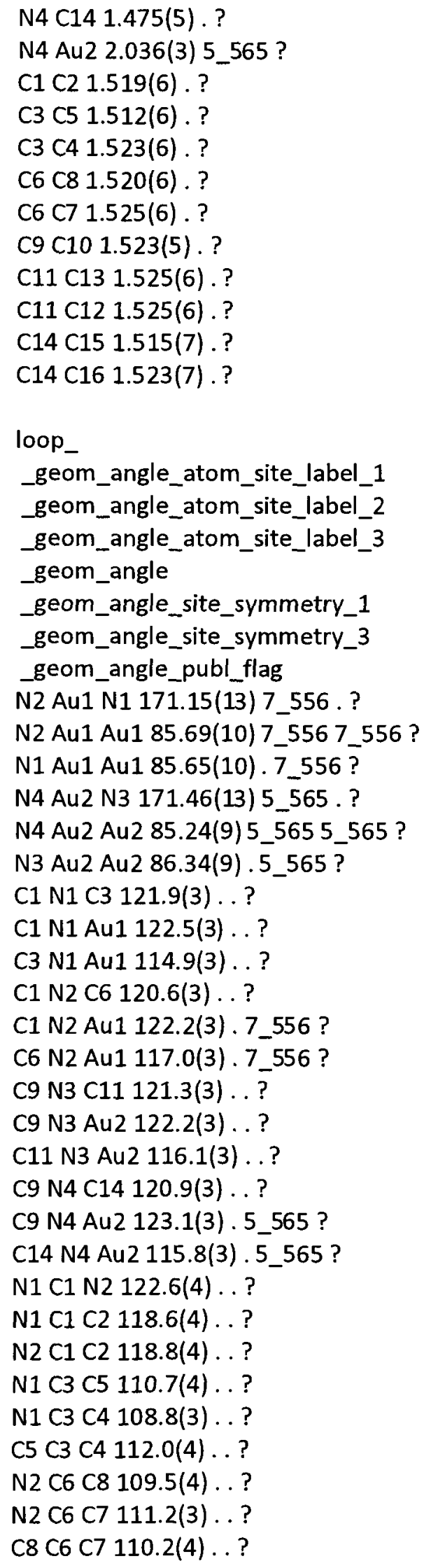




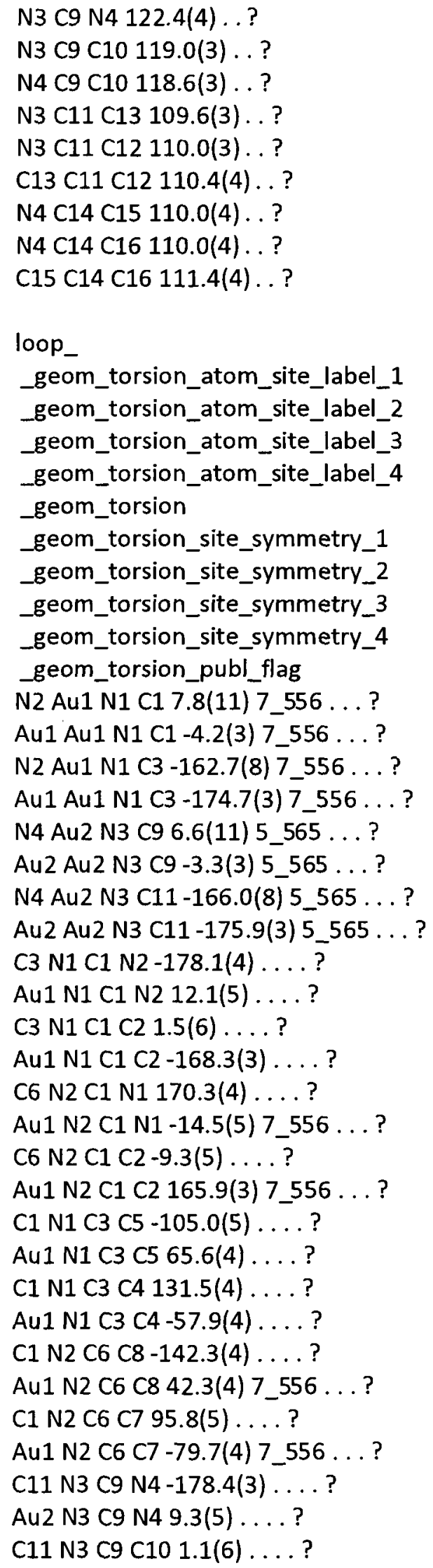




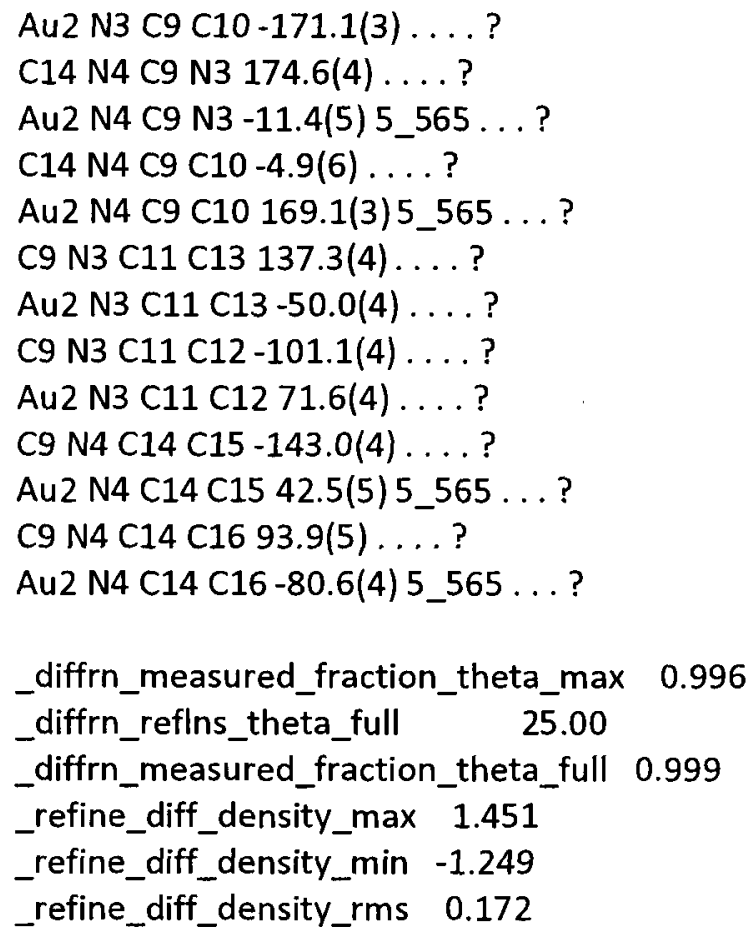




\section{Compound 2}

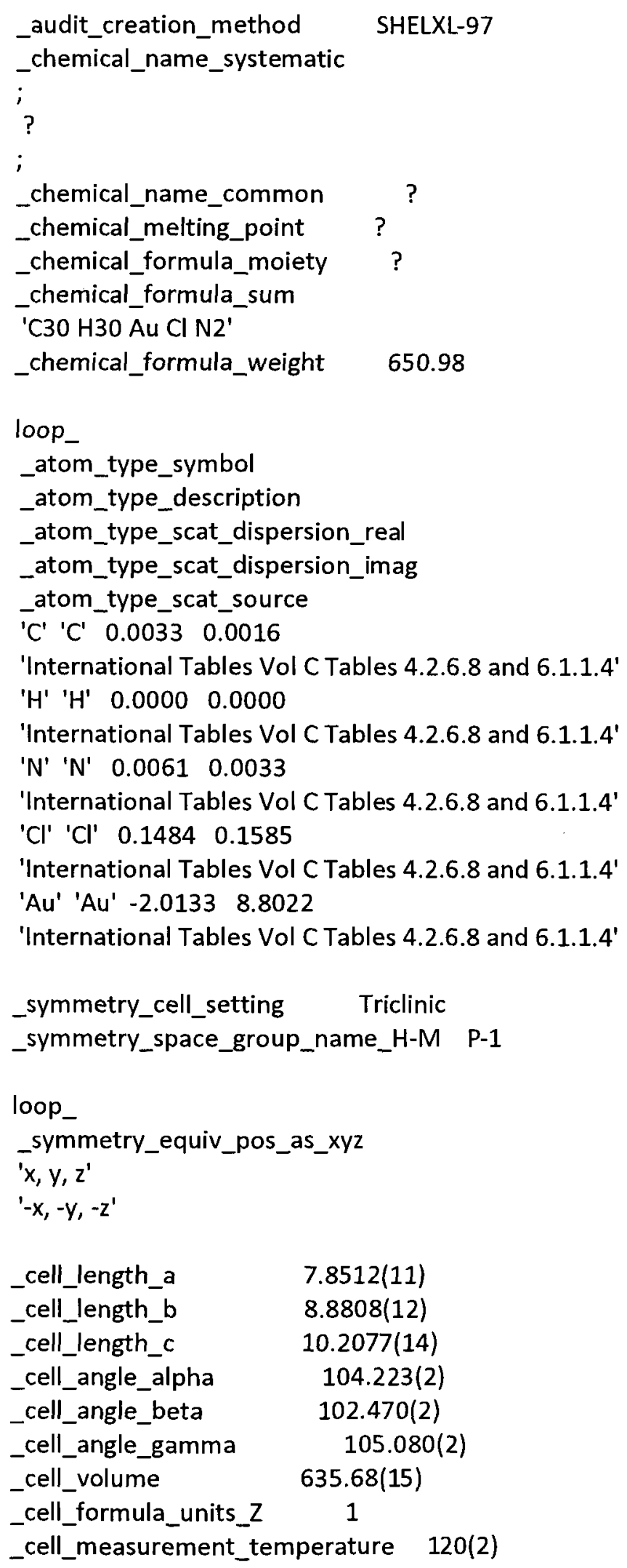




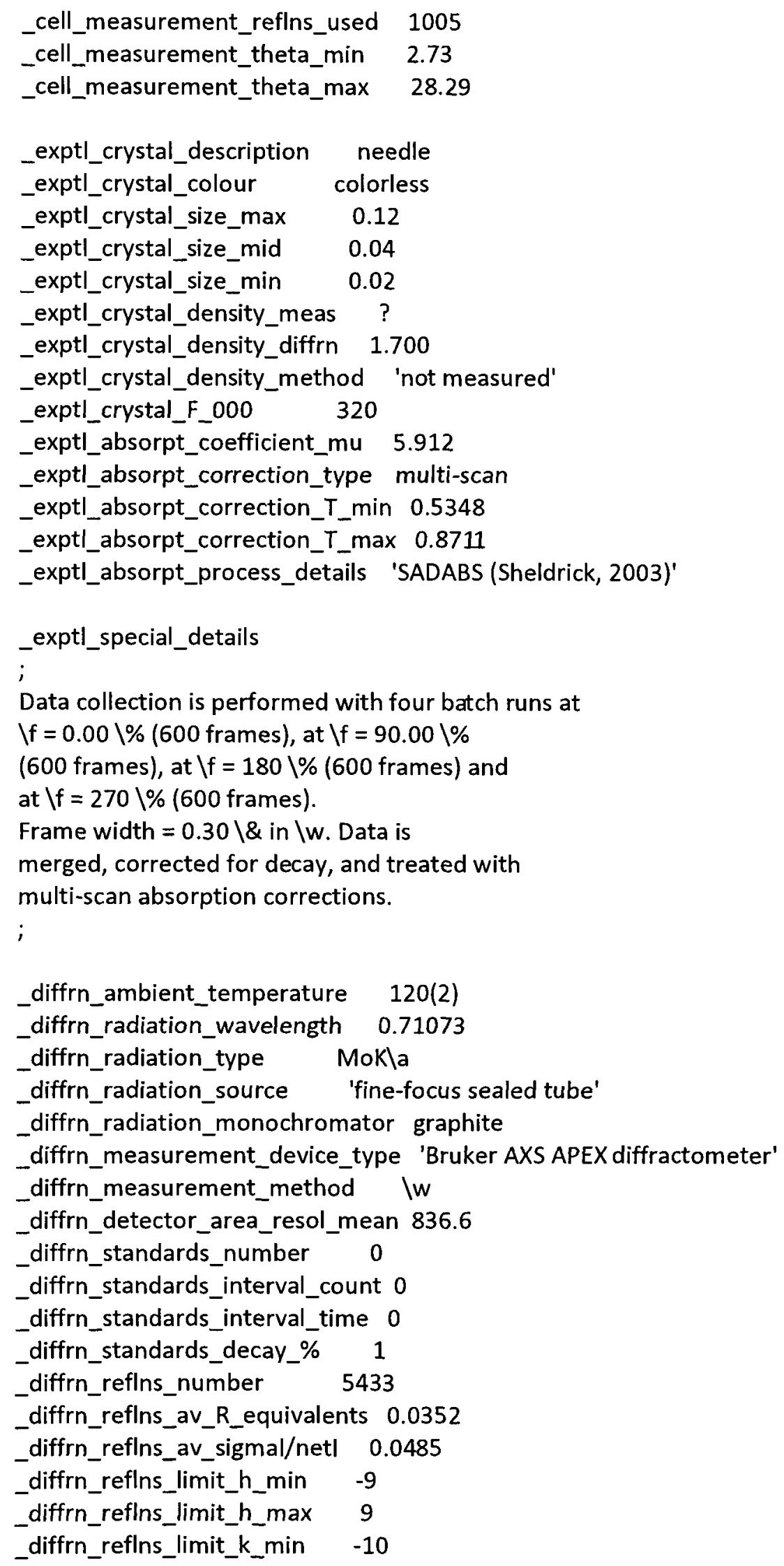




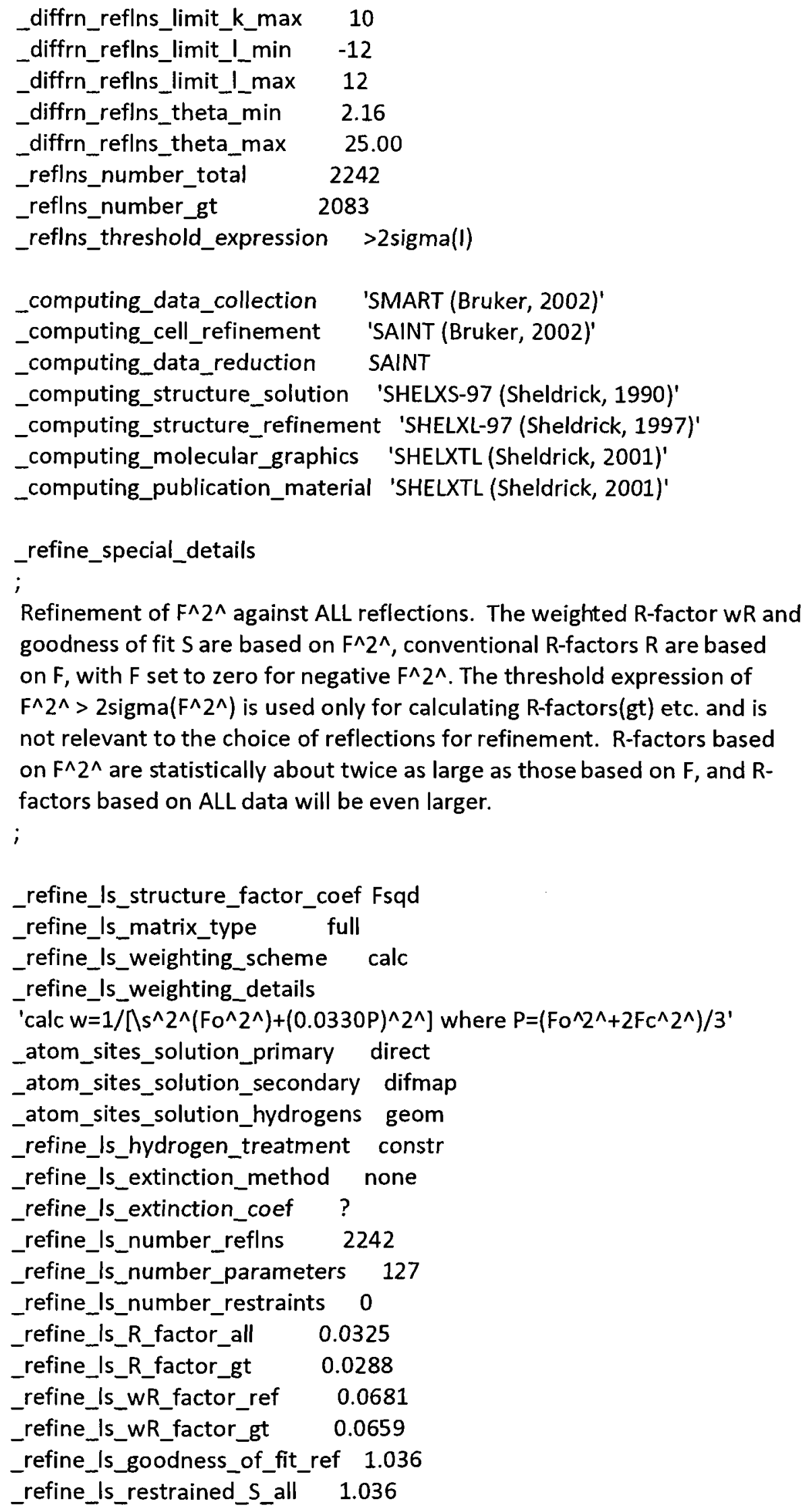




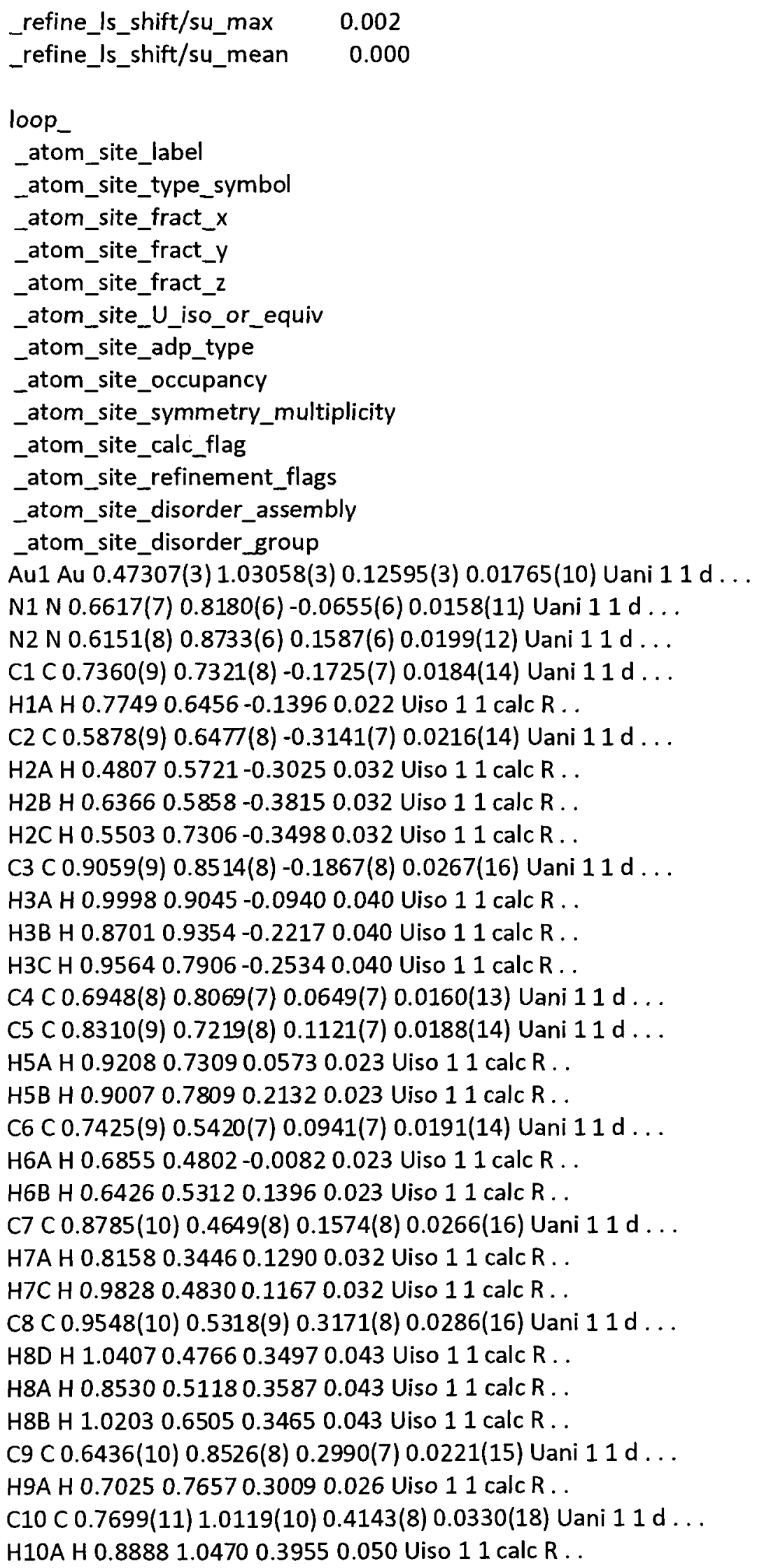


H10B H 0.78990 .99370 .50650 .050 Uiso 11 calc R . . H10D H 0.71221 .09750 .41510 .050 Uiso 11 calc R . .

C11 C $0.4596(10) 0.7979(9) 0.3275(8) 0.0288(16)$ Uani $11 \mathrm{~d} \ldots$ H11A H 0.37860 .69540 .25310 .043 Uiso 11 calc R . . H11B H 0.40170 .88330 .32820 .043 Uiso 11 calc $R$. . H11CH 0.47940 .77950 .41960 .043 Uiso 11 calc R. .

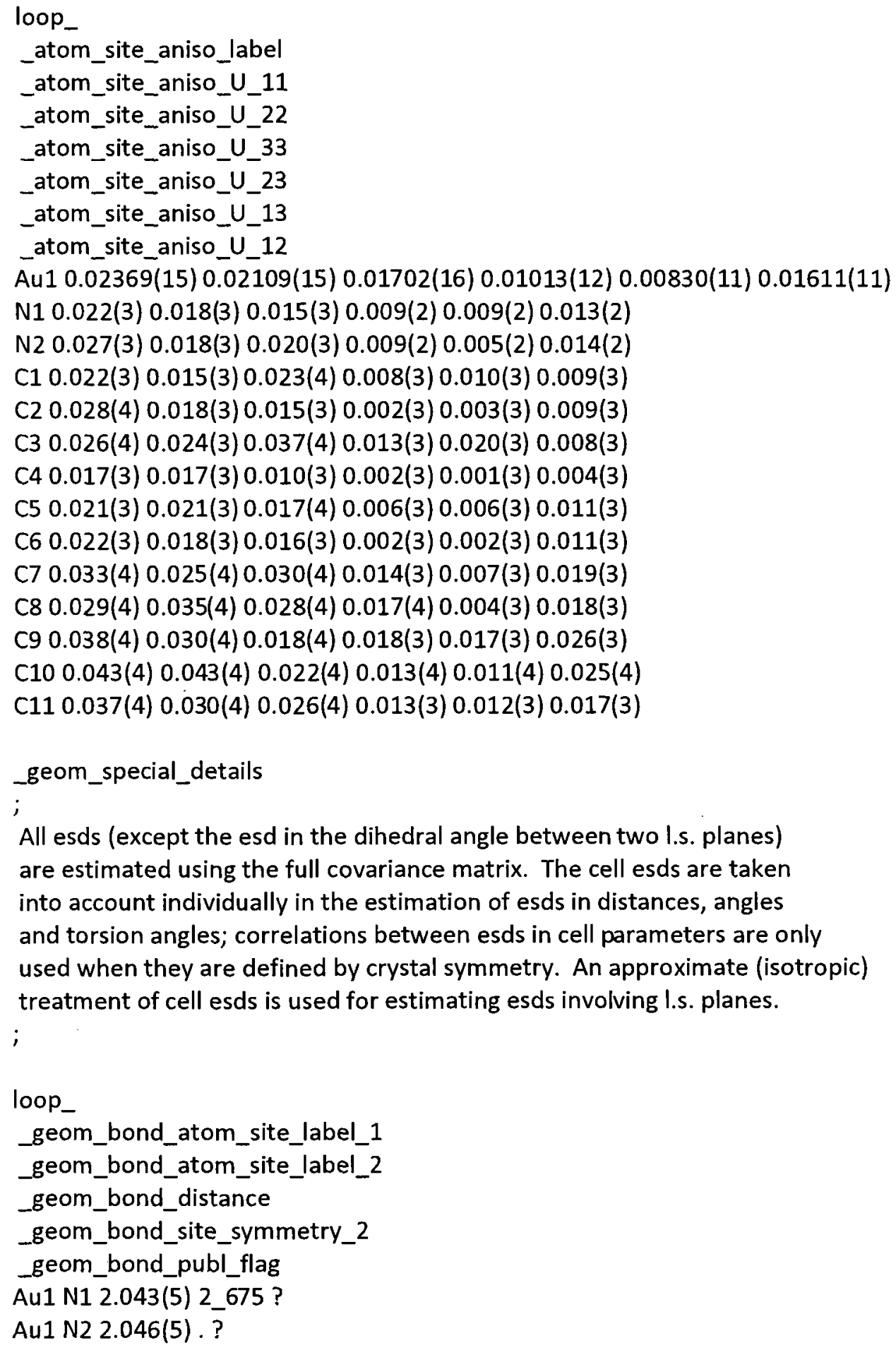




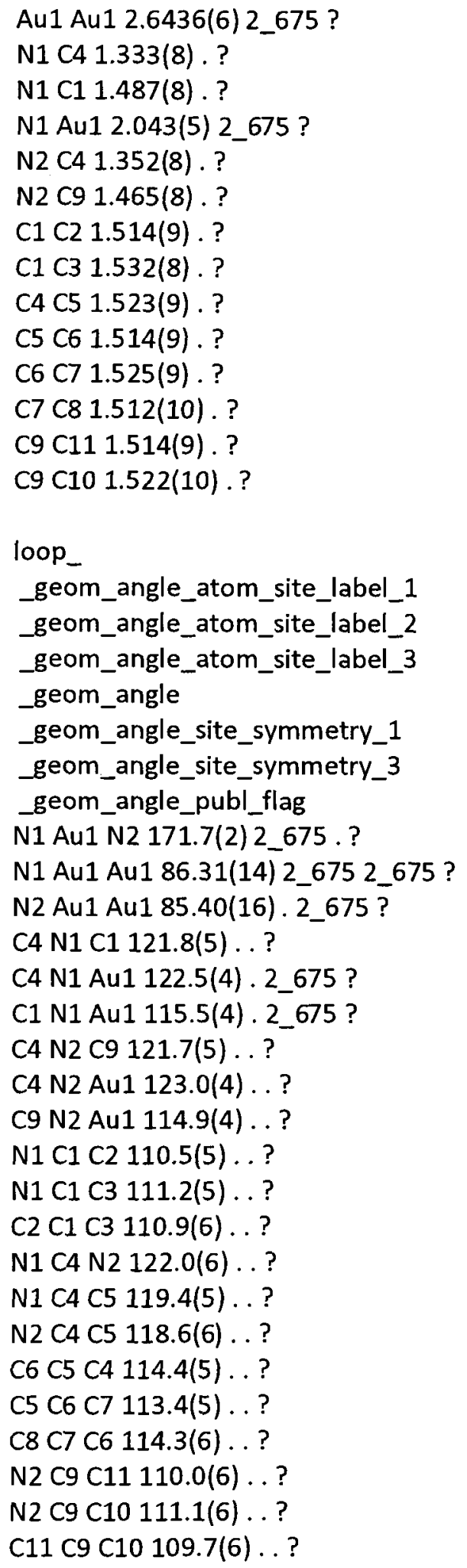




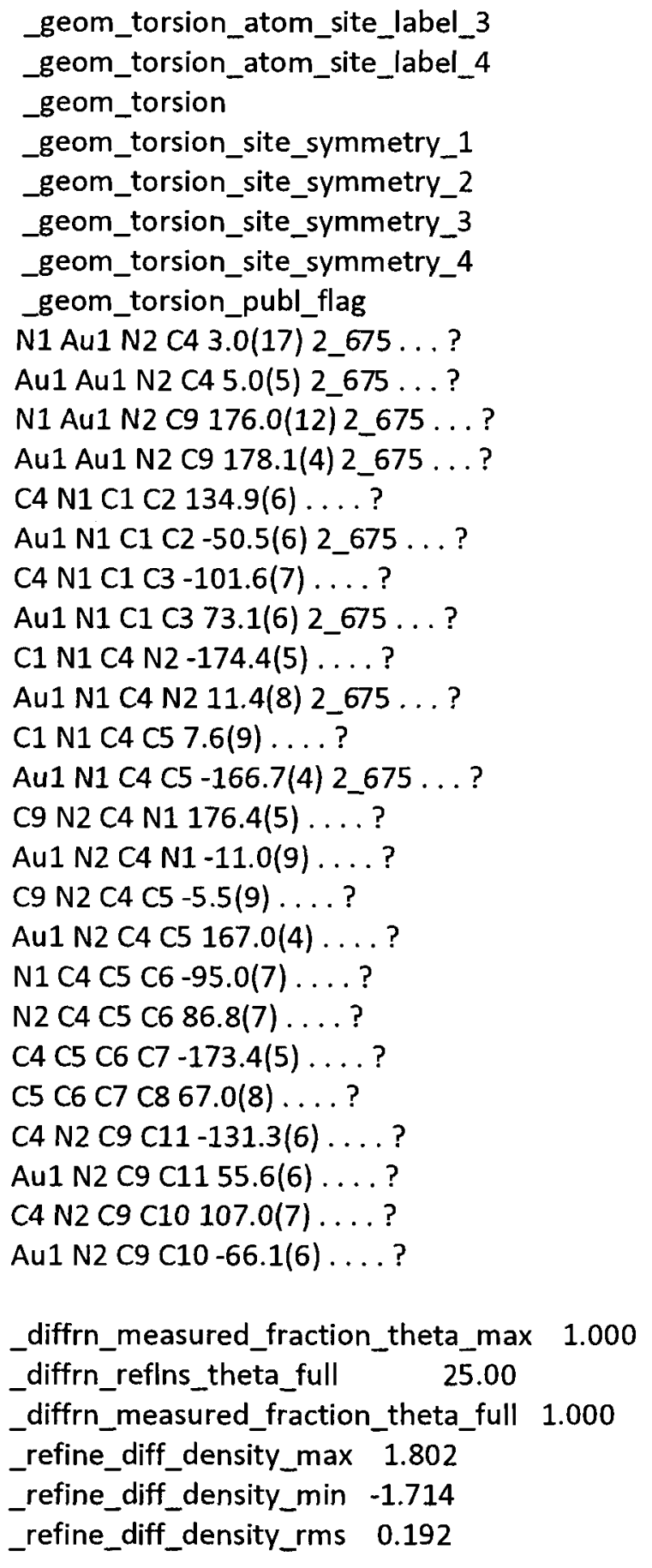




\section{Compound 3}

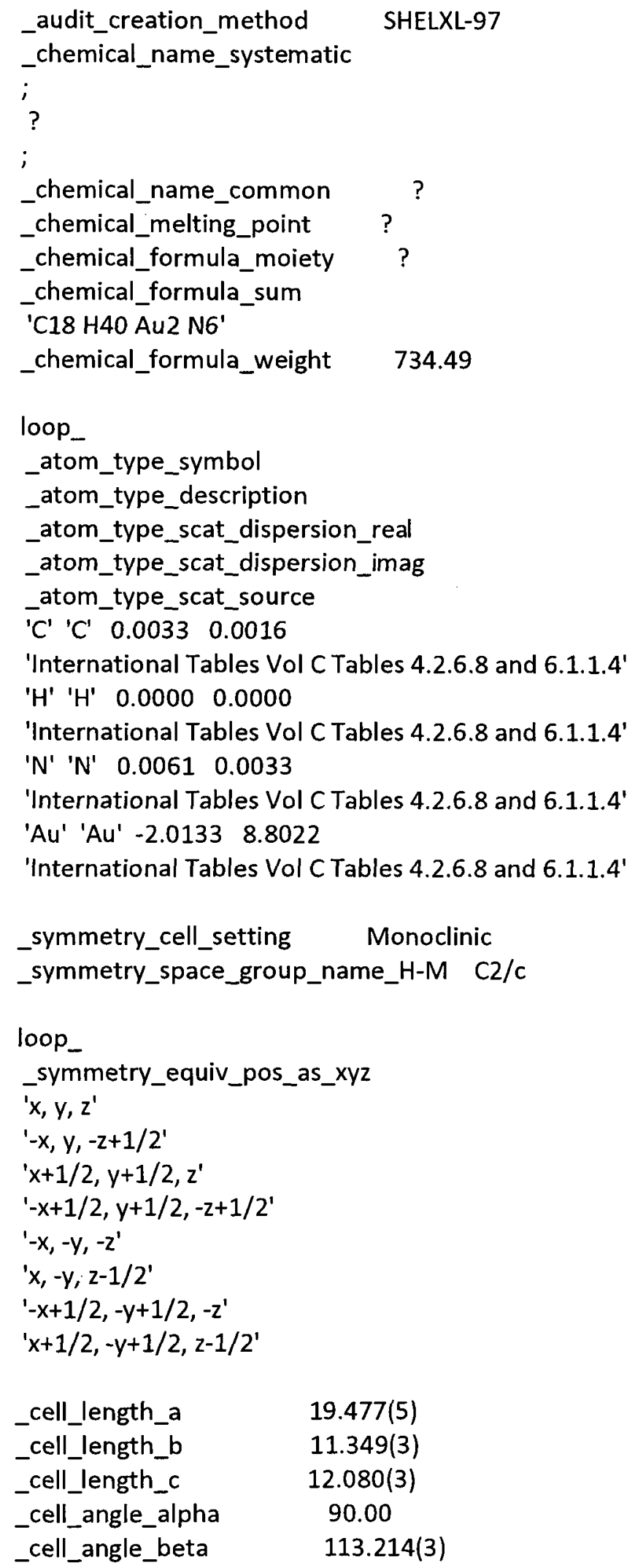




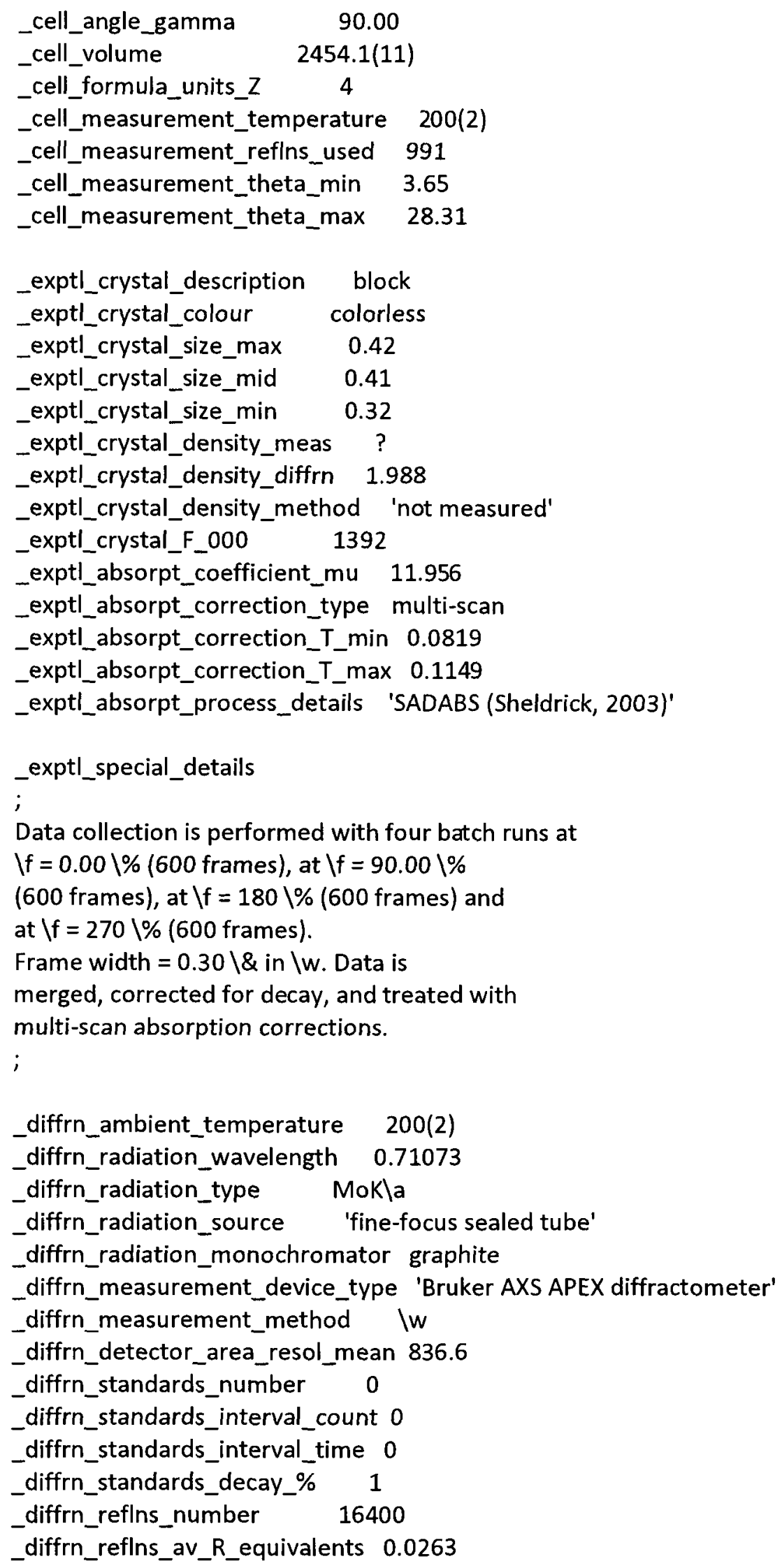




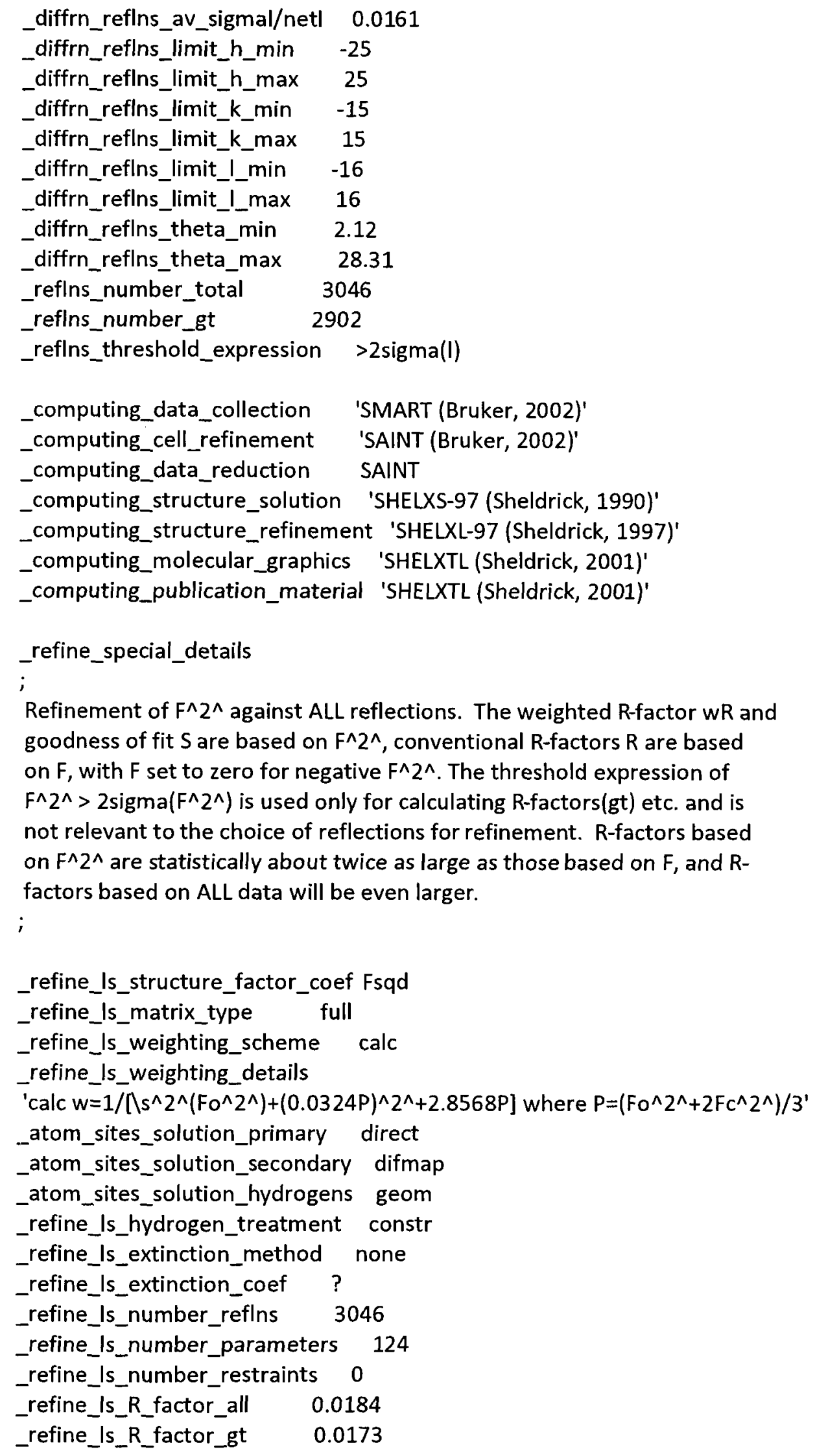
goodness of fit $S$ are based on $F^{\wedge} 2^{\wedge}$, conventional $R$-factors $R$ are based on $F$, with $F$ set to zero for negative $F^{\wedge} 2^{\wedge}$. The threshold expression of $\mathrm{F}^{\wedge} 2^{\wedge}>2 \operatorname{sigma}\left(\mathrm{F}^{\wedge} 2^{\wedge}\right)$ is used only for calculating $\mathrm{R}$-factors (gt) etc. and is not relevant to the choice of reflections for refinement. $R$-factors based on $F^{\wedge} 2^{\wedge}$ are statistically about twice as large as those based on $F$, and $R$ factors based on ALL data will be even larger. ;

_refine_Is_structure_factor_coef Fsqd

_refine_Is_matrix_type full

_refine_Is_weighting_scheme calc

refine_ls_weighting_details

'calc $w=1 /\left[\backslash s^{\wedge} 2^{\wedge}\left(F o^{\wedge} 2^{\wedge}\right)+(0.0324 \mathrm{P})^{\wedge} 2^{\wedge}+2.8568 \mathrm{P}\right]$ where $\mathrm{P}=\left(\mathrm{Fo} \mathrm{o}^{\wedge} 2^{\wedge}+2 \mathrm{Fc}^{\wedge} 2^{\wedge}\right) / 3^{\prime}$

._atom_sites_solution_primary direct

_atom_sites_solution_secondary difmap

_atom_sites_solution_hydrogens geom

_refine_ls_hydrogen_treatment constr

_refine_Is_extinction_method none

_refine_Is_extinction_coef ?

_refine_Is_number_reflns 3046

_refine_Is_number_parameters 124

_refine_Is_number_restraints 0

_refine_Is_R_factor_all $\quad 0.0184$

_refine_Is_R_factor_gt $\quad 0.0173$ 


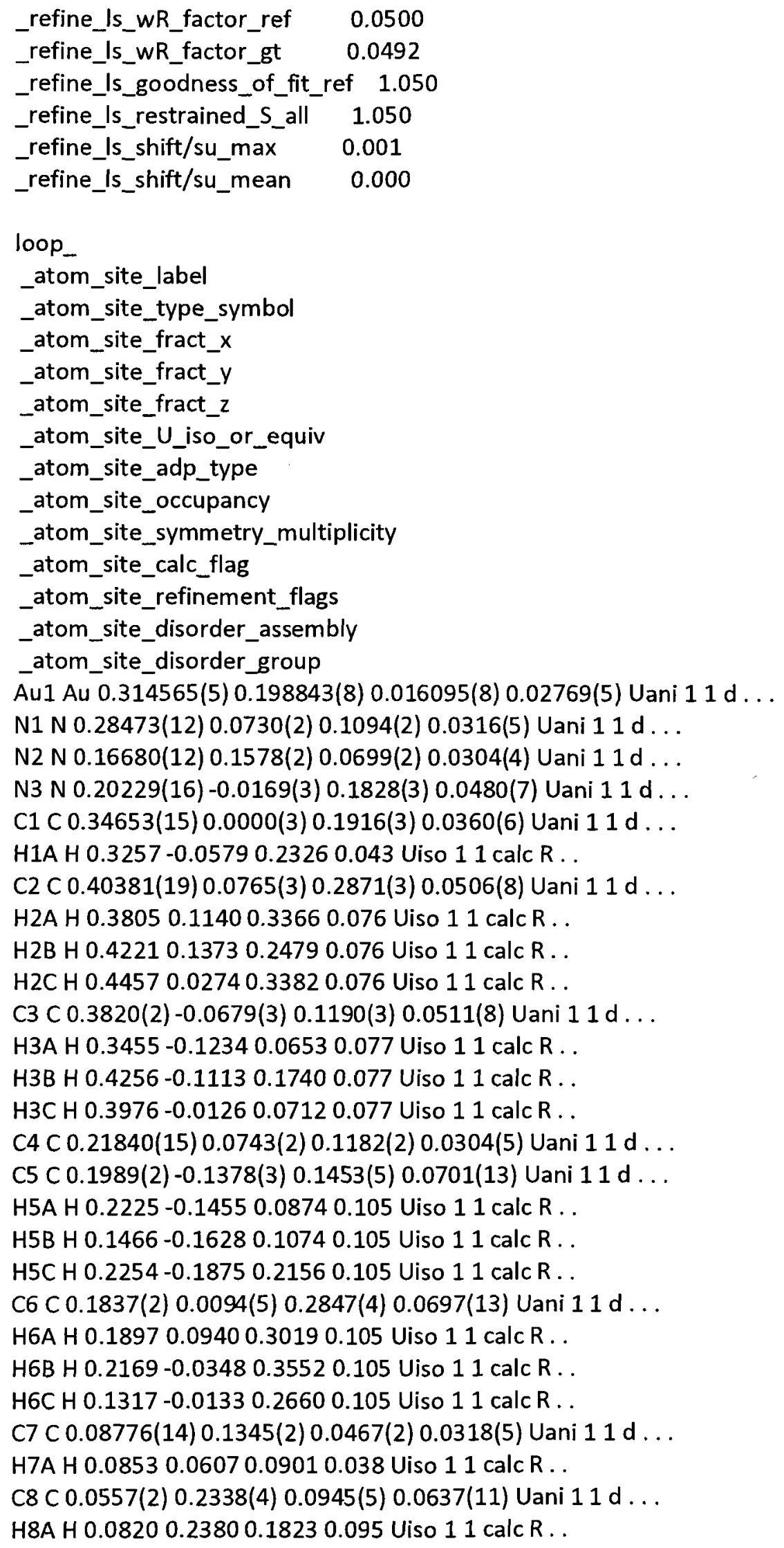




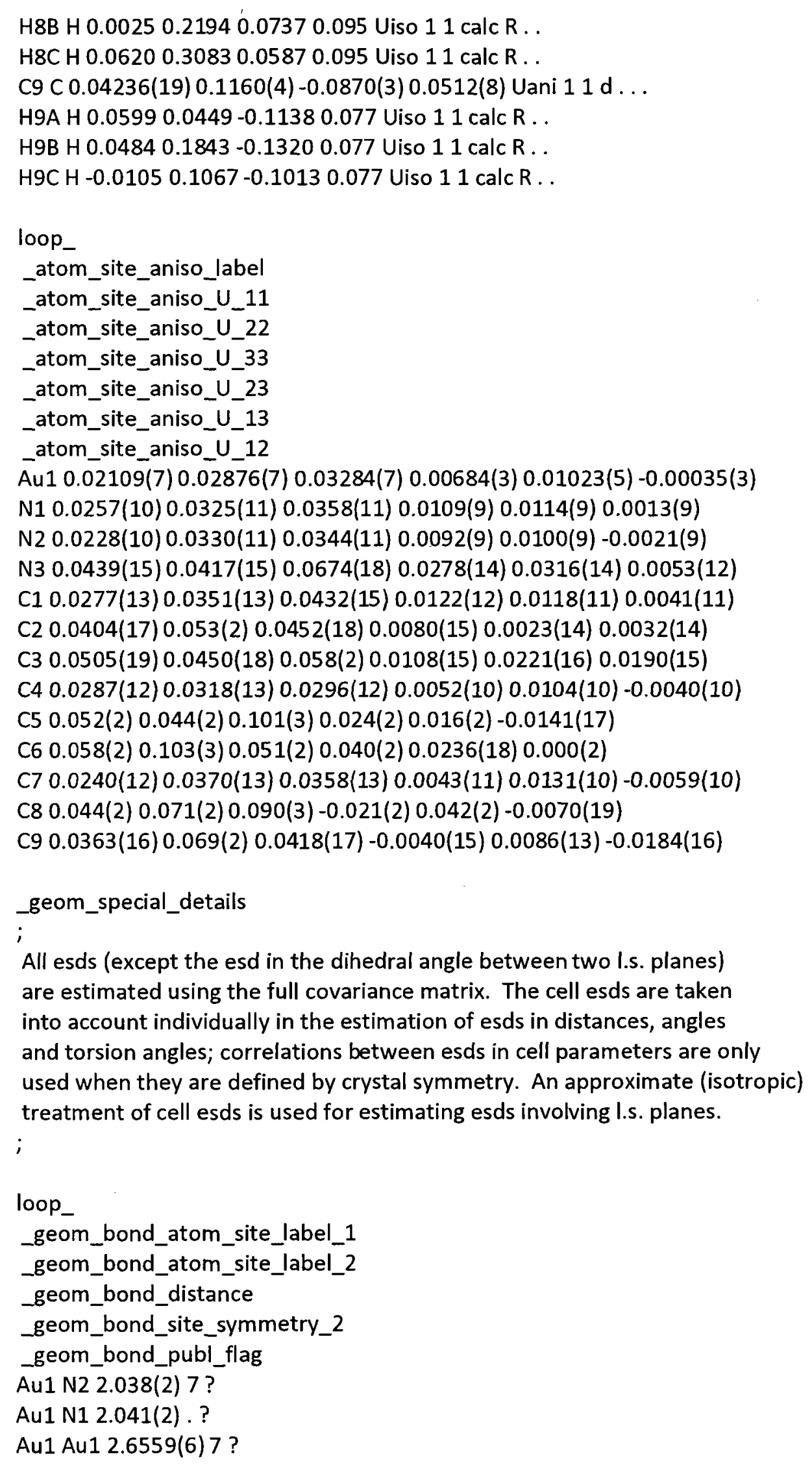




\begin{abstract}
N1 C4 1.337(3). ?
N1 C1 1.477(3). ?

N2 C4 1.337(4) . ?

N2 C7 1.476(3) . ?

N2 Au1 2.038(2) 7 ?

N3 C4 1.404(3) . ?

N3 C5 1.438(5) . ?

N3 C6 1.445(6) . ?

C1 C2 1.521(4) . ?

C1 C3 1.521(5) . ?

C7 C8 1.508(5) . ?

C7 C9 1.519(4) . ?
\end{abstract}

loop

_geom_angle_atom_site_label_1

_geom_angle_atom_site_label_2

_geom_angle_atom_site_label_3

_geom_angle

_geom_angle_site_symmetry_1

_geom_angle_site_symmetry_3

_geom_angle_publ_flag

N2 Au1 N1 170.64(10) 7 . ?

N2 Au1 Au1 85.69(7) 77 ?

N1 Au1 Au1 85.83(6) . 7 ?

C4 N1 C1 120.6(2) . . ?

C4 N1 Au1 122.06(17) . . ?

C1 N1 Au1 115.49(17). . ?

C4 N2 C7 120.3(2) . . ?

C4 N2 Au1 122.30(17). 7 ?

C7 N2 Au1 115.36(17). 7 ?

C4 N3 C5 121.4(3)..?

C4 N3 C6 120.5(3) . . ?

C5 N3 C6 118.0(3) .. ?

N1 C1 C2 110.4(2) . . ?

N1 C1 C3 109.4(2) . . ?

C2 C1 C3 111.2(3) . . ?

N2 C4 N1 123.8(2) .. ?

N2 C4 N3 118.1(2)..?

N1 C4 N3 118.1(2) .. ?

N2 C7 C8 110.6(2) . . ?

N2 C7 C9 110.6(2)..?

C8 C7 C9 110.8(3) . . ?

loop

_geom_torsion_atom_site_label_1

_geom_torsion_atom_site_label_2

_geom_torsion_atom_site_label_3

_geom_torsion_atom_site_label_4 


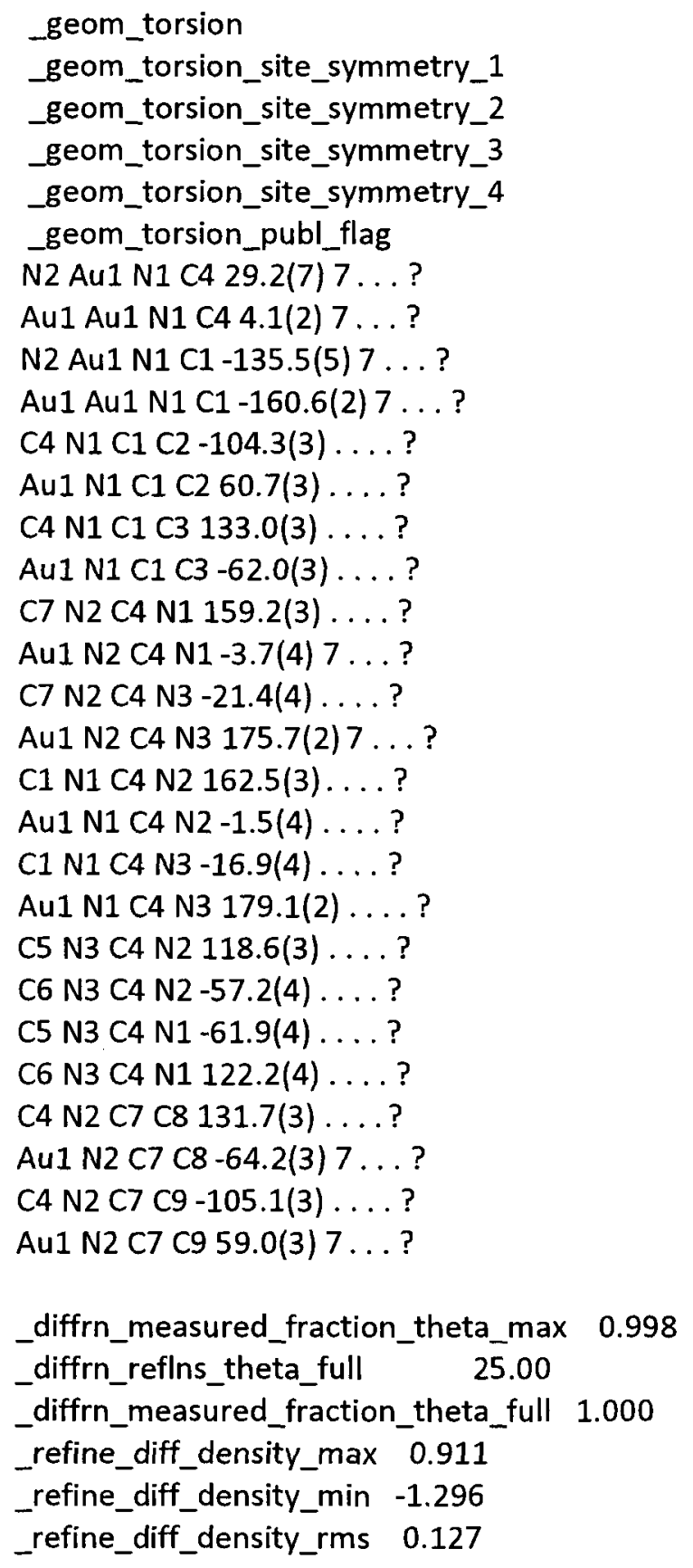




\section{Compound 10}

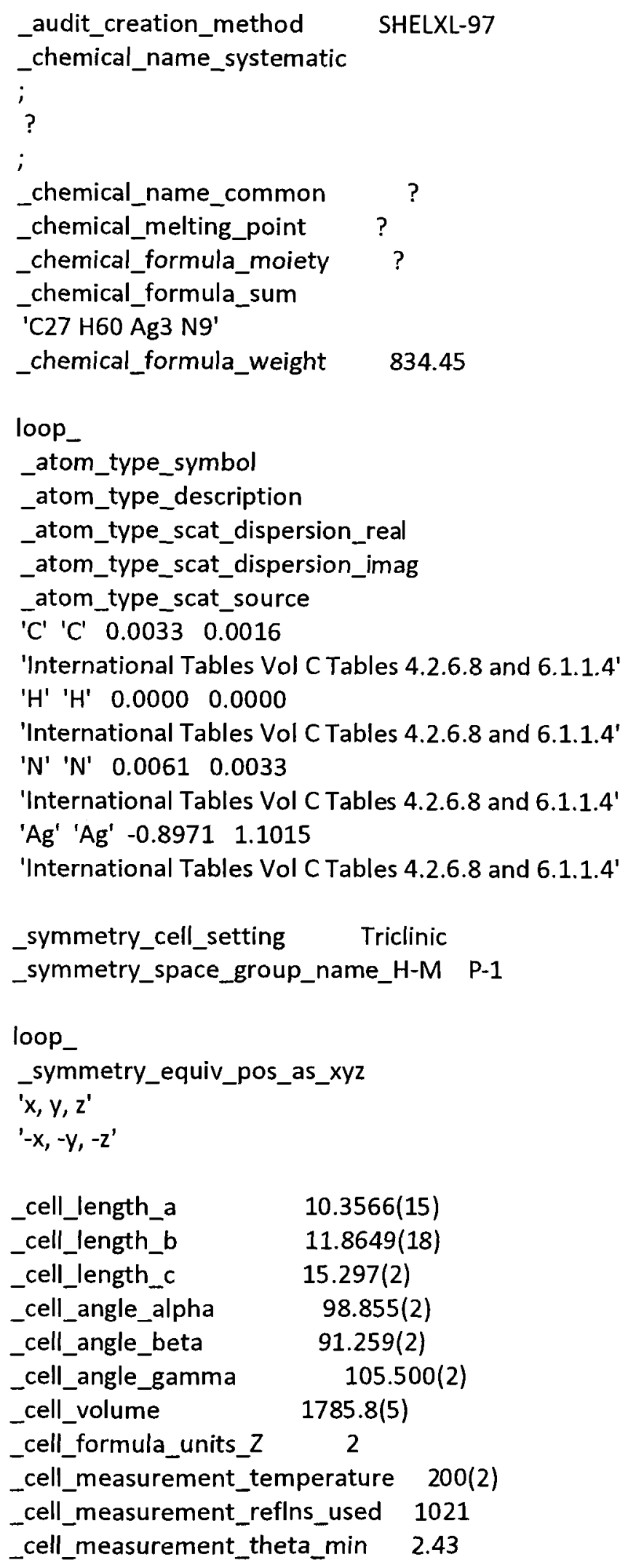




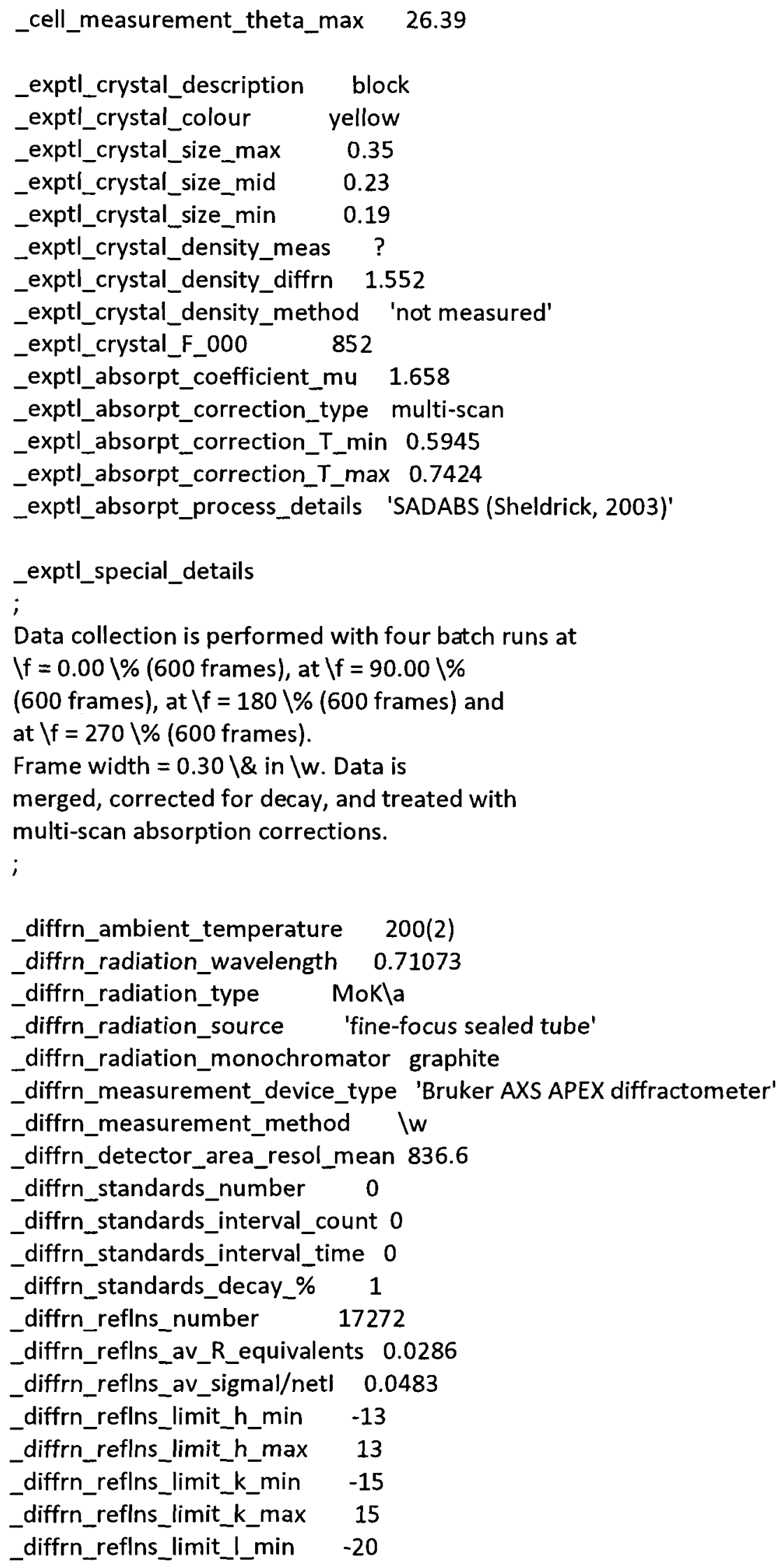




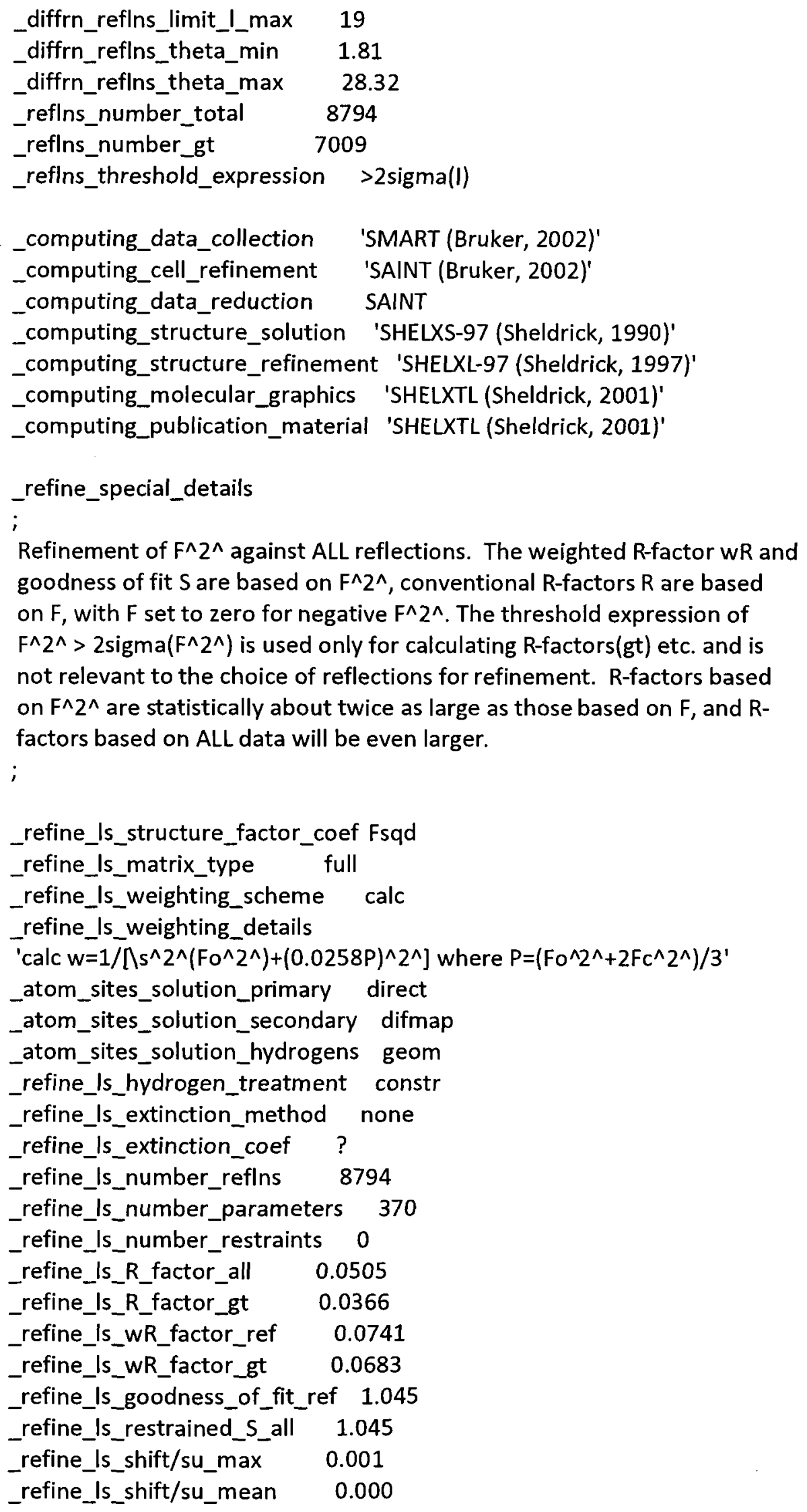
goodness of fit $S$ are based on $F^{\wedge} 2^{\wedge}$, conventional $R$-factors $R$ are based on $F$, with $F$ set to zero for negative $F^{\wedge} 2^{\wedge}$. The threshold expression of $F^{\wedge} 2^{\wedge}>2 \operatorname{sigma}\left(F^{\wedge} 2^{\wedge}\right)$ is used only for calculating $R$-factors (gt) etc. and is not relevant to the choice of reflections for refinement. R-factors based on $\mathrm{F}^{\wedge} 2^{\wedge}$ are statistically about twice as large as those based on $F$, and $R$ factors based on ALL data will be even larger.

;

_refine_Is_structure_factor_coef Fsqd

_refine_Is_matrix_type full

_refine_Is_weighting_scheme calc

_refine_Is_weighting_details

'calc $w=1 /\left[\Lambda s^{\wedge} 2^{\wedge}\left(F o^{\wedge} 2^{\wedge}\right)+(0.0258 \mathrm{P})^{\wedge} 2^{\wedge}\right]$ where $P=\left(F o^{\wedge} 2^{\wedge}+2 F c^{\wedge} 2^{\wedge}\right) / 3^{\prime}$

_atom_sites_solution_primary direct

_atom_sites_solution_secondary difmap

_atom_sites_solution_hydrogens geom

_refine_Is_hydrogen_treatment constr

_refine_Is_extinction_method none

_refine_Is_extinction_coef ?

_refine_Is_number_reflns 8794

_refine_Is_number_parameters 370

_refine_Is_number_restraints 0

_refine_Is_R_factor_all $\quad 0.0505$

_refine_Is_R_factor_gt $\quad 0.0366$

_refine_Is_wR_factor_ref 0.0741

_refine_Is_wR_factor_gt 0.0683

_refine_Is_goodness_of_fit_ref 1.045

_refine_Is_restrained_S_all 1.045

_refine_ls_shift/su_max $\quad 0.001$

_refine_Is_shift/su_mean $\quad 0.000$ 


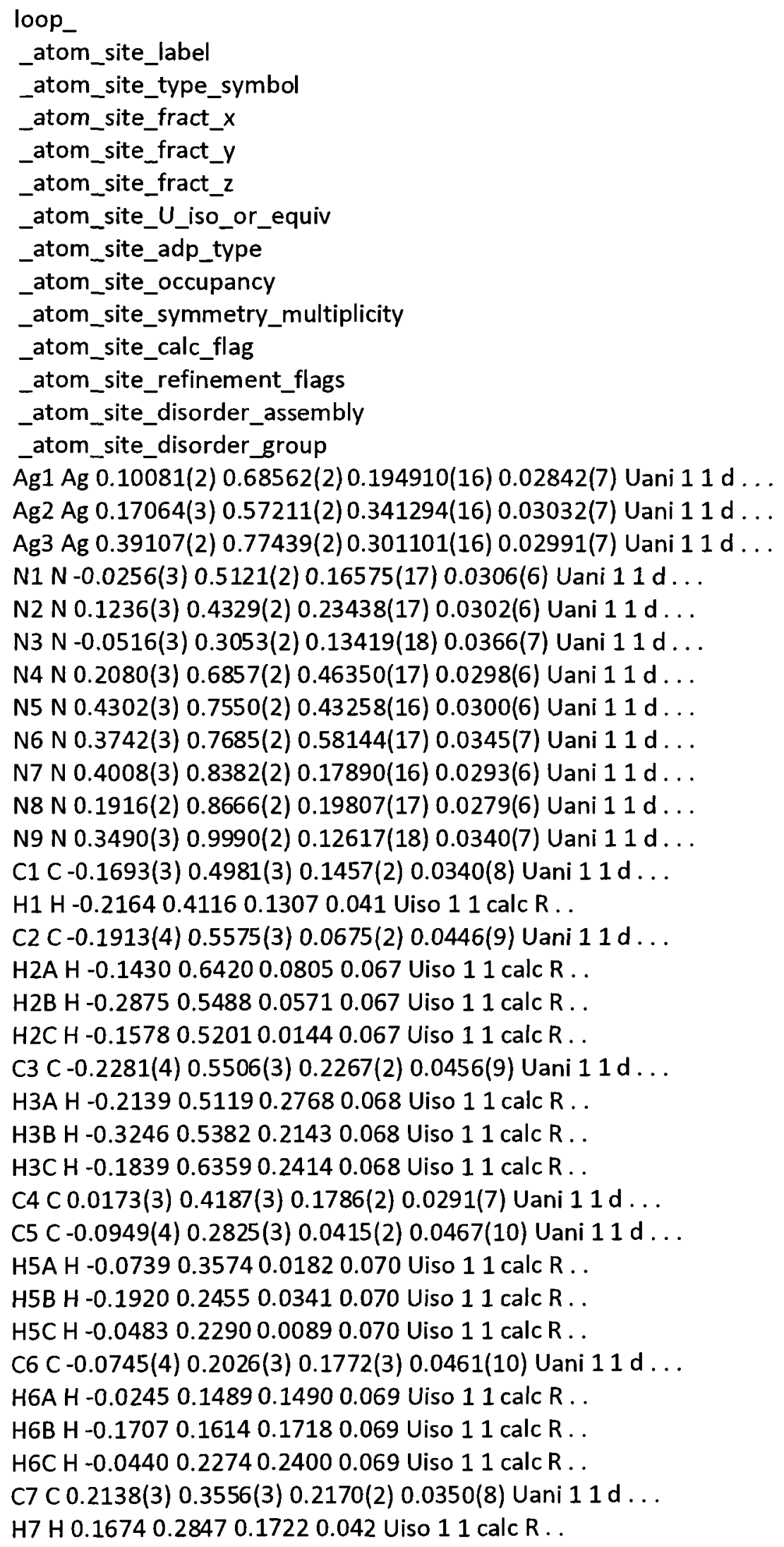


C8 C 0.3401 (4) $0.4235(3) 0.1796(3) 0.0488(10)$ Uani $11 d \ldots$ H8A H 0.31640 .44710 .12410 .073 Uiso 11 calc R. . H8B H 0.40080 .37290 .16820 .073 Uiso 11 calc R . . H8C H 0.38480 .49450 .22240 .073 Uiso 11 calc R. . C9 C $0.2480(4) 0.3144(3) 0.3016(2) 0.0473(10)$ Uani $11 \mathrm{~d}$... H9A H 0.29120 .38350 .34650 .071 Uiso 11 calc $R$. . H9B H 0.30930 .26460 .28930 .071 Uiso 11 calc R. . $\mathrm{H} 9 \mathrm{CH} 0.16550 .26850 .32370 .071$ Uiso 11 calc $\mathrm{R}$. . C10 C 0.0990 (3) $0.7035(3) 0.5207(2) 0.0321$ (7) Uani $11 \mathrm{~d} \ldots$ H10 H 0.10110 .66110 .57220 .039 Uiso 11 calc R . . C11 C $-0.0343(3) 0.6475(4) 0.4673(2) 0.0473(10)$ Uani $11 \mathrm{~d} \ldots$ H11A H -0.03830 .68830 .41670 .071 Uiso 11 calc $R$. . H11B H -0.10800 .65450 .50500 .071 Uiso 11 calc $R$. . $\mathrm{H} 11 \mathrm{CH}-0.04260 .56350 .44580 .071$ Uiso 11 calc $R$. . C12 C 0.1110 (4) $0.8332(3) 0.5564$ (2) 0.0452 (9) Uani $11 \mathrm{~d} \ldots$ H12A H 0.19080 .86590 .59750 .068 Uiso 11 calc R . . H12B H 0.03090 .83930 .58760 .068 Uiso 11 calc R . . H12C H 0.11890 .87780 .50700 .068 Uiso 11 calc R . . C13 C $0.3360(3) 0.7358(3) 0.4912(2) 0.0293(7)$ Uani $11 \mathrm{~d} \ldots$ C14 C $0.3286(4) 0.6886(3) 0.6435(2) 0.0432$ (9) Uani $11 \mathrm{~d} \ldots$ H14A H 0.26690 .71830 .68250 .065 Uiso 11 calc R . . H14B H 0.40590 .68330 .67920 .065 Uiso 11 calc $R$. . $\mathrm{H} 14 \mathrm{C} H 0.28190 .60980 .61090 .065$ Uiso 11 calc $R$. . C15 C 0.4684(4) 0.8812 (3) 0.6166 (2) 0.0445 (9) Uani $11 \mathrm{~d} \ldots$ H15A H 0.49840 .92480 .56790 .067 Uiso 11 calc R . . H15B H 0.54600 .86770 .64680 .067 Uiso 11 calc R. . $\mathrm{H} 15 \mathrm{CH} 0.42470 .92750 .65880 .067$ Uiso 11 calc $R$. . C16 C 0.5644 (3) 0.7428 (3) 0.4556 (2) 0.0359 (8) Uani $11 \mathrm{~d} \ldots$ H16 H 0.57470 .74810 .52140 .043 Uiso 11 calc R . . C17 C $0.5743(4) 0.6223(4) 0.4130$ (3) $0.0627(13)$ Uani $11 \mathrm{~d} \ldots$ H17A H 0.50530 .56070 .43460 .094 Uiso 11 calc R . . H17B H 0.66330 .61400 .42810 .094 Uiso 11 calc R . . H17C H 0.56050 .61390 .34840 .094 Uiso 11 calc $R$. . C18 C 0.6752 (4) 0.8413 (4) 0.4286(3) 0.0605 (12) Uani $11 \mathrm{~d} \ldots$ H18A H 0.66560 .83880 .36440 .091 Uiso 11 calc $R$. . H18B H 0.76280 .83060 .44460 .091 Uiso 11 calc R . . H18C H 0.66860 .91820 .45940 .091 Uiso 11 cale $R$. . C19 C $0.4990(3) 0.8237(3) 0.1133(2) 0.0333(8)$ Uani $11 \mathrm{~d} \ldots$ H19 H 0.50240 .88180 .07200 .040 Uiso 11 calc R . . C20 C 0.4552 (4) 0.6992 (4) 0.0601 (3) 0.0528 (11) Uani $11 \mathrm{~d} \ldots$ H20A H 0.45530 .64140 .09950 .079 Uiso 11 calc R . . H20B H 0.51760 .69150 .01370 .079 Uiso 11 calc $R$. . $\mathrm{H} 20 \mathrm{CH} 0.36450 .68440 .03280 .079$ Uiso 11 calc R . . C21 C $0.6377(4) 0.8470$ (4) 0.1579 (3) 0.0534 (11) Uani $11 \mathrm{~d} \ldots$ H21A H 0.66540 .92780 .19140 .080 Uiso 11 calc R . . H21B H 0.70160 .83800 .11280 .080 Uiso 11 calc $R$. . H21C H 0.63590 .79020 .19840 .080 Uiso 11 calc R . . C22 C 0.3150 (3) $0.8996(3) 0.16691(19) 0.0234(6)$ Uani $11 \mathrm{~d}$... 
C23 C 0.4812 (3) 1.0815 (3) 0.1370 (2) 0.0418 (9) Uani $11 \mathrm{~d} \ldots$

H23A H 0.53571 .06130 .18220 .063 Uiso 11 calc $R$. .

H23B H 0.47361 .16220 .15560 .063 Uiso 11 calc R . .

H23C H 0.52401 .07710 .08050 .063 Uiso 11 calc R . .

C24 C 0.2522 (4) 1.0311 (3) 0.0710 (2) 0.0400 (9) Uani $11 \mathrm{~d} \ldots$

H24A H 0.16670 .96900 .06450 .060 Uiso 11 calc $R$. .

H24B H 0.28661 .03920 .01250 .060 Uiso 11 calc R . .

H24C H 0.23821 .10650 .09910 .060 Uiso 11 calc R . .

C25 C 0.1274(3) 0.9549(3) 0.2411 (2) 0.0348 (8) Uani $11 \mathrm{~d} \ldots$

$\mathrm{H} 25 \mathrm{H} 0.17371 .03440 .22620 .042$ Uiso 11 calc R. .

C26 C 0.1413(4) 0.9600 (4) 0.3409(2) 0.0505(10) Uani $11 \mathrm{~d} \ldots$

H26A H 0.09540 .88250 .35580 .076 Uiso 11 calc R . .

H26B H 0.10081 .02020 .37070 .076 Uiso 11 calc R . .

$\mathrm{H} 26 \mathrm{CH} 0.23660 .98070 .36060 .076$ Uiso 11 calc R . .

C27 C $-0.0198(3) 0.9224(3) 0.2099(3) 0.0482(10)$ Uani $11 \mathrm{~d} \ldots$

H27A H -0.02800 .92140 .14580 .072 Uiso 11 calc R . .

H27B H -0.06160 .98100 .24060 .072 Uiso 11 calc R . .

$\mathrm{H} 27 \mathrm{CH}-0.06510 .84370 .22310 .072$ Uiso 11 calc $R$. .

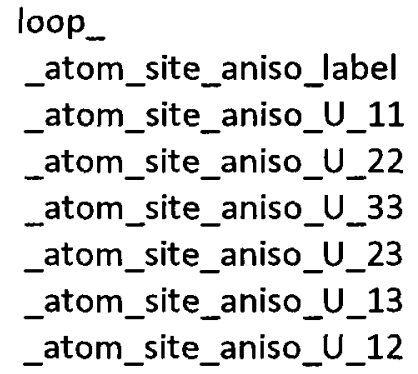




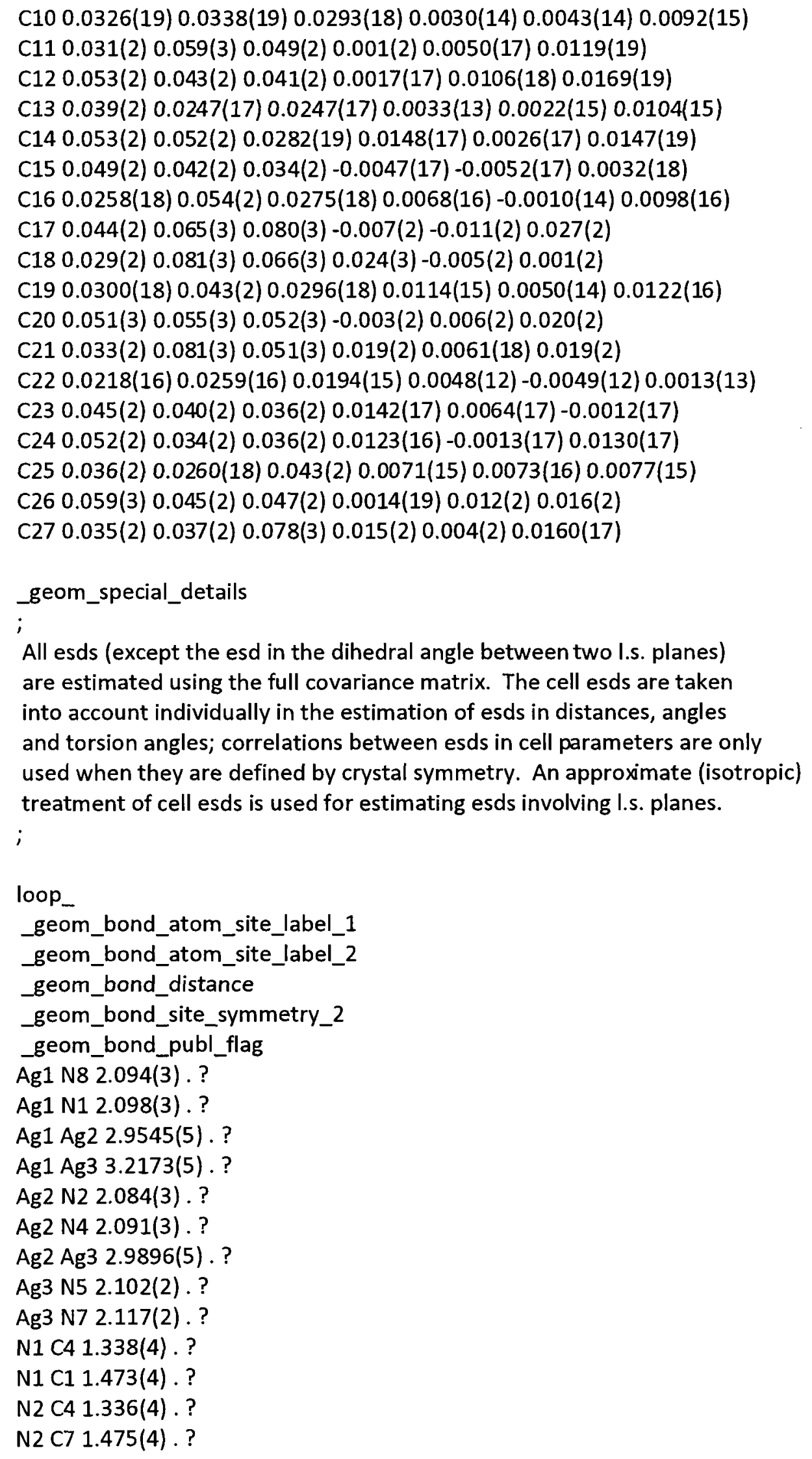




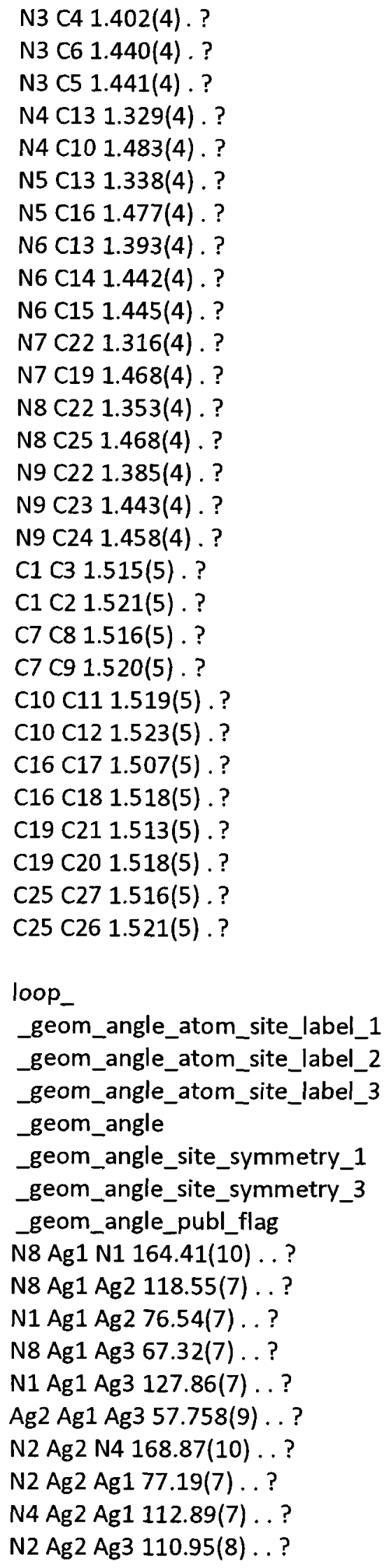




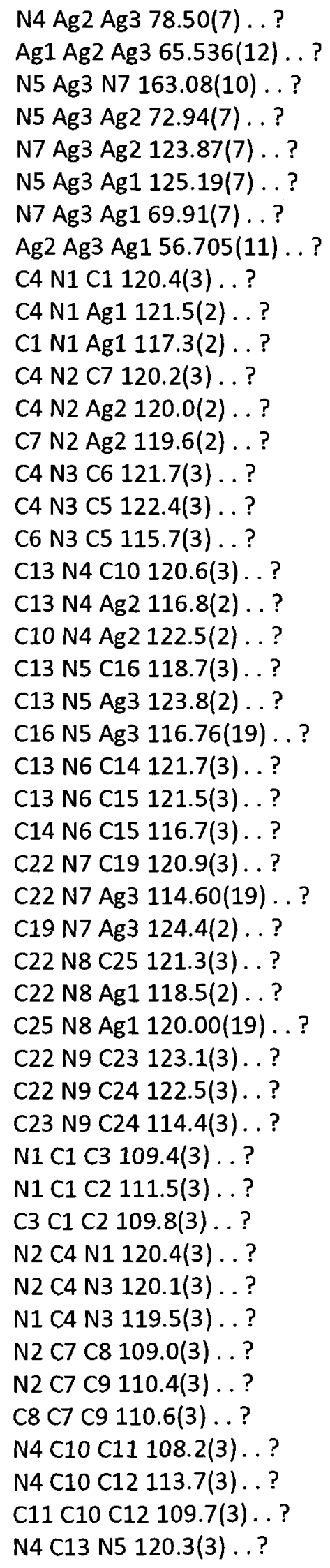


N4 C13 N6 120.7(3) . .?

N5 C13 N6 119.0(3) .. ?

N5 C16 C17 109.3(3) . . ?

N5 C16 C18 111.5(3) . . ?

C17 C16 C18 111.4(3) . . ?

N7 C19 C21 111.0(3). . ?

N7 C19 C20 109.6(3) . ?

C21 C19 C20 110.2(3) . . ?

N7 C22 N8 118.8(3) .. ?

N7 C22 N9 121.9(3) . . ?

N8 C22 N9 119.2(3) .. ?

N8 C25 C27 110.7(3) . . ?

N8 C25 C26 108.5(3) . . ?

C27 C25 C26 109.9(3) . . ?

loop_

_geom_torsion_atom_site_label_1

_geom_torsion_atom_site_label_2

_geom_torsion_atom_site_label_3

_geom_torsion_atom_site_label_4

_geom_torsion

_geom_torsion_site_symmetry_1

_geom_torsion_site_symmetry_2

_geom_torsion_site_symmetry_3

_geom_torsion_site_symmetry_4

_geom_torsion_publ_flag

N8 Ag1 Ag2 N2 -150.86(11) ... ?

N1 Ag1 Ag2 N2 33.35(11) ....?

Ag3 Ag1 Ag2 N2 -120.42(8) ... . ?

N8 Ag1 Ag2 N4 34.09(11) ... . ?

N1 Ag1 Ag2 N4 -141.70(11) ... . ?

Ag3 Ag1 Ag2 N4 64.54(8) ... ?

N8 Ag1 Ag2 Ag3 -30.44(8) .... ?

N1 Ag1 Ag2 Ag3 153.76(7) ....?

N2 Ag2 Ag3 N5 -138.47(11) ... ?

N4 Ag2 Ag3 N5 35.39(10) ... ?

Ag1 Ag2 Ag3 N5 157.31(8) ... . ?

N2 Ag2 Ag3 N7 43.58(12) ... ?

N4 Ag2 Ag3 N7 -142.55(11) ... ? ?

Ag1 Ag2 Ag3 N7 -20.63(9) ... . ?

N2 Ag2 Ag3 Ag1 64.21(8) ... . ?

N4 Ag2 Ag3 Ag1 -121.92(7) ... . ?

N8 Ag1 Ag3 N5 124.34(12) . . . ?

N1 Ag1 Ag3 N5 -59.81(13) . . . ?

Ag2 Ag1 Ag3 N5 -26.82(9) ... ? ?

N8 Ag1 Ag3 N7 -46.99(11) ... . ?

N1 Ag1 Ag3 N7 128.86(12) ... . ?

Ag2 Ag1 Ag3 N7 161.85(8) .... ? 


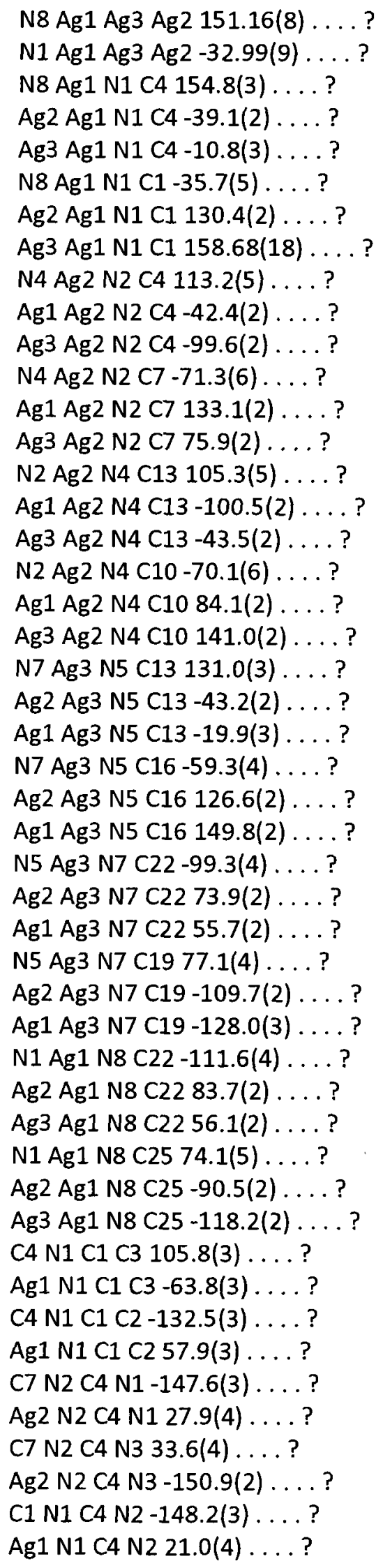




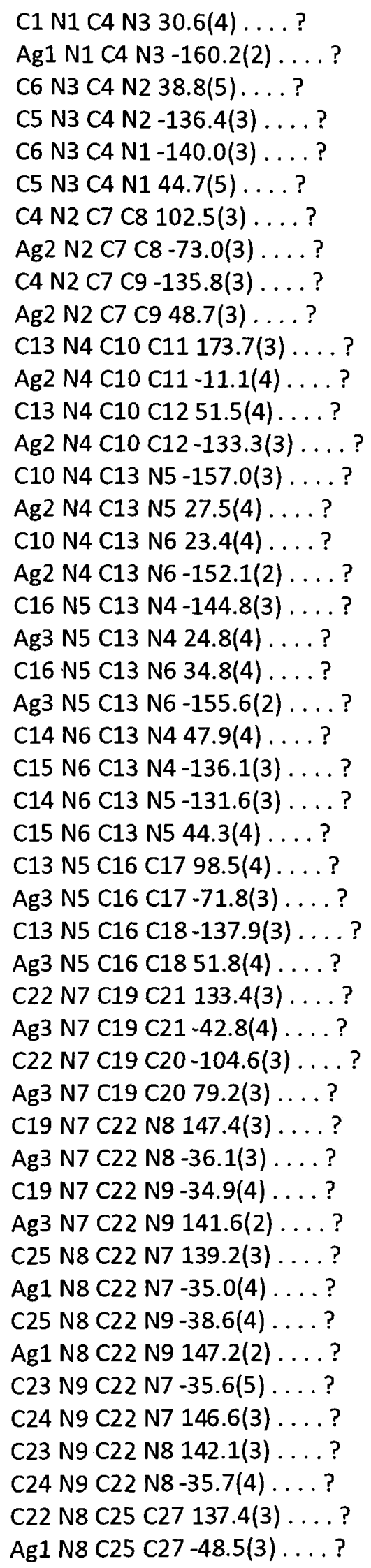


C22 N8 C25 C26-101.9(3) ... ?

Ag1 N8 C25 C26 72.1(3) ... . ?

_diffrn_measured_fraction_theta_max 0.991

_diffrn_refins_theta_full 25.00

_diffrn_measured_fraction_theta_full 1.000

_refine_diff_density_max 1.164

_refine_diff_density_min -0.461

_refine_diff_density_rms 0.102 


\section{Compound 14}

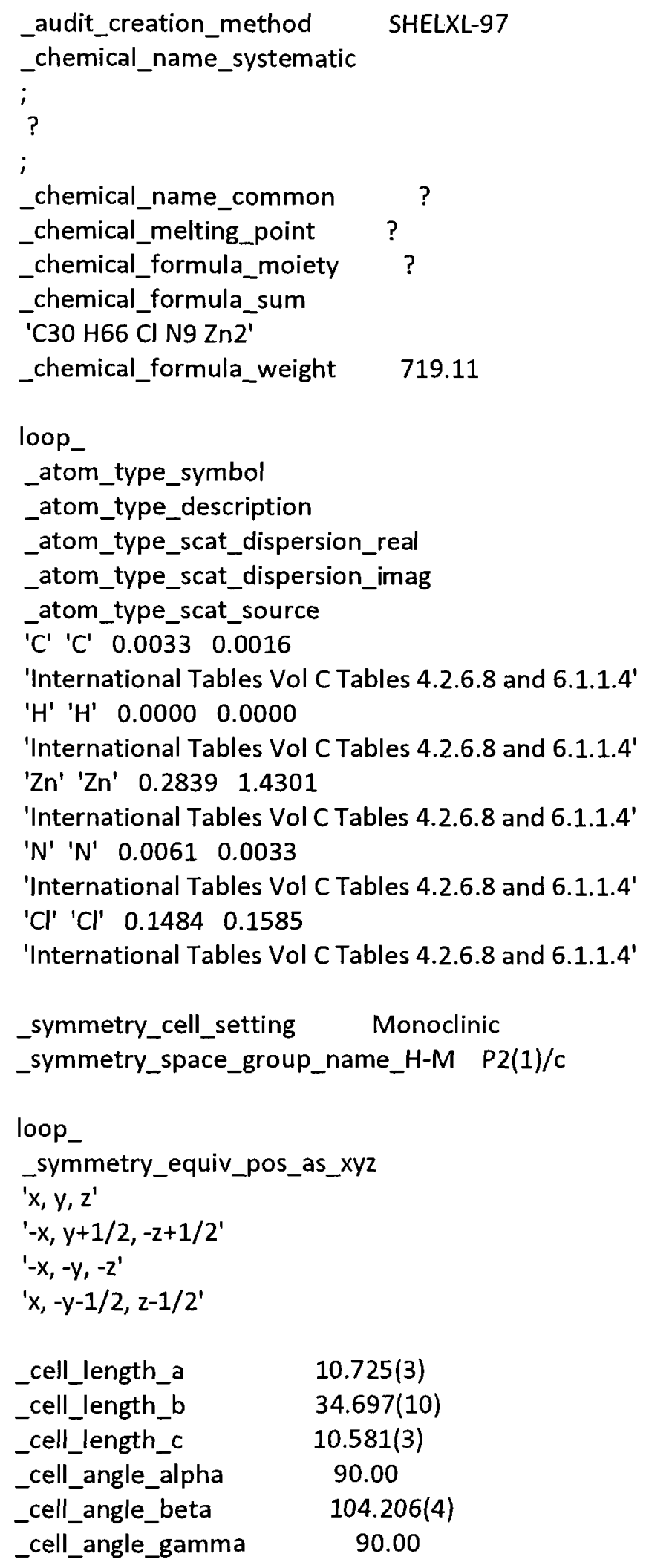




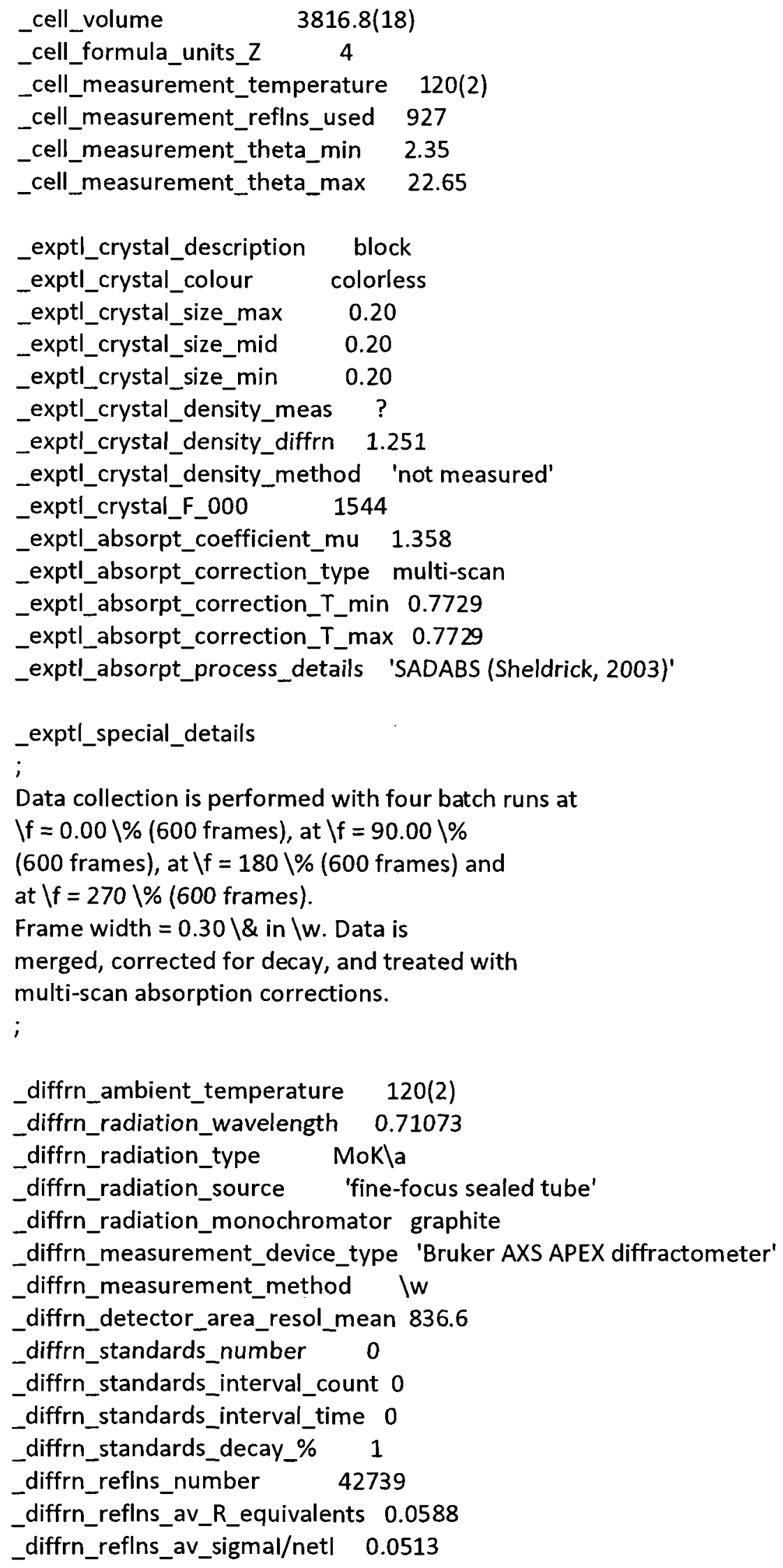




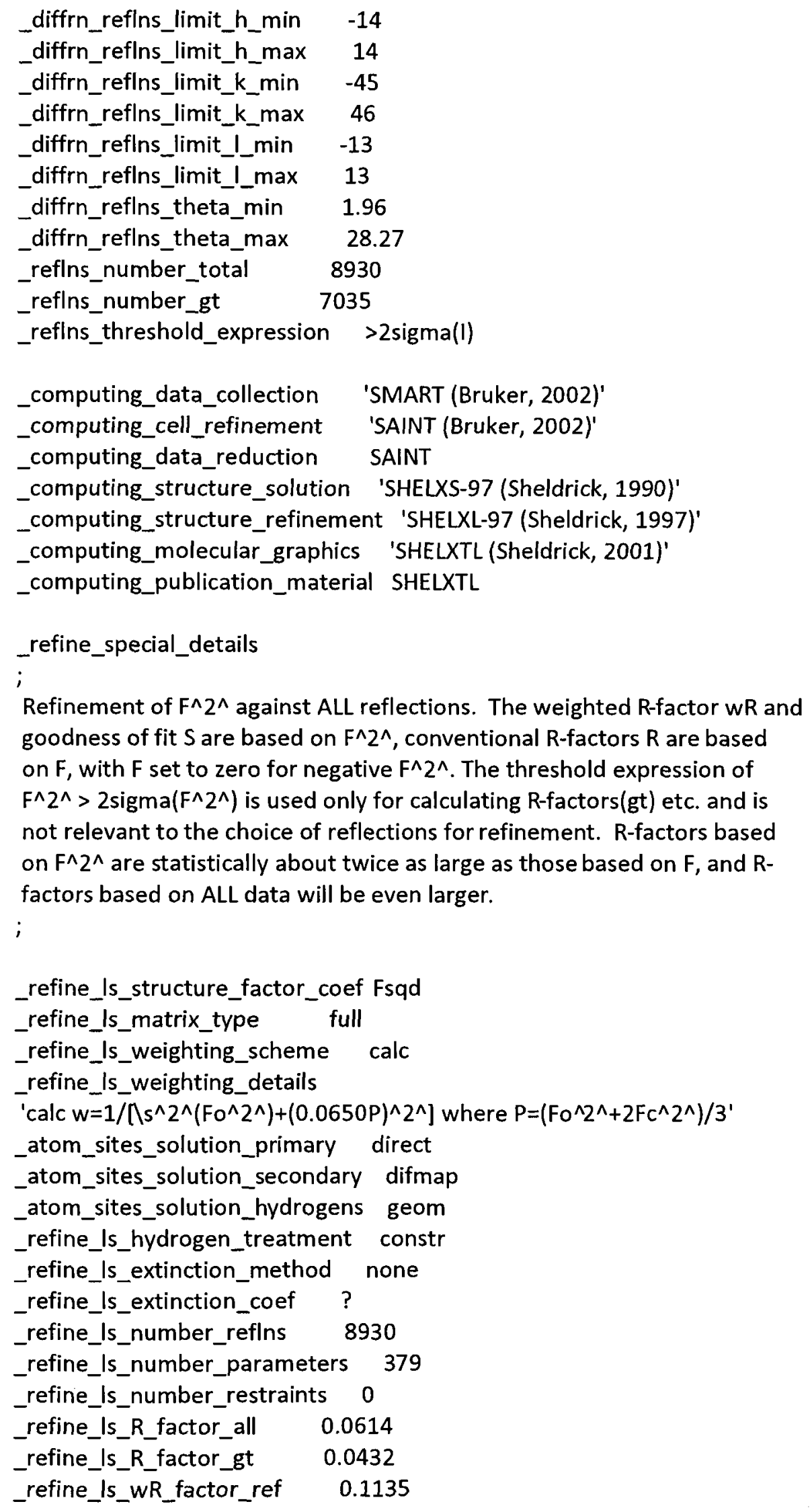
goodness of fit $S$ are based on $F^{\wedge} 2^{\wedge}$, conventional $R$-factors $R$ are based on $F$, with $F$ set to zero for negative $F^{\wedge} 2^{\wedge}$. The threshold expression of $F^{\wedge} 2^{\wedge}>2 \operatorname{sigma}\left(F^{\wedge} 2^{\wedge}\right)$ is used only for calculating R-factors(gt) etc. and is not relevant to the choice of reflections for refinement. R-factors based on $\mathrm{F}^{\wedge} 2^{\wedge}$ are statistically about twice as large as those based on $\mathrm{F}$, and $\mathrm{R}$ factors based on ALL data will be even larger. 


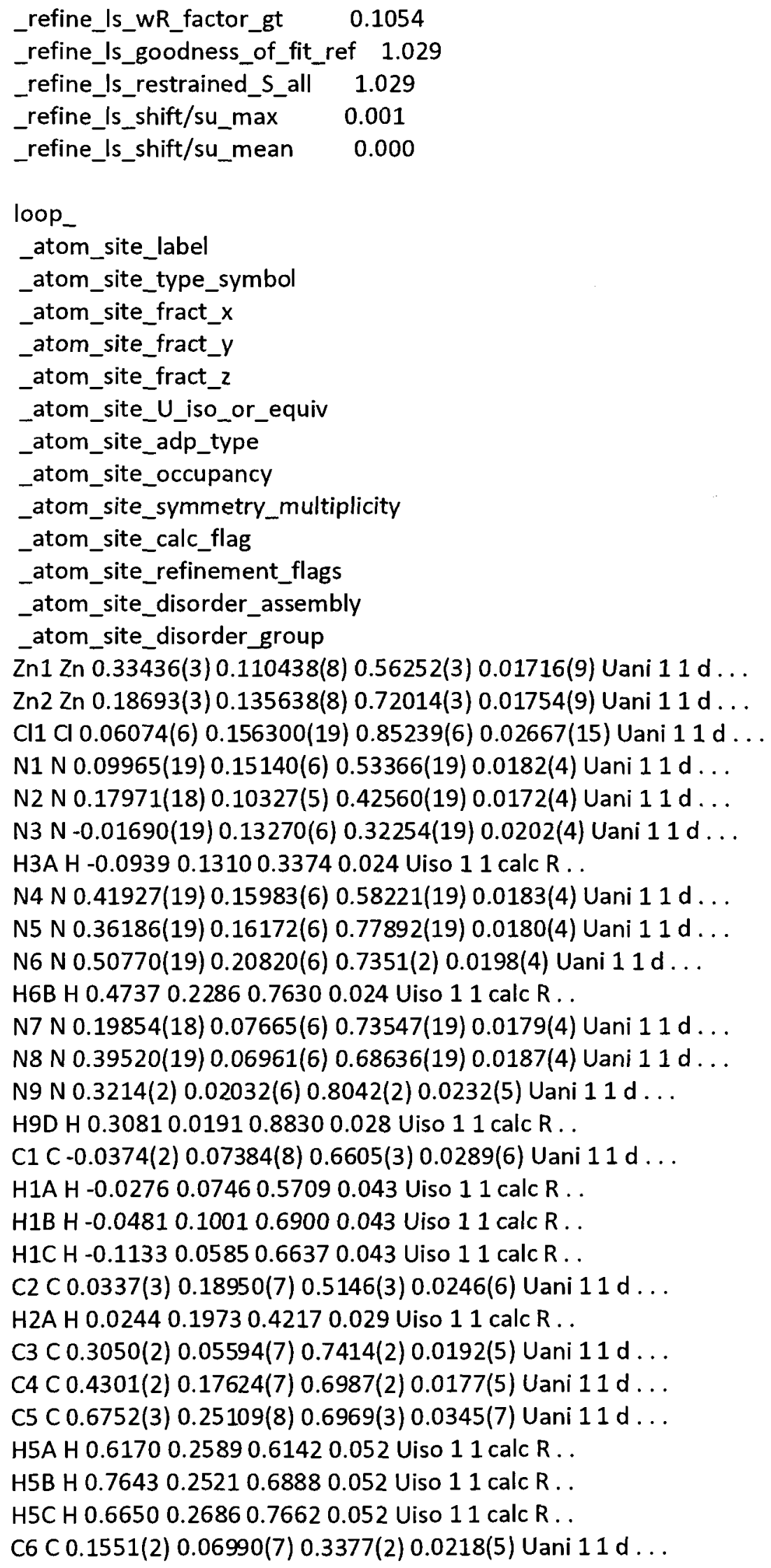


H6A H 0.07070 .07360 .27290 .026 Uiso 11 calc R . .

C7 C $0.5304(2) 0.05766(7) 0.7281(3) 0.0236(5)$ Uani $11 \mathrm{~d} \ldots$ H7A H 0.53710 .03500 .78770 .028 Uiso 11 calc R . .

C8 C 0.0692 (3) $0.05453(8) 0.8907(3) 0.0352$ (7) Uani $11 \mathrm{~d} \ldots$ H8A H 0.14670 .04290 .94640 .053 Uiso 11 calc R . . H8B H -0.00610 .03910 .89530 .053 Uiso 11 calc R . . H8C H 0.05910 .08080 .92080 .053 Uiso 11 calc R. . C9 C $0.2426(3)-0.03877(8) 0.6797(3) 0.0330(7)$ Uani $11 \mathrm{~d} \ldots$ H9A H $0.1879-0.02310 .61080 .050$ Uiso 11 calc R . . H9B H $0.1937-0.04640 .74270 .050$ Uiso 11 calc R . . H9C H $0.2708-0.06190 .64120 .050$ Uiso 11 calc $R$. . C10 C $0.0886(2) 0.12928$ (7) 0.4279 (2) 0.0184 (5) Uani $11 \mathrm{~d} \ldots$ C11 C $0.6433(2) 0.21021$ (7) 0.7302 (2) 0.0222 (5) Uani $11 \mathrm{~d} \ldots$ H11A H 0.65570 .19270 .65920 .027 Uiso 11 calc R . .

C12 C $0.3305(3) 0.18889(8) 0.3653(2) 0.0275(6)$ Uani $11 \mathrm{~d} \ldots$ H12A H 0.27220 .20490 .40120 .041 Uiso 11 calc $R$. . H12B H 0.28760 .16470 .33260 .041 Uiso 11 calc $R$. . $\mathrm{H} 12 \mathrm{CH} 0.35400 .20270 .29360 .041$ Uiso 11 calc $\mathrm{R}$. . C13 C $0.2607(3) 0.06662(8) 0.2654$ (3) $0.0314(6)$ Uani $11 \mathrm{~d} \ldots$ H13A H 0.26290 .09020 .21480 .047 Uiso 11 calc R . . H13B H 0.24360 .04440 .20640 .047 Uiso 11 calc R. . $\mathrm{H} 13 \mathrm{C} \mathrm{H} 0.34380 .06320 .32830 .047$ Uiso 11 calc R . . C14 C 0.6145(2) $0.09005(8) 0.7997(3) 0.0288(6)$ Uani $11 \mathrm{~d} \ldots$ H14A H 0.58450 .09750 .87650 .043 Uiso 11 calc $R$. . H14B H 0.60940 .11230 .74150 .043 Uiso 11 calc $R$. . $\mathrm{H} 14 \mathrm{C}$ H 0.70390 .08120 .82720 .043 Uiso 11 calc $\mathrm{R}$. . C15 C 0.5784(3) 0.04612(9) 0.6100(3) 0.0356(7) Uani $11 \mathrm{~d} \ldots$ H15A H 0.52500 .02510 .56370 .053 Uiso 11 calc R . . H15B H 0.66790 .03750 .63830 .053 Uiso 11 calc R. . $\mathrm{H} 15 \mathrm{CH} 0.57320 .06830 .55170 .053$ Uiso 11 calc $R$. . C16 C $0.3593(3)-0.01540$ (7) $0.7486(3) 0.0250(6)$ Uani $11 \mathrm{~d} \ldots$ H16A H $0.4089-0.00830 .68340 .030$ Uiso 11 calc $R$. . C17 C 0.4512 (2) 0.18031 (7) 0.4715 (2) 0.0218 (5) Uani $11 \mathrm{~d} \ldots$ H17A H 0.49460 .20520 .50370 .026 Uiso 11 calc $R$. . C19 C $0.3878(3) 0.13413$ (7) 0.9993(2) 0.0272(6) Uani $11 \mathrm{~d}$... H19A H 0.42630 .11120 .96990 .041 Uiso 11 calc $R$. . H19B H 0.29510 .13020 .98630 .041 Uiso 11 calc R. . $\mathrm{H} 19 \mathrm{C} \mathrm{H} 0.42700 .13851 .09200 .041$ Uiso 11 calc R . . C20 C - 0.0109 (3) 0.18185 (7) $0.1558(2) 0.0270$ (6) Uani $11 \mathrm{~d} \ldots$ H2OA H 0.06080 .19470 .21640 .040 Uiso 11 calc R . . H2OB H -0.09240 .19300 .16440 .040 Uiso 11 calc $R$. . $\mathrm{H} 2 \mathrm{OC} \mathrm{H}-0.00280 .18540 .06630 .040$ Uiso 11 calc $R$. . C21 C - 0.1003 (3) 0.18834 (9) 0.5389(3) 0.0368(7) Uani $11 \mathrm{~d}$... H21A H -0.15230 .16900 .48210 .055 Uiso 11 calc $R$. . H21B H -0.14090 .21370 .52000 .055 Uiso 11 calc $R$. . $\mathrm{H} 21 \mathrm{CH}-0.09400 .18160 .63020 .055$ Uiso 11 calc $R$. . C22 C 0.5438(3) $0.15553(8) 0.4176(3) 0.0302(6)$ Uani $11 \mathrm{~d} \ldots$ H22A H 0.62110 .15030 .48690 .045 Uiso 11 calc $R$. . 
H22B H 0.56780 .16920 .34610 .045 Uiso 11 calc $R$. . H22C H 0.50190 .13110 .38510 .045 Uiso 11 calc R . .

C23 C 0.4116 (2) 0.16924 (7) 0.9205 (2) 0.0209 (5) Uani $11 \mathrm{~d} \ldots$ H23A H 0.50660 .17320 .93790 .025 Uiso 11 calc $R$. .

C24 C 0.1496(3) 0.03287 (7) 0.4148 (3) 0.0270 (6) Uani $11 \mathrm{~d} \ldots$ H24A H 0.08040 .03490 .46010 .040 Uiso 11 calc R . . H24B H 0.23190 .02920 .47880 .040 Uiso 11 calc R . . H24C H 0.13310 .01090 .35490 .040 Uiso 11 calc R . .

C25 C 0.4462 (3) -0.03907 (8) 0.8560 (3) 0.0374 (7) Uani $11 \mathrm{~d}$. . . H25A H $0.5216-0.02370 .89820 .056$ Uiso 11 calc $R$. . H25B H $0.4740-0.06240 .81830 .056$ Uiso 11 calc R . . H25C H $0.3988-0.04630 .92070 .056$ Uiso 11 calc $R$. . C26 C $0.1161(3) 0.21983$ (7) $0.6006(3) 0.0312(6)$ Uani $11 \mathrm{~d} \ldots$ H26A H 0.20140 .22050 .58240 .047 Uiso 11 calc $R$. . H26B H 0.12490 .21330 .69240 .047 Uiso 11 calc R. . H26CH 0.07520 .24510 .58210 .047 Uiso 11 calc R . . C27 C - $0.0086(2) 0.13900$ (7) $0.1873(2) 0.0209(5)$ Uani $11 \mathrm{~d} \ldots$ H27A H 0.07460 .12800 .17710 .025 Uiso 11 calc $R$. . C28 C $0.0817(2) 0.05578$ (7) $0.7492(3) 0.0250$ (6) Uani $11 \mathrm{~d} \ldots$ H28A H 0.08800 .02860 .71970 .030 Uiso 11 calc R . . C29 C 0.7329(2) 0.19725(8) 0.8571(3) 0.0302(6) Uani $11 \mathrm{~d}$. . H29A H 0.71100 .17090 .87690 .045 Uiso 11 calc R . . H29B H 0.72380 .21450 .92760 .045 Uiso 11 calc $R$. . H29C H 0.82190 .19800 .84890 .045 Uiso 11 calc R . . C50 C 0.3528 (3) 0.20538 (7) 0.9662 (3) 0.0280 (6) Uani $11 \mathrm{~d} \ldots$ H5OA H 0.36880 .22770 .91560 .042 Uiso 11 calc $R$. . H50B H 0.39230 .20981 .05890 .042 Uiso 11 calc $R$. . H50C H 0.25990 .20180 .95340 .042 Uiso 11 calc $R$. .

C51 C $-0.1184(3) 0.11802(8) 0.0937(2) 0.0284(6)$ Uani $11 \mathrm{~d} .$. H51A H - 0.11520 .09060 .11590 .043 Uiso 11 calc $R$. . H51B H - 0.10970 .12120 .00420 .043 Uiso 11 calc $R$. . H51C H - 0.2007 0.1289 0.1009 0.043 Uiso 11 calc R . .

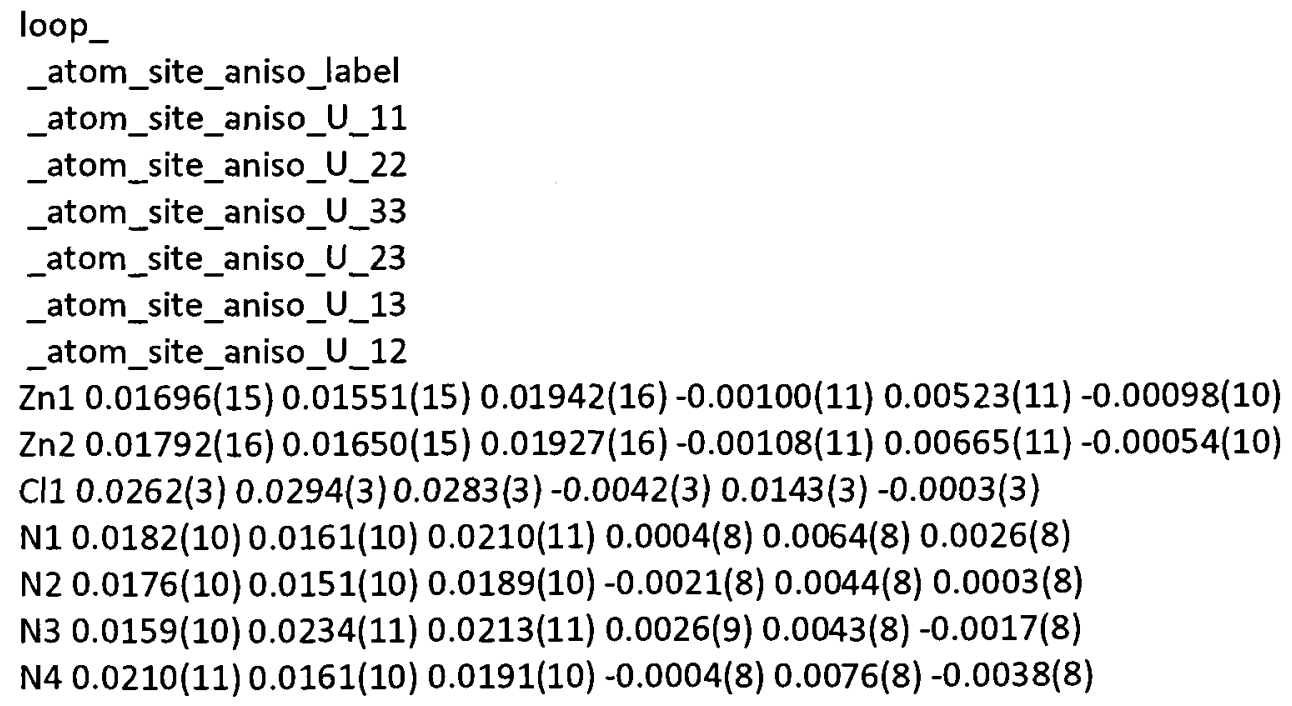


N5 $0.0183(10) 0.0169(10) 0.0197(10)-0.0029(8) 0.0061(8)-0.0008(8)$ N6 $0.0188(11) 0.0139(10) 0.0277(11)-0.0026(8) 0.0075(9)-0.0013(8)$ N7 $0.0153(10) 0.0175(10) 0.0214(11)-0.0020(8) 0.0053(8)-0.0027(8)$ N8 $0.0170(10) 0.0160(10) 0.0226(11) 0.0009(8) 0.0039(8) 0.0003(8)$ N9 $0.0298(12) 0.0183(11) 0.0223(11) 0.0032(9) 0.0081(9) 0.0027(9)$ C1 $0.0207(14) 0.0243(14) 0.0425(17)-0.0027(12) 0.0091(12)-0.0051(11)$ C2 $0.0294(14) 0.0197(13) 0.0251$ (13) $0.0028(10) 0.0075$ (11) $0.0096(11)$ C3 $0.0223(13) 0.0175(12) 0.0169(12)-0.0021(9) 0.0033(10)-0.0030(9)$ C4 0.0151 (11) $0.0152(11) 0.0218(12) 0.0021$ (9) 0.0024 (9) $0.0019(9)$ C5 $0.0264(15) 0.0272(15) 0.0500$ (19) 0.0040 (13) $0.0099(13)-0.0065(12)$ C6 $0.0244(13) 0.0188(12) 0.0212(13)-0.0043(10) 0.0035(10)-0.0014(10)$ C7 $0.0196(13) 0.0187(13) 0.0308(14) 0.0007(11) 0.0032(11) 0.0013(10)$ C8 0.0411 (18) $0.0310(16) 0.0400$ (17) $0.0057(13) 0.0221(14)-0.0027(13)$ C9 $0.0383(17) 0.0215(14) 0.0383(16) 0.0007(12) 0.0076(13)-0.0045(12)$ C10 0.0178(12) $0.0176(12) 0.0201(12) 0.0023(10) 0.0053(10)-0.0021(9)$ C11 $0.0199(13) 0.0224(13) 0.0262(13)-0.0036(10) 0.0093(10)-0.0036(10)$ C12 $0.0317(15) 0.0272$ (14) 0.0225 (13) $0.0034(11) 0.0049(11)-0.0061(11)$ C13 $0.0376(17) 0.0289(15) 0.0302(15)-0.0075(12) 0.0130(13) 0.0000(12)$ C14 0.0219(14) $0.0277(14) 0.0337(15)-0.0034(12) 0.0009(11)-0.0008(11)$ C15 0.0222(14) $0.0356(16) 0.0501(19)-0.0145(14) 0.0108(13)-0.0006(12)$ C16 0.0305(15) $0.0177(13) 0.0265(14) 0.0011$ (10) 0.0066 (11) $0.0008(10)$ C17 $0.0260(13) 0.0210(13) 0.0201(13)-0.0014(10) 0.0088(10)-0.0066(10)$ C19 0.0331 (15) $0.0284(15) 0.0190$ (13) 0.0020 (11) $0.0045(11)-0.0010(11)$ $\mathrm{C} 200.0369(16) 0.0222(13) 0.0221(13) 0.0018(11) 0.0076(12) 0.0023(11)$ C21 $0.0316(16) 0.0436(18) 0.0353(16)-0.0035(13) 0.0086(13) 0.0160(13)$ C22 0.0321(16) $0.0328(16) 0.0302(15)-0.0027(12) 0.0165(12)-0.0046(12)$ C23 $0.0230(13) 0.0213(13) 0.0188(12)-0.0014(10) 0.0060(10)-0.0031(10)$ C24 0.0285(15) $0.0185(13) 0.0321(15)-0.0040(11) 0.0041(12)-0.0011(10)$ C25 0.0439(18) 0.0230 (14) $0.0406(17) 0.0034(13) 0.0010$ (14) $0.0078(13)$ $\mathrm{C} 260.0443(17) 0.0160(13) 0.0336(15)-0.0006(11) 0.0106(13) 0.0056(12)$ C27 $0.0222(13) 0.0203(13) 0.0195(13) 0.0012(10) 0.0036(10) 0.0013(10)$ C28 0.0250(14) $0.0194(13) 0.0329$ (15) 0.0001 (11) $0.0114(11)-0.0053(10)$ C29 0.0209(14) $0.0366(16) 0.0323(15)-0.0015(13) 0.0047$ (11) $0.0010(12)$ C50 0.0341(16) 0.0255 (14) 0.0274(14) $-0.0075(11) 0.0133(12)-0.0063(11)$ C51 $0.0302(15) 0.0306(15) 0.0216(13) 0.0019(11) 0.0011(11)-0.0066(12)$

_geom_special_details

;

All esds (except the esd in the dihedral angle between two I.s. planes) are estimated using the full covariance matrix. The cell esds are taken into account individually in the estimation of esds in distances, angles and torsion angles; correlations between esds in cell parameters are only used when they are defined by crystal symmetry. An approximate (isotropic) treatment of cell esds is used for estimating esds involving l.s. planes.

;

loop_ _geom_bond_atom_site_label_1 


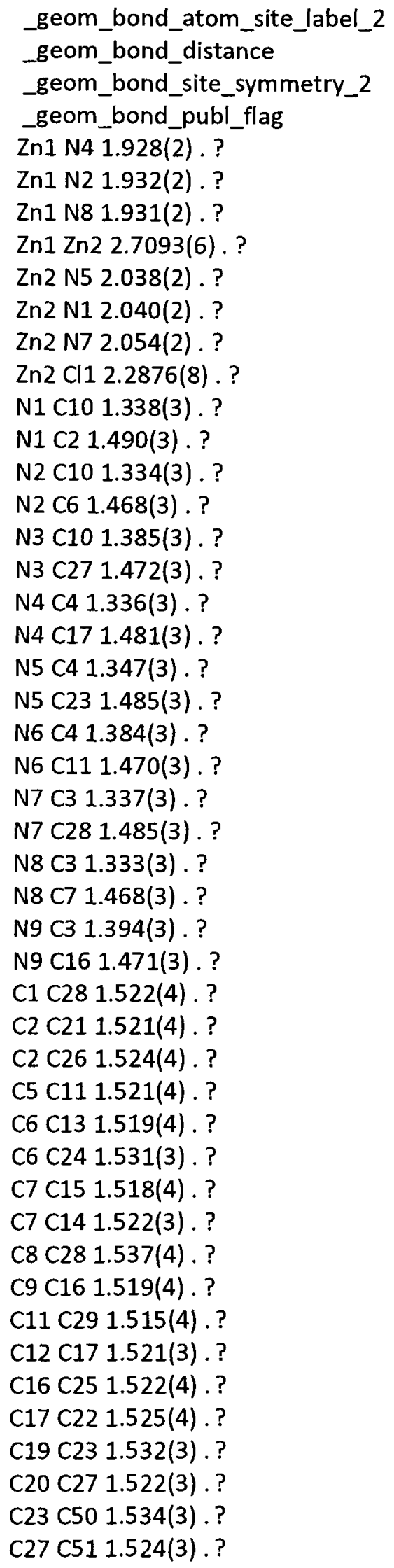




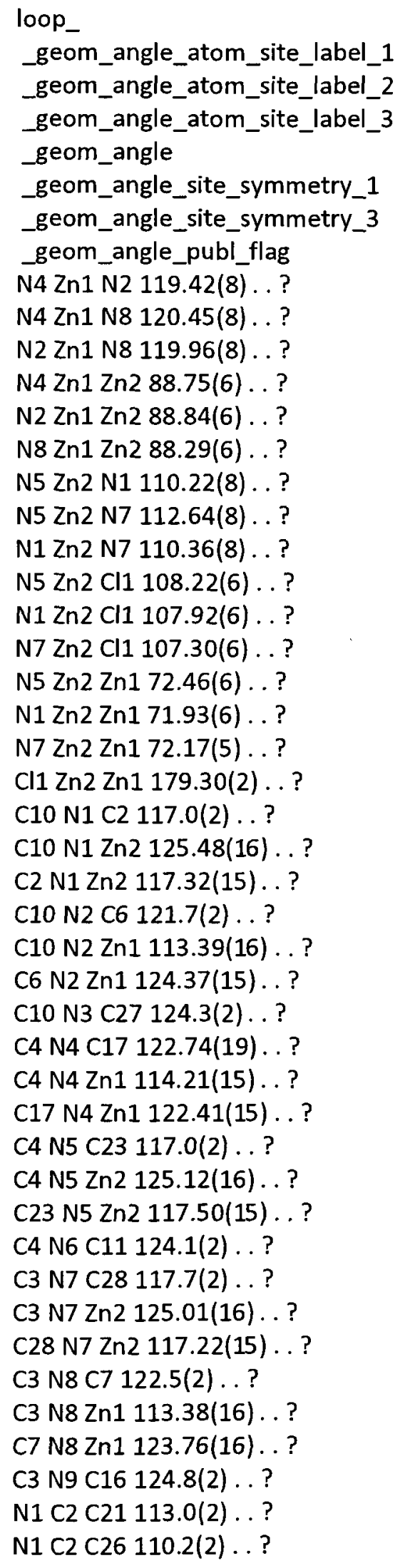




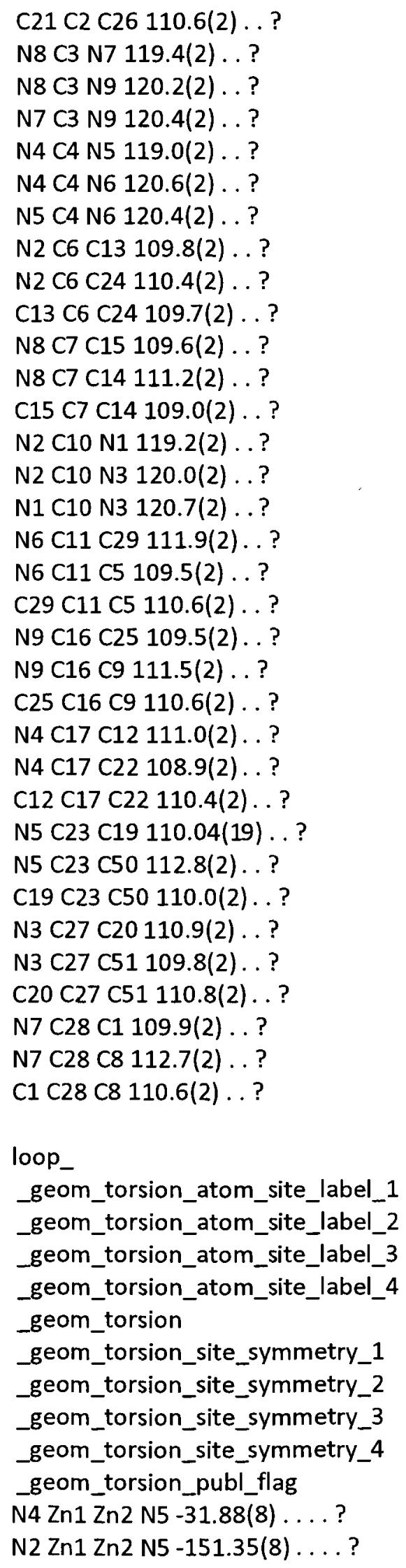


N8 Zn1 Zn2 N5 88.64(8) ... ? N4 Zn1 Zn2 N1 87.09(8) ....?

N2 Zn1 Zn2 N1 -32.37(8) ... ?

N8 Zn1 Zn2 N1 -152.39(8).... ?

N4 Zn1 Zn2 N7 -153.60(8) ... . ?

N2 Zn1 Zn2 N7 86.93(8) ... ?

N8 Zn1 Zn2 N7 -33.08(8) ... . ?

N4 Zn1 Zn2 Cl1 165(2) ... ?

N2 Zn1 Zn2 Cl1 45(2) ... ? ?

$\mathrm{N} 8 \mathrm{Zn} 1 \mathrm{Zn} 2 \mathrm{Cl} 1-75(2) \ldots$ ?

N5 Zn2 N1 C10 104.8(2)....?

N7 Zn2 N1 C10-20.2(2) ... ?

$\mathrm{Cl} 1 \mathrm{Zn} 2 \mathrm{~N} 1 \mathrm{C} 10-137.20(18) . .$. ?

Zn1 Zn2 N1 C10 42.08(18). ... ?

N5 Zn2 N1 C2 -80.32(18) ... . ?

N7 Zn2 N1 C2 154.63(16) . . . ?

Cl1 Zn2 N1 C2 37.66(18) ... . ?

Zn1 Zn2 N1 C2 -143.06(17) ... . ?

N4 Zn1 N2 C10 -54.04(19) ... . ?

N8 Zn1 N2 C10 121.22(17) ... . ?

Zn2 Zn1 N2 C10 33.86(16).... ?

N4 Zn1 N2 C6 133.95(18) ... . ?

N8 Zn1 N2 C6 $-50.8(2) \ldots$ ?

Zn2 Zn1 N2 C6 -138.14(18) ... . ?

N2 Zn1 N4 C4 120.98(17) . . . ?

N8 Zn1 N4 C4 -54.26(19) ... . ?

Zn2 Zn1 N4 C4 33.02(16).... ?

N2 Zn1 N4 C17 -50.1(2) ....?

N8 Zn1 N4 C17 134.69(17) ... . ?

Zn2 Zn1 N4 C17-138.03(18) ... ?

N1 Zn2 N5 C4 -20.8(2) ... ?

N7 Zn2 N5 C4 102.93(19) ... . ?

Cl1 Zn2 N5 C4 -138.61(17) ... . ?

Zn1 Zn2 N5 C4 41.60(17) .... ?

N1 Zn2 N5 C23 152.02(15) ... . ?

N7 Zn2 N5 C23-84.24(17).... ?

Cl1 Zn2 N5 C23 34.22(17) ... . ?

Zn1 Zn2 N5 C23-145.57(17) ... . ?

N5 Zn2 N7 C3 -20.6(2) ... ?

N1 Zn2 N7 C3 103.07(19) ... . ?

Cl1 Zn2 N7 C3 -139.58(18) ... . ?

Zn1 Zn2 N7 C3 40.91(18)... . ?

N5 Zn2 N7 C28 155.43(16) ... . ?

N1 Zn2 N7 C28-80.91(17)... . ?

Cl1 Zn2 N7 C28 36.43(17) .... ?

Zn1 Zn2 N7 C28 -143.07(17) . . . ?

N4 Zn1 N8 C3 123.98(17) ... . ?

N2 Zn1 N8 C3 $-51.23(19) \ldots$. . ? 


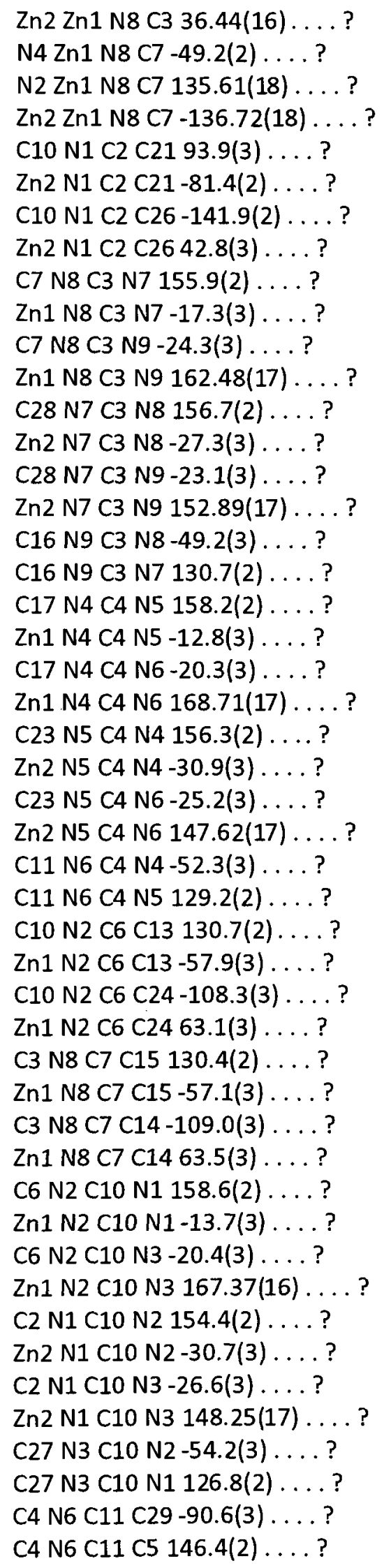




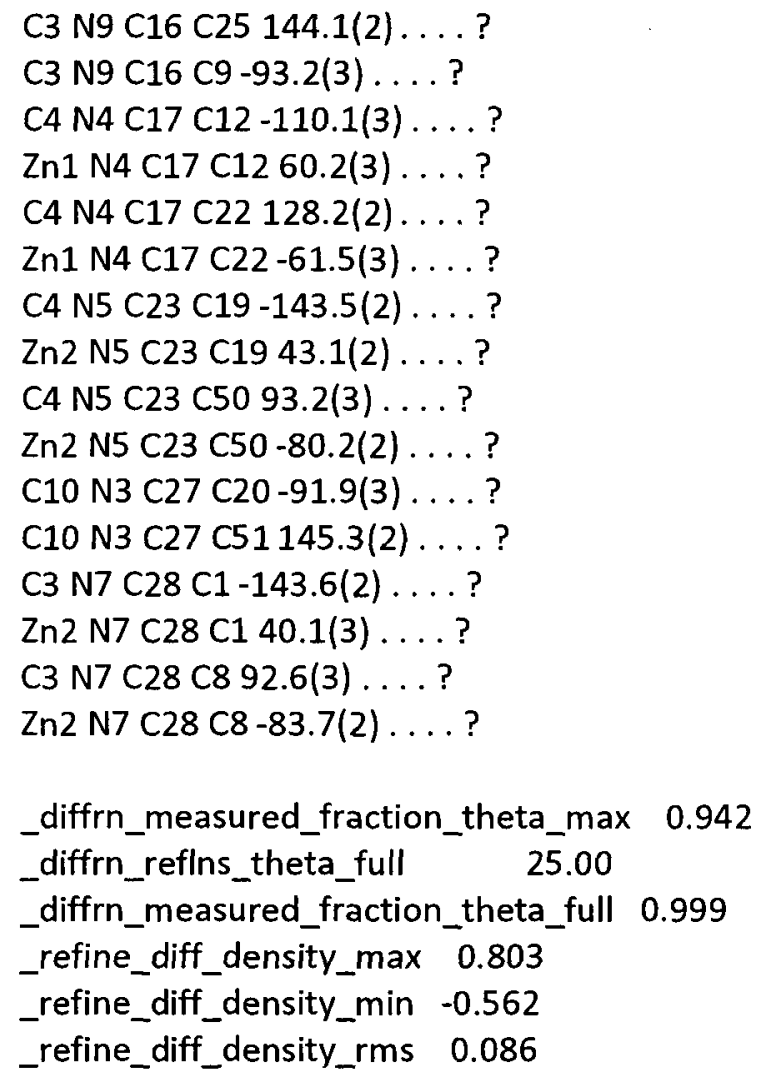




\section{Compound 16}

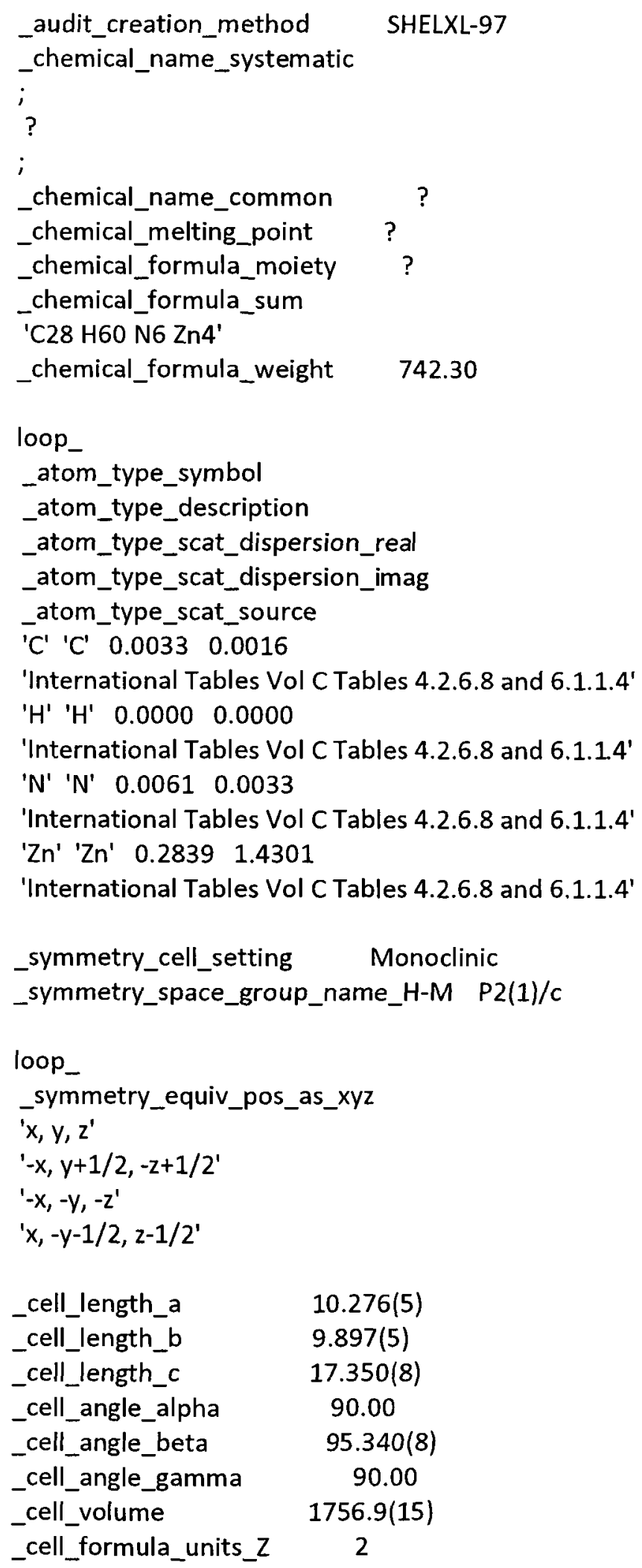




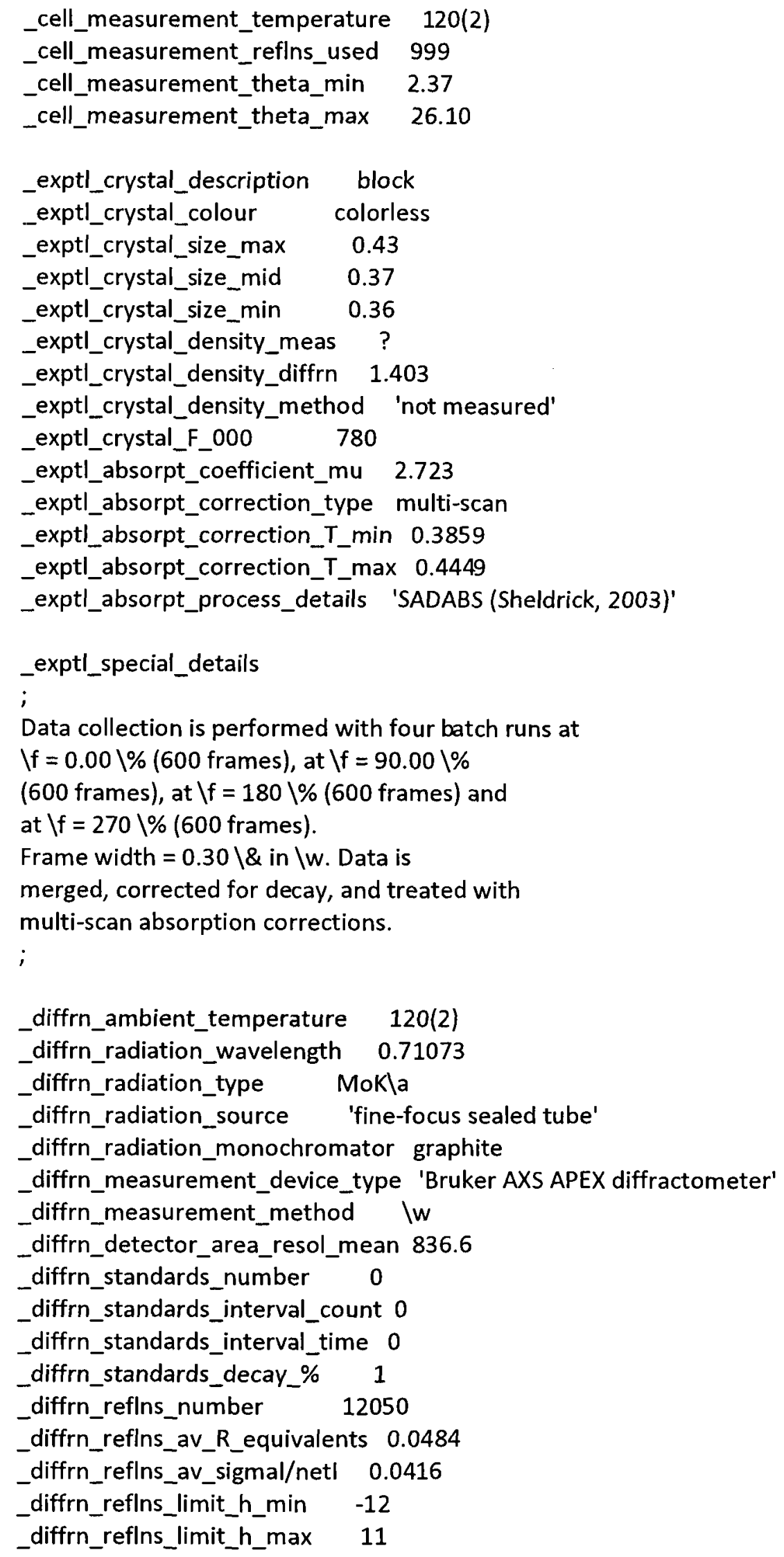




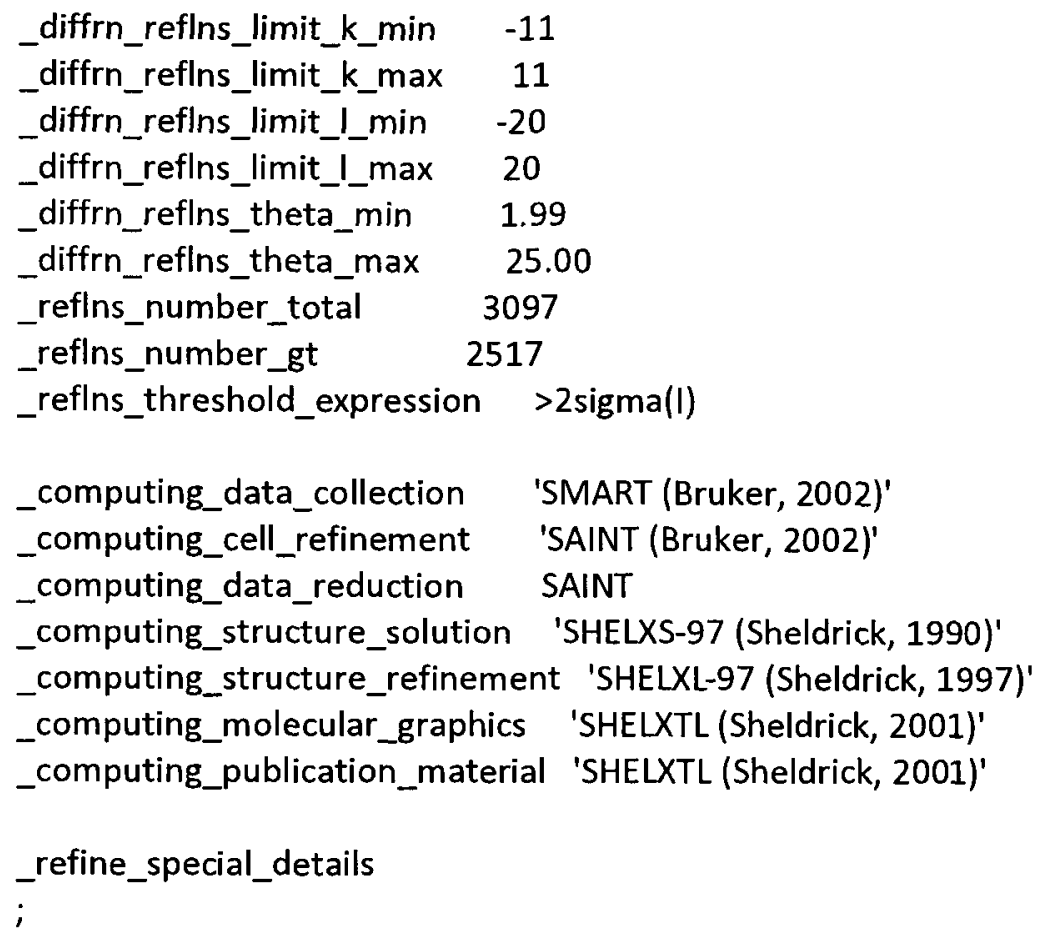

Refinement of $F^{\wedge} 2^{\wedge}$ against $A L L$ reflections. The weighted $R$-factor $W R$ and goodness of fit $S$ are based on $F^{\wedge} 2^{\wedge}$, conventional $R$-factors $R$ are based on $F$, with $F$ set to zero for negative $F^{\wedge} 2^{\wedge}$. The threshold expression of $\mathrm{F}^{\wedge} 2^{\wedge}>2 \operatorname{sigma}\left(\mathrm{F}^{\wedge} 2^{\wedge}\right)$ is used only for calculating $R$-factors $(\mathrm{gt})$ etc. and is not relevant to the choice of reflections for refinement. $R$-factors based on $\mathrm{F}^{\wedge} 2^{\wedge}$ are statistically about twice as large as those based on $F$, and $R-$ factors based on ALL data will be even larger. ;

_refine_Is_structure_factor_coef Fsqd

_refine_Is_matrix_type full

_refine_ls_weighting_scheme calc

_refine_ls_weighting_details

'calc $w=1 /\left[\backslash \mathrm{s}^{\wedge} 2^{\wedge}\left(F \mathrm{Fo}^{\wedge} 2^{\wedge}\right)+(0.0440 \mathrm{P})^{\wedge} 2^{\wedge}\right]$ where $\mathrm{P}=\left(\mathrm{Fo} \mathrm{O}^{\wedge}+2 \mathrm{Fc} \mathrm{c}^{\wedge} 2^{\wedge}\right) / 3^{\prime}$

_atom_sites_solution_primary direct

_atom_sites_solution_secondary difmap

_atom_sites_solution_hydrogens geom

_refine_Is_hydrogen_treatment constr

_refine_Is_extinction_method none

_refine_Is_extinction_coef ?

_refine_Is_number_reflns 3097

_refine_Is_number_parameters 262

_refine_Is_number_restraints 0

_refine_Is_R_factor_all $\quad 0.0412$

_refine_Is_R_factor_gt $\quad 0.0314$

_refine_Is_wR_factor_ref 0.0838

_refine_Is_wR_factor_gt $\quad 0.0778$

_refine_Is_goodness_of_fit_ref 1.037 


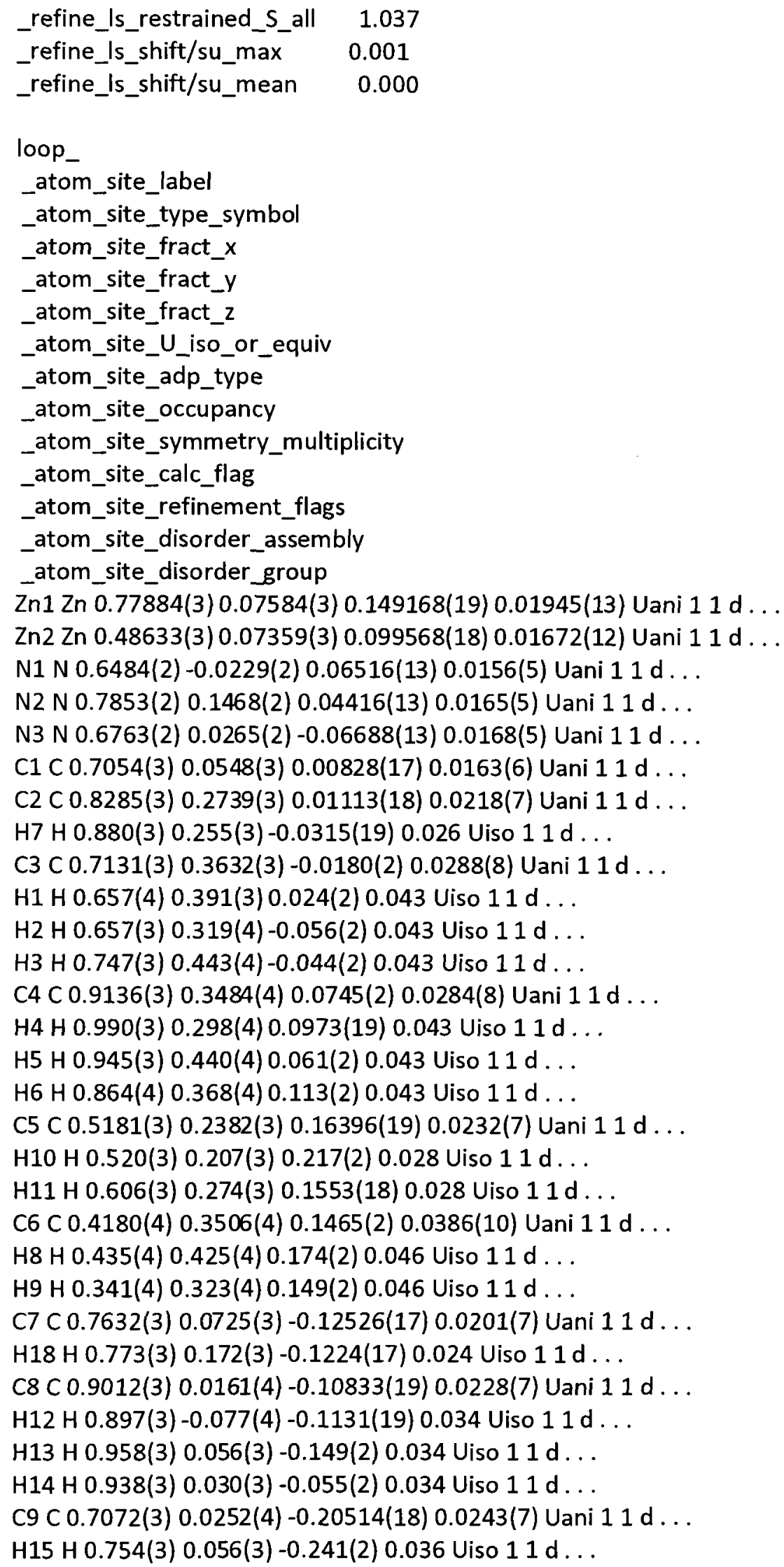


$\mathrm{H} 16 \mathrm{H} \mathrm{0.624(4)} \mathrm{0.066(3)}-0.218(2) 0.036$ Uiso $11 \mathrm{~d} \ldots$

$\mathrm{H} 17 \mathrm{H} 0.707(3)-0.073(4)-0.211(2) 0.036$ Uiso $11 \mathrm{~d} \ldots$

C10 C $0.6443(3)-0.1718(3) 0.05693(17) 0.0184(6)$ Uani $11 \mathrm{~d} \ldots$

$\mathrm{H} 25 \mathrm{H} 0.580$ (3) $-0.202(3) 0.0153(17) 0.022$ Uiso $11 \mathrm{~d} \ldots$

C11 C 0.6010 (3) $-0.2326(4) 0.13093(19) 0.0248(7)$ Uani $11 \mathrm{~d} \ldots$

$\mathrm{H} 19 \mathrm{H} 0.599(3)-0.327(4) 0.1264(18) 0.037$ Uiso $11 \mathrm{~d} \ldots$

$\mathrm{H} 20 \mathrm{H} 0.512(3)-0.200$ (3) $0.1384(18) 0.037$ Uiso $11 \mathrm{~d} \ldots$

$\mathrm{H} 21 \mathrm{H} 0.660$ (3) -0.209 (3) $0.172(2) 0.037$ Uiso $11 \mathrm{~d} \ldots$

C12 C $0.7767(3)-0.2303(3) 0.0413(2) 0.0262(7)$ Uani $11 \mathrm{~d} \ldots$

$\mathrm{H} 22 \mathrm{H} 0.804(3)-0.197(3)-0.008(2) 0.039$ Uiso $11 \mathrm{~d} \ldots$

$\mathrm{H} 23 \mathrm{H} 0.839$ (3) -0.209 (3) $0.086(2) 0.039$ Uiso $11 \mathrm{~d} \ldots$

H24 H 0.772(3) $-0.325(4) 0.0409$ (19) 0.039 Uiso $11 \mathrm{~d} \ldots$

C13 C 0.8408(3) 0.0649(4) $0.25877(19) 0.0286(8)$ Uani $11 \mathrm{~d} \ldots$

$\mathrm{H} 29 \mathrm{H} 0.765$ (3) 0.096 (3) 0.280 (2) 0.034 Uiso $11 \mathrm{~d} \ldots$

$\mathrm{H} 30 \mathrm{H} 0.850$ (3) -0.026 (4) 0.2700 (19) 0.034 Uiso $11 \mathrm{~d} \ldots$

C14 C 0.9608(3) $0.1483(4) 0.2853(2) 0.0316(8)$ Uani $11 \mathrm{~d} .$.

$\mathrm{H} 26 \mathrm{H} 1.036(4) 0.126(4) \quad 0.259$ (2) 0.047 Uiso $11 \mathrm{~d} \ldots$

$\mathrm{H} 27 \mathrm{H} 0.953(4) 0.242(4) 0.272(2) 0.047$ Uiso $11 \mathrm{~d} \ldots$

$\mathrm{H} 28 \mathrm{H} 0.983(3) 0.147(4) 0.341(2) 0.047$ Uiso $11 \mathrm{~d} \ldots$

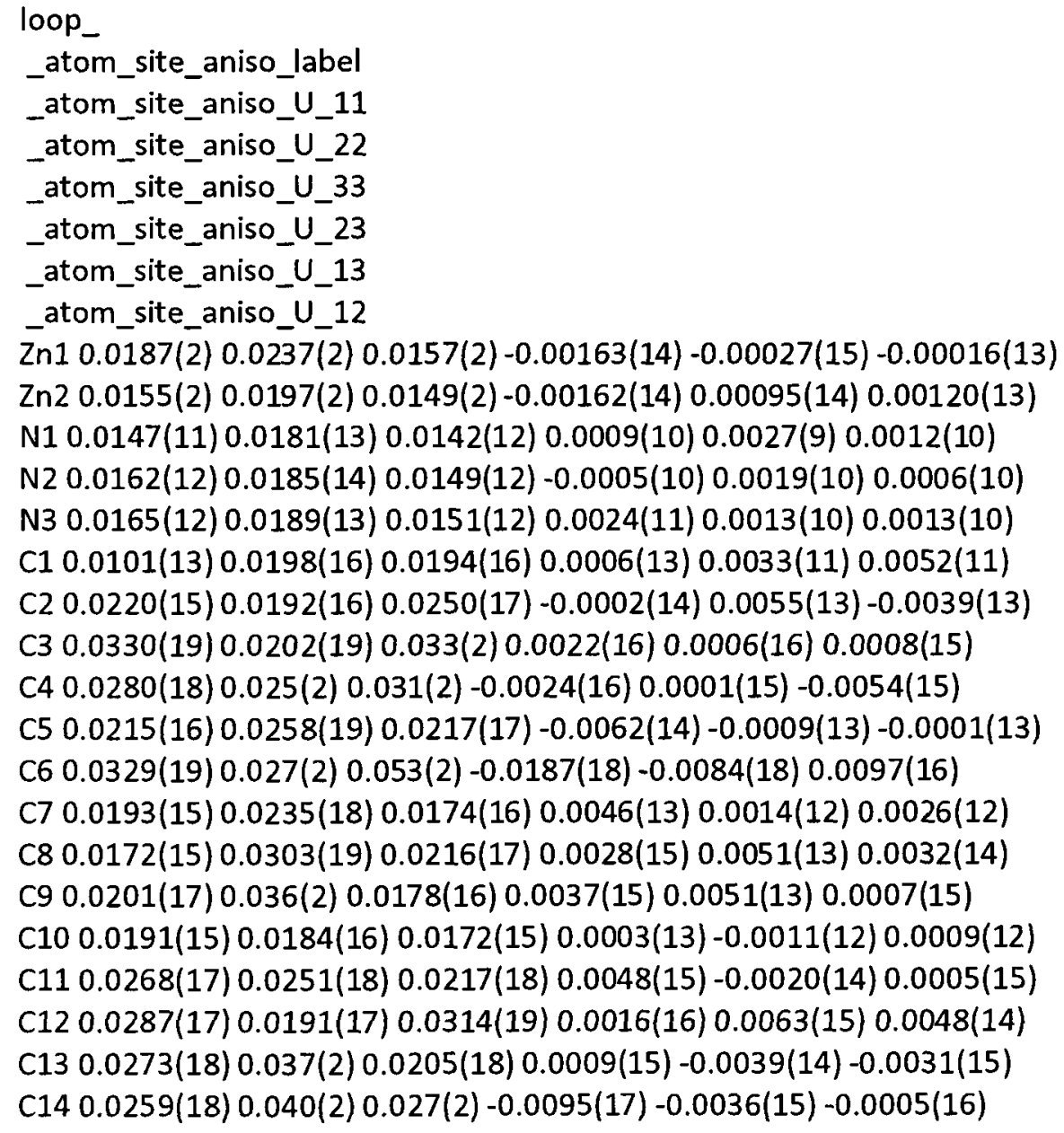




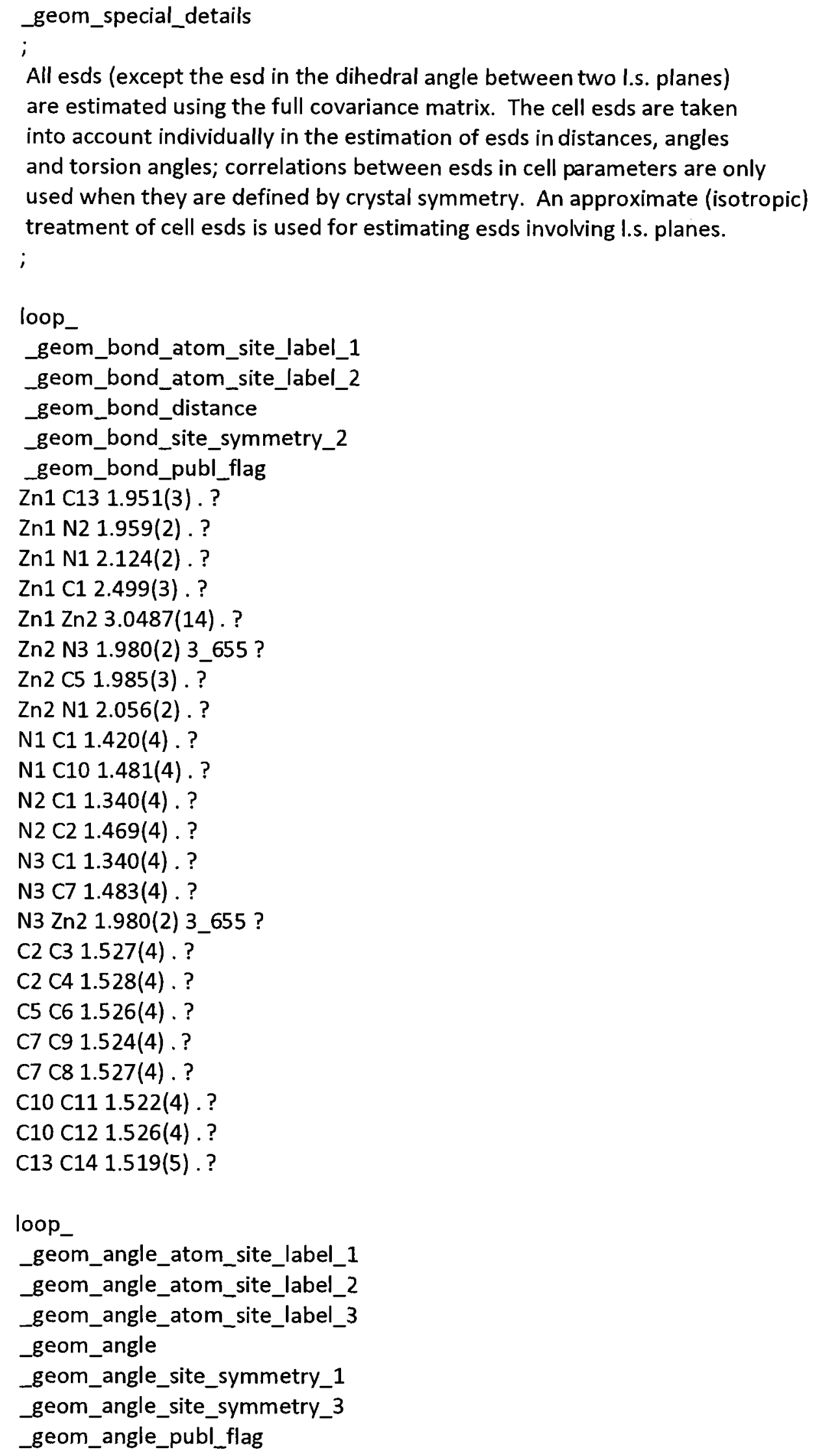


C13 Zn1 N2 152.83(12) . . ?

C13 Zn1 N1 140.45(12) . . ?

N2 Zn1 N1 66.47(9) . . ?

C13 Zn1 C1 171.92(13) . . ?

N2 Zn1 C1 32.18(9) .. ?

N1 Zn1 C1 34.58(9) . . ?

C13 Zn1 Zn2 119.90(11) .. ?

N2 Zn1 Zn2 81.85(6) . . ?

N1 Zn1 Zn2 42.30(6). . ?

C1 Zn1 Zn2 61.53(6) .. ?

N3 Zn2 C5 131.47(11)3_655 . ?

N3 Zn2 N1 111.67(10) 3_655 . ?

C5 Zn2 N1 116.70(11).. ?

N3 Zn2 Zn1 150.25(7) 3_655 . ?

C5 Zn2 Zn1 74.27(9) . . ?

N1 Zn2 Zn1 44.06(7) . . ?

C1 N1 C10 118.8(2) . . ?

C1 N1 Zn2 110.37(17). . ?

C10 N1 Zn2 118.28(17) . . ?

C1 N1 Zn1 87.31(15) . . ?

C10 N1 Zn1 122.30(16) . .?

Zn2 N1 Zn1 93.64(10) . . ?

C1 N2 C2 126.5(2) . . ?

C1 N2 Zn1 96.67(18) . . ?

C2 N2 Zn1 135.04(19) . . ?

C1 N3 C7 120.4(2) . . ?

C1 N3 Zn2 119.30(19). 3_655?

C7 N3 Zn2 120.25(18). 3_655?

N3 C1 N2 131.7(3) .. ?

N3 C1 N1 119.6(2) . . ?

N2 C1 N1 108.6(2) .. ?

N3 C1 Zn1 171.5(2) . . ?

N2 C1 Zn1 51.14(14) . . ?

N1 C1 Zn1 58.11(13) . . ?

N2 C2 C3 111.8(2) . . ?

N2 C2 C4 107.8(2) . . ?

C3 C2 C4 109.5(3) .. ?

C6 C5 Zn2 114.5(2). . ?

N3 C7 C9 109.0(2) .. ?

N3 C7 C8 111.3(2) .. ?

C9 C7 C8 109.1(3) . ?

N1 C10 C11 108.7(2). . ?

N1 C10 C12 112.1(2). . ?

C11 C10 C12 109.6(3) . . ?

C14 C13 Zn1 116.6(2) . . ?

loop_

_geom_torsion_atom_site_label_1 


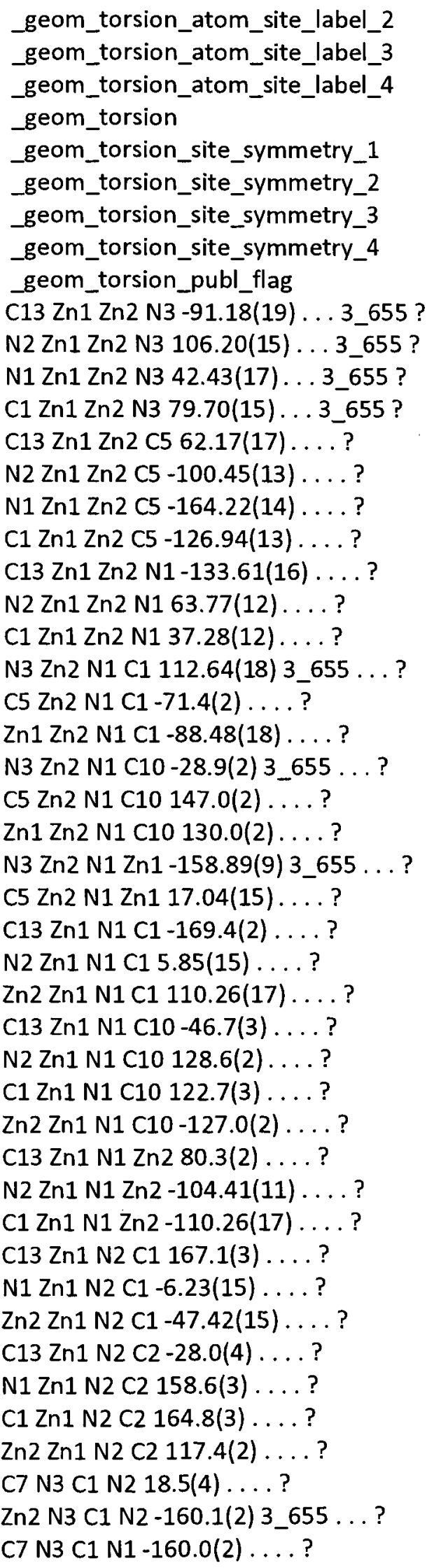


Zn2 N3 C1 N1 21.4(3) 3_655 ...?

C7 N3 C1 Zn1 -87.9(14) ... ?

Zn2 N3 C1 Zn1 93.5(14) 3_655 ... ?

C2 N2 C1 N3 23.7(5) ....?

Zn1 N2 C1 N3 -169.5(3) ....?

C2 N2 C1 N1 -157.7(2) ... . ?

Zn1 N2 C1 N1 9.0(2) ....?

C2 N2 C1 Zn1-166.7(3) ....?

C10 N1 C1 N3 44.7(3) ....?

Zn2 N1 C1 N3 -96.6(3) ... ? ?

Zn1 N1 C1 N3 170.5(2) ... ?

C10 N1 C1 N2-134.1(2) ... ?

Zn2 N1 C1 N2 84.6(2)....?

Zn1 N1 C1 N2 -8.3(2) ....?

C10 N1 C1 Zn1-125.8(2) ... . ?

Zn2 N1 C1 Zn1 92.89(13) ... . ?

C13 Zn1 C1 N3-20.5(19) ... . ?

N2 Zn1 C1 N3 113.2(15).... ?

N1 Zn1 C1 N3 -76.9(14) ....?

Zn2 Zn1 C1 N3 -122.8(14) ... . ?

C13 Zn1 C1 N2 -133.7(8) .... ?

N1 Zn1 C1 N2 169.9(2) ... ?

Zn2 Zn1 C1 N2 123.99(17).... ?

C13 Zn1 C1 N1 56.4(9) . . . ?

N2 Zn1 C1 N1 -169.9(2).... ?

Zn2 Zn1 C1 N1 -45.91(13)....?

C1 N2 C2 C3 57.1(4) ....?

Zn1 N2 C2 C3 -104.1(3).... ?

C1 N2 C2 C4 177.5(3).... ?

$\mathrm{Zn} 1 \mathrm{~N} 2 \mathrm{C2}$ C4 16.3(4).... ?

N3 Zn2 C5 C6 -42.6(3) 3_655 ...?

$\mathrm{N} 1 \mathrm{Zn} 2 \mathrm{C5}$ C6 142.4(2) ... . ?

$\mathrm{Zn} 1 \mathrm{Zn} 2 \mathrm{C5}$ C6 154.6(3).... ?

C1 N3 C7 C9 179.4(3) .... ?

Zn2 N3 C7 C9-2.1(3) 3_655 ... ?

C1 N3 C7 C8 58.9(4) ....?

Zn2 N3 C7 C8 -122.5(2) 3_655 ...?

C1 N1 C10 C11 170.4(2).... ?

Zn2 N1 C10 C11 -51.3(3) ... . ?

Zn1 N1 C10 C11 63.9(3) ... . ?

C1 N1 C10 C12 49.1(3) ....?

Zn2 N1 C10 C12-172.6(2) ... ?

Zn1 N1 C10 C12 -57.4(3) ... . ?

N2 Zn1 C13 C14 -3.2(5) ....?

N1 Zn1 C13 C14 167.2(2).... ?

C1 Zn1 C13 C14 119.3(8) ... ?

Zn2 Zn1 C13 C14-142.8(2) ... ? 
_diffrn_measured_fraction_theta_max 1.000

_diffrn_refins_theta_full 25.00

_diffrn_measured_fraction_theta_full 1.000

_refine_diff_density_max 0.714

_refine_diff_density_min -0.365

_refine_diff_density_rms 0.082 